\title{
DISPOSAL OF CHEMICAL AGENTS AND MUNITIONS STORED AT UMATILLA DEPOT ACTIVITY, HERMISTON, OREGON
}

FINAL PHASE I ENVIRONMENTAL REPORT

\author{
G.P. Zimmerman \\ E.L. Hillsman \\ R.O. Johnson \\ R.L. Miller \\ T.G. Patton \\ G.M. Schoepfle \\ V.R. Tolbert
}

D.L. Feldman

D.B. Hunsaker, Jr.

R.L. Kroodsma

J. Morrissey

L.W. Rickert

W.P. Staub

D.C. West

Date Published: February 1993

\begin{abstract}
Research supported by
Program Manager for Chemical Demilitarization Aberdeen Proving Ground, Maryland 21010-5401
\end{abstract}

Prepared by

OAK RIDGE NATIONAL LABORATORY

Oak Ridge, Tennessee 37831

Managed by

MARTIN MARIETTA ENERGY SYSTEMS, INC.

for the

U.S. DEPARTMENT OF ENERGY

under Contract No. DE-AC05-84OR21400 


\section{CONTENTS}

LIST OF FIGURES $\ldots \ldots \ldots \ldots \ldots \ldots \ldots \ldots \ldots \ldots \ldots \ldots \ldots \ldots$ vii

LIST OF TABLES $\ldots \ldots \ldots \ldots \ldots \ldots \ldots \ldots \ldots \ldots \ldots \ldots \ldots \ldots \ldots \ldots$ ix

ABBREVIATIONS AND ACRONYMS $\ldots \ldots \ldots \ldots \ldots \ldots \ldots \ldots \ldots$ xi

FOREWORD $\ldots \ldots \ldots \ldots \ldots \ldots \ldots \ldots \ldots \ldots \ldots \ldots \ldots \ldots \ldots \ldots \ldots \ldots$

PREFACE $\ldots \ldots \ldots \ldots \ldots \ldots \ldots \ldots \ldots \ldots \ldots \ldots \ldots \ldots \ldots \ldots \ldots \ldots$ xvii

EXECUTIVE SUMMARY $\ldots \ldots \ldots \ldots \ldots \ldots \ldots \ldots \ldots \ldots \ldots \ldots \ldots \ldots$ xxi

ABSTRACT $\ldots \ldots \ldots \ldots \ldots \ldots \ldots \ldots \ldots \ldots \ldots \ldots \ldots \ldots \ldots \ldots \ldots$

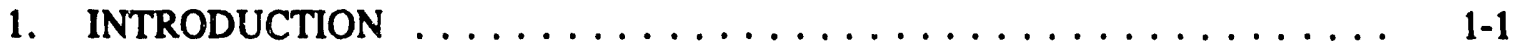

1.1 BACKGROUND $\ldots \ldots \ldots \ldots \ldots \ldots \ldots \ldots \ldots \ldots \ldots, 1-1$

1.2 UMATILLA DEPOT ACTIVITY $\ldots \ldots \ldots \ldots \ldots \ldots \ldots \ldots \ldots$ 1-1

1.3 OBJECTIVES AND SCOPE $\ldots \ldots \ldots \ldots \ldots \ldots \ldots \ldots \ldots, 1-3$

1.4 REFERENCES $\ldots \ldots \ldots \ldots \ldots \ldots \ldots \ldots \ldots \ldots \ldots \ldots \ldots$

2. APPROACH $\ldots \ldots \ldots \ldots \ldots \ldots \ldots \ldots \ldots \ldots \ldots \ldots$ 2-1

2.1 IDENTIFYING THE PROGRAMMATIC ENVIRONMENTALLY

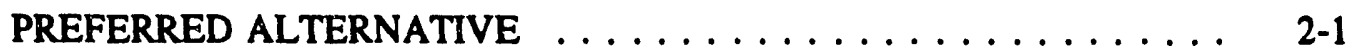

2.2 PHASE I CONCEPTUAL FRAMEWORK $\ldots \ldots \ldots \ldots \ldots \ldots .2-5$

2.3 DATA COLLECTION AND AGENCIES CONTACTED $\ldots \ldots \ldots \ldots, 2-8$

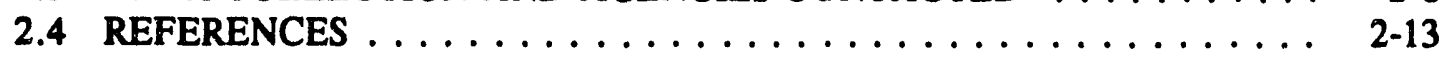

3. COMPARISON OF SITE-SPECIFIC AND PROGRAMMATIC DATA ..... 3-1

3.1 REEXAMINING ON-SITE DISPOSAL AS THE

ENVIRONMENTALLY PREFERRED ALTERNATIVE $\ldots \ldots \ldots \ldots, 3-2$

3.1.1 New Values for Programmatic Data and Assumptions

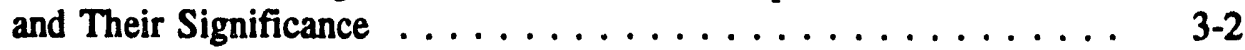

3.1.1.1 Accident database $\ldots \ldots \ldots \ldots \ldots \ldots \ldots \ldots \ldots, 3-2$

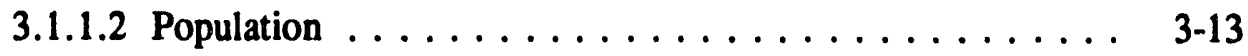

3.1.1.3 Summary ..................... 3-16

3.1.2 Evaluating Measures of Risk with Data Collected During

Phase I . . . . . . . . . . . . . . . . . 3-16

3.1.2.1 Differences in the measures of risk from those in the FPEIS . . . . . . . . . . . . . 3-17

3.1.2.2 Effect of various meteorological conditions

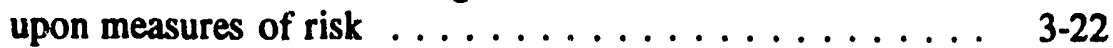

3.1.3 Identifying the Site-Specific Environmentally Preferred

Alternative . . . . . . . . . . . . . . . . . . 3-23

3.2 NEW INFORMATION AFFECTING ON-SITE DISPOSAL AT THE

UMATILLA DEPOT ACTIVITY $\ldots \ldots \ldots \ldots \ldots \ldots \ldots \ldots \ldots$. $\ldots \ldots$.23

3.2.1 Meteorology/Air Quality $\ldots \ldots \ldots \ldots \ldots \ldots \ldots \ldots \ldots$ 3-25 


\section{CONTENTS}

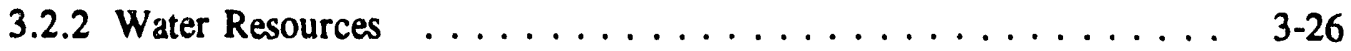

3.2.3 Land Use . . . . . . . . . . . . . . . . . . . 3-27

3.2.4 Ecological Resources . . . . . . . . . . . . . . . . . . . . 3-28

3.2.5 Social, Economic, and Cultural Resources . . . . . . . . . . . 3-32

3.2.6 Aircraft Activity . . . . . . . . . . . . . . . . . 3-35

3.2.7 Emergency Planning and Preparedness . . . . . . . . . . 3-35

3.3 TECHNOLOGY STATUS/MATURITY $\ldots \ldots \ldots \ldots \ldots \ldots \ldots \ldots$ 3-36

3.3.1 BZ Demilitarization Operations . . . . . . . . . . . . . . . 3-38

3.3.2 Johnston Atoll . . . . . . . . . . . . . . . . . . . 3-40

3.3.3 1989 Agent VX Test Program at the Chemical Agent Munitions Disposal System (CAMDS) . . . . . . . . . . . . 3-41

3.3.4 1990 Mustard Agent (HD) Test Program at CAMDS . . . . . . . . 3-42

3.3.5 Award of the Systems Contract for the Chemical Demilitarization Training Facility $\ldots \ldots \ldots \ldots$ 3-43

3.3.6 Award of the Systems Contract for the Tooele Chemical Agent Disposal Facility . . . . . . . . . . . . . . 3-43

3.3.7 Equipment Acquisition Contracts . . . . . . . . . . . . . . . 3-43

3.3.8 Individual Equipment Advancements . . . . . . . . . . . . 3-44

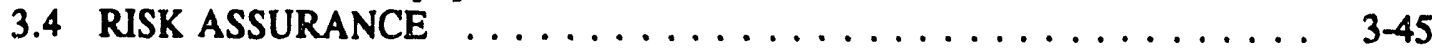

3.4.1 Rationale and Basis for Risk Assurance at the Umatilla Depot Activity . . . . . . . . . . . . . . . . . . . 3-45

3.4.2 Design Changes Requiring Reexamination of Risk at the Umatilla Depot Activity . . . . . . . . . . . . . . . . . . . 3-47

3.4.2.1 Container handling building $\ldots \ldots \ldots \ldots \ldots \ldots . \ldots \ldots$

3.4.2.2 Redesigned on-site container . . . . . . . . . . . . 3-48

3.4.2.3 Addition of a mustard thaw capability . . . . . . . . 3-49

3.5 REFERENCES ......................... 3-50

4. FINDINGS AND CONCLUSIONS . . . . . . . . . . . . . . . 4-1

4.1 REEXAMINING ON-SITE DISPOSAL AT THE UMATILLA DEPOT

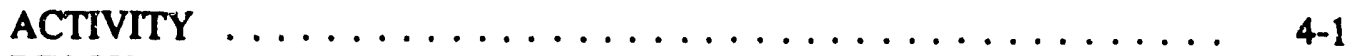

4.2 RESOURCE DATA RELATED TO IMPLEMENTATION OF ON-SITE DISPOSAL . . . . . . . . . . . . . . . . 4-2

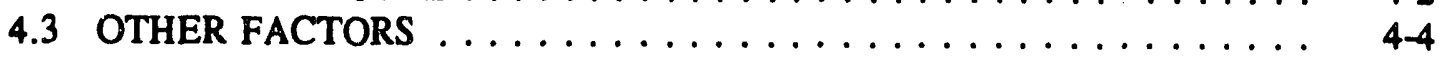

APPENDIX A. IMPACT ANALYSES IN THE FINAL PROGRAMMATIC ENVIRONMENTAL IMPACT STATEMENT . . . . . . . A A 


\section{CONTENTS}

APPENDIX B. DESCRIPTION OF SITE-SPECIFIC COMMUNITY

RESOURCES $\ldots \ldots \ldots \ldots \ldots \ldots \ldots \ldots \ldots$ B-1

APPENDIX C. DESCRIPTION OF SITE-SPECIFIC SURFACE WATER

AND GROUNDWATER RESOURCES $\ldots \ldots \ldots \ldots \ldots$ C- 1

APPENDIX D. DESCRIPTION OF SITE-SPECIFIC LAND USE $\ldots \ldots \ldots$ D-1

APPENDIX E. DESCRIPTION OF SITE-SPECIFIC ECOLOGICAL

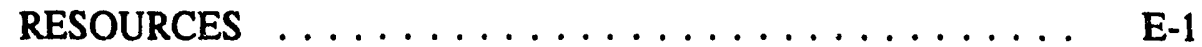

APPENDIX F. RESPONSES TO COMMENTS FROM STATE AND

F-1 


\section{LIST OF FIGURES}

Page

1. Regional location of the Umatilla Depot Activity . . . . . . . . . . 1-2

2. General layout of the Umatilla Depot Activity showing the site of the proposed disposal facility . . . . . . . . . . . 1-4

3. Location of the Umatilla Depot Activity with respect to zones of potential impact $\ldots \ldots \ldots \ldots \ldots \ldots \ldots \ldots$

4. Flowchart illustrating the process used for identifying the programmatic environmentally preferred alternative (i.e., on-site disposal) for the Chemical Stockpile Disposal Program . . . . . . . 2-2

5. Conceptual overview of data types used in identifying the programmatic environmentally preferred alternative $\ldots \ldots \ldots . \ldots 2-4$

6. Flowchart illustrating the Phase I concept $\ldots \ldots \ldots \ldots$ 2-6

7. Location of the Portland General Electric Company meteorological tower which provided site-specific data $\ldots \ldots \ldots \ldots . \ldots . \ldots$ 3-5

8. Wind rose (joint annual frequency distribution of wind speed and wind direction) for the data collected at the Portland General Electric Company meteorological tower $\ldots \ldots \ldots \ldots \ldots$ 3-6

9. Earthquakes in Columbia Plateau and Blue Mountain tectonic provinces and adjacent regions . . . . . . . . . . . . 3-12

10. Risk with mitigation in the vicinity of the Umatilla Depot Activity for programmatic alternatives ................ 3-20

11. Ecological resources of special interest within $100 \mathrm{~km}$ (62 miles) of the proposed disposal facility at the Umatilla Depot Activity . . . 3 3-33

12. Projected chemical agent stockpile destruction versus time $\ldots \ldots \ldots$ 3-37 


\section{LIST OF TABLES}

1. Joint frequency distribution (in percent) of stability and wind speed for the Umatilla Depot Activity . . . . . . . . . . . . 3-8

2. Summary of site-specific and programmatic earthquake parameters and site-specific earthquake design parameters at the Umatilla Depot Activity

3. Residential population distribution around the proposed disposal facility site at the Umatilla Depot Activity as given in the final programmatic environmental impact statement $\ldots \ldots \ldots \ldots . \ldots 3-14$

4. Residential population distribution around the proposed disposal facility site at the Umatilla Depot Activity using data

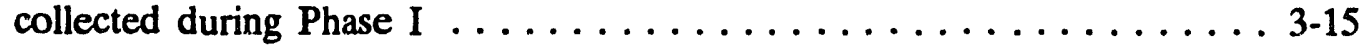

5. Estimated fatalities by downwind distance for selected meteorological conditions at the Umatilla Depot Activity using data collected during Phase I . . . . . . . . . . . . . 3-18

6. Estimated fatalities by downwind distance for selected meteorological conditions at the Umatilla Depot Activity as given in the final programmatic environmental impact statement . . . . . . . 3-19

7. Results of comparing the recomputed measures of risk for alternatives at the Umatilla Depot Activity . . . . . . . . . . . . . . . . . 3-24

8. Number of ecological resources of special interest in the vicinity of the proposed facility site at the Umatilla Depot Activity as

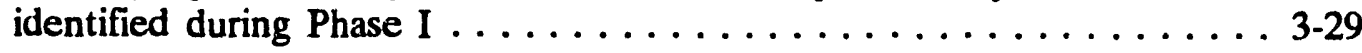

9. Ecological resources within $100 \mathrm{~km}$ (62 miles) of proposed disposal site at the Umatilla Depot Activity . . . . . . . . . . . . . . 3-30

10. On-post population at Umatilla Depot Activity by time of day . . . . . 3-34

11. Summary of U.S. Army's experience in industrial-scale lethal chemical agent/munitions disposal ................. 3-39

12. Summary of major changes in design and operating procedures for the proposed disposal facility at the Umatilla Depot Activity . . . . 3-46 


\section{ABBREVIATIONS AND ACRONYMS}

$\begin{array}{ll}\text { ACAMS } & \text { automatic continuous air monitoring system } \\ \text { agl } & \text { above ground level } \\ \text { ANAD } & \text { Anniston Army Depot } \\ \text { APG } & \text { Aberdeen Proving Ground } \\ \text { ATC } & \text { Applied Technology Council } \\ \text { BZ } & \text { a nonlethal, but incapacitating, chemical agent } \\ \text { CAMDS } & \text { Chemical Agent Munitions Disposal System } \\ \text { CDTF } & \text { Chemical Demilitarization Training Facility } \\ \text { CEQ } & \text { Council on Environmental Quality } \\ \text { CFR } & \text { Code of Federal Regulations } \\ \text { CHB } & \text { container handling building } \\ \text { CML } & \text { conservative most likely } \\ \text { CONUS } & \text { continental United States } \\ \text { CPTP } & \text { Columbia Plateau Tectonic Province } \\ \text { CSDP } & \text { Chemical Stockpile Disposal Program } \\ \text { DATS } & \text { Drill and Transfer System } \\ \text { DEQ } & \text { Department of Environmentai Quality } \\ \text { DFS } & \text { deactivation furnace system } \\ \text { DHHS } & \text { U.S. Department of Human Health and Services } \\ \text { DPEIS } & \text { draft programmatic environmental impact statement } \\ \text { D2PC } & \text { an atmospheric dispersion model computer program } \\ \text { E } & \text { east } \\ \text { EIS } & \text { environmental impact statement } \\ \text { EMA } & \text { Emergency Management Agency } \\ \text { ENE } & \text { east-northeast } \\ \text { EOC } & \text { emergency operations center } \\ \text { EPA } & \text { U.S. Environmental Protection Agency } \\ \text { EPGA } & \text { effective peak ground acceleration } \\ \text { ERCP } & \text { Emergency Response Concept Plan } \\ \text { ESE } & \text { east-southeast } \\ \text { FEMA } & \text { Federal Emergency Management Agency } \\ \text { FPEIS } & \text { final programmatic environmental impact statement } \\ \text { ft } & \text { feet } \\ \text { FWS } & \text { U.S. Fish and Wildlife Service } \\ \text { GB } & \text { a chemical nerve agent, also called Sarin } \\ \text { H } & \text { a chemical blister agent, also generally called sulfur mustard } \\ \text { ha } & \text { hectare } \\ \text { HD } & \text { a chemical blister agent, also generally called distilled mustard } \\ \text { hr } & \text { hour } \\ & \end{array}$




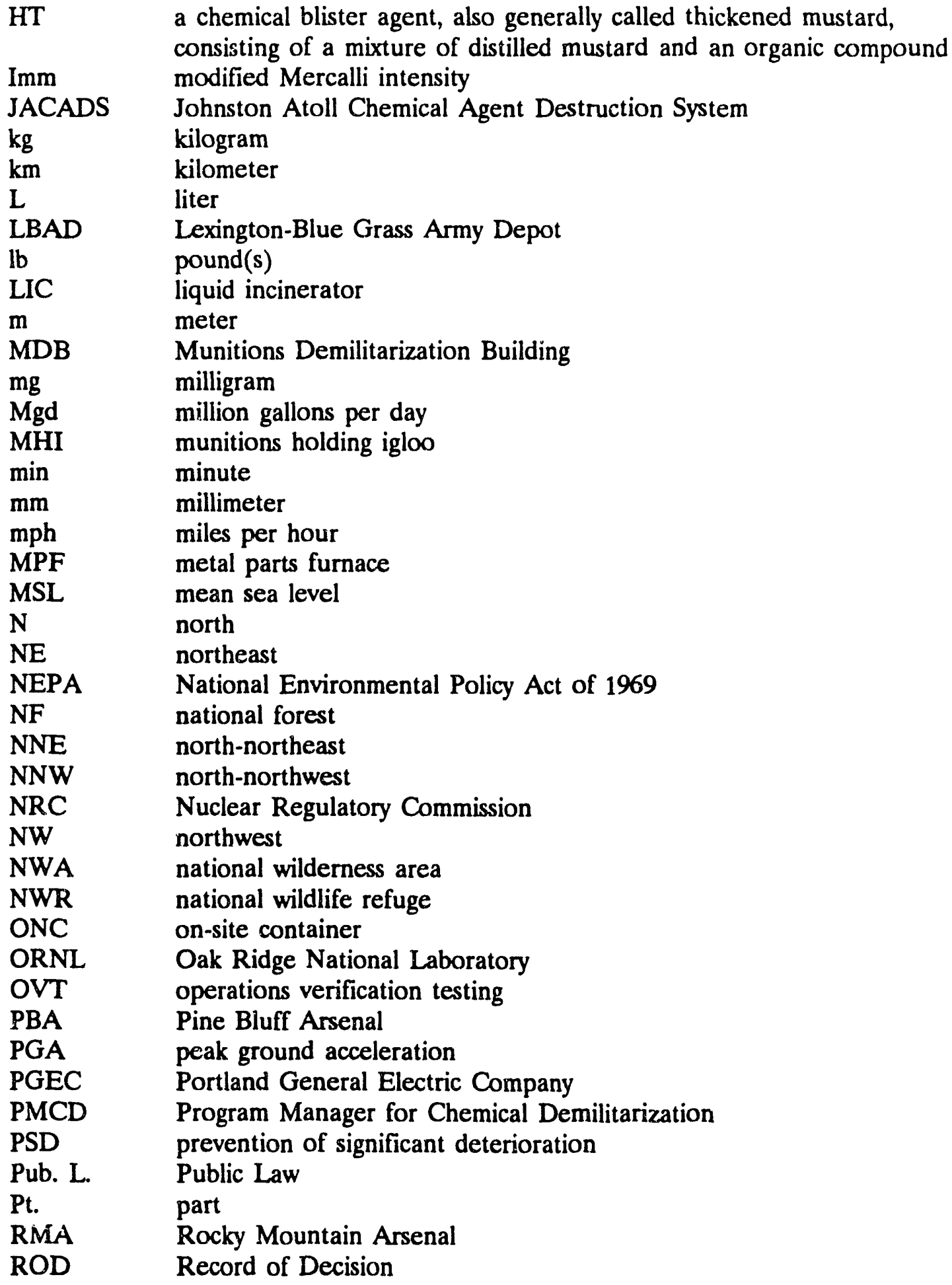




$\begin{array}{ll}\text { S } & \text { second } \\ \text { S } & \text { south } \\ \text { SE } & \text { southeast } \\ \text { SSE } & \text { (1) south-southeast } \\ & \text { (2) safe-shutdown earthquake } \\ \text { SSW } & \text { south-southwest } \\ \text { SW } & \text { southwest } \\ \text { TEAD } & \text { Tooele Army Depot } \\ \text { TWA } & \text { time weighted average } \\ \text { UBC } & \text { uniform building code } \\ \text { UMDA } & \text { Umatilla Depot Activity } \\ \text { VX } & \text { a chemical nerve agent } \\ \text { W } & \text { (1) watt } \\ & \text { (2) west } \\ \text { WC } & \text { worst case } \\ \text { WNW } & \text { west-northwest } \\ \text { WPPSS } & \text { Washington Public Power Supply System } \\ \text { WSW } & \text { west-southwest }\end{array}$




\section{FOREWORD}

Under the Chemical Stockpile Disposal Program (CSDP), the U.S. Army proposes to dispose of lethal chemical agents and munitions stored at eight existing Army installations in the continental United States. In compliance with the National Environmental Policy Act (NEPA), the Army initiated a site-specific NEPA review of this proposed action at the Umatilla Depot Activity (UMDA), near Hermiston, Oregon. The environmental compliance documentation is to be prepared in two phases.

In Phase I, the overall CSDP decision to dispose of the UMDA stockpile by an on-site reverse-assembly and incineration process was further considered, and its validity at UMDA was reviewed with newer, more detailed data than those providing the basis for the final programmatic environmental impact statement (FPEIS) (completed in January 1988) for the CSDP. A Phase I Environmental Report was prepared to present the findings of the Phase I review.

Phase II [the preparation of a site-specific environmental impact statement (EIS)] will focus on the site-specific implementation (plant construction and disposal operations) of onsite disposal at UMDA. It should be emphasized that the Phase I Environmental Report is the starting point for the site-specific decision-making process, and it provides the environmental information by which the impacts of the proposed action can be assessed in the site-specific EIS.

A final Phase I Environmental Report for UMDA was issued by the Army in February 1990 (Disposal of Chemical Agents and Munitions Stored at Umatilla Depot Activity, Hermiston, Oregon: Final Phase I Environmental Report, Program Manger for Chemical Demilitarization, Aberdeen Proving Ground, Md.) The report concluded that the FPEIS environmentally preferred alternative (on-site disposal), which is also the Army's preferred alternative, is indeed valid for UMDA. No new or unique site-specific information was found that would change or contradict the conclusions of the FPEIS with respect to UMDA. The report recommended that preparation of the site-specific EIS should proceed and should focus on implementation of the on-site incineration program and should not consider other alternatives for disposing of the UMDA stockpile.

The UMDA Phase I report was independently reviewed by Argonne National Laboratory (ANL) and the review summarized in a report (Chemical Stockpile Disposal Program: Review and Comment on the Phase I Environmental Report for the Umatilla Depot Activity, Hermiston, Oregon, ANL/EAIS/TM-33, Argonne, Ill., October 1990). Additional recommendations for the content of the site-specific EIS are included in the ANL review. On November 28, 1990, the findings and conclusions of the UMDA Phase I report and the independent ANL review, were certified to Congress by the Hon. Susan Livingstone, Assistant Secretary of the Army. Preparation of the site-specific EIS for UMDA was initiated following the Phase I certification.

This Oak Ridge National Laboratory Technical Memorandum consists of the February 1990 Final Phase I report. It was prepared to document the Phase I process for disposal of chemical agents and munitions stored at UMDA. 


\section{PREFACE}

The U.S. Department of the Army proposes under the Chemical Stockpile Disposal Program (CSDP) to destroy the nation's total stockpile of lethal unitary chemical agents and munitions. The unitary chemical agents to be destroyed under the CSDP include nerve agents that directly affect the nervous system and blister agents that produce blisters on exposed tissue. Unitary agents are so named because they can produce their desired hazardous effect on human health in their form as stored; they do not require mixing with another component to become hazardous (as is the case with binary chemical agents). These agents are maintained in two general storage configurations: (1) some agents are stored inside munitions (e.g., rockets, land mines, mortars, cartridges, and projectiles) that in addition to agents contain various explosive components (e.g., fuses, propellants, and bursters), and (2) other agents are stored inside bulk containers, which include bombs, spray tanks, and steel one-ton containers, none of which contain any explosives.

The proposed action is being carried out in response to a congressional mandate in Title 14, Part B, Section 1412 of Pub. L. 99-145, the Department of Defense Authorization Act of 1986, which directs that the destruction of the agents and munitions be accomplished by September 30,1994, in conjunction with the acquisition of binary chemical weapons. In March 1988, the Army received from Congress an extension of the 1994 deadline to April 30, 1997, under Pub. L. 100-456. Under emergency conditions or if there is a significant delay in the acquisition of an adequate number of binary chemical weapons to meet the requirements of the Armed Forces, Pub. L. 99-145 allows the Secretary of Defense to defer, beyond April 30, 1997, the destruction of not more than 10\% ("useful 10\%") of the existing unitary stockpile.

Congress has directed the Army to accomplish the proposed destruction in a manner that provides (1) maximum protection of the environment, the general public, and the personnel involved in the destruction process; (2) adequate and safe facilities designed solely for the destruction of the lethal chemical stockpile; and (3) cleanup, dismantling, and disposal of the facilities when the disposal program is complete.

The existing unitary chemical agents and munitions are stored at eight U.S. Army installations located in the continental United States: Aberdeen Proving Ground (APG), near Edgewood, Maryland; Anniston Army Depot (ANAD), near Anniston, Alabama; LexingtonBlue Grass Army Depot (LBAD), near Lexington, Kentucky; Newport Army Ammunition Plant, near Newport, Indiana; Pine Bluff Arsenal, near Pine Bluff, Arkansas; Pueblo Depot Activity, near Pueblo, Colorado; Tooele Army Depot (TEAD), near Tooele, Utah; and Umatilla Depot Activity, near Hermiston, Oregon. None of the agents and munitions currently in storage have been manufactured since 1968, and although some of them are "like new," others are in various stages of deterioration, with a few items developing leaks. All items that have been verified as leaking have been either repaired and decontaminated on the spot or containerized and placed in isolated storage.

At each of the eight sites, the Army proposes to remove the agents and munitions from existing storage, transport them to a proposed on-site disposal facility, disassemble 
theri, and incinerate the agent and explosive components, while thermally decontaminating the metal munition bodies and bulk containers. No stockpiled agents or munitions are proposed to be transported to other storage installations or sites for destruction. Incineration, the selected disposal technology, has been endorsed by the National Research Council as the safest means of destroying these lethal chemical agents. For the purpose of this Phase I Report, "on-site disposal facility" refers to the incinerator and all associated structures and equipment for storing, handling, disassembling, and processing the munitions and agents.

A federal program such as the CSDP requires a National Environmental Policy Act of 1969 (NEPA) review to ensure that environmental factors are given adequate consideration early in the decision-making process. For the CSDP, a NEPA review strategy has been structured to address two levels of decision making: (1) the programmatic level and (2) the site-specific level.

Implementation of this NEPA review strategy for the CSDP began in January 1986 with initiation of the programmatic environmental impact statement (EIS). In January 1988, the Army issued the final programmatic EIS (FPEIS). The FPEIS discussed five alternatives: four for destroying the stockpile and the no action alternative [required by regulations implementing NEPA (40 CFR Pts. 1500-1508)]. The five alternatives are as follows:

1. continued storage of the stocks at their present locations (the no action alternative);

2. on-site destruction of the stocks at their present storage locations;

3. relocation of the stocks to regional disposal centers at ANAD and TEAD for destruction;

4. relocation of the stocks to a national disposal center at TEAD for destruction; and

5. relocation of the inventories at some sites to alternate sites, with the remainder destroyed at their present storage locations (this alternative includes air movement of the APG and LBAD inventories to TEAD for destruction).

The FPEIS identified on-site disposal as the environmentally preferred alternative (i.e., the alternative with the least potential for significant adverse impacts). In addition, the Army's Record of Decision (ROD) for the FPEIS selected on-site disposal for implementation. The ROD stated that environmental impacts, including the hazard and risk analyses presented in the FPEIS, were a contributing but not the determining factor in the decision. Other factors included the feasibility and effectiveness of emergency response measures, vulnerability to terrorism and sabotage, and logistical complexity. 
On-site disposal, having been selected for implementation, will require that the Army prepare eight site-specific NEPA compliance documents for each installation to assist with the site-level decision making. The programmatic ROD stated that the site-specific NEPA documents would focus on the implementation of the programmatic decision at a given site and on specific issues and concerns related to implementation at a given site. 


\section{EXECUTIVE SUMMARY}

The Umatilla Depot Activity (UMDA), near Hermiston, Oregon, is one of eight continental United States Army installations where lethal unitary chemical agents ${ }^{1}$ and munitions are stored, and where destruction of agents and munitions is proposed under the U.S. Army's Chemical Stockpile Disposal Program (CSDP). The chemical agent inventory at UMDA consists of approximately $12 \%$, by weight, of the total U.S. stockpile. None of the agents or munitions at UMDA have been manufactured since 1968, and although some of them are "like new," others are in various stages of deterioration, with a few items developing leaks. The destruction of the stockpile is necessary to eliminate the risk to the public from continued storage and to dispose of obsolete and leaking munitions.

In January 1988 the U.S. Army issued a final programmatic environmental impact statement (FPEIS) for the CSDP that identified on-site disposal of agents and munitions as the environmentally preferred alternative (i.e., the alternative with the least potential to cause adverse environmental impacts). In some instances, the FPEIS included generic data and assumptions that were developed to allow a consistent comparison of potential impacts among programmatic alternatives and did not include detailed conditions at each of the eight installations. The environmentally preferred alternative was identified using a method based on five measures of risk directed at potential human health and ecosystem/environmental effects; the adequacy of emergency response also played a key role in the selection process. In the Record of Decision following the FPEIS, on-site disposal was selected for implementation of the program.

The purpose of this Phase I Report is to examine the proposed implementation of on-site disposal at UMDA in light of recent, more detailed data than those included in the FPEIS. Two principal issues are addressed in this Phase I Report:

(1) whether or not the new data would result in the rejection of on-site disposal at UMDA as the environmentally preferred alternative (using the same selection method and data analysis tools as in the FPEIS), and (2) whether or not the new data indicate the presence of significant environmental resources that could be affected by the implementation of on-site disposal at UMDA. In addition, status reports are presented on the maturity of the disposal technology (and how it could affect on-site disposal at UMDA) and on the effort in tracking technological changes and ensuring that the overall levels of on-site disposal risk, as identified in the FPEIS for UMDA, do not change in a manner that could revise the relative ranking of the various FPEIS alternatives. Confirmation of on-site disposal in Phase I allows the site-specific EIS (addressing on-site disposal) to begin under Phase II.

${ }^{1}$ Unitary agents are so named because they produce their desired hazardous effect on human health in their form as stored. They do not require mixing with another component to become hazardous as is the case with binary chemical agents. 
More recent and more detailed site-specific data of the same types used in the FPEIS to identify the environmentally preferred alternative were gathered during the Phase I process. These new data were then examined and compared with the FPEIS data to determine if they have changed enough to warrant recomputation of the five measures of risk that were used to select the programmatic environmentally preferred alternative. Of all the data types examined, only two were identified as having changed enough to warrant recomputation of risk: changes in residential population (primarily because of population growth and a change in the location of the residents) and the selection of a most likely meteorological condition. For the areas of seismicity, aircraft activity, on-site transport distance, and meteorite/tornado frequency, either new data were not identified during the Phase I process or were not sufficiently different from data used in the FPEIS to warrant reevaluation of risk.

The new population data were used to compute fatalities using the same computation methods and values for all other parameters as in the FPEIS. The revised fatality estimates were then used to compute the five measures of risk for on-site disposal, continued storage, and on-site activities associated with off-site transport of the UMDA stockpile. Results indicate that continued storage at UMDA can be rejected because four of the five measures of risk were greater, by a significant amount, than the values for the on-site disposal alternative. Likewise, off-site transport from UMDA can be rejected because one of the measures of risk is significantly greater than for on-site disposal. The conclusion is that onsite disposal remains valid as the environmentally preferred alternative for UMDA. If the off-site transportation risks (not addressed in this document because they are beyond its scope) are also included, the on-site alternative is clearly preferable given the opportunity for risk reductions associated with emergency planning and preparedness activities that are under way at UMDA.

During the Phase I process, data on resources that could be affected by implementation of on-site disposal activities at UMDA were gathered to determine if any significant new resources are present that could prevent or delay construction and operation of the on-site disposal facility. The resources that were considered included population, meteorology/air quality, surface and groundwater, land use, ecology, socioeconomics, and aircraft activity. Some of these resources were examined in the FPEIS in assessing potential impacts of the programmatic alternatives, whereas others represent information that was not appropriate for examination on the programmatic level. No assessment of potintial impacts was done during the Phase I process with these data. Rather, the data were examined to help identify potential issues to be analyzed under Phase II (i.e., the preparation of a sitespecific environmental impact statement for UMDA). No unique resources with the potential to prevent or delay implementation of on-site disposal at UMDA have been identified during Phase I.

Technology status/maturity and technology risk assurance were also examined during the Phase I process, although neither factor was instrumental in reaching the conclusions for UMDA identified in the previous paragraphs. Four principal technology developments have occurred since the publication of the FPEIS: (1) the disposal of nonlethal chemical agent by incineration at Pine Bluff Arsenal, located near Pine Bluff, Arkansas; (2) construction and 
testing of facilities for disposal of lethal chemical agents stored at Johnston Atoll, located about $1300 \mathrm{~km}$ (800 miles) south of Hawaii in the Pacific Ocean; (3) disposal tests with lethal chemical agent at the Chemical Agent Munitions Disposal System pilot plant at Tooele Army Depot, Utah; and (4) equipment advances. The experience gained during the "prooftesting" of the CSDP disposal technology should be of value in the implementation of on-site disposal at UMDA.

Efforts are also under way within the Army to identify and examine major changes to facility designs and operating procedures that have occurred since the FPEIS. These changes are being reviewed and evaluated to ensure that the relative ranking of alternatives as presented in the FPEIS risk pictograms for UMDA will not change; hence, the phrase "risk assurance" has been applied to this effort. No currently proposed design changes have been found that result in increases above those levels of risk presented in the FPEIS for UMDA. 


\begin{abstract}
The Umatilla Depot Activity (UMDA) near Hermiston, Oregon, is one of eight U.S. Army installations in the continental United States where lethal unitary chemical agents and munitions are stored, and where destruction of agents and munitions is proposed under the Chemical Stockpile Disposal Program (CSDP). The chemical agent inventory at UMDA consists of $11.6 \%$, by weight, of the total U.S. stockpile. The destruction of the stockpile is necessary to eliminate the risk to the public from continued storage and to dispose of obsolete and leaking munitions.

In 1988 the U.S. Army issued a Final Programmatic Environmental Impact Statement (FPEIS) for the CSDP that identified on-site disposal of agents and munitions as the environmentally preferred alternative (i.e., the alternative with the least potential to cause significant adverse impacts). The FPEIS identified the environmentally preferred alternative using a method based on five measures of risk for potential human health and ecosystem/environmental effects; the effectiveness and adequacy of emergency preparedness capabilities also played a key role in the FPEIS selection methodology.

In some instances, the FPEIS included generic data and assumptions that were developed to allow a consistent comparison of potential impacts among programmatic alternatives and did not include detailed conditions at each of the eight installations. The purpose of this Phase I report is to examine the proposed implementation of on-site disposal at UMDA in light of more recent and more detailed data than those included in the FPEIS. Specifically, this Phase I report is intended to either confirm or reject the validity of on-site disposal for the UMDA stockpile.

Using the same computation methods as in the FPEIS, new population data were used to compute potential fatalities from hypothetical disposal accidents. Results indicate that onsite disposal is clearly preferable to either continued storage at UMDA or transportation of the UMDA stockpile to another depot for disposal. Furthermore, no unique resources with the potential to prevent or delay implementation of on-site disposal at UMDA have been identified. Therefore, on-site disposal remains valid as the preferred alternative for the UMDA stockpile.

This Phase I report contains information that will be used in the development of environmental analyses and assessments to be included in a site-specific environmental impact statement regarding the disposal of the UMDA stockpile.
\end{abstract}




\section{INTRODUCTION}

\subsection{BACKGROUND}

This Phase I Environmental Report has been prepared by the U.S. Department of the Army to assist in the development of site-specific National Environmental Policy Act of 1969 (NEPA) (Pub. L. 91-190) compliance documentation for disposal of the lethal unitary chemical agents and munitions stored at the Umatilla Depot Activity (UMDA) located near Hermiston, Oregon. Under the Chemical Stockpile Disposal Program (CSDP), the U.S. Army proposes to destroy the national stockpile of lethal unitary chemical agents (nerve and blister) and munitions. UMDA is one of eight Army installations where such on-site disposal is proposed.

Following the issuance in January 1988 of the CSDP final programmatic environmental impact statement (FPEIS) (U.S. Army 1988a) and its accompanying record of decision (ROD) (U.S. Army 1988b) in February 1988, the Army began sitespecific NEPA reviews for the eight installations involved in the CSDP. The Army has developed a two-phase process for conducting the site-specific NEPA reviews. In Phase I, the programmatic decision of on-site disposal is to be given further consideration by a review of its validity at each storage installation using more detailed and more recent data than those used in the FPEIS. Phase II [the preparation of a site-specific environmental impact statement (EIS)] is to address potential impacts from site-specific implementation (plant construction and disposal operations) of on-site disposal.

The site-specific NEPA reviews for the CSDP began with the Tooele Army Depot (TEAD) (U.S. Army 1988c; Argonne National Laboratory 1989) and the Anniston Army Depot (ANAD) (U.S. Army 1989) and continue with this report for UMDA. This Phase I Environmental Report is the starting point for the site-specific decision-making process at UMDA; it provides the environmental information by which the site-specific impacts of the proposed action are to be assessed in Phase II.

\subsection{UMATILLA DEPOT ACTIVITY}

The Umatilla Depot Activity, named for a territorial Indian tribe, is located in northeastern Dregon in Umatilla and Morrow Counties, approximately $6 \mathrm{~km}$ (4 miles) west of Hermiston, and $4 \mathrm{~km}$ ( 3 miles) south of the Washington state line (see Fig. 1). The installation encompasses an area of 7,990 ha (19,700 acres; 30 miles $\left.^{2}\right)$. UMDA is located near several major cities including the Tri-Cities (Pasco, Richland, and Kennewick) area of Washington about $56 \mathrm{~km}$ ( 35 miles) to the north.

Originally, the Army purchased some of the land for the Umatilla Ordnance Depot in 1940 from private owners; other acreage was transferred from the Bureau of Land Management. In 1941 the installation began storing ammunition. The depot 
ORNL-DWG 89-18315

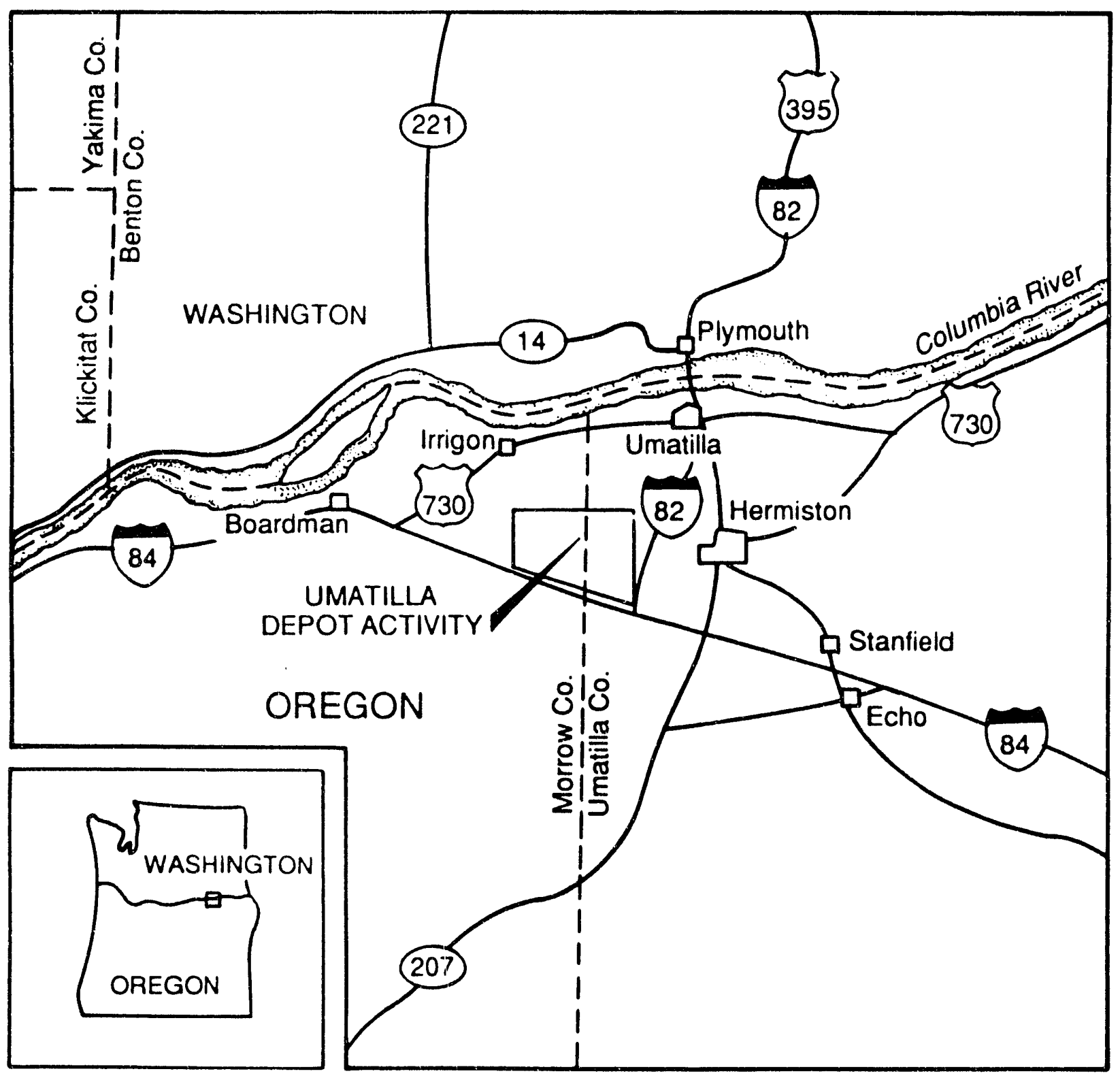

Fig. 1. Regional location of the Umatilla Depot Activity (UMDA). 
extended its functions to include ammunition demolition in 1945, renovation of an ammunition complex in 1947, and maintenance and storage of conventional munitions in 1955. Storage of lethal unitary chemical munitions at UMDA began in 1962. UMDA is a storage facility; chemical weapons have never been used, tested, or manufactured at the depot. However, munitions have been reworked and demilitarization has occurred.

In August 1973, the installation was redesignated by the U.S. Army Materiel Command as an Activity within the Tooele Army Depot complex. The Tooele complex consists of the headquarters at Tooele Army Depot, Tooele, Utah, and depot activities in Oregon, Colorado, New Mexico, and Arizona.

The primary mission at UMDA is the operation of a reserve storage depot activity. This includes storage, preservation, and minor maintenance of stocks; limited preventive maintenance of the facilities and equipment to assure minimum deterioration; and the retention of limited shipping and receiving capabilities. Additionally, UMDA performs ammunition surveillance and required demilitarization and provides support for the Reserve Components of the U.S. Army.

The chemical agent and munition storage area, as well as the proposed disposal facility site, is located in the north central part of the UMDA installation (see Fig. 2). The storage area is approximately $750 \mathrm{~m}(0.5 \mathrm{mile})$ from the installation's northern border [not including a $1.6-\mathrm{km}$ (1-mile) restricted easement]; the site of the proposed disposal facilities is $1.6 \mathrm{~km}$ ( 1 mile) from the northern boundary (again, not including the restricted easement).

The lethal unitary chemical munitions stored at UMDA are $11.6 \%$ (by weight) of the total U.S. stockpile; this represents the third largest chemical agent inventory among the Army's eight continental U.S. storage sites. The lethal chemical munitions in storage at UMDA include nerve and blister agents. Nerve agent GB is contained inside 155 -mm projectiles, 8 -in. projectiles, M55 rockets, 500 -lb bombs, and $750-\mathrm{lb}$ bombs. Nerve agent $\mathrm{VX}$ is contained inside 155 -mm projectiles, 8-in. projectiles, M55 rockets, M23 land mines, and spray tanks. The GB and VX agents and munitions are stored in approximately 90 igloos. The inventory of munitions at UMDA is classified except for the M55 rockets which have been declared to be obsolete munitions. There are 91,606 GB rockets and 14,519 VX rockets (a total of 106,125 M55 rockets) at UMDA. Blister agent $\mathrm{HD}$ (mustard) is stored in steel one-ton containers inside a single storage warehouse.

\subsection{OBJECTTVES AND SCOPE}

To reasonably and objectively compare the various programmatic alternatives, the FPEIS employed some generic assumptions and inputs such as process and handling descriptions, on-site distances (such as storage-to-plant transport distances and distances to the nearest installation boundary), and certain meteorological data. Other assumptions and inputs were more site-specific, as appropriate, to allow a reasonable comparison of alternatives. For example, the actual chemical munitions inventory, as 

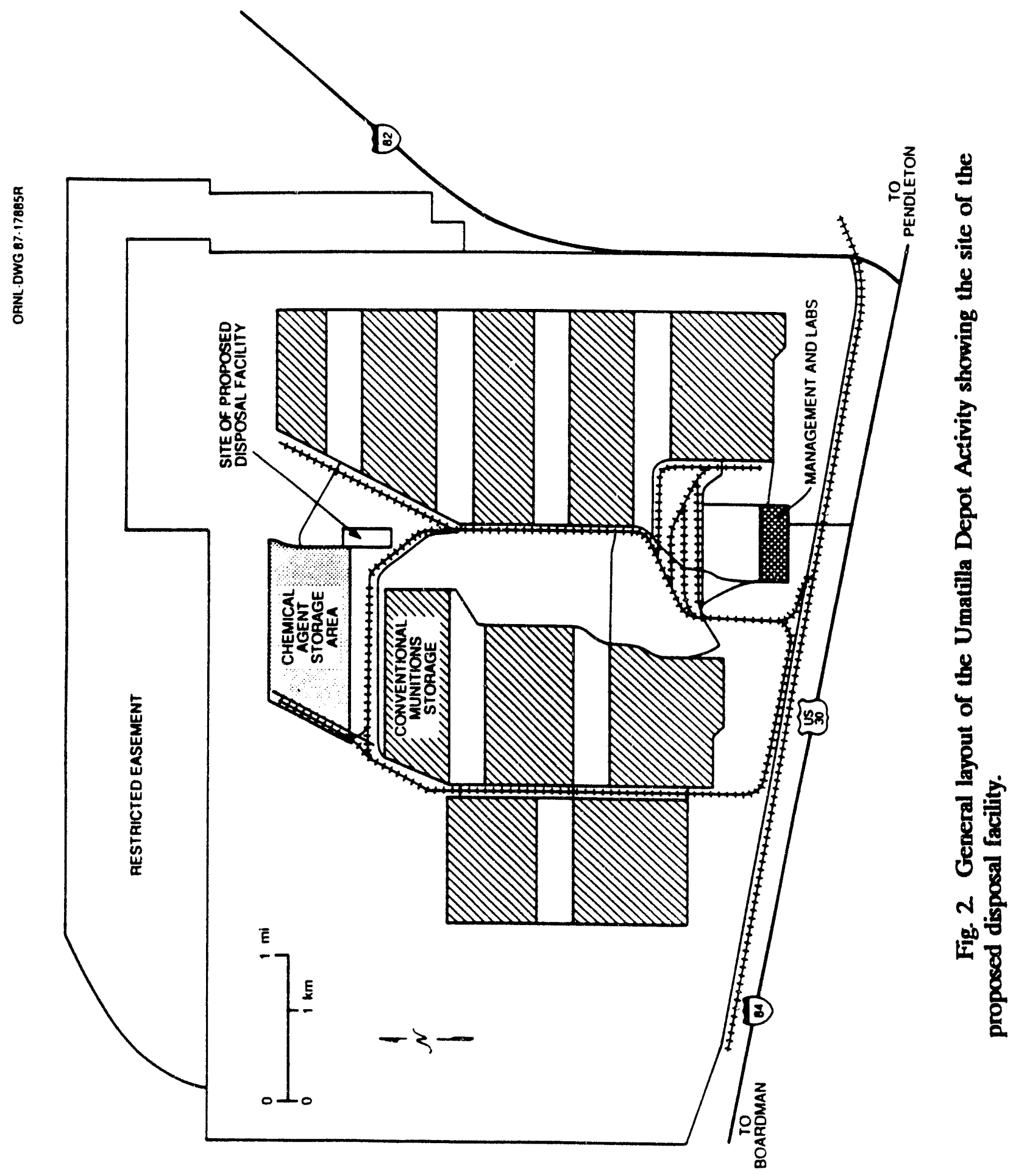
well as the residential population, at each site were incorporated into the FPEIS accident analyses.

The purpose of this report is to examine the proposed implementation of on-site disposal at UMDA in light of more recent and more detailed data than those on which the FPEIS is based. Two principal issues are addressed (1) whether or not the nuw data would result in the rejection of on-site disposal at UMDA as the environmentally preferred alternative (using the same methods and data analysis tools as in the FPEIS), and (2) whether or not the new data indicate the presence of significant environmental resources that could be affected by implementation of on-site disposal at UMDA. For the first issue, the data are confined to those same data types used in the FPEIS to identify the environmentally preferred alternative. To address the second issue, existing data on all environmental resources that could potentially be affected by on-site disposal at UMDA are examined and summarized. In addition, status reports are also presented on the technical progress and maturity of the disposal technology (and how it could affect on-site disposal at UMDA) and on the tracking of changes in plant design and operating procedures to ensure that the overall risk presented in the FPEIS for UMDA is not exceeded.

This Phase I Environmental Report is not intended to validate the Army's programmatic ROD for the CSDP; it can only confirm or reject the environmentally preferred alternative (on-site disposal) as identified in the FPEIS for UMDA. Data gathered during the Phase I process include (1) any new information that was not available for use in the FPEIS, (2) more detailed information than was required for the programmatic purpose of comparing alternatives in the FPEIS, and (3) any information that may have been overlooked in the FPEIS.

In light of the first issue to be addressed in Phase I, the scope of this Phase I Environmental Report is limited to reexamining the FPEIS environmentally preferred alternative (i.e., on-site disposal) in light of more recent and detailed data. The scope of the reexamination is limited to on-site activities associated with the UMDA stockpile: continued storage; on-site disposal; or any packaging, on-site movement, and temporary storage associated with off-site disposal. This report does not address potential risks or impacts from possible actions taken outside the installation boundary (e.g., transportation from one installation to another, unloading at the receiving installation, etc.). However, on-site activities associated with the national disposal alternative are considered in the reexamination and comparison of risks among alternatives at UMDA. The technological and procedural characteristics used to reexamine the environmentally preferred alternative in this Phase I Report are the same as those given in the FPEIS (U.S. Army 1988a, Vol. 1, Sect. 2 and Vol. 3, Appendices A, C, and G) and in support studies referenced in the FPEIS. In terms of the second major issue to be addressed in Phase I, the scope is limited to potential resources that could be affected by on -site disposal at UMDA.

The potential impact region addressed by this document is limited to the area within $100 \mathrm{~km}$ (62 miles) of the site of the proposed disposal facility at UMDA (see Fig. 3). This area [which is also referred to as the $100-\mathrm{km}$ (62-mile) zone] is the largest credible zone of potential human health impacts as identified in the FPEIS. At UMDA, 
ORNL.DWG 89.1780

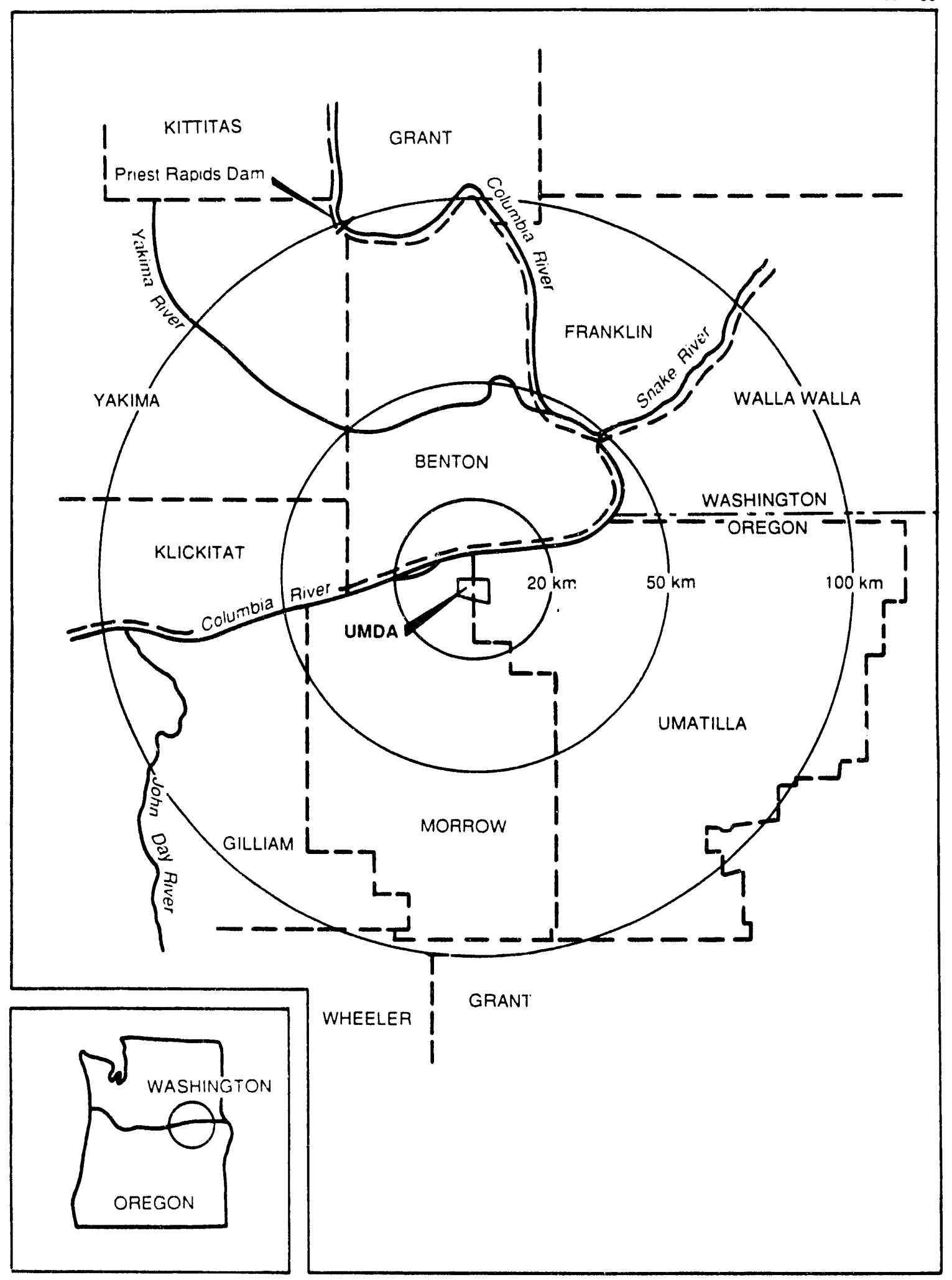

Fig. 3. Location of the Umatilla Depot Activity with respect to zones of potential impact. 
the continued storage alternative, as well as the regional and national disposal alternatives, were postulated in the FPEIS to result in potential human fatalities to a distance of $100 \mathrm{~km}$ (62 miles); on-site disposal at UMDA was estimated to result in potential human fatalities to a distance of $50 \mathrm{~km}$ ( 31 miles). Thus, different impact zones are applicable to different alternatives. Also, in the FPEIS, information on some of the resources was collected for zones of different sizes [e.g., socioeconomic information was collected for a 10-km (6.2-mile) zone]. This Phase I Report summarizes information on potentially affected resources to the minimum distance applicable for the alternatives under consideration. Some resources are described for larger regions as appropriate (e.g., ecological impacts do not necessarily coincide with the zone for human fatalities; economic impacts are more appropriately described on a multi-county or regional basis).

Section 2 describes the approach taken to reassess the programmatic data for UMDA. It defines and outlines the framework under which the reexamination of FPEIS data is to be performed. The section also provides an overview of the methodology employed in the FPEIS to identify the environmentally preferred alternative (more detail is given in Appendix A).

Section 3 presents and compares the newly collected site-specific information and data for UMDA. Data are organized according to those affecting the process for identifying the environmentally preferred alternative (Sect. 3.1) and those relevant to site-specific implementation of on-site disposal (Sect. 3.2). Section 3.3 addresses technological considerations, such as maturity and status of the disposal process, and Sect. 3.4 discusses risk assurance.

A summary of Phase I findings is given in Sect. 4, along with conclusions regarding preparation of the site-specific EIS for UMDA.

\subsection{REFERENCES}

Argonne National Laboratory 1989. Chemical Stockpile Disposal Program: Review and Comment on the Phase I Environmental Report for the Tooele Army Depot, Tooele, Utah, ANL/EES-TM-359 Argonne, III., January.

U.S. Army 1988a. Chemical Stockpile Disposal Program Final Programmatic Environmental Impact Statement, Vols. 1, 2, and 3, Program Executive Officer-Program Manager for Chemical Demilitarization, Aberdeen Proving Ground, Md., January.

U.S. Army 1988b. Record of Decision for the Chemical Stockpile Disposal Program, Office of the Under Secretary of the Army, Washington, D.C., February.

U.S. Army 1988c. Chemical Stockpile Disposal Program-Final Phase I Environmental Report for Tooele Army Depot, Tooele, Utah, Program Executive Officer-Program Manager for Chemical Demilitarization, Aberdeen Proving Ground, Md., September.

U.S. Army 1989. Disposal of Chemical Agents and Munitions Stored at Anniston Army Depot, Anniston, Alabama-Final Phase Environmental Report, Office of the Program Manager for Chemical Demilitarization, Aberdeen Proving Ground, Md., July. 


\section{APPROACH}

This section provides a general discussion of the process used to identify the environmentally preferred programmatic alternative in the FPEIS (U.S. Army 1988) and the types of data, assumptions, and information that were used. This then provides a basis for a conceptual overview of the Phase I Environmental Report. The approach used to gather data and information during the Phase I process for UMDA is also discussed.

\subsection{IDENTIFYING THE PROGRAMMATIC ENVIRONMENTALLY PREFERRED ALTERNATTVE}

During preparation of the FPEIS, a method was developed to systematically compare programmatic alternatives to identify an environmentally preferred alternative. Alternatives are compared with respect to potential impacts from implementing the alternatives under normal operations and accident scenarios.

The FPEIS concluded that potential impacts from normal operations would be minimal and mitigable and would not be useful for distinguishing among program alternatives. Consequently, potential effects from accident scenarios figured prominently in identifying the environmentally preferred alternative. The method consists of sequential examination and comparison of factors reflecting the programmatic goals of no fatalities and minimal environmental insult. The comparison involved three consecutive tiers of examination for each programmatic alternative: (1) human health impacts, (2) ecosystem and environmental impacts, and (3) feasibility and potential effectiveness of emergency planning and preparedness. Appendix A presents details on how the method was developed and used in the FPEIS. Figure 4 provides an overview of how the method was used to identify on-site disposal as the programmatic environmentally preferred alternative (i.e., the alternative with the least potential for causing adverse impacts). alternatives:

For the first two tiers, five measures of risk were developed to compare

1. Probability of one or more fatalities is the sum of probabilities for only those credible accidents (i.e., accidents with a probability of occurrence greater than one chance in $100,000,000$ ) that could result in one or more fatalities under conservative most likely meteorological conditions. (See Appendix A for description of these conditions.)

2. Maximum number of fatalities is the largest number of potential fatalities from accidental releases of chemical agent. It is the consequence of that single credible accident having the greatest lethal downwind distance and one in which the wind is 


\section{$2-2$}

ORNL. OWG 89M.8762A

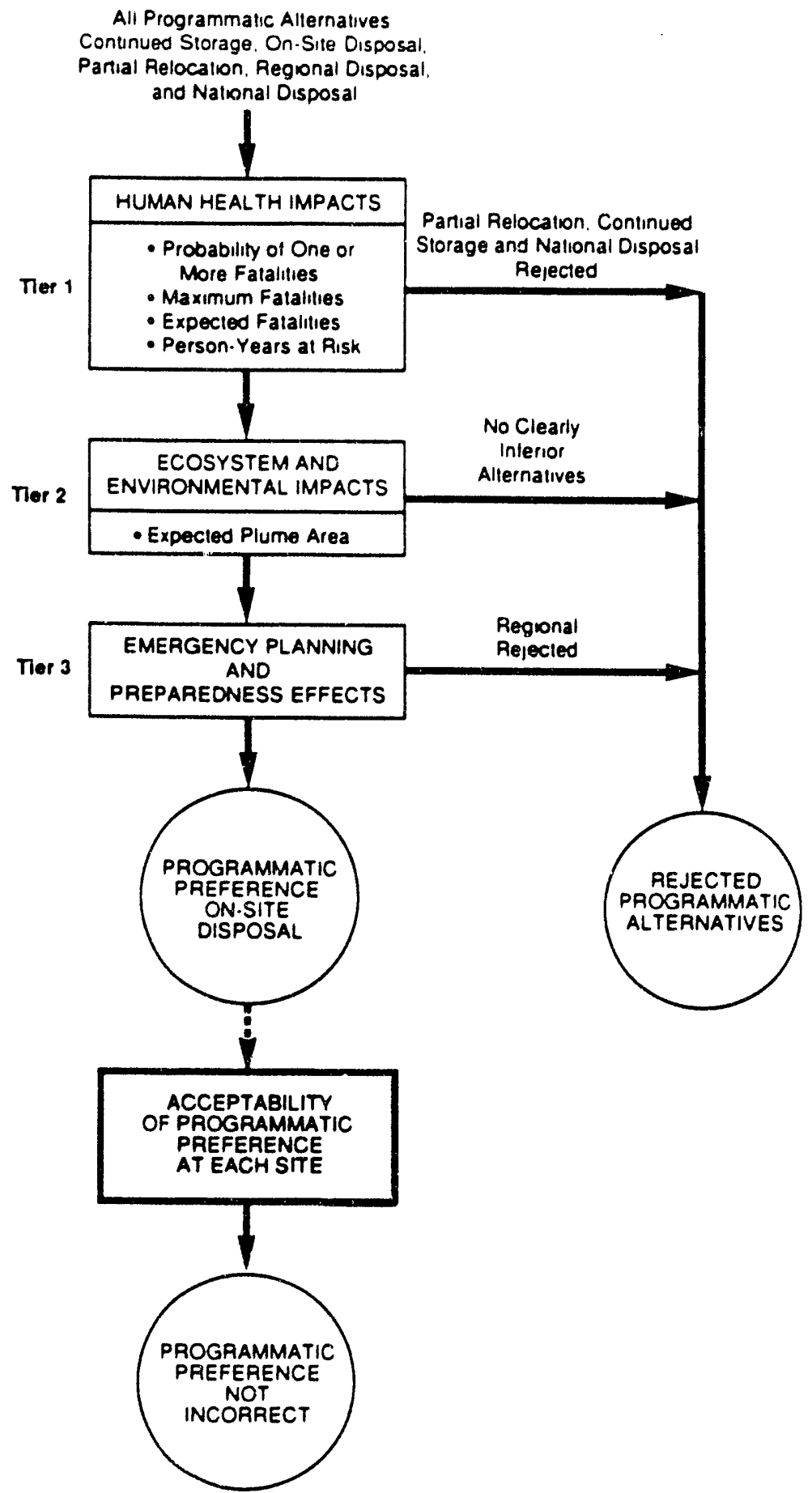

Fig. 4. Flowchart illustrating the process used for identifying the programmatic environmentally preferred alternative (i.e., on-site disposal) for the Chemical Stockpile Disposal Program. 
directed toward the area of maximum population under worst-case meteorological conditions (see Appendix A for description).

3. Expected fatalities are computed as the sum of the products of probabilities and consequences (potential fatalities) for all credible accidents under conservative most likely meteorological conditions.

4. Person-years at risk are computed as the product of the number of people near a site at risk from that credible accident with the greatest downwind distance and the length of time during which that accident could occur.

5. Expected plume area is computed as the sum of the products of plume areas and associated probabilities for all credible accidents under conservative most likely meteorological conditions.

Figure 5 presents a simplified generalization of the types of data used to formulate the five measures of risk. The risk measures can be thought of as being ccmprised of two types of data: residential population and accident probabilities/agent release quantities (the risk measure "expected plume area" is the only one of the five that does not reflect population estimates and is represented solely by the physical characteristics of the accident). Within the population data category, the number of people and their location are of primary interest. Within the accident category, two types of s.ata are of interest: internal and external. Internal data are the technology factors affecting the accident probabilities and agent release quantities: the types of equipment in the technology, the procedures by which the technology is used, and the transportation of the agents and munitions on-site. These are termed "internal" data because they are internal to the Army-that is, the Army can control these through design shanges, procedure changes, or changes in the location of the proposed disposal facility (or railhead loading facility in the case of national disposal). External data, those over which the Army has little (if any) control, are meteorological factors; the amount of aircraft activity (which can be controlled over an installation through the use of prohibited airspace but which cannot be controlled outside this airspace); the frequency and intensity of earthquakes (seismicity); and the frequency of meteorite strikes. The assumptions and information used for the external dara are described in more detail in Appendix A, as are the mathematical processes used to analyze the data for the computation of measures of isk.

Of the five risk measures discussed above, the first four were used for the health effects tier, and the fifth risk measure was used for the ecosystem/environment tier. No risk measures were deemed necessary for the third tier, which dealt primarily with the adequacy of emergency planning and preparedness. The FPEIS method thus consisted of comparing a particular risk measure for a given alternative with the same risk measures for the other alternatives. To avoid presenting classified data on the stockpile at any particular site, the exact numbers calculated for these risk messures were not used on a site-by-site basis. Site-specific numbers were translated into shading patterns in the form of pictograms (Appendix A). 


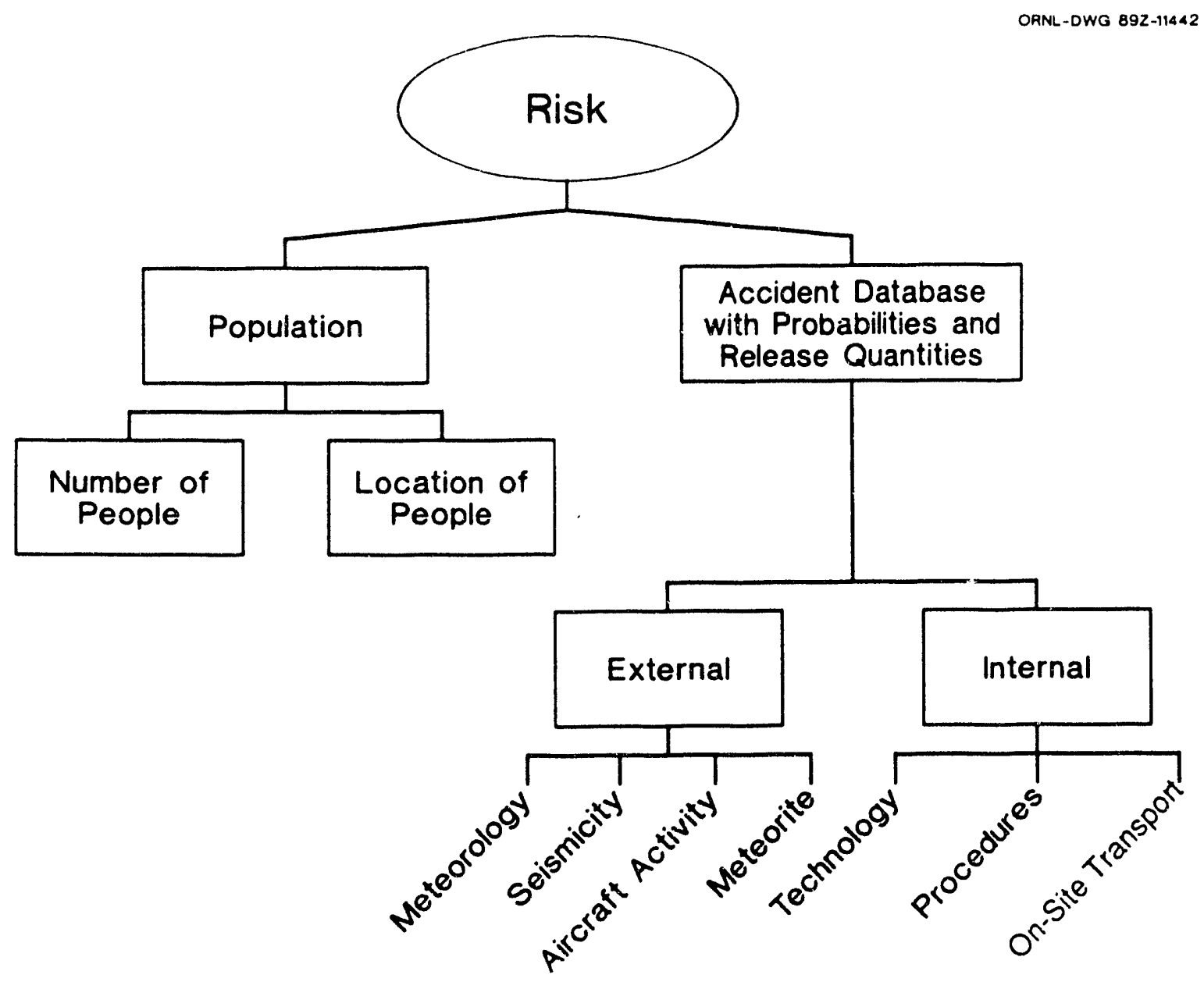

Fig. 5. Conceptual overview of data types used in identifying the programmatic environmentally preferred alternative. 
Because of the uncertainty in the computational value of each measure or risk, it was determined that if the numerical values of risks between alternatives were different by at least a factor of ten, then this would represent a "significant difference." Because the pictogram shading patterns were developed to avoid disclosing classified information, a difference of at least two pictogram shading patterns (such as the difference between the single-diagonal shading and the all-black shading) was thus used as the FPEIS criterion against which a "significance difference" could be determined. If a one-shading difference had been used as the criterion, then the pictograms could not be used to guarantee the factor of ten difference, because the numerical range assigned to each pictogram shading pattern spanned a factor of ten from its lower limit to its upper one. Accepting or rejecting alternatives at a given tier was therefore based upon the fact that a difference between risk measures of at least two pictogram shading patterns represented a "significant difference."

As shown in Fig. 4, all five programmatic alternatives were examined at the first tier (human health) of the process using the first four measures of risk. The FPEIS rejected partial relocation by air, continued storage, and national disposal based on the first four risk measures, leaving regional disposal and on-site disposal for consideration in the second tier. Examining the regional and on-site disposal alternatives in light of ecosystem and environmental impacts did not distinguish between alternatives.

In the third tier (emergency planning and preparedness), regional disposal was rejected because of the greater difficulties in providing adequate emergency response along transportation corridors versus on-site. On-site disposal thus survived the three tiers to become the FPEIS preferred alternative.

The FPEIS went one step further and examined the preferred alternative, using the above process and programmatic-level data for each site, to determine whether or not the risks from on-site disposal were greater than the risks from the other alternatives considered. Note that the FPEIS method for identifying the environmentally preferred alternative was never used to identify on-site disposal at a given installation. Rather it was used to identify a programmatic alternative and was then used to verify that the alternative identified was not incorrect for any given installation. This completed the environmental impact analysis that served as input into the decision process for identifying on-site disposal as the programmatic environmentally preferred alternative.

\section{PHASE I CONCEPTUAL FRAMEWORK}

Figure 6 presents an overview of the Phase I process. The figure is directed at the use of the Phase I data to reexamine the environmentally preferred alternative. The second function of Phase I-examining site-specific resources-is not unique to the Phase I/Phase II process and thus is not highlighted in the figure. In the first step, the data, information, and assumptions used to identify the environmentally preferred alternative are identified (see Sect. 2.1). More recent and site-specific data in these 


\section{$2-6$}

ORNL OWG B9M 8963R

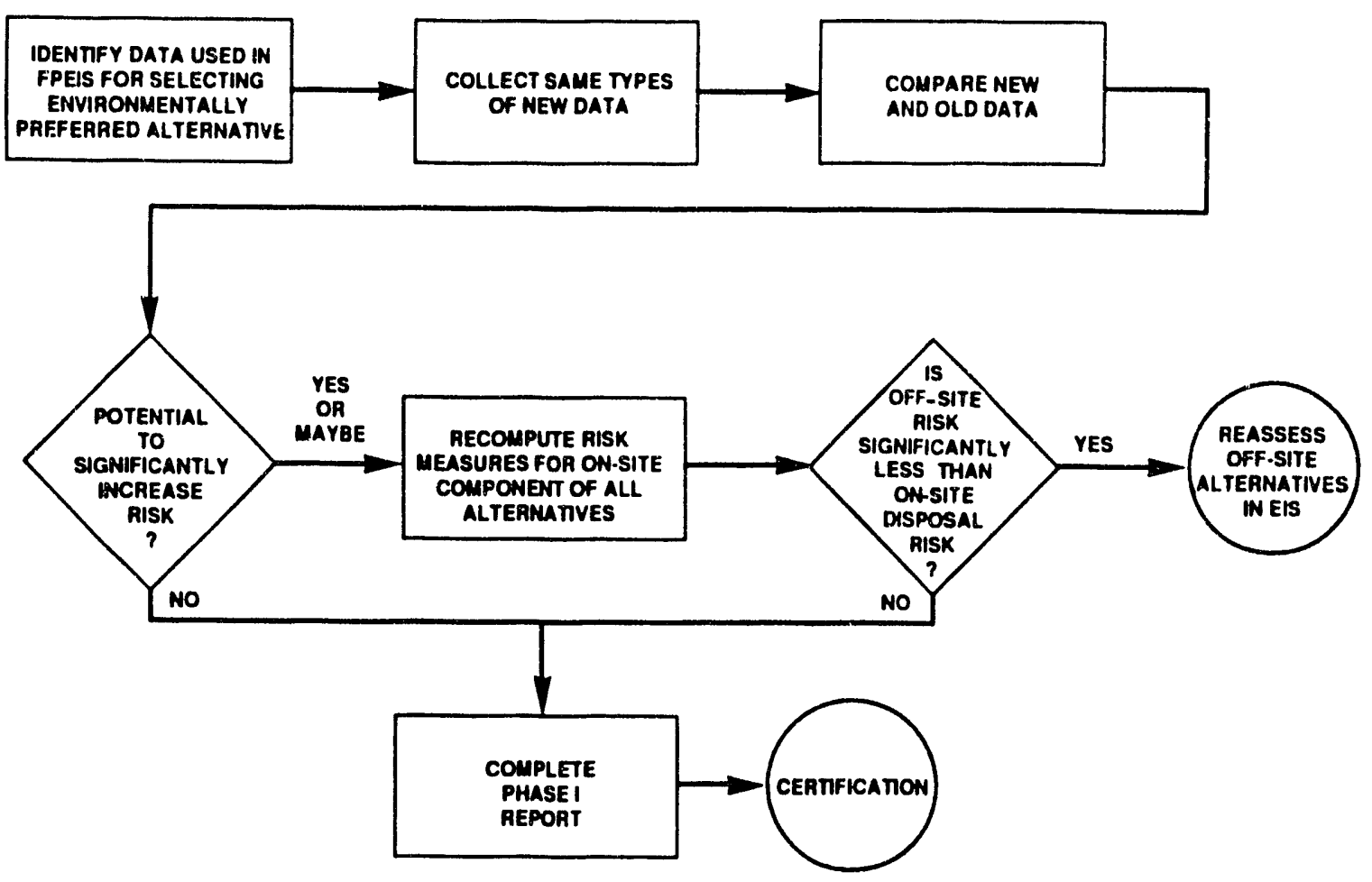

Fig. 6. Flowchart illustrating the Phase I concept. 
areas are then gathered (from scoping meetings, installation visits, contacts with agencies, and other sources) and examined to determine if any changes have occurred that warrant repeating the process for identifying the environmentally preferred alternative. This type of screening function is done to avoid the complex task of recomputing measures of risk "from the ground up" using every piece of new information. The changes in data that show no potential to change the relative ranking in risk for one alternative over another are merely mentioned in the Phase I report. For example, if a given risk measure significantly increases for on-site disposal without increasing the same for the other alternatives, then the programmatic conclusion (that risks from on-site disposal are no greater than those for other alternatives considered) could be changed, thereby triggering reevaluation of off-site alternatives with more recent and detailed data. Thus, major changes in the data are not the only criteria for recomputing risk measures; the data must also demonstrate a potential to affect one alternative more than the others.

New data that are judged to have the potential to increase risk or that are judged to have an uncertain effect on risk are fed into the risk computation. The new data are used to compute the five measures of risk for each applicable alternative (continued storage, on-site disposal, and on-site activities associated with off-site disposal). Those risks are incorporated into the FPEIS method for identifying the environmentally preferred alternative. The results are examined to determine if the risk from off-site disposal is significantly less than the risk from on-site disposal. If the answer is no, the Phase I report is completed, and the Phase I process is certified (thereby allowing preparation of the site-specific EIS). If the answer is yes, then an EIS with a different scope is begun-one that addresses continued storage, on-site disposal, and off-site transportation and disposal at another installation as alternatives.

The use of the FPEIS method is expected to differ slightly in the Phase I report from that in the FPEIS. In the FPEIS, emergency planning and preparedness played an important role in identifying the environmentally preferred alternative, as shown in Fig. 4. For the scope of this Phase I Report, which is directed at distinguishing among disposal alternatives with respect to the population near UMDA, emergency planning will not be an important factor because the Army has begun enhancements of emergency planning and preparedness for UMDA and vicinity (as well as for the other seven installations). Because the population near UMDA will benefit from the effort to enhance emergency planning and preparedness regardless of the alternative under consideration, emergency planning has limited, if any, potential to affect the identification of the environmentally preferred alternative. For the population along a transportation corridor to an off-site disposal location, the planned enhancements to local emergency preparedness would provide no benefit. For these reasons, the reexamination of the environmentally preferred alternative in this Phase I report is based primarily on the five measures of risk and the first two tiers of the FPEIS selection method (see Fig. 4).

As discussed in Sect. 2.1, the risk measures can be thought of as being comprised of two principal types of data: internal and external. The internal data in the accident 
database can change as the Army revises procedures and modifies the technology of the disposal process. However, a risk assurance study is underway (see Sect. 3.4) that examines the ramifications of major design changes on risk. Any change in risk will be evaluated to determine whether there is a reason for the selection of the programmatic alternative (on-site disposal) to be revisited. Thus, the risk assurance study is petforming the function of Phase I with a slightly different approach-instead of assessing the risk ramifications of design changes, it is ensuring that such changes will not produce values for on-site disposal risk that could revise the relative ranking of the FPEIS alternatives. Therefore, data on technology and procedures are not examined in this Phase I report. The Phase I approach can thus be considered as conservative in that credit has not been taken for those technology changes that have been made to enhance public safety. Onsite transport is examined in this Phase I Environmental Report because it is concerned with factors that can change due to the characteristics of each installation and its associated stockpile (even though they are still factors over which the Army has control). The primary factors associated with on-site transport are the type of agents and munition to be transported and the distance over which the agents and munitions would be transported.

External data represent factors largely beyond Army control that could affect risk and, therefore, identification of the environmentally-preferred alternative. Each of these data types is examined in this Phase I report to determine if FPEIS data are representative of actual conditions at a given installation. For example, an evaluation is made as to the extent to which meteorological conditions (mixing height, atmospheric stability, and wind speed) at an installation are representative of the values generically assumed in the FPEIS analyses. Recent and more detailed data on earthquake, tornado, and meteorite frequencies are examined to see if they confirm the values given in the FPEIS. Data on levels of aircraft activity, including the presence of restricted areas, the type of aircraft, the type of airspace use, and flight frequencies are also evaluated.

\section{DATA COLLECTION AND AGENCIES CONTACTED}

This document is supported by data collected by the authors during site visits to the Umatilla, Oregon, area in February 1989. A scoping meeting was also held in Hermiston, Oregon, on February 15, 1989, to solicit public input to the NEPA process and to determine the significant issues relating to the proposed action. Six persons registered to make public comments at the scoping meeting. In addition, six letters were received after the scoping meeting.

Comments from the scoping process dealt with (1) the adequacy of emergency response capabilities in the UMDA area; (2) concern for protecting the segment of the Oregon Trail that crosses the northeast corner of the UMDA installation; (3) a recommendation for chemical agent monitoring stations to be established around UMDA along with the acquisition of baseline data; (4) concern that the disposal facility would not be dismantled as proposed, but would be sold as a commercial enterprise; (5) a request for the details of facility closure to be addressed in the EIS; (6) a request that 
all applicable local, state, and federal environmental laws and regulations be included in the EIS along with an indication of how these will be adhered to; (7) concern about the economics of bringing large numbers of plant workers into the "economically depressed" UMDA region; (8) concern over who would bear the cost (liability) of incidents or accidents if they occur; (9) concern that the "useful $10 \%$ " of the U.S. stockpile, as reserved in Pub. L. 99-145 for delayed destruction pending acquisition of binary chemical weapons, would affect the UMDA disposal activities; (10) concern over how the Army's proposed actions would fit with the Pacific Northwest Hazardous Waste Advisory Council in regard to incineration and management of hazardous wastes in the region; and (11) concern that the state of Washington could be affected and was not considered in the EIS scoping process. Each of the above comments is to be addressed in the site-specific EIS for UMDA; because they involve impact assessment, they are beyond the scope of this Phase I report.

To support the identification and assessment of issues in the FPEIS, the Army funded community studies for five of the eight storage sites. (The other three sites declined the opportunity to prepare such studies). UMDA was one of the five sites for which studies were prepared. The UMDA community study (Umatilla County Soil and Water Conservation District 1987) has been reviewed for this Phase I report. While 41 recommendations and conclusions are contained in that community study, none are specifically related to the data or assessment framework of this Phase I report. Their specific comments, relating to the adequacy and use of the FPEIS atmospheric dispersion model have been addressed in Sects. 3 and 3.1.2.2. The other community comments, will be addressed in the site-specific EIS for UMDA.

Written comments on the FPEIS, received since its publication, also have been reviewed. While comments were received from the state of Oregon (Department of Environmental Quality), the Audubon Society of Portland, and S. Hargrove (a private citizen), none has dealt specifically with the identification of new or overlooked environmental resources near UMDA for inclusion in this Phase I report.

Input was also solicited from the state of Washington and from the EIS cooperating agencies, which include the U.S. Department of Health and Human Services (DHHS); the U.S. Environmental Protection Agency (EPA); the Federal Emergency Management Agency (FEMA); and the state of Oregon. Information obtained from these agencies was considered in conducting this analysis. Letters were received from the cooperating agencies and from the state of Washington commenting on the draft version of this document. Appendix $\mathrm{F}$ displays these letters and also provides responses to the written comments.

In addition to the documents referenced throughout this report, the following agencies were contacted during the collection of data during the Phase I process:

Benton-Franklin Governmental Conference, Richland, Wash. (M. Bigby, Planning Coordinator).

Boardman Fire Department, Boardman, Oreg. (B. McKinley, Fire Chief). 
Boardman Police Department, Boardman, Oreg. (S. Zielinski, City Clerk).

Cascade Natural Gas Corporation, Hermiston, Oreg. (A. Piquet).

Confederated Umatilla Tribes, Umatilla, Oreg. (C. Spencer, Safety Officer).

City of Hermiston Fire Department, Hermiston, Oreg. (S. Frazier, Assistant Fire Chief).

City of Hermiston Poïice Department, Hermiston, Oreg. (M. Vancleave).

East Central Oregon Association of Counties, Pendleton, Oreg. (K. Cooper, Planner).

Eastern Oregon Correctional Institution, Pendleton, Oreg. (S. Jackson, Executive Assistant to the Superintendent).

Federal Aeronautics and Aviation Administration, Seattle, Wash. (R. Brown, Regional Office).

Heppner Fire Department, Heppner, Oreg. (F. Burkenbine, Fire Chief).

Hermiston Good Samaritan Center, Hermiston, Oreg. (A. Kendall, Office Manager).

Heppner Police Department, Heppner, Oreg. (M. Cowett, Assistant Chief).

Hermiston School District, Hermiston, Oreg. (D. Gaylord, Personnel Manager).

Irrigon Police Department, Irrigon, Oreg. (J. Cooley, Police Chief; M. McKay, Public Safety Officer).

Lexington Fire Department, Lexington, Oreg. (B. Sheirdon, Fire Chief).

Lifecare Center of Kennewick, Kennewick, Wash. (H. Batchelor, Administrator).

Mayor of Irrigon, Irrigon, Oreg. (D.V. Eppenbach).

Morrow County Emergency Management, Irrigon, Oreg. (D. Seager, Director).

Morrow County Sheriff's Office, Heppner, Oreg. (T. Denton, Assistant Office Manager).

Naval Air Station Whidby 1, Medium Attack Electronic Warfare Wing Pacific, Oak

Harbor, Wash. (Sr. Chief Haley, Operations Officer).

Oregon Department of Environmental Quality, Salem, Oreg. (D. Brannock). 
Oregon State Office of Historical Preservation, Salem, Oreg. (R. Whitlam, State Archaeologist).

Pendleton Police Department, Pendleton, Oreg. (C. Strafy, Police Chief).

Portland General Electric Company, Portland, Oreg. (T. Worrell).

Port of Umatilla, Umatilla, Oreg. (O. Dugger).

Royal Columbia Retirement Inn, Kennewick, Wash. (J. Knighten).

Stanfield Police Department, Stanfield, Oreg. (T. Wainright, City Clerk).

State Department of Geology and Mineral Industries, Portland, Oreg.

Umatilla County Agricultural Extension, Umatilla, Oreg. (L. Fitch, County Extension Agent).

Umatilla County Planning Office, Pendleton, Oreg. (D. Olson, Planning Director and Emergency Planning Coordinator).

Umatilla County Sheriff's Office, Pendleton, Oreg. (T. Hamby, Administrative Assistant).

Umatilla Police Department, Umatilla, Oreg. (Lt. Polliver).

Umatilla School District \#6, Umatilla, Oreg. (C. Brown, Business Manager and K. Foster).

UMDA National Guard/Reserve Activities, Umatilla, Oreg. (R. White, Coordinator).

U.S. Department of the Interior, Office of the National Register, Washington, D.C. (J. Byrne).

U.S. Department of the Interior, U.S. Geological Survey, Water Resources Division, Pacific Northwest District, Portland, Oreg. (E. Bolke, Supervisory Hydrologist).

U.S. Fish and Wildlife Service, Portland, Oreg. (D. Hwang).

U.S. Fish and Wildlife Service, Portland, Oreg. (R. Peterson).

U.S. Geological Survey, Books and Open-File Reports Section, Denver.

Vista View Care Center, Kennewick, Wash. (T. McLenegan, Administrator). 
Washington Department of Natural Resources, Division of Geology and Earth Resources, Olympia, Wash.

Washington State Penitentiary, Walla Walla, Wash. (R. Johnson, Safety Program Manager).

\section{REFERENCES}

U.S. Army 1988. Chemical Stockpile Disposal Program Final Programmatic Environmental Impact Statement, Vols. 1, 2, and 3, Program Executive OfficerProgram Manager for Chemical Demilitarization, Aberdeen Proving Ground, Md., January.

Umatilla County Soil and Water Conservation District 1987. Evaluation of the Draft Programmatic Environmental Impact Statement for the Destruction of Chemical Munitions Stored at the Umatilla Army Depot and Other Army Facilities, SAPEOCDE-IS-87016, Pendleton, Oreg. 


\section{COMPARISON OF SITE-SPECIFIC AND PROGRAMMATIC DATA}

The two major parts of this section deal with (1) reexamining the identification of the environmentally preferred alternative for UMDA using recent and more detailed data than those in the FPEIS and (2) describing those environmental resources that could be affected by on-site disposal at UMDA.

As discussed in Sect. 2, the reexamination of the FPEIS environmentally preferred alternative in this Phase I Report is largely based on the evaluation and comparison of human health risks. Two major components of this comparative analysis are population data and atmospheric dispersion modeling.

The choice of an atmospheric dispersion model in the FPEIS was limited by the nature of the accidentally released chemical agents and the complexity of the disposal program. One requirement of the model or models selected for use in estimating environmental impacts was to calculate the downwind doses from agents emitted to the atmosphere from accidents (e.g., spills of liquid agent, detonation of munitions, and vapor releases from fires). In addition, the model was required to analyze the effects of thousands of potential releases under various meteorological conditions.

The atmospheric dispersion model D2PC developed by the U.S. Army's Chemical Research, Development, and Engineering Center (Whitacre et al. 1986) was used to assess the potential impacts of the proposed action and alternatives in the FPEIS. The D2PC model assumes a Gaussian distribution of agent in the vertical and cross-wind directions as the agent disperses downwind. This assumption has been documented extensively in the literature and is used by a multitude of current models. Although more sophisticated dispersion codes are available, the assumption of straight-line downwind transport of chemical agent with non-varying meteorological conditions results in conservative estimates (i.e., overpredictions) of the effects of releases. A specific point of release was not identified in the D2PC analyses, but instead a generic location was used. This assumption was made due to the number of potential release sites at each facility as well as the potential for release during the transportation alternatives analyzed. Therefore, identical downwind distances were obtained for identical accidents for all alternatives. This simple approach, while inappropriate for estimating the impacts of any given release under real-time conditions, is appropriate for analyzing and comparing the potential effects of the many postulated accidental releases.

To ensure consistency between the FPEIS and the site-specific EISs, and to allow direct risk comparisons among the site-specific and programmatic documents, the same model (D2PC) is used in this Phase I Report. Use of a model other than D2PC could result in a risk estimate different than in the FPEIS due solely to the new model and not to any significant changes in facility design or the incorporation of site-specific data into the assessment.

In order to reexamine the five FPEIS measures of risk, Sect. 3.1 uses data collected during Phase I as input data to the FPEIS method for identifying the 
environmentally preferred alternative. Section 3.1 is thus an extension of Sect. 2.6.3.3.8 in the FPEIS, which incorporated programmatic data in the examination of on-site disposal at UMDA using human health impacts, ecosystem/environmental impacts, and emergency planning and preparedness considerations.

Section 3.2 presents data collected during Phase I for site-specific resources that could be affected by construction and operation of a disposal facility at UMDA. Potential effects on these resources will be addressed in the site-specific EIS for UMDA. Section 3.3 addresses the status and maturity of the disposal technology, and Sect. 3.4 discusses technology risk assurance.

Only highlights concerning the newly collected data are given in this section. For some of the resource areas, a more complete presentation of detailed, site-specific information is contained in appendices to this report.

\subsection{REEXAMINING ON-SITE DISPOSAL AS THE ENVIRONMENTALLY PREFERRED ALTERNATTVE}

In the FPEIS, identification of the environmentally preferred alternative was based on a risk analysis for accident conditions. As discussed in Sect. 2, the two types of data germane to the identification process are population and the accident database. Population data are concerned with the number of people and their locations. The accident data are concerned with the probabilities and agent release quantities of various hypothetical accidents associated with each alternative. The probabilities and release quantities can, in turn, be thought of as being affected by external factors (e.g., meteorology, earthquakes, meteorite strikes, etc.) and internal factors (e.g., technology, procedures, and facility location). This section examines population and accident database information collected during Phase I for its potential to affect the programmatic environmentally preferred alternative at UMDA. Using those data that have appreciable potential to preferentially affect a given risk measure for a given alternative, this section reevaluates the risk measures with the new data. The new risk measures are then used as inputs to the FPEIS method for identifying the environmentally preferred alternative to determine if the risks of off-site disposal are less than those for on-site disposal.

\subsubsection{New Values for Programmatic Data and Assumptions and Their Significance}

\subsubsection{Accident database}

As discussed in Sect. 2, of the two major types of data that can affect the accident database (internal and external), the focus in this Phase I Report is on the external data because they represent factors over which the Army has little or no control. 
This section discusses those factors that could have changed from the assumptions in the FPEIS: on-site transportation (haul distances), meteorological factors, earthquakes (seismicity), and aircraft activity, as discussed below.

On-Site Transportation. As discussed in the FPEIS, the risks of on-site transport of agents and munitions are related to accidents that could occur during movement of agents and munitions from storage to the designated disposal facility (whether it is an on-site facility or an off-site facility). The potential risk from a transportation accident is dependent upon a number of factors, including road conditions, vehicle speed on the roads, distance travelled, the types and numbers of agents and munitions to be transported, and whether or not the on-site transportation is associated with on-site or off-site disposal. For this UMDA Phase I Report, on-site transport is relevant to the on-site disposal and national disposal alternatives; the risks from continued storage would be unaffected by any changes in parameters affecting transportation risk. The FPEIS risks to the population near UMDA for the regional disposal alternative were identical to those from national disposal.

The FPEIS assumed that all on-site transport (for on-site, as well as off-site, disposal) at all sites involved a distance of $1.6 \mathrm{~km}$ (1 mile). On-site transportation was assumed to be restricted to a maximum speed limit of $32 \mathrm{~km} / \mathrm{hr}(20 \mathrm{mph})$ during daylight hours and was assumed to occur only under suitable weather conditions (see

Sect. 2.3.2.2.1 of the FPEIS). The condition of the existing roads at UMDA, subsequent to proposed upgrades, are comparable to the road conditions assumed in the FPEIS risk analysis. Factors, other than on-site travel distances, that can be controlled by the Army are incorporated into the standard operating procedures for on-site movement of agents and munitions and, thus, will not be addressed further in this report. The key factor of interest with respect to transportation risks at UMDA is the on-site transport distances.

Transport distances are dependent on the actual roads to be used in moving agents and munitions during on-site disposal and during on-site activities associated with off-site disposal (i.e., national or regional disposal). As shown in Fig. 2, the site of the proposed disposal facility is located about $1.6 \mathrm{~km}$ (1 mile) south of the northern UMDA installation boundary [not including the additional $1.6-\mathrm{km}$ (1-mile) restricted easement]. The actual road distance from the storage area to the site of the proposed disposal facility ranges from $180 \mathrm{~m}$ to $3 \mathrm{~km}$ (600 ft to 1.9 miles), based upon the locations of the storage igloos located the closest and the most distant from the site. The average road distance using these two values is $1.6 \mathrm{~km}$ (1 mile)-the same as assumed in the FPEIS.

For the off-site disposal alternatives assumed in the FPEIS for UMDA, the chemical agents and munitions would be removed from storage and transported to a central, on-site loading area where they would be prepared for off-site transport. The site of such an area for UMDA has not been identified. However, many of the siting criteria used to locate the proposed disposal facility would also be used to locate the central loading area. Consequently, it is concluded that if off-site disposal were selected for the UMDA stockpile, the central loading facility would be located either at the site of the proposed disposal facility or at a location whose distance from the storage area would not appreciably differ from the distance between the storage area and the disposal facility. 
It is therefore concluded that there is no potential for on-site transportation differences between the FPEIS and Phase I to affect risk. The recomputation of on-site transportation risk is unwarranted, and this area will not be addressed further in this report.

Meteorology. The principal type of metcorological data of interest to the selection of the environmentally preferred alternative is the applicability of meteorological conditions assumed in the FPEIS: wind speed, atmospheric stability, and mixing height. Tornadoes are discussed in a separate section in conjunction with meteorites.

Meteorological data for UMDA were examined to evaluate the appropriateness of the "conservative most likely" (CML) and "worst case" (WC) meteorological conditions as used in the FPEIS. The CML scenario represents a frequently occurring meteorological condition that results in relatively large doses compared with other frequently occurring conditions. Specifically, neutral atmospheric stability (Class D) with a wind speed of $3 \mathrm{~m} / \mathrm{s}$ [6.6 miles per hour (mph)] was selected for the CML condition. The WC scenario represents a credible condition that results in near-maximum doses. Specifically, a stable atmosphere (Class E) with a wind speed of $1 \mathrm{~m} / \mathrm{s}(2.2 \mathrm{mph})$ was chosen for the WC condition.

In order to evaluate the appropriateness of these two meteorological conditions for UMDA, it is necessary to obtain accurate measurements of wind speed and to derive accurate stabilities. As discussed in Sect. 3.2.1, wind data from the meteorological tower at UMDA are recorded and saved on analog 24-hr circular charts, but the information is not in a ready-to-access form because it has not been digitized. In addition, atmospheric stability information is not recorded at the UMDA meteorological tower.

The wind data used in the FPEIS was taken from the Portland General Electric Company (PGEC) meteorological tower, located $6.5 \mathrm{~km}$ south of the chemical exclusion area (see Fig. 7). During Phase I, these data were reexamined for quality assurance and appear to be both accurate and reliable. The distribution of stabilities derived from the wind data is also reasonable, both by time of day and for the overall period of record.

An attempt was made to compare the FPEIS data (i.e., the data from the PGEC meteorological tower) to appropriate data from the UMDA metcorological tower; however, the appropriate UMDA data cannot be located. In fact, there are no periods of matching data for the PGEC and the UMDA meteorological towers. A direct comparison of data cannot be made.

Figure 8 shows data for the winds blowing from each direction at the PGEC tower. Wind directions are shown in Fig. 8 as individual bars; the bar widths denote wind speed, while the frequency of occurrence for each wind speed is denoted by the length of the bar. It should be noted in Fig. 8 that the points on the wind rose represent the directions from which the winds come.

Concerns have been raised as to the relevance of the PGEC data with respect to the meteorological conditions at the site of the proposed UMDA disposal facility because the proposed facility is closer to the Columbia River than is the PGEC tower. Note that Fig. 8 depicts a strong upriver (eastward) bias in wind direction and frequency. 
ORNL-DWG 89-18315

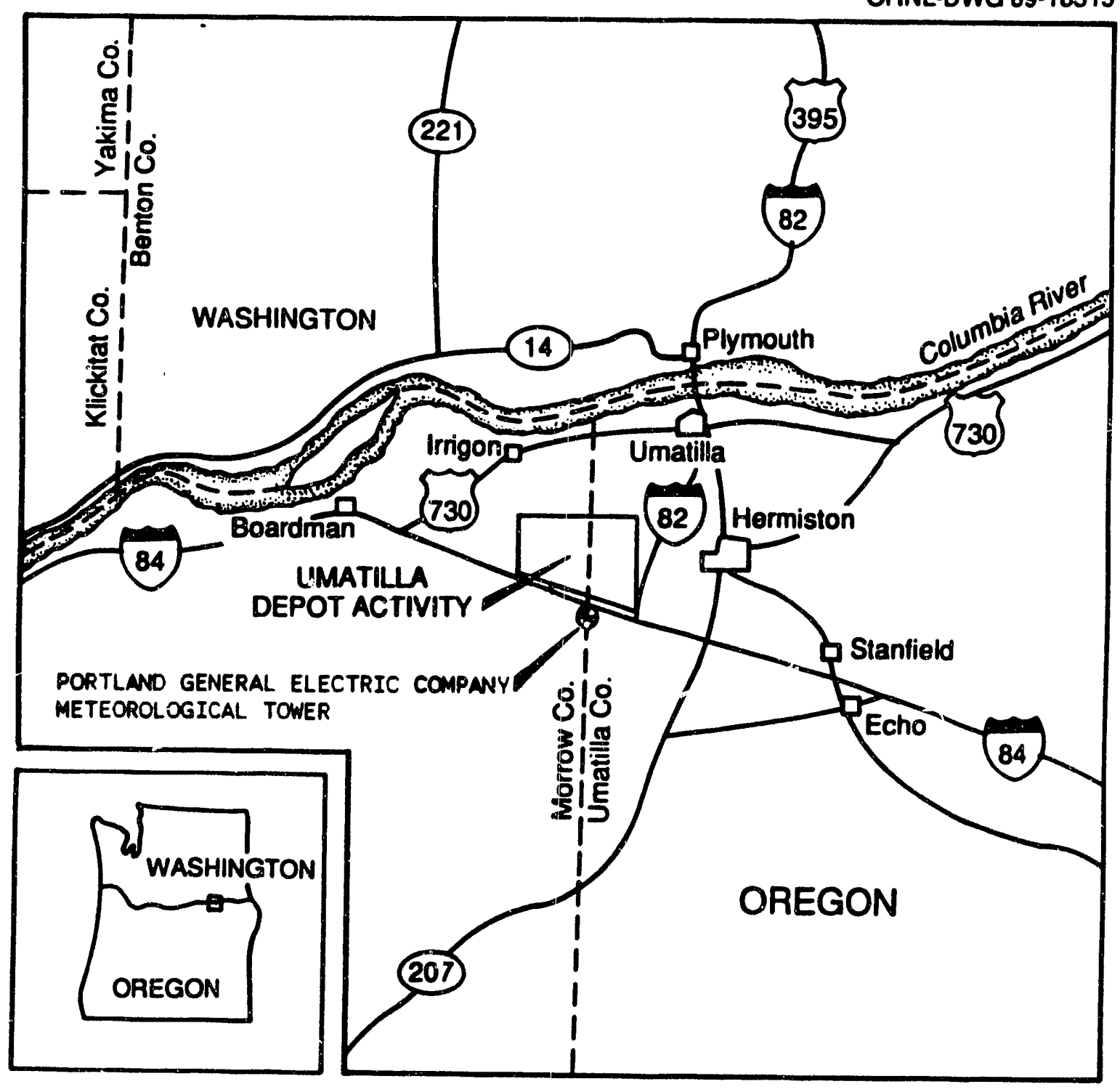

Fig. 7. Location of the Portland General Electric Company meteorological tower which provided site-specific data. 
3-6

ORNL-DWG $87 \cdot 15367 R$

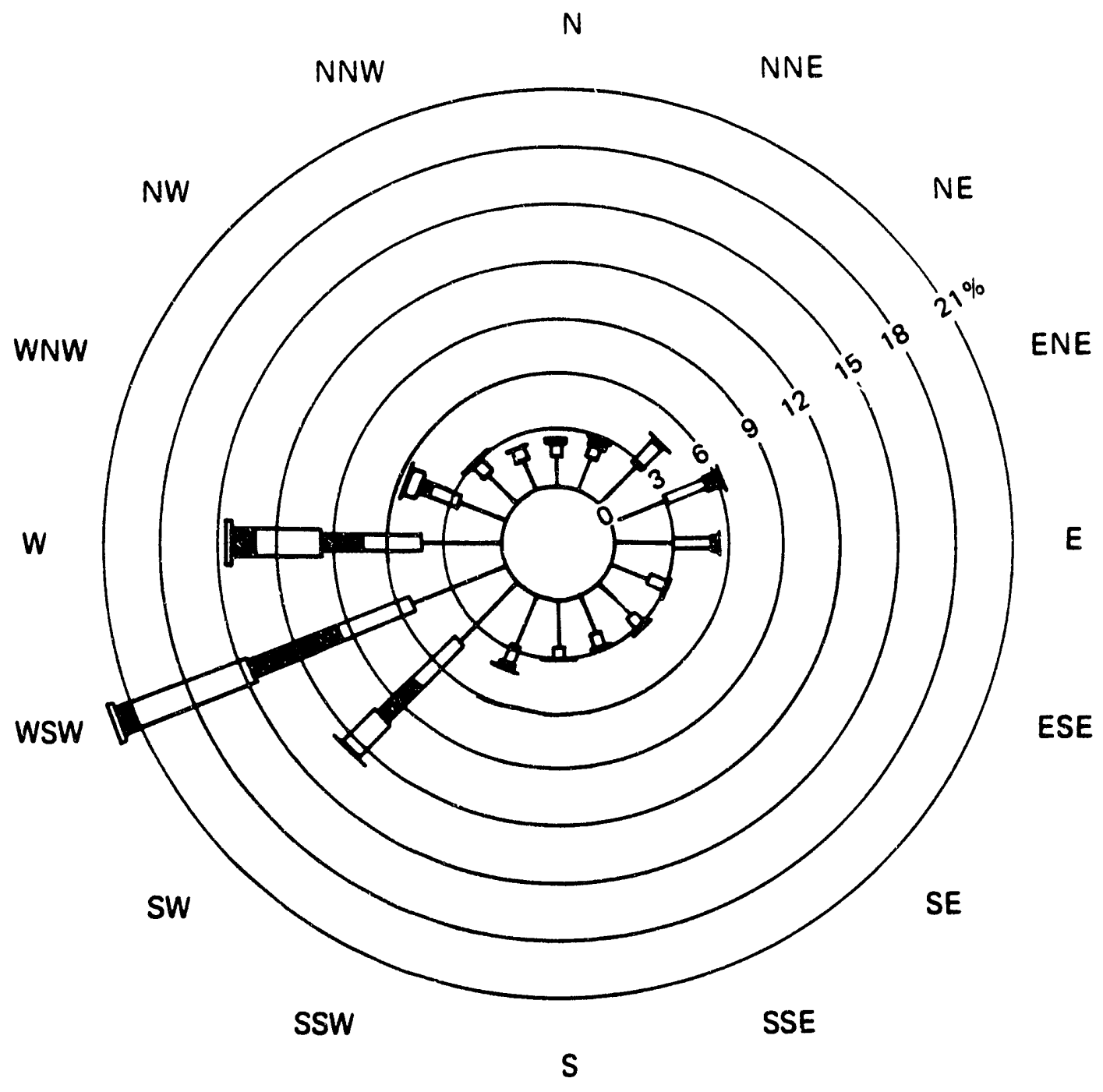

ORDNANCE, OR

(PORTLAND GENERAL ELECTRIC CO.)

JAN 1, 1980 - DEC 31, 1980

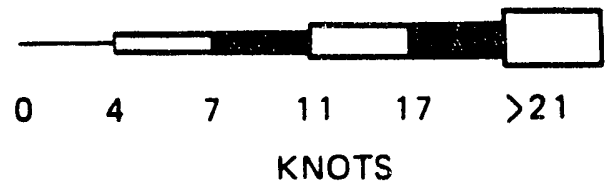

Fig. 8. Wind rose (joint annual frequency distribution of wind speed and wind direction) for the data collected at the Portland General Electric Company meteorological tower. 
It is difficult to imagine how the Columbia River might affect meteorological conditions more severely than already indicated at the PGF:C tower.

The joint frequency distribution of stabilities and wind speed classes was constructed to determine the applicability to UMDA of the CML and WC meteorological conditions (see Table 1). In other words, the distribution was examined because it depicts the frequency of occurrence of conditions that are nearly identical to CML (D stability with $3 \mathrm{~m} / \mathrm{s}$ wind speed) and WC (E stability with $1 \mathrm{~m} / \mathrm{s}$ wind speed) conditions. The distribution in Table 1 indicates that neutral atmospheric stability (Class D) occurs more often (greater than $52 \%$ of the time) than any of the other classes, and D stability with winds between 2.1 and $3.6 \mathrm{~m} / \mathrm{s}$ (4.7 and $8.1 \mathrm{mph}$ ) occurs about $10 \%$ of the time, more than any other wind speed class within D stability except the $16 \%$ and $14 \%$ occurrences of winds less than or equal to $2.1 \mathrm{~m} / \mathrm{s}(4.7 \mathrm{mph})$ and between 5.7 and $8.7 \mathrm{~m} / \mathrm{s}$ (12.8 and $19.5 \mathrm{mph}$ ), respectively. The higher wind speeds would result in less conservative predictions (lower estimated doses) than the CML conditions chosen in the FPEIS; however, the lower wind speeds have the potential to result in higher doses of chemical agent and, therefore, potentially larger estimated fatalities from accidents. The risk implications of using a lower wind speed for CML conditions are addressed in Sect. 3.1.2.2.

With regard to WC conditions, although maximum predicted doses result from Class F stability with low wind speeds and F stability occurs approximately $16 \%$ of the time at UMDA, F stability was intentionally not used for the WC scenario because predicted doses are greater than doses realistically expected in a credible scenario. During F stability, a puff or plume meanders along a "snakelike" path rather than moving downwind in a line; therefore, actual maximum doses at given locations would be reduced compared with predicted doses that assume continuous exposure along a centerline downwind axis. Class $\mathrm{E}$ stability with low wind speeds produces the next highest predicted doses, and meandering is not as pronounced for $\mathrm{E}$ stability. For this reason, E stability with low wind speeds was selected in the FPEIS as the WC scenario. From Table 1, Class E stability with winds less than or equal to $2.1 \mathrm{~m} / \mathrm{s}$ (4.7 mph) occurs $3 \%$ of the time. Based on these results, it is concluded that the WC meteorological conditions used in the FPEIS are appropriate for UMDA.

The height of the mixed layer is another important meteorological factor affecting predictions of dispersion. Lowering this value would tend to decrease the volume of the atmosphere available for dispersion of agent and potentially increase predicted concentrations of agent in the atmosphere. Data on the height of the mixed layer at UMDA are not available. The best available estimates for this parameter are calculated using a combination of National Weather Service surface data from Pendleton, Oregon, $50 \mathrm{~km}$ ( 31 miles) east-southeast of UMDA, and upper-air data collected at Spokane, Washington, $240 \mathrm{~km}$ (149 miles) northeast of UMDA, the nearest National Weather Service station with upper-air data. Because the height of the mixed layer usually is quite uniform throughout eastern Oregon and Washington at any given time, these estimates of the height are representative of the conditions at UMDA.

The FPEIS used a value of $750 \mathrm{~m}(2461 \mathrm{ft})$ for accidental-release scenarios. An examination of morning and afternoon mixing heights by season for Spokane reveals that 
3-8

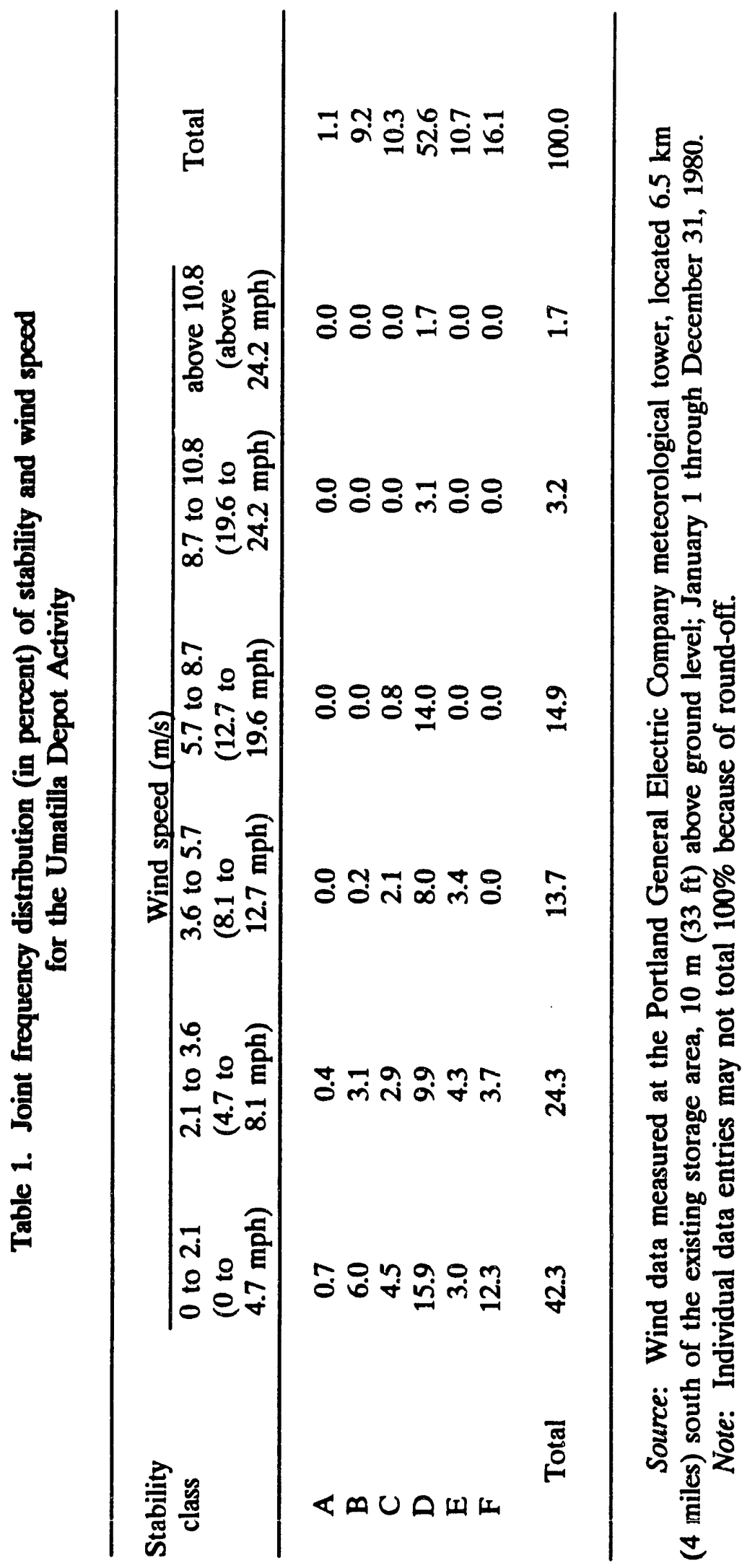


mean morning mixing heights range from $259 \mathrm{~m}(850 \mathrm{ft})$ in the summer to $414 \mathrm{~m}$ $(1358 \mathrm{ft})$ in the winter, and mean afternoon mixing heights range from $523 \mathrm{~m}(1716 \mathrm{ft})$

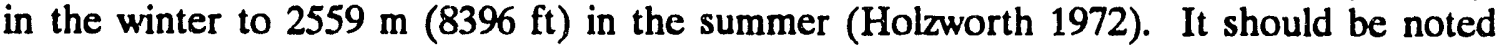
that the mean morning mixing heights are lowered considerably by ground-level inversions during stable conditions and usually would be higher for the CML scenario of neutral atmospheric stability. For the WC scenario, the height of the mixed layer is not of concern because it is unlikely that more intense stable conditions would occur above the surface inversion that causes the stable conditions. Therefore, based on mean values reported by Holzworth (1972), the selection of a height of $750 \mathrm{~m}(2461 \mathrm{ft})$ is appropriate for UMDA.

Seismicity. Seismic data collected during Phase I supplement those in the FPEIS in two important respects. First, foundation conditions (an uncertainty discussed in general terms in the FPEIS) are now known in greater detail. Second, corroborating evidence has been compiled that is consistent with the FPEIS assertion that on-site surface rupture along a fault in the vicinity of UMDA is unlikely. Table 2 summarizes this information.

When the FPEIS was prepared, very little site-specific information was available. The maximum expected earthquake and associated peak ground acceleration (PGA) were not provided. Further, the potential for liquefaction, ground motion magnification, and faults capable of producing on-site surface rupture were considered to be low (based on professional judgment rather than site-specific geotechnical data). Last, earthquake design parameters had not been finalized for the proposed UMDA disposal facility.

Data collected during Phase I show that the proposed disposal facilities will not be damaged by earthquake-generated soil liquefaction. The site for the proposed facility is located on high ground where the water table is more than $30 \mathrm{~m}(100 \mathrm{ft})$ beneath the surface as indicated by nearby water wells (Roy F. Weston, Inc., 1989). The upper $2 \mathrm{~m}$ ( $7 \mathrm{ft}$ ) of soil consists of fine sand and silt of low relative density, but these soils would be removed to prepare the foundation for the toxic cubicle. Deeper soils (up to $60 \mathrm{~m}$ [200 ft] thick) are poorly sorted, gravelly sands of moderate to high relative density as determined by lithologic logs and standard penetrometer tests, respectively (U.S. Army Corps of Engineers open-file data). Such soils are not sensitive to liquefaction (EPRI 1975).

Information collected during Phase I confirms the FPEIS assertion that on-site surface rupture along at active fault at UMDA is unlikely. The nearest recognized fault is $10 \mathrm{~km}$ ( 7 miles) east of the proposed disposal site. This fault is not known to be active [the last known displacement having taken place during Pliocene time ( 2 to 5 million years ago)]. The average slip rate on this fault since the end of Miocene time ( 5 million years ago) is $0.002 \mathrm{~mm} / \mathrm{year}$ [based on data provided by Robison (1971)] or $2 \mathrm{~cm}$ per 10,000 years. In comparison, a major earthquake along an active fault in the western United States might be expected to produce surface ruptures up to 1 or $2 \mathrm{~m}$ per 10,000 years. 


\section{3-10}

Table 2 Summary of sile-epecific and programmatic carthquate parameters and site-epecific earthquate deaign parametern at the Umatillx Depot Activity

\begin{tabular}{|c|c|c|c|}
\hline $\begin{array}{l}\text { Earthquaite } \\
\text { parameters }\end{array}$ & Programmatic EIS & Site-epecific data & $\begin{array}{l}\text { Site-apecific } \\
\text { dexign } \\
\text { parametcrs }\end{array}$ \\
\hline $\begin{array}{l}\text { EPGA } 10 \% \text { probability } \\
\text { of crocodance in } 50 \text { years }\end{array}$ & $\begin{array}{l}\text { Seiamic Zone } 1 \\
\text { EPGA }=0.05 \text { s }^{b}\end{array}$ & $\begin{array}{l}\text { Seidenic Zooc } 1 \\
\text { EPGA }=0.058^{a b}\end{array}$ & $\begin{array}{l}\text { GPSF: } \\
\text { Seismic Zone } 1 \text {, } \\
\text { EPGA }=0.05 \mathrm{~g}^{2, b}\end{array}$ \\
\hline $\begin{array}{l}\text { Mrrimum epected/ } \\
\text { wort care earthquake } \\
\text { on the nearest capable } \\
\text { fault }\end{array}$ & Not provided & 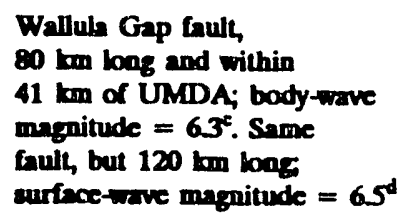 & \\
\hline $\begin{array}{l}\text { PGA for mrimum expected } \\
\text { Carthquike on Wallula } \\
\text { Gap fault }\end{array}$ & Not provided & PGA $=0.10 g^{e}$ & $\begin{array}{l}\text { MDB: } \\
\text { Scirmic Zone } 3 \\
\text { PGA }=0.21 \mathrm{~g}^{\mathrm{ab}}\end{array}$ \\
\hline $\begin{array}{l}\text { PGA for merimum eppected } \\
\text { carthquate on Rattleanate- } \\
\text { Wallula Gap faults combined }\end{array}$ & Nor provided & $\begin{array}{l}\text { Not provided by NRC, but } \\
\text { presumed to differ } \\
\text { incignificantly froes } \\
\text { PGA }=0.10 g^{\varepsilon}\end{array}$ & \\
\hline 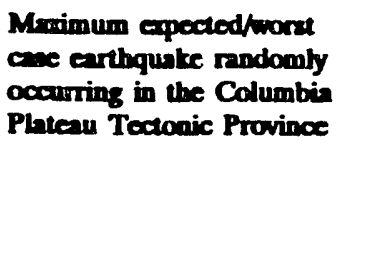 & Not provided & $\begin{array}{l}\text { Mrrimum expected intensity } \\
=\text { VIII (one intensity unit } \\
\text { lareer than mrimum } \\
\text { historical earthquate); } \\
\text { Intcanity VII i } \\
\text { equivalent to body-wave } \\
\text { magnitude = } 5.6^{6}\end{array}$ & \\
\hline $\begin{array}{l}\text { PGA for marimum erpected, } \\
\text { randomb cocurring carth- } \\
\text { quike in the Columbin } \\
\text { Plateau Tectonic Province }\end{array}$ & Nol provided & $\begin{array}{l}\text { PGA }=0.258^{6}, \text { epicenter } \\
\text { at UMDA }\end{array}$ & $\begin{array}{l}\text { Toric cubicle } \\
\text { inaide MDB: } \\
P G A=0.818\end{array}$ \\
\hline $\begin{array}{l}\text { Potential for } \\
\text { liquefinction }\end{array}$ & $\begin{array}{l}\text { Unlikely } \\
\text { (protesional } \\
\text { judgenent) }\end{array}$ & $\begin{array}{l}\text { Unlitety, low than } 2 \mathrm{~m} \text { (7 ft) } \\
\text { of bose woil and more than } \\
30 \mathrm{~m}(100 \mathrm{f}) \text { to water table }\end{array}$ & \\
\hline $\begin{array}{l}\text { Potentivl for ground } \\
\text { magnification }\end{array}$ & $\begin{array}{l}\text { Slight } \\
\text { (proferaional } \\
\text { judgment) }\end{array}$ & $\begin{array}{l}\text { Slight; wo more than } 60 \mathrm{~m} \\
\text { (200 f) of unconeclidated } \\
\text { rediments and lem than } \\
2 \mathrm{~m}(7 \mathrm{ft}) \text { of bowe soi }\end{array}$ & $\begin{array}{l}\text { Appropriate motion } \\
\text { response spectra } \\
\text { for decign PGA } \\
\text { and duration of } \\
\text { ahaking }\end{array}$ \\
\hline $\begin{array}{l}\text { Potential for on-aile } \\
\text { surfece rupture along } \\
\text { a capable faull) }\end{array}$ & $\begin{array}{l}\text { Slipht } \\
\text { (profenional } \\
\text { judgenent) }\end{array}$ & $\begin{array}{l}\text { Stight; neareas mapped fault } \\
\text { in apparently no younger than } \\
\text { Pliocese. Average slip nate } \\
\text { aince the cod of Miocene time } \\
\text { appean to be inaignificant } \\
\text { (lem than } 0.002 \text { mmbyear) }\end{array}$ & \\
\hline
\end{tabular}

Nowe: EPGA is effective peat ground socelention; PGA is peak ground scockention; GPSF is General Purpose Support Facility, MDB is Munitions Demilitarization Building.

ATC (Applied Tochnolowy Council), Tentative Provivions for the Development of Seimic Regulations for Buildings, Applied Technology CouncilNational Bureau of Standards Specin Publication 510, U.S. Deph. of Commeroe, Wahington, D.C, 1978.

WS. Army, Saimic Daxign for Building, TM 5-809-10, US. Army Corpe of Engineers, Washington, D.C., 1982.

Isoobs Engineering Group, Inc and URSJohn A Blume and Amociates, Geological-Sciomological Investigition

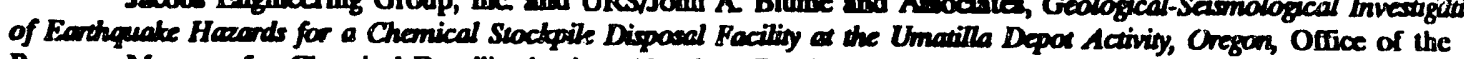
Program Manager for Chemical Demilitarization, Aberdeen Proving Ground, Md, 1987.

WRC (Nuclear Regulatory Comminion), Safety Evaluation Report Related to the Operation of WPPSS Nuctear Project No. 2" doctet no. 50-397, NUREG-0892, Office of Nuctear Reactor Regulation, Washington, D.C., 1982 
No significant geologic features have been found beneath the UMDA site, despite the existence of sufficiently detailed geotechnical information. Any undetected fault beneath the proposed site would be smaller than the above described fault.

Site-specific analysis identifies the worst case earthquake as unconstrained with respect to location within the Columbia Plateau Tectonic Province (CPTP) where the proposed site is located. According to Jacobs Engineering Group, Inc., and URS/John A. Blume and Associates (1987), the PGA $=0.25 \mathrm{~g}$ for the worst case earthquake [body-wave magnitude $(\mathrm{mb})=5.6$ ] with its epicenter at UMDA. The modified Mercalli intensity (Imm) $=$ VIII for this earthquake and is one intensity unit higher than the maximum historically recorded earthquake $(\mathrm{Imm}=\mathrm{VII})$ within the CPTP.

The site-specific study also investigated faults near the Washington Public Power Supply System (WPPSS) Unit 2 Reactor near Hanford, Washington. This study identified an active fault [the Wallula Gap fault (see Fig. 9)] about $20 \mathrm{~km}$ (12 miles) southwest of WPPSS and $40 \mathrm{~km}$ ( 25 miles) northeast of the proposed UMDA site (NRC 1982). The fault and the proposed site are both in the CPTP. However, strongmotion earthquakes are constrained to locations along this fault and their closest approach to UMDA is $40 \mathrm{~km}$ (25 miles). The PGA is $0.10 \mathrm{~g}$ at UMDA for a maximum expected earthquake along the Wallula Gap fault. As such, this earthquake is not the worst case for UMDA.

Foundation conditions and topography at the UMDA site may require that some process facility foundations be supported on deep foundation systems. If a deep foundation system is used for process facilities, the potential for magnification of earthquake induced ground motions will exist. Magnification is a design consideration under the control of the U.S. Army.

UMDA is located in seismic zone 1 (potential for slight earthquake damage) (U.S. Army Corps of Engineers 1982). All process facilities (except the toxic cubicle) inside the main Munitions Demilitarization Building (MDB) will be designed in accordance with U.S. Army 1982 standards for seismic zone 3 (potential for major earthquake damage), based on Applied Technology Council (ATC) guidelines (ATC 1978). Seismic zone 3 standards are much more stringent than those for seismic zone 1. The MDB has been assigned the highest importance factor (I-1.5) permitted by the ATC. To reduce the risk associated with a seismic event, the toxic cubicle is to be designed for a worst case earthquake response spectra defined by the maximum PGA and duration of shaking.

In conclusion, no significant differences exist between the FPEIS and the sitespecific seismic risk characterization. The potential for on-site liquefaction and surface rupture during earthquakes at UMDA remains the same as presented in the FPEIS.

Aircraft Activity. No differences in data from those presented in the FPEIS for aircraft activity near UMDA were found during Phase I. The FPEIS data appear to be appropriate and remain valid. Thus, aircraft activity is not considered further in this section. However, aircraft activity data could be of interest in assessing the potential benefits from airspace controls as interim mitigation measures for continued storage until UMDA stockpile can be destroyed. These data have been gathered and are reviewed in Sect. 3.2.6. 

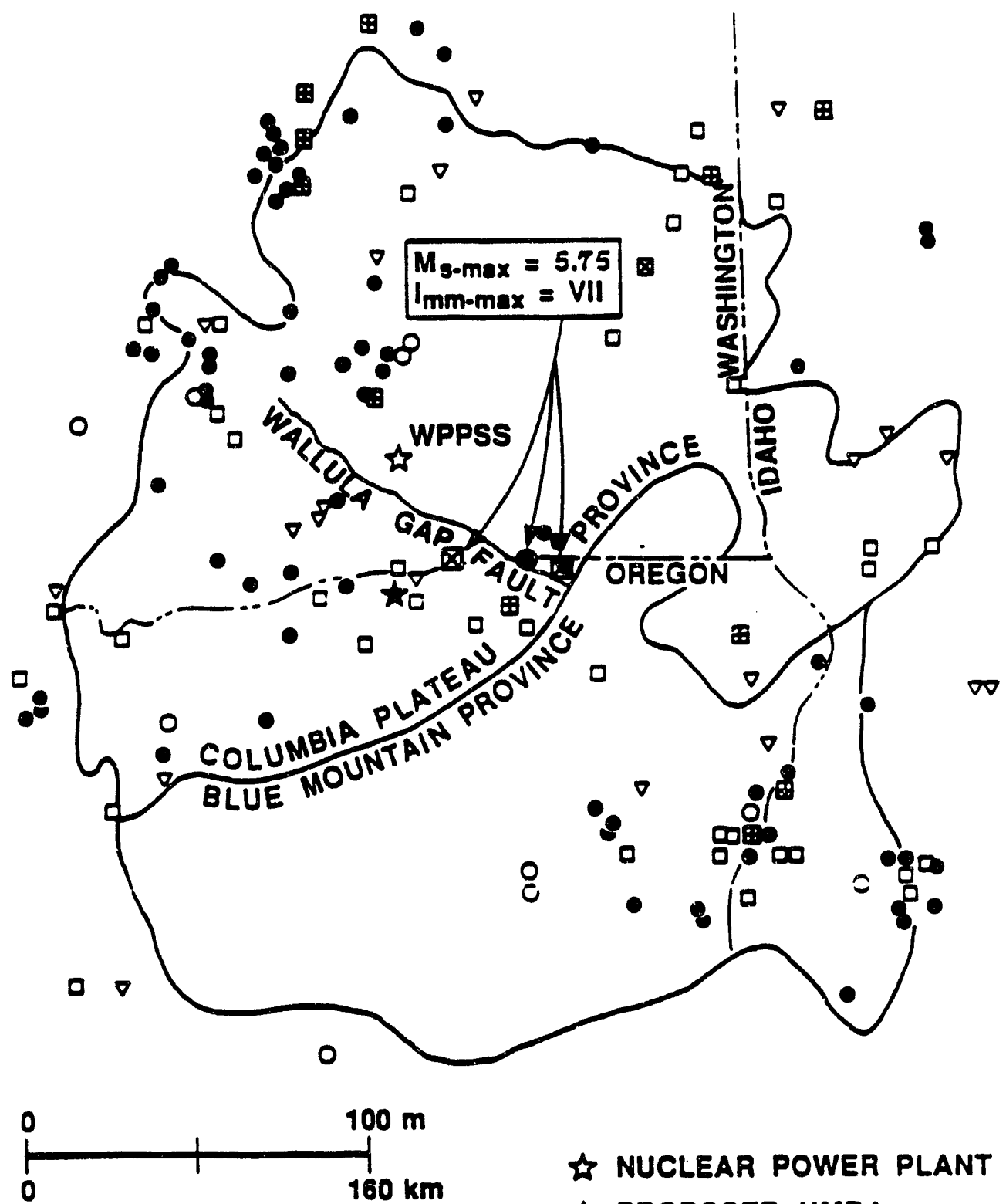
\& NUCLEAR POWER PLANT
$\rightarrow$ PROPOSED UMDA
DISPOSAL SITE

RICHTER MAGNITUDES

$0<4.0$

$04.0 \leq M<5.5$

$0.5 \leq M<6.5$
MODIFIED MERCALLI INTENSITIES

I $-I V$
$V I-V I I$

D NO INTENSITY OR MAGNITUDE

Fig. 9. Earthquakes in Columbia Plateau and Blue Mountain tectonic provinces and adjacent regions. The nearest capable fault to the Umatilla Army Depot (UMDA) and the Washington Public Power Supply System (WPPSS). 
Meteorites/Tornadoes. Data used in the FPEIS for expected frequencies of tornadoes and meteorite strikes in the UMDA vicinity are contained in Appendix A (Table A.1). These data were examined and found to be reasonable. No more recent or detailed data for these parameters beyond those in the FPEIS were located.

\subsubsection{Population}

The FPEIS presented residential population as of the 1980 census by radial sector and distance out to $100 \mathrm{~km}$ (62 miles), as shown in Table 3 (U.S. Army 1988a). As stated in Sect. 2, the FPEIS method for identifying the environmentally preferred alternative is based on residential population only, and does not include place-of-work or on-post populations. Because the 1980 census data will be over ten years old by the time construction and operation of the proposed disposal facility begin at UMDA, the latest population estimates (i.e., for 1986) have been used to adjust the 1980 census data. Population estimates in noncensus years are limited to estimates of county populations and populations within incorporated areas. A two-step process was used in this assessment for each potentially impacted county to estimate the population change at the enumeration district level. First, the estimated population changes for incorporated areas were equally apportioned among enumeration districts comprising the named area. Second, the unaccounted-for change in county population was equally apportioned among enumeration districts comprising the nonincorporated areas.

As in the FPEIS, these population estimates were assigned to a grid. Whereas the estimates used in the FPEIS considered only population and enumeration district location in creating the grid-based population, the Phase I method excludes population from areas that are clearly not residential (e.g., within the UMDA installation boundary and in the Columbia River).

The effect of using this exclusion information is to create population distributions with larjer concentrations of population than were in the FPEIS. However, these concentrated population areas are now accompanied by completely unpopulated areas which had small, but nonzero, populations in the FPEIS.

The revised residential population data are presented in Table 4 in the same format used in the FPEIS. The effect of including the 1986 population estimates is to increase the total population within the $100-\mathrm{km}$ (62-mile) zone by $1.7 \%$. It is estimated that 5426 additional people are located in the potentially impacted $100-\mathrm{km}$ zone around UMDA compared with the population in that zone as described in the FPEIS. The data collected during Phase I show that no off-post residents are located within $4 \mathrm{~km}$ (2.5 miles) of the proposed disposal facilities at UMDA. This is reflected in Table 4 under the 0 - to $2-\mathrm{km}$ and 2- to $5-\mathrm{km}$ headings; however, there are residents between 4 and $5 \mathrm{~km}$ from the site. The FPEIS assumed persons lived as close as $500 \mathrm{~m}$ $(1500 \mathrm{ft})$ to the proposed UMDA disposal facility.

Even though the relative change in residential population is not large, it does warrant reexamination of the FPEIS measures of risk for two reasons: (1) the absolute number of people affected is important, regardless of percentages, when dealing with potential fatalities, and (2) the relocation of the population resulting from use of the 
Table 3. Residential population distribution around the proposed disposal facility site at the Umatilla Depot Activity as given in the final programmatic environmental impact statement

\begin{tabular}{|c|c|c|c|c|c|c|c|c|}
\hline \multirow{2}{*}{ Direction } & \multicolumn{8}{|c|}{ Incremental population data at specified distances $(\mathrm{km})^{\mathrm{a}}$} \\
\hline & $\overline{0-1}$ & $1-2$ & $2-5$ & $5-10$ & $10-20$ & $20-35$ & $35-50$ & $50-100$ \\
\hline $\mathbf{N}$ & 0 & 1 & 39 & 137 & 354 & 383 & 4,932 & 6,140 \\
\hline NNE & 0 & 1 & 50 & 347 & 525 & 200 & 79,946 & 30,179 \\
\hline NE & 0 & 1 & 65 & 588 & 1,335 & 383 & 10,410 & 5,195 \\
\hline ENE & 0 & 1 & 61 & 794 & 854 & 127 & 283 & 43,678 \\
\hline $\mathrm{E}$ & 0 & 0 & 11 & 742 & 9,923 & 314 & 104 & 10,843 \\
\hline ESE & 0 & 0 & 3 & 741 & 3,310 & 933 & 752 & 18,625 \\
\hline SE & 0 & 0 & 3 & 73 & 1,378 & 293 & 198 & 2,552 \\
\hline SSE & 0 & 0 & 2 & 44 & 208 & 204 & 195 & 329 \\
\hline S & 0 & 0 & 1 & 32 & 111 & 122 & 159 & 1,480 \\
\hline SSW & 0 & 0 & 1 & 18 & 232 & 138 & 240 & 794 \\
\hline SW & 0 & 0 & 2 & 44 & 577 & 307 & 275 & 1,254 \\
\hline WSW & 0 & 0 & 2 & 61 & 723 & 270 & 218 & 1,012 \\
\hline W & 0 & 0 & 3 & 23 & 442 & 374 & 261 & 1,297 \\
\hline WNW & 0 & 1 & 8 & 3 & 126 & 112 & 169 & 508 \\
\hline NW & 0 & 2 & 20 & 13 & 11 & 31 & 2,356 & 49,700 \\
\hline NNW & 0 & 3 & 24 & 70 & 127 & 408 & 5,422 & 3,720 \\
\hline Total & 0 & 10 & $\overline{295}$ & $\overline{3,730}$ & $\overline{20,236}$ & $\overline{4,599}$ & 105,920 & $\overline{177,306}$ \\
\hline
\end{tabular}

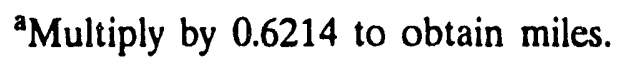

Source: U.S. Department of Commerce, Bureau of the Census, County and City Data Book; U.S. Government Printing Office, Washington, D.C., 1983.

Note: The location used for the center of the above population is at $45.5^{\circ}$ north latitude and $119.4^{\circ}$ west longitude. 
Table 4. Residential population distribution around the proposed disposal facility site at the Umatilla Depot Activity using data collected during Phase I

\begin{tabular}{|c|c|c|c|c|c|c|c|}
\hline \multirow{2}{*}{ Direction } & \multicolumn{7}{|c|}{ Incremental population data at specified distances $(\mathrm{km})^{\mathrm{a}}$} \\
\hline & $0-2$ & $2-5$ & $5-10$ & $10-20$ & $20-35$ & $35-50$ & $50-100$ \\
\hline $\mathbf{N}$ & 0 & 50 & 280 & 459 & 419 & 9,708 & 7,739 \\
\hline NNE & 0 & 112 & 325 & 249 & 167 & 84,404 & 27,893 \\
\hline $\mathrm{NE}$ & 0 & 75 & 728 & 2,115 & 89 & 5,527 & 3,201 \\
\hline ENE & 0 & 65 & 546 & 644 & 103 & 964 & 44,056 \\
\hline $\mathbf{E}$ & 0 & 114 & 4,879 & 6,609 & 229 & 98 & 11,523 \\
\hline ESE & 0 & 114 & 1,324 & 3,670 & 520 & 1,368 & 17,666 \\
\hline SE & 0 & 20 & 107 & 155 & 355 & 278 & 2,518 \\
\hline SSE & 0 & 0 & 45 & 149 & 112 & 208 & 220 \\
\hline $\mathbf{S}$ & 0 & 0 & 54 & 148 & 123 & 169 & 1,363 \\
\hline SSW & 0 & 0 & 68 & 266 & 163 & 236 & 901 \\
\hline SW & 0 & 0 & 62 & 528 & 182 & 290 & 1,190 \\
\hline WSW & 0 & 0 & 49 & 815 & 270 & 221 & 680 \\
\hline W & 0 & 0 & 18 & 493 & 863 & 241 & 1,345 \\
\hline WNW & 0 & 8 & 13 & 58 & 123 & 155 & 639 \\
\hline NW & 0 & 24 & 53 & 7 & 34 & 2,885 & 50,849 \\
\hline NNW & 0 & 40 & 148 & 207 & 379 & 4,216 & 4,747 \\
\hline Total & $\overline{0}$ & $\overline{622}$ & 8,699 & 16,572 & $\overline{4,131}$ & 110,968 & 176,530 \\
\hline
\end{tabular}

${ }^{a}$ Multiply by 0.6214 to obtain miles.

Source: U.S. Department of Commerce, U.S. Bureau of the Census, Current Population Reports, Series T-26, No. 86-NW, 1986 and 1985 Per Capita Income Estimates for Counties and Incorporated Places, U.S. Government Printing Office, Washington, D.C., 1988.

Note: The location used for the center of the above population is at $45.85^{\circ}$ north latitude and $119.4^{\circ}$ west longitude. 
actual boundary of UMDA could affect the FPEIS measures of risk in a beneficial way because the number of accident scenarios may decrease.

An examination of the accident database for UMDA shows that at least $15 \%$ of the total number of accidents at UMDA would cause no fatalities beyond distances of $2 \mathrm{~km}$ (1.2 miles) from the point of release. Accurately excluding off-post, residential population within this distance could thus have a significant effect on reducing the magnitudes of some of the FPEIS measures of risk for UMDA. Also, the effects of the new population data on the risk measures for the three alternatives being addressed are not clear and warrant closer examination.

\subsubsection{Summary}

Evaluation of data collected during Phase I for UMDA indicates that in terms of information used to develop the five FPEIS measures of risk, only the choice of CML meteorological conditions and the new residential population data warrant recalculation of risk. The accident database did not undergo sufficient change to be factored into computation of risk and thus is not further considered in this Phase I Environmental Report. The use of actual on-site transportation distances at UMDA has little, if any, potential to increase the probability of a transportation-related accident above that presented in the FPEIS. Thus, on-site transport is not examined further in this report. Similarly, because no new aircraft activity data for the region near UMDA were located during Phase I, aircraft activity is not examined further in this report.

\subsection{Evaluating Measures of Risk with Data Collected During Phase I}

As discussed in Sect. 2, comparison of FPEIS and Phase I data is used as a screening tool to identify those factors that should be incorporated into a recalculation

of the FPEIS measures of risk. Recomputing the five measures of risk with the data collected during Phase I and evaluating the results using the FPEIS decision method allow an evaluation of the suitability of on-site disposal at UMDA.

As discussed in Sect. 3.1.1.3, changes in population data were found to be large enough to warrant reestimation of fatalities and recomputation of the five measures of risk. To maintain consistency with the FPEIS, only residential population is considered. On-post population data have been gathered for use in the UMDA EIS and are presented in Sect. 3.2.5. All population data will be considered in estimating fatalities for the site-specific EIS.

Another factor which warrants consideration in the recomputation of risk is the choice of a CML meteorological condition for UMDA. The discussion below addresses the effect of updated population data for the region around UMDA (see Sect. 3.1.2.1) and the effect of using a CML meteorological condition different from that used in the FPEIS (see Sect. 3.1.2.2).

The first step in evaluating the measures of risk is to compute the estimated maximum fatalities, as well as the average fatalities, for a finite set of accidental releases. These accidental releases have been placed into distance categories, as used in the 
FPEIS, corresponding to downwind no-deaths distances of $1,2,5,10,20,50$, and $100 \mathrm{~km}$, respectively (see Appendix A for a more detailed discussion). For each distance category, average fatalities are computed by calculating the mean number of fatalities among 360 plumes of chemical agent atmospherically dispersed by an accidental release. The "maximum number of fatalities" measure of risk is taken to be the largest number of fatalities from among all of these 360 plumes. Each plume is directed radially away from the site of the proposed disposal facility and is aimed at a particular point of the compass-beginning at due east. Thus, for each distance category there are 360 such plumes with each plume directed one compass degree differently than the next.

Overlaying the updated population of Table 4 with plumes resulting from the same assumed meteorological conditions (i.e., CML and WC) used in the FPEIS (see Appendix A, Fig. A.3) gives new fatality estimates for accidental releases of agent at UMDA. These revised fatality estimates are presented in Table 5. For comparison, Table 6 repeats the original UMDA fatality estimates from the FPEIS (see U.S. Army 1988a, Vol. 1, Table 4.3.27). One major difference between the revised estimates and the FPEIS fatality estimates is that the number of fatalities for accident distance categories of $2 \mathrm{~km}$ (1.2 miles) or less drops to zero because, contrary to what was assumed in the FPEIS, there is actually no off-post residential population that close to the site of the proposed disposal facility. The data in Tables 5 and 6 indicate that for distance categories larger than $5 \mathrm{~km}$ ( 1.2 miles), the fatality estimates based on the new residential population data are larger than those in the FPEIS. This increase is due to the increased population since the 1980 census and to the consideration of the population exclusion areas (e.g., the UMDA installation boundary and the Columbia River).

The greatest percentage increase in estimated potential maximum fatalities is in the $10-\mathrm{km}$ (6.2-mile) WC category, in which the estimate increases $40 \%$ (from 20 in the FPEIS to 28 in Phase I). The largest numerical increase is 670 persons in the $50-\mathrm{km}$ (31-mile) category-a $27 \%$ increase in estimated fatalities from that given in the FPEIS. This $50-\mathrm{km}$ category contains the largest accident at UMDA for the on-site disposal option.

The fatality estimates given in Table 5 were then used to compute each of the five measures of risk for on-site disposal, continued storage, and on-site activities associated with off-site transport. The revised risk pictogram is shown in Fig. 10b along with values from the original FPEIS pictogram in Fig. 10a (U.S. Army 1988a, Vol. 1, Fig. 4.3.8) for comparison. Because this Phase I report is concerned with differences in site-specific data from those in the FPEIS, the only alternatives included in Fig. 10 are continued storage, on-site disposal, and national disposal. The risks to the residential population near UMDA for the national disposal alternative are the same as those for off-site transport of the UMDA stockpile under the regional disposal alternative.

\subsubsection{Differences in the measures of risk from those in the FPEIS}

Figures 10a and 10b present pictograms depicting the five measures of risk for appropriate alternatives at UMDA using FPEIS and Phase I population data, 
Table 5. Estimated fatalities by downwind distance for selected meteorological conditions at Umatilla Depot Activity using data collected during Phase I

\begin{tabular}{|c|c|c|c|c|}
\hline \multirow[b]{3}{*}{$\begin{array}{l}\text { Downwind } \\
\text { distance } \\
(\mathbf{k m})\end{array}$} & \multicolumn{4}{|c|}{ Phase I fatalities ${ }^{\mathrm{a}, \mathrm{b}}$} \\
\hline & \multicolumn{2}{|l|}{ Average } & \multicolumn{2}{|c|}{ Potential maximum } \\
\hline & $\begin{array}{l}\text { Conservative } \\
\text { most likely } \\
\text { meteorological } \\
\text { conditions }\end{array}$ & $\begin{array}{l}\text { Worst case } \\
\text { meteorological } \\
\text { conditions }^{\mathbf{c}}\end{array}$ & $\begin{array}{c}\text { Conservative } \\
\text { most likely } \\
\text { meteorological } \\
\text { conditions }\end{array}$ & $\begin{array}{l}\text { Worst case } \\
\text { meteorological } \\
\text { conditions }\end{array}$ \\
\hline 1.0 & 0 & 0 & 0 & 0. \\
\hline 2.0 & 0 & 0 & 0 & 0 \\
\hline 5.0 & 1 & 1 & 3 & 2 \\
\hline 10.0 & 15 & 7 & 57 & 28 \\
\hline 20.0 & 140 & $5 ?$ & 1,660 & 875 \\
\hline 50.0 & 565 & 250 & 5,920 & 3,170 \\
\hline 100.0 & $\mathrm{NA}^{\mathrm{d}}$ & 1,060 & $N^{d}$ & 10,350 \\
\hline
\end{tabular}

${ }^{2}$ The number of deaths is rounded. The fatality estimates are cumulative in that the data entries for a particular downwind distance include fatalities at all smaller distances.

'The average fatalities equals the mean of fatalities from all possible plumes in a $360^{\circ}$ arc around the site. The potential maximum fatalities equals the fatalities from a plume traveling over the greatest population density.

'Conservative most likely (CML) conditions are D stability and a windspeed of $3 \mathrm{~m} / \mathrm{s}$; worst case (WC) conditions are E stability and a wind speed of $1 \mathrm{~m} / \mathrm{s}$. Note that the fatality entries in this table are organized by downwind distance and not by the quantity of chemical agent released. The fatality estimates are larger for an accident in the same downwind distance category under CML, conditions than for WC conditions because the CML plume is larger and hence covers a larger area. However, for a given quantity of chemical agent released in an accident, the WC conditions would produce a larger downwind distance than CML conditions and would therefore give a larger number for estimated fatalities.

${ }^{\mathrm{N}} \mathrm{NA}=$ not applicable, because the largest credible accident does not travel this distance under CML conditions. 
Table 6. Estimated fatalities by downwind distance for selected meteorological conditions at the Umatilla Depot Activity as given in the final programmatic environmental impact statement

\begin{tabular}{|c|c|c|c|c|}
\hline \multirow[b]{3}{*}{$\begin{array}{l}\text { Downwind } \\
\text { distance } \\
(\mathrm{km})\end{array}$} & \multicolumn{4}{|c|}{ FPEIS fatalities $^{a, b}$} \\
\hline & \multicolumn{2}{|c|}{ Average } & \multicolumn{2}{|c|}{ Potential maximum } \\
\hline & $\begin{array}{l}\text { Conservative } \\
\text { most likely } \\
\text { meteorological } \\
\text { conditions }\end{array}$ & $\begin{array}{l}\text { Worst case } \\
\text { meteorological } \\
\text { conditions }^{c}\end{array}$ & $\begin{array}{l}\text { Conservative } \\
\text { most likely } \\
\text { meteorological } \\
\text { conditions }\end{array}$ & $\begin{array}{l}\text { Worst case } \\
\text { meteorological } \\
\text { conditions }^{\mathrm{c}}\end{array}$ \\
\hline 1.0 & 0 & 0 & 1 & $\mathbf{0}$ \\
\hline 2.0 & 0 & 0 & 1 & 1 \\
\hline 5.0 & 1 & 1 & 3 & 2 \\
\hline 10.0 & 15 & 5 & 40 & 20 \\
\hline 20.0 & 125 & 50 & 1,400 & 650 \\
\hline 50.0 & 450 & 175 & 5,300 & 2,500 \\
\hline 100.0 & $N A^{d}$ & 800 & $N^{d}$ & 9,800 \\
\hline
\end{tabular}

${ }^{a}$ The number of deaths is rounded. The fatality estimates are cumulative in that the data entries for a particular downwind distance include fatalities at all smaller distances. FPEIS = final programmatic environmental impact statement.

bThe average fatalities equals the mean of fatalities from all possible plumes in a $360^{\circ}$ arc around the site. The potential maximum fatalities equals the fatalities from a plume traveling over the greatest population density.

Conservative most likely (CML) conditions are $\mathrm{D}$ stability and a windspeed of $3 \mathrm{~m} / \mathrm{s}$; worst case (WC) conditions are E stability and a wind speed of $1 \mathrm{~m} / \mathrm{s}$. Note that the fatality entries in this table are organized by downwind distance and not by the quantity of chemical agent released. The fatality estimates are larger for an accident in the same downwind distance category under CML conditions than for WC conditions because the CML plume is larger and hence covers a larger area. However, for a given quantity of chemical agent released in an accident, the WC conditions would produce a larger downwind distance than $\mathrm{CML}$ conditions and would therefore give a larger number for estimated fatalities.

${ }^{\mathrm{N} A}=$ not applicable, because the largest credible accident does not travel this distance under $\mathrm{CML}$ conditions. 
A. ORIGINAL RISK PICTOGRAM (FROM THE FPEIS)

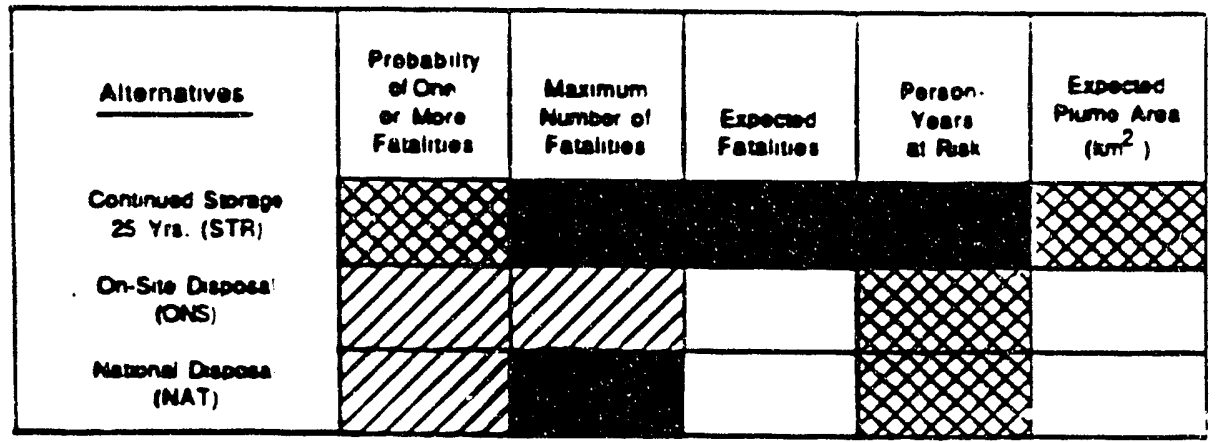

B. REVISED RISK PICTOGRAM (USING PHASE I FATALITY DATA)
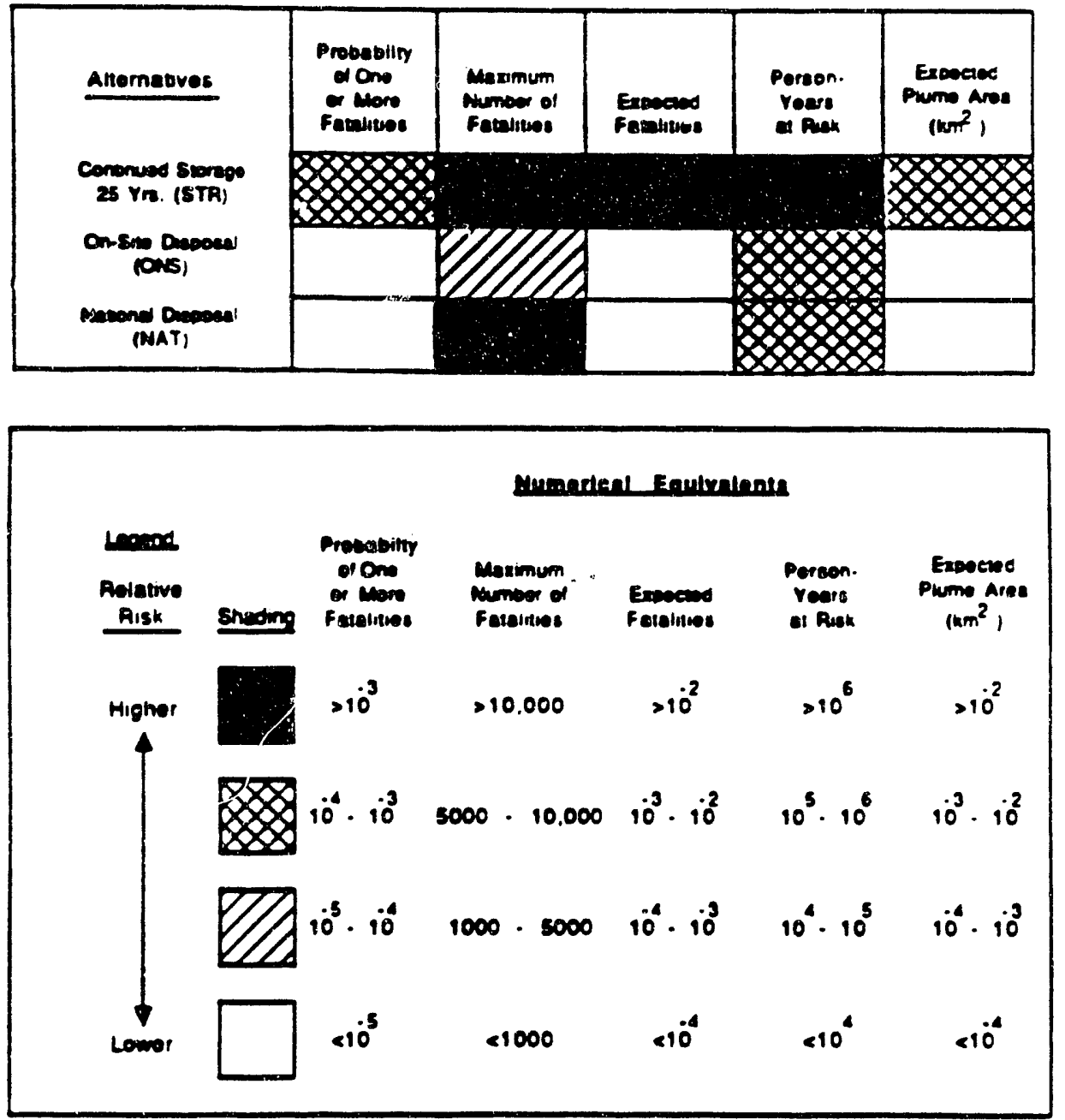

Fig. 10. Risk with mitigation in the vicinity of the Umatilla Depot Activity (UMDA) for programmatic alternatives. (Risk along transportation corridors or at a national destruction site is not included. For the on-site and national disposal alternatives, this diagram does not include the risk associated with approximately three years of stockpile storage at UMDA.) 
respectively. Details on the computation of the five measures of risk presented in Fig. 10 are discussed in Appendix A. The summary discussion below is limited to the differences between the FPEIS risks and the risks computed with the FPEIS meteorological conditions and the new population data collected during Phase I. Sitespecific conclusions are presented in Sect. 3.1.3.

Probability of one or more fatalities. As shown in Table 4, there are no off-post residents within $2 \mathrm{~km}$ (1.2 miles) of the proposed disposal site at UMDA. This value should be compared to the 10 residents specified in the FPEIS for the same region. As explained in Sect. 3.1.1.2, the difference is due to the use of the actual UMDA installation boundary and the distance to the nearest off-site resident. The FPEIS generically assumed that this distance was $500 \mathrm{~m}(1640 \mathrm{ft})$. The significance of this difference in population is directly reflected in the revisions to fatality estimates (Table 5) from those presented in the FPEIS (Table 6). As a result of fewer people living close to the UMDA installation boundary, small accidental releases of chemical agent-which in the FPEIS were cited as causing fatalities within $2 \mathrm{~km}$ (1.2 miles)-now produce no fatalities. Many accidents are therefore eliminated from consideration in the accident database. Thus, the "probability of one or more fatalities," which is the sum of probabilities for all accidents causing at least one fatality, decreases for all alternatives except continued storage (see Fig. 10). This is because continued storage accidents are predominantly large-distance accidents; only a few of these storage accidents are contained within $2 \mathrm{~km}$ (1.2 miles) of the existing storage area.

Maximum number of fatalities. Based upon newly collected population data, the "maximum number of fatalities" for a $50-\mathrm{km}$ accident under WC meteorological conditions at UMDA would be 3170 (Table 5). For a 100-km (62-mile) accident the number would be 10,350 . These numbers compare to 2500 and 9800 respectively as presented in the FPEIS (Table 6).

The on-site disposal alternative at UMDA has a $50-\mathrm{km}(31-\mathrm{mile})$ accident as its WC event. For the purpose of this document, the $100-\mathrm{km}(62-\mathrm{mile})$ accident can be associated with the continued storage and national disposal alternatives; the FPEIS assigned the $500-\mathrm{km}$ (310-mile) accident distance category to these alternatives, even though it acknowledged that atmospheric dispersion of lethal doses of agent was "almost impossible" beyond $100 \mathrm{~km}$ from UMDA. Collection of updated residential population data for an area of this size [500-km (310-mile) radius] was considered for this document; however, upon examination of the accident database in light of the FPEIS risk pictogram for UMDA, it was determined that minor changes in residential population within this zone would not change the ranking of the alternatives with respect to the "maximum number of fatalities." Thus, residential population for the region beyond $100 \mathrm{~km}$ (62 miles) from UMDA is not examined further in this report.

The revised UMDA pictogram shadings for the "maximum number of fatalities" under all alternatives do not change from those in the FPEIS.

Expected fatalities. The revised UMDA pictogram shadings for the "expected fatalities" measure of risk do not change from those presented in the FPEIS for any of the UMDA alternatives. 
Person-years at risk. The total population within the $100-\mathrm{km}$ (62-mile) potential impact zone increased by only $1.7 \%$ over the population data presented in the FPEIS for the UMDA area. For the $50-\mathrm{km}(31-\mathrm{mile})$ potential impact zone, the increase was $4.6 \%$. Because the durations of the disposal alternatives at UMDA are the same as they were in the FPEIS, "person-years at risk" for each alternative can increase by only a maximum of $4.6 \%$. Therefore, the revised UMDA pictogram shadings for "person-years at risk" do not change from those presented in the FPEIS.

Expected plume area. Since neither the probability of an accident nor the resulting plume area was changed by the collection of new data during Phase $I$, the "expected plume area" measure of risk for UMDA did not change from that presented in the FPEIS.

\subsubsection{Effect of various meteorological conditions upon measures of risk}

As discussed in Sect. 3.1.1.1, high wind speeds are associated with a more effective atmospheric dispersion of chemical agent and result in a lower estimated dose than do low wind speeds. It is therefore not necessary to study the effect of atmospheric dispersion of chemical agent under meteorological conditions in stability class D with wind speeds higher than $3 \mathrm{~m} / \mathrm{s}$ (the FPEIS choice for CML conditions) or in stability class $E$ with wind speeds higher than $1 \mathrm{~m} / \mathrm{s}$ (the choice for WC conditions). Based on the meteorological data in Table 1, it does appear that D stability and wind speeds below $3 \mathrm{~m} / \mathrm{s}$ warrant further study in regard to atmospherically dispersed doses of chemical agent and the recomputation of risk. The results of such a study are presented in this section.

A new site-specific CML meteorological condition was selected for study. Instead of D stability and a wind speed of $3 \mathrm{~m} / \mathrm{s}$, the new CML condition was defined as $\mathrm{D}$ stability and $1 \mathrm{~m} / \mathrm{s}$. To further amplify any effect of the new CML condition compared to the FPEIS CML condition, the height of the mixed layer was chosen as $500 \mathrm{~m}$ for the new CML condition (as compared to $750 \mathrm{~m}$ in the FPEIS). It should be noted that the use of the new CML condition provides very conservative results (i.e., high fatality estimates) compared to the FPEIS CML which is closer to the weighted average of the meteorological conditions provided in Table 1.

The combined effect of the lower wind speed and reduced height of the mixed layer produced higher doses of chemical agent at larger downwind distances than were reported in the FPEIS. New plume contours and new downwind accident distance categories (see Appendix A for a discussion of the concept) were generated from the D2PC atmospheric dispersion model with the new CML condition as input. The FPEIS methodology of computing estimated fatalities and then computing the five measures of risk was used to study the implications of the new CML meteorological condition at UMDA.

Two sets of pictogram results were computed (1) using the new CML condition with the population distribution from the FPEIS (Table 4) and (2) using the new CML condition with the updated population distribution (Table 5). The new pictograms were intended for direct comparison to those in Fig. 10; however, the new pictograms were 
virtually identical to those in Fig. 10. Only the shading pattern for "expected plume area" for the continued stora ${ }_{0}$ e alternative changed; it increased by one shading pattern in both of the two new sets of pictograms. None of the other shading patterns changed for any of the other alternatives.

It is therefore concluded that the choice of meteorological conditions for the purpose of computing risks at UMDA is inconsequential; it has no potential to change the FPEIS ranking of the alternatives. The risks of both on-site disposal and national disposal as computed with the FPEIS CML condition (see Fig. 10) did not change when a new site-specific CML condition was used at UMDA.

\subsubsection{Identifying the Site-Specific Environmentally Preferred Alternative}

Figure 10 depicts risks from the perspective of the population residing near UMDA. Figure 10b presents the revised, site-specific measures of risk. The on-site risks of the national disposal alternative serve as a surrogate for the risks of

off-site transport from UMDA. Cross-country transportation risks for an off-site disposal alternative are not shown, but would be the same as presented in the FPEIS for a regional or national disposal option (see U.S. Army 1988, Vol. 1, Figs. 4.4.1 and 4.4.2). Results for the five measures of risk are summarized in Table 7.

Based on examination of Fig. 10b and Table 7, the continued storage alternative at UMDA can be rejected. Off-site disposal (i.e., the national and regional disposal alternatives) can also be rejected. The conclusion is that on-site disposal remains valid as the "environmentally preferred alternative" for UMDA. From the perspective of the population near UMDA, the risks from on-site disposal are in all cases equal to, or less than, the risks from other alternatives. If one adds the off-site transportation risks-addressed in the FPEIS, but beyond the scope of this Phase I Report-the on-site alternative is clearly preferable given the opportunity for risk reductions associated with emergency planning and preparedness activities that are under way at UMDA. These transportation risks are not shown in Fig. 10.

\subsection{NEW INFORMATION AFFECTING ON-SITE DISPOSAL AT THE UMATILLA DEPOT ACTIVITY}

As discussed in Sect. 2, some of the resources and information, although considered in the FPEIS, were not overriding factors in comparing programmatic alternatives or in identifying the environmentally preferred alternative. These resources included: air quality; surface water and groundwater; land use; ecology; and social, economic, and cultural resources. Some types of resource data (e.g., meteorology and aircraft activity) are germane to both Sects. 3.1 and 3.2 of this Phase I Report in that they were used to identify the environmentally preferred alternative, and they were also used to assess potential environmental impacts not considered in the risk-oriented method for identifying the environmentally preferred alternative in the FPEIS. Aspects of these data types are discussed in this section as they pertain to potential impacts from construction, incident-free operation, and accident scenarios. In this Phase I review, 
Table 7. Results of comparing the recomputed measures of risk for alternatives at the Umatilla Depot Activity

\begin{tabular}{|c|c|}
\hline Measure of risk & $\begin{array}{l}\text { Comparison between } \\
\text { alternatives }\end{array}$ \\
\hline Probability of one or more fatalities & $\begin{array}{l}\text { Continued storage can be rejected, } \\
\text { since it is substantially worse than } \\
\text { others (i.e., its risk is higher by two } \\
\text { pictogram shading patterns than either } \\
\text { on-site or national disposal). Other } \\
\text { alternatives are indistinguishable (i.e., } \\
\text { their risks differ by no more than one } \\
\text { pictogram shading pattern) }\end{array}$ \\
\hline Maximum number of fatalities & $\begin{array}{l}\text { On-site disposal is better than any } \\
\text { other alternative (i.e., its risk is lower } \\
\text { by two pictogram shading patterns } \\
\text { than either continued storage or } \\
\text { national disposal) }\end{array}$ \\
\hline Expected fatalities & $\begin{array}{l}\text { Continued storage can be rejected } \\
\text { because it is substantially worse than } \\
\text { others. Other alternatives are } \\
\text { indistinguishable }\end{array}$ \\
\hline Person-years at risk & $\begin{array}{l}\text { All alternatives are indistinguishable. } \\
\text { Although continued storage appears to } \\
\text { be worse than the others }\end{array}$ \\
\hline Expected plume area & $\begin{array}{l}\text { Continued storage can be rejected } \\
\text { because it is substantially worse than } \\
\text { others. Other alternatives are } \\
\text { indistinguishable }\end{array}$ \\
\hline
\end{tabular}


these resources are examined to determine if significant resources are present that could be affected by the construction and operation of the proposed on-site disposal facilities at UMDA. Emergency response is also discussed to provide a status of planning and preparedness activities at UMDA.

\subsection{Meteorology/Air Quality}

Site-specific meteorological data at UMDA are measured at a meteorological tower located approximately $60 \mathrm{~m}(200 \mathrm{ft})$ south of the southern perimeter of the existing chemical agent storage area. Wind speed and direction are monitored at $10 \mathrm{~m}$ ( $32 \mathrm{ft}$ ) above ground level (agl) and temperature is measured at $0.5 \mathrm{~m}(1.6 \mathrm{ft}$ ) agl. In addition, wind socks are positioned at the corners of the chemical storage area.

Meteorological data from the tower are recorded and saved on analog 24-hr circular charts, but the information is not in a ready-to-access form because it has not been digitized. Measurements of the height of the mixed layer, a meteorological factor affecting predictions of dispersion, are not performed, and no criteria pollutants are monitored in the ambient air at UMDA (D. Smythe, UMDA Chemical Surety Officer, Umatilla Depot Activity, Oreg., personal communication with R. L. Miller, Oak Ridge National Laboratory, Oak Ridge, Tenn., Feb. 15, 1989).

Meteorological data used in the FPEIS for UMDA were obtained from an off-post meteorological tower located $6.5 \mathrm{~km}$ (4 miles) south of the chemical storage area (see Fig. 7). This tower was operated for the Portland General Electric Company (PGEC) from 1976 to 1984 as part of a four-station network to monitor ambient air quality and meteorological data during the construction and early operation of a coal-fired electrical generating station in Boardman, Oregon, situated about $15 \mathrm{~km}$ (9 miles) west of UMDA (T. Worrell, Portland General Electric Company, Portland, Oreg., personal communication with R. L. Miller, Oak Ridge National Laboratory, Oak Ridge, Tenn., Mar. 22, 1989). The PGEC meteorological tower measured wind speed

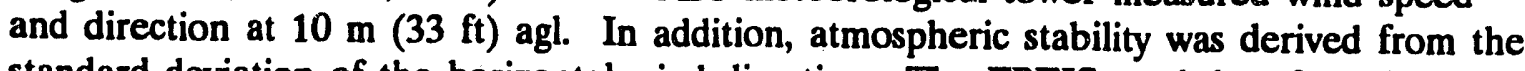
standard deviation of the horizontal wind direction. The FPEIS used data from January through December 1980 . These data were reexamined for quality assurance and appear to be accurate and reliable. The distribution of stabilities is also reasonable, both by time of day and for the overall period of record.

Although the site-specific meteorological data at UMDA would be desirable if the data were in a ready-to-access form, the difficulty in attempting to digitize the data and the lack of recorded atmospheric stability information results in a preference for using the data from the PGEC meteorological tower. Because this tower and the chemical storage area are in close proximity and because the terrain is very similar, the meteorological conditions measured at the tower should be representative of those at the UMDA storage area.

With regard to existing ambient air quality, the UMDA area is currently designated as an attainment area for all criteria pollutants (D. Brannock, Oregon Department of Environmental Quality (DEQ), Portland, Oreg., personal communication with R. L. Miller, Oak Ridge National Laboratory, Oak Ridge, Tenn., Apr. 27, 1989]. 
Oregon has adopted the same standards as the National Ambient Air Quality Standards (NAAQS). This attainment status is in agreement with the discussion in the FPEIS. The nearest Class I Prevention of Significant Deterioration (PSD) area, designated to greatly restrict the degradation of ambient air quality, is Eagle Cap Wilderness Area, located $150 \mathrm{~km}$ (95 miles) east-southeast of the proposed disposal facility. The Blue Mountains are located between the proposed facility and the Class I area and, for many meteorological conditions, would provide a partial barrier to the transport of emissions.

An existing deactivation furnace for small-arms munitions, located in the southwest corner of UMDA, has recently been denied a permit by the Oregon DEQ to discharge air contaminants at a rate of up to $450 \mathrm{~kg} / \mathrm{hr}(1000 \mathrm{lb} / \mathrm{hr})$. Plans for new furnaces that may replace the existing furnace are being developed; an alternative to constructing new furnaces is to close the present furnace and ship the remaining smallarms munitions to another site for destruction. The destruction by open-air detonation and open burning of obsolete or nonfunctional munitions and crates and pallets contaminated with explosive material is currently permitted with the Oregon DEQ. In addition, three heating plants with capacities greater than $220,000 \mathrm{~W}(750,000 \mathrm{Btu} / \mathrm{hr})$ and 50 plants with capacities less than $220,000 \mathrm{~W}(750,000 \mathrm{Btu} / \mathrm{hr})$ are located on the UMDA installation (U.S. Army 1982).

\subsection{Water Resources}

While the FPEIS discussed the potential impacts to surface water and groundwater at UMDA, no unique resources were identified. No federally designated wild or scenic rivers were identified within $100 \mathrm{~km}$ (62 miles) of UMDA. Likewise, no federally protected aquifers were identified near UMDA. The continuing validity of this information was confirmed during the Phase I process.

Major rivers, streams, and reservoirs in the vicinity of UMDA were identified in the FPEIS (U.S. Army 1988, Vol. 1, Sect. 3.2.8.4). No permanent bodies of water occur within the UMDA installation boundary, and all precipitation infiltrates into the soil. The importance of and extensive use of groundwater as both a municipal source of drinking water and as a source of water for irrigation of crops was acknowledged in the FPEIS. Water level declines in the unconfined aquifer near the surface were discussed as well as the fact that this aquifer is receiving artificial recharge.

A description of the site-specific surface water and groundwater regimes is summarized in Appendix C. Additional information collected since publication of the FPEIS indicates that a confined basalt aquifer system resides immediately beneath the unconfined surficial aquifer in the glaciofluviatile deposits. The surficial aquifer and the basalt aquifer system are hydraulically interconnected. The thickness of the surficial aquifer in the glaciofluviatile deposits ranges from 18 to $61 \mathrm{~m}(60$ to $200 \mathrm{ft}$ )

(Roy F. Weston, Inc., 1989), while the basalt aquifer system may be as much as $3,050 \mathrm{~m}$ $(10,000 \mathrm{ft})$ thick (Davies-Smith, Bolke, and Collins 1988). Extensive use of the shallow portion of the basalt aquifer system is made for irrigation of crops as well as fire protection and drinking water at UMDA. 
Groundwater beneath UMDA generally flows in a northwesterly direction. During the growing season when extensive pumping of groundwater occurs for irrigation of crops, the cones of depression emanating from the large irrigation wells change the direction of flow. Parcels of groundwater within the zone of influence of an irrigation well flow toward that well, while parcels outside of the zone ultimately discharge as base flow into the Columbia River.

Water resources in the vicinity of UMDA can be impacted by large accidental releases of chemical agent through two environmental pathways: (1) surface water can be directly impacted by atmospheric dispersion and subsequent deposition of agent, and (2) groundwater can be directly impacted by chemical agent spills. Because assessment of impacts is beyond the scope of this Phase I Report, the size of the accident has been used to quantify the potential impact to water resources near UMDA and to determine the significance of water resource data.

The size of the largest hypothetical accident for each alternative at UMDA is representative of the size of the potential area for surface water impacts (i.e., for atmospheric dispersion and deposition impacts). Regardless of the location of the surface water resource, higher concentrations of chemical agent could potentially be deposited onto surface water bodies during large accidents than for smaller accidents. On-site disposal has a 50-km (31-mile) accident as its worst case; the other alternatives-continued storage, regional disposal, and national disposal-have larger accidents that fall into the $100-\mathrm{km}$ (62-mile) downwind accident category. Based on the relative size of the worst case accident for each alternative, there is a greater potential for surface water impacts to occur for the continued storage, regional disposal, and national disposal alternatives. The on-site disposal alternative presents the least potential for surface water impact.

The potential for impact to groundwater resources can be represented by the quantity of chemical agent spilled during a hypothetical accident. From the FPEIS accident database, the worst case spill quantities can be obtained; at UMDA the largest spills for each alternative involve mustard agent and a large aircraft crash with no fire. For the continued storage alternative the largest spill is $154,025 \mathrm{~kg}(339,625 \mathrm{lb}$ or $32,082 \mathrm{gal}$ ) from an aircrash into the storage warehouse. For the regional and national alternatives, the largest spill is $183,481 \mathrm{~kg}(404,576 \mathrm{lb}$ or $38,217 \mathrm{gal})$ from an aircrash into the railhead storage area. For on-site disposal, the largest spill is $3860 \mathrm{~kg}(8511 \mathrm{lb}$ or $804 \mathrm{gal}$ ) from an aircrash into the disposal facility. Based on the relative size of the largest accidental spill for each alternative, on-site disposal presents the least potential for groundwater impact.

\subsubsection{Land Use}

Supplemental information collected for the UMDA area indicates that there has been relatively little change in the generalized data presented in the FPEIS. No unique land-use resources have been identified for the region around UMDA. Additional, detailed information about site-specific land use in the vicinity of UMDA is given in Appendix D. 


\subsection{Ecological Resources}

Ecological resources are of interest because they provide the backbone of support for the human population, including employment (e.g., agriculture, lumber, industry, etc.) and recreational opportunities (e.g., fishing, hunting, and outdoor sports). Threatened and endangered species are of particular interest because of their greater sensitivity to extinction that results from their limited numbers. Protecting species from extinction is important because of the need to maintain biodiversity, which has direct bearing on the quality of the human environment. Furthermore, the Endangered Species Act of 1973 (Pub. L 93-205) requires federal agencies to ensure that their actions neither jeopardize the continued existence of endangered or threatened species, nor destroy or adversely modify designated critical habitat for such species. Resource areas of special ecological interest include wilderness and wildlife areas, Nature Conservancy and Natural Resource Areas, and national parks.

Additional, detailed information on ecological resources gathered since preparation of the FPEIS is shown in Tables 8 and 9. Information on ecological resources included in the FPEIS was based on data from the GEOECOLOGY database at Oak Ridge National Laboratory (ORNL). Use of a standardized database allowed the same level of coverage for all sites and transportation options during preparation of the FPEIS and reduced the potential bias in determination of the ecologically preferred alternative.

Information obtained during preparation of this Phase I Report has verified the federal level data obtained for the UMDA area during preparation of the FPEIS. Information gathered during preparation of this Phase I Report (R. D. Peterson, U.S. Fish and Wildlife Service (FWS), Portland, Oreg., personal communication V. R. Tolbert, Oak Ridge National Laboratory, Oak Ridge, Tenn., Apr. 19, 1989) showed that the only federally listed species that occur within the $100-\mathrm{km}$ (62-mile) potential impact zone around UMDA are the bald eagle and peregrine falcon. (These were the only two federally listed threatened and endangered species identified during preparation of the FPEIS.) Additional species that are listed as candidate species will be included in the site-specific EIS. No critical habitat was identified within the UMDA $100-\mathrm{km}$ (62-mile) zone. Information on wetlands in the UMDA area has been requested but not yet received; wetlands will be addressed in the site-specific EIS.

Peregrine falcons may be present along the Columbia River during migration periods. Efforts are underway to reintroduce falcons along the Columbia River. Bald eagles may be present from October to March throughout the potential impact area and may be present particularly at large bodies of water, such as the Umatilla Wildlife Refuge, along the Columbia and Grande Ronde rivers, and near the McKay and Cold Springs reservoirs. Wind direction in the UMDA vicinity is primarily from the westsouthwest (see Sect. 3.2.1). Those ecological resources of special concern located primarily to the east-northeast of the site would be within the general downwind direction of an accidental release of chemical agent. No threatened or endangered aquatic species were identified during preparation of either the FPEIS or Phase I Report. 
Table 8. Number of ecological resources of special interest in the vicinity of the proposed facility site at the Umatilla Depot Activity as identified during Phase I

\begin{tabular}{lcc}
\hline & $\begin{array}{c}\text { Agent involved in } \\
\text { accidental release }\end{array}$ \\
\cline { 2 - 3 } Resource & $\mathrm{H}, \mathrm{HD}, \mathrm{HT}^{\mathrm{b}}$ & $\mathrm{GB}^{\mathrm{b}}$ and VXc \\
\hline National park units & 0 & 0 \\
Wilderness areas & 0 & 2 \\
National forests & 0 & 2 \\
Threatened and endangered species & \\
Wild and scenic rivers & 2 & 2 \\
Natural Resource and Nature Conservancy areas & 0 & 0 \\
\multicolumn{1}{c}{$\quad-$} & - \\
\cline { 2 - 3 } Total & 2 & 6 \\
\hline
\end{tabular}
conditions.

aased on the most serious on-site accidents under worst case meteorological

bo-effects distances for mustard agent are unknown; analysis is based on accidents with a "no-deaths" distance of $5 \mathrm{~km}$.

"Analysis is based on accidents with a "no-deaths" distance of $33 \mathrm{~km}$.

'Does not include candidate species.

'Additional information requested, but not yet received. 
3-30

Table 9. Ecological resources within $100 \mathrm{~km}(62 \mathrm{mi})$ of proposed disposal site at the Umatilla Depot Activity

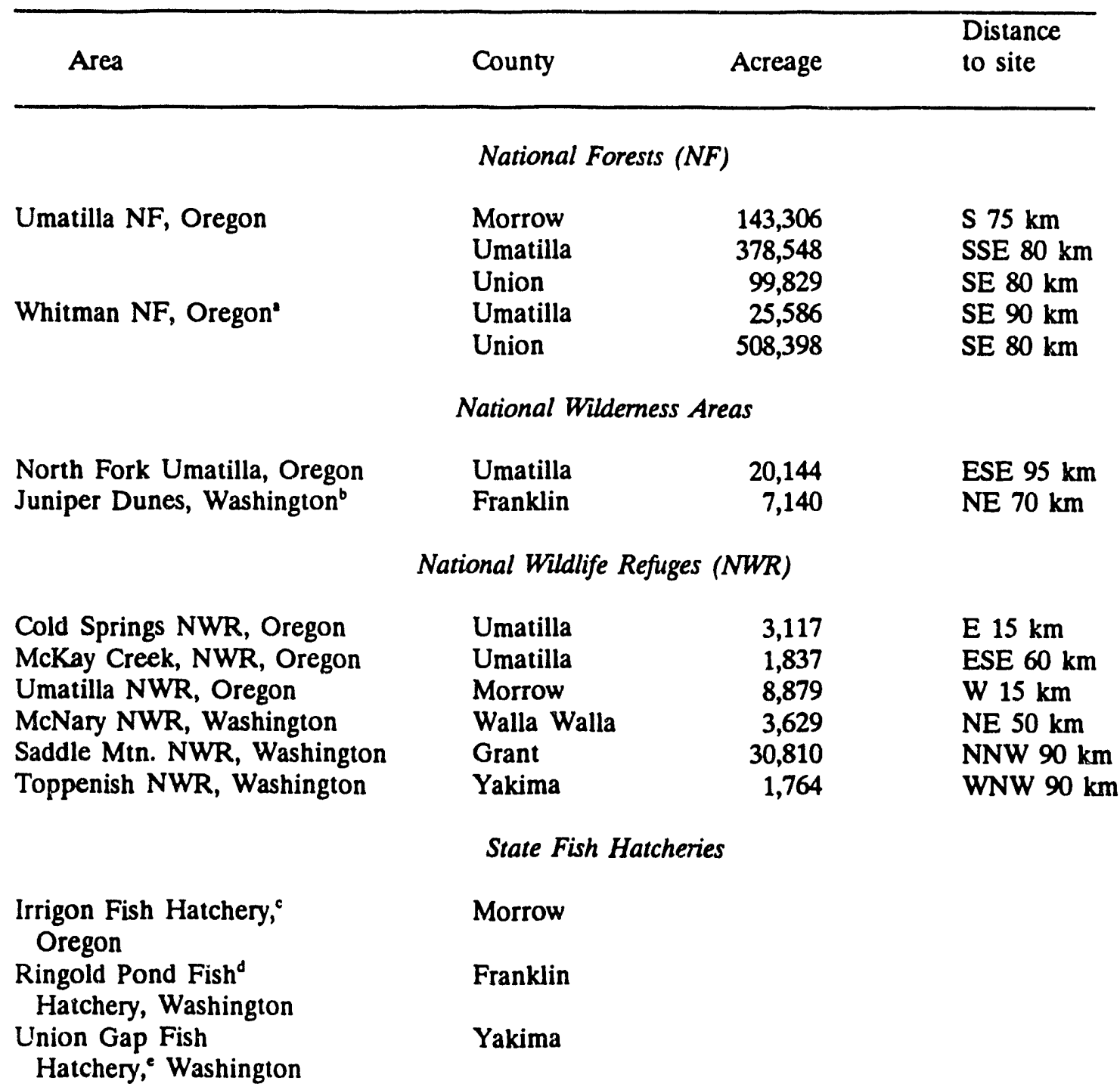

State Forest Waysides (Ws)

Blue Min. WS, Oregon

Ukiah Dale Ws, Oregon

Battle Mtn. SP, Oregon

Emigrant Springs SP, Oregon

Hat Rock SP, Oregon

J.S. Burres SP, Oregon

Crow Butte SP, Washington

Sacajawea SP, Washington
Umatilla

Umatilla

State Parks (SP)

Umatilla

Umatilla

Umatilla

Gilliam

Benton

Franklin
$S 75 \mathrm{~km}$ SSE $80 \mathrm{~km}$ SE $80 \mathrm{~km}$ SE $90 \mathrm{~km}$ $S E 80 \mathrm{~km}$

ESE $95 \mathrm{~km}$ $\mathrm{NE} 70 \mathrm{~km}$

E $15 \mathrm{~km}$ ESE $60 \mathrm{~km}$ W $15 \mathrm{~km}$ NE $50 \mathrm{~km}$ NNW $90 \mathrm{~km}$ WNW $90 \mathrm{~km}$ 
Table 9. (continued)

\begin{tabular}{|c|c|c|c|}
\hline Area & County & Acreage & $\begin{array}{l}\text { Distance } \\
\text { to site }\end{array}$ \\
\hline \multicolumn{4}{|c|}{ State Habitat Management Units/Areas } \\
\hline McNary HMA, Washington & Walla Walla & 9,496 & NE $50 \mathrm{~km}$ \\
\hline $\begin{array}{l}\text { Rattlesnake Slope HMU, } \\
\text { Washington }\end{array}$ & Benton & 3,622 & $\mathrm{~N} 50 \mathrm{~km}$ \\
\hline $\begin{array}{l}\text { Snake River HMA, } \\
\text { Washington }\end{array}$ & $\begin{array}{l}\text { Franklin/ } \\
\text { Walla Walla }\end{array}$ & 14,000 & $\mathrm{NE} 80 \mathrm{~km}$ \\
\hline $\begin{array}{l}\text { Sunnyside Wildlife } \\
\text { Recreation Area, } \\
\text { Washington }\end{array}$ & Yakima & 7,604 & NW $50 \mathrm{~km}$ \\
\hline $\begin{array}{l}\text { Wahluke Unit Columbia Basin } \\
\text { HMU, Washington }\end{array}$ & Grant & 57,839 & $\mathrm{~N} 90 \mathrm{~km}$ \\
\hline
\end{tabular}

"Forty-one parcels are located within the confines of the Umatilla National Forest within Umatilla Co.

In the 17,367-acre Juniper Forest, public domain forestland is managed by the Bureau of Land Management. is under construction.

'Irrigon Fish Hatchery is west of Hermiston, Oregon, at Irrigon; a second hatchery

${ }^{\mathrm{J}}$ Ringold Pond Fish Hatchery is north of Richland, Washington, and adjacent to Wahluke Slope HMU and the Hanford Reservation. Yakima River.

Union Gap Fish Hatchery is south of Yakima, Washington, and is adjacent to the

Sources:

P. Reed, National Wilderness Preservation System, Fort Collins, Colorado, Wilderness Research Foundation, 1987.

U.S. Fish and Wildlife Service, Annual Report of Lands under Control of the U.S. Fish and Wildlife Service as of September 30, 1987, 1987.

U.S. Forest Service, Land Areas of the National Forest System, as of September 30, 1987, Washington, D.C., 1988.

U.S. Forest Service, A Summary of Recreation Use (M/RVDS) for FY 1986 by Activity, Washington, D.C., 1987.

Washington Dept. of Game (no date), Habitat Management Areas, Department of Game, Fish and Wildlife Facilities, Olympia Headquarters. 
Other protected ecological resources identified in preparation for the site-specific EIS are listed in Table 8. Their locations are identified in Fig. 11. There were no national parks identified within the $100-\mathrm{km}$ (62-mile) zone during site-specific data collection; one park was identified during the FPEIS process. Additional information has been obtained on the number of wilderness areas (1); wildlife refuges (6); fish hatcheries (4); state parks (6); and habitat management units (5) (see Table 8). There were three wilderness areas identified during preparation of the FPEIS. Information on wildlife refuges, fish hatcheries, state parks, and habitat management units constitutes additional information obtained during the Phase I process. This additional information, however, does not change the conclusions that were reached in the FPEIS concerning ecological resources. These resources are distributed throughout the potential zone of impact and are not concentrated in the general downwind direction from the proposed UMDA disposal site. This additional information will help to better estimate the extent of effects on important ecological resources during preparation of the site-specific EIS.

\section{Social, Economic, and Cultural Resources}

Additional data have been collected as part of Phase I for the region beyond the $10-\mathrm{km}$ (6-mile) zone-as ured in the FPEIS—but within $100 \mathrm{~km}$ (62 miles) of the proposed disposal facility at UMDA. Detailed information about site-specific social, economic, and cultural resources is given in Appendix B. Supplemental information collected for the UMDA region since the preparation of the FPEIS indicates that there has been relatively little change in the data presented in the FPEIS. With the exception of the new and larger database that extends beyond the $10-\mathrm{km}$ (6-mile) zone, no unique resources were identified.

The cumulative social, economic, and cultural impacts from other projects in the UMDA area were not discussed in the FPEIS; however, a preliminary survey of incomeand population-driven socioeconomic resources in the region indicates only small potential for cumulative impacts. These will be addressed in the site-specific EIS for UMDA.

For the purposes of examining site-specific human health impacts for the region near UMDA, additional data were gathered on nonresidential populations. The FPEIS did not consider the on-post population at any of the eight storage installations. Table 10 describes the day and night on-post population for UMDA. Likewise, the FPEIS did not consider the daytime population around any of the eight storage installations. The state of Oregon lacks detailed data on place-of-work population for the area surrounding UMDA. This information has been sought from other sources but has not yet been obtained. If adequate daytime population data can be located, they will be included in the site-specific EIS for UMDA. Special populations, such as those attending sporting events, have been identified in the area around UMDA, including transient populations involved in military training exercises; institutional populations in schools, hospitals and prisons; and migrant worker populations. Detailed information regarding off-post populations within $100 \mathrm{~km}$ (62 miles) of UMDA, sensitive populations by age group, and transient populations are provided in Appendix B. All population data will be considered in estimating fatalities in the site-specific EIS for UMDA. 


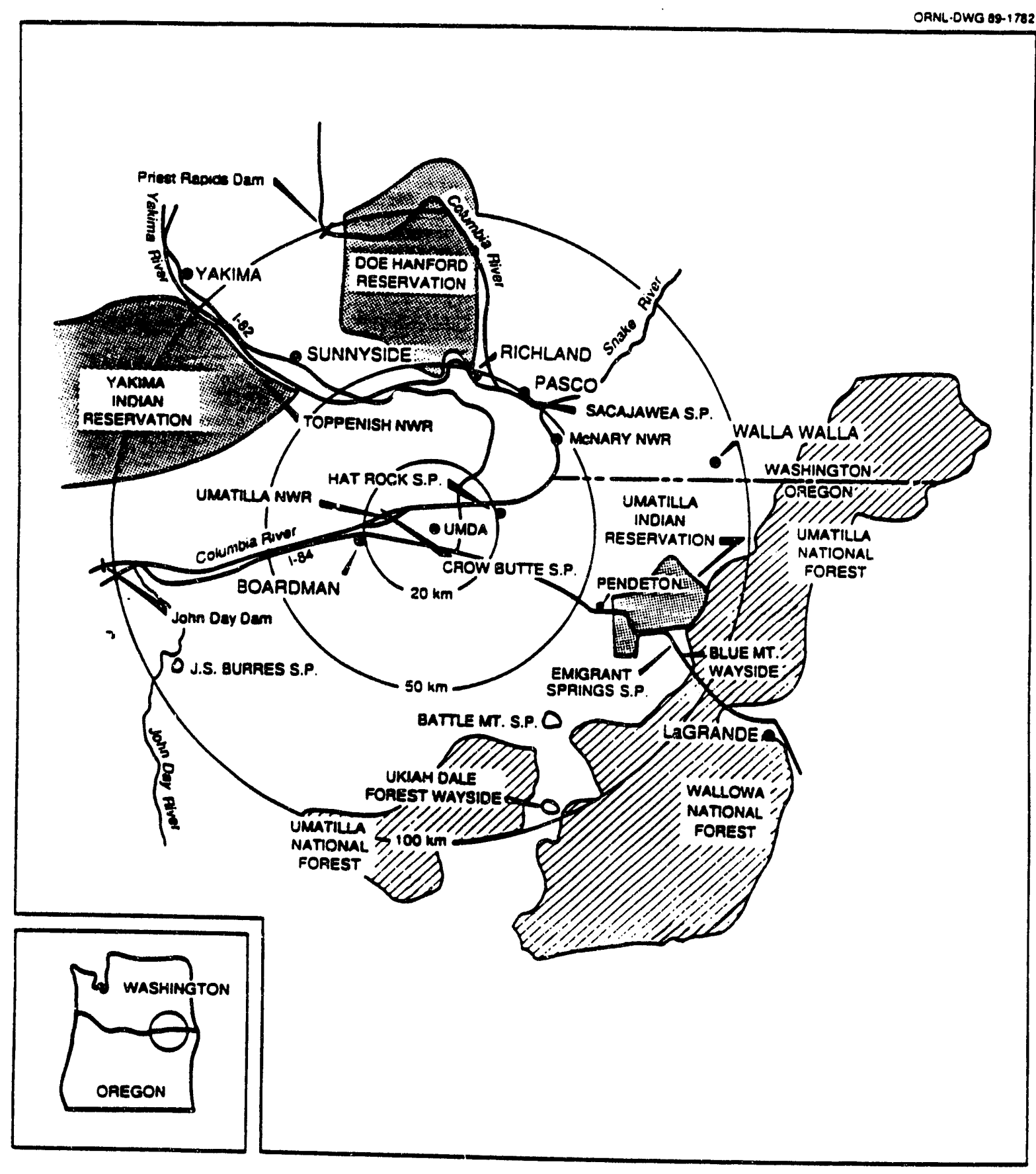

Fig. 11. Ecological resources of special interest within $100 \mathrm{~km}$ (62 miles) of the proposed disposal facility at the Umatilla Depot Activity. 
Table 10. On-post population at Umatilla Depot Activity by time of day

\begin{tabular}{lccc}
\hline & Employees & Dependents & $\begin{array}{l}\text { Total base } \\
\text { population }\end{array}$ \\
\hline $\begin{array}{l}\text { Capacity } \\
\begin{array}{l}\text { Present population } \\
\text { (July 1989) }\end{array}\end{array}$ & 250 & 80 & 330 \\
$\begin{array}{l}\text { Present daytime } \\
\text { population (from }\end{array}$ & 244 & 46 & 290 \\
$\begin{array}{l}\text { 7:00 a.m.-3:30 p.m.) } \\
\begin{array}{l}\text { Present nighttime } \\
\text { population (after }\end{array}\end{array}$ & 5 & 30 & 274 \\
3:30 p.m.) & & 55 & 60 \\
\hline
\end{tabular}




\subsubsection{Aircraft Activity}

The nearest active airfield to UMDA is Hermiston Municipal Airport approximately $19 \mathrm{~km}$ (12 miles) from the installation. A single 1200-m (4000-ft) runway is limited to aircraft no larger than corporate jets. The Tri-Cities Airport in Pasco, Washington, with a maximum runway length of $2300 \mathrm{~m}(7700 \mathrm{ft})$, is approximately $48 \mathrm{~km}$ (30 miles) from UMDA. General aviation facilities are also available at Kennewick and Richland, Washington. There also is a 900-m (3000-ft) paved runway within the UMDA installation boundary; this runway is capable of handling small aircraft up to the size of a Beech U-21 light utility aircraft. The nearest military airfields are in Spokane, Washington; Moses Lake, Washington; and Mountain Home, Idaho.

There are three restricted airspace areas in the vicinity of UMDA. The Medium Attack Tactical Electronic Warfare Wing, stationed at Whidby Naval Air Station in Oak Hill, Washington, conducts bombing exercises within two of these restricted areas (R-5071 and R-5706) in a bombing range located $16 \mathrm{~km}$ (10 miles) southwest of the UMDA chemical storage area near Boardman, Oregon. Altitudes up to $3,500 \mathrm{~m}$ $(10,000 \mathrm{ft})$ mean sea level (MSL) are permitted within these restricted areas. An average of nine sorties per day and four sorties per night are flown Monday through Friday. Hours of use are from 8:00 a.m. to 12:00 midnight. With preapproval, the range is flown occasionally on weekends by the Wing. One weekend per month, the U.S. Naval Air Reserve uses the range. Each sortie may consist of Grumman A-6 aircraft, in groups of four or less. They drop inert $11-\mathrm{kg}$ (25-lb) bombs and, occasionally, 225 - to $450-\mathrm{kg}$ (500- to $1000-\mathrm{lb})$ inert bombs during practice runs.

The third restricted area (R-5704) is located over the western portion of the UMDA installation. It is under the control of the UMDA Commander. Airspace is controlled from the surface to $1200 \mathrm{~m}(4000 \mathrm{ft}) \mathrm{MSL}$.

There are two low-altitude federal airways in the general vicinity of UMDA: $\mathrm{V}-4$ and V-112. Three high altitude airways (J-16, J-20, and J-54) cross within $10 \mathrm{~km}$ (6 miles) of the installation toward Pendleton, Oregon. On the flight charts, military training route VR-1354 appears to pass over area R-5704; the route is flown within a

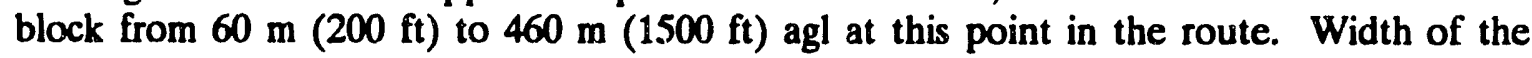
route is $7.4 \mathrm{~km}$ ( 4 nautical iniles) on either side of the centerline. An advisory, however, has been issued to aircraft using VR-1354 that overflight of R-5704 must be avoided.

The absence of low-altitude operations in the airspace over the site of the proposed disposal facility would decrease the likelihood of aircraft crashes and damage to the proposed disposal facility. The site of the proposed disposal facility meets the criteria set by the Nuclear Regulatory Commission (NRC) for distance from airports and federal airways.

\section{Emergency Planning and Preparedness}

Emergency planning and preparedness played a key role in identifying the programmatic environmentally preferred alternative. The difficulty of planning 
emergency response activities for an accident along any off-site transportation route was an important consideration in rejecting those alternatives requiring off-site transport. The Army has begun enhancement of emergency planning and preparedness at each installation regardless of the proposed action; thus, emergency planning will benefit equally each of the alternatives under consideration in this report (continued storage, on-site disposal, and on-site activities associated with off-site disposal) and was not a key factor in reexamining the environmentally preferred alternative in Sect. 3.1.

Consequently, emergency planning and preparedness are discussed in the context of new information affecting on-site disposal that will be addressed in the site-specific EIS. The following is a brief discussion of emergency planning activities in the UMDA vicinity.

The Army has begun enhancement of emergency response capabilities at UMDA by requesting funds from Congress to implement the Emergency Response Concept Plan (ERCP) (Jacobs Engineering Group, Inc., and Schneider EC Planning and Management Services 1987) at all eight storage sites, including UMDA. The Army also has funded planners to work with local goveruments to upgrade existing plans. In addition, the Army is committed to provide technical assistance and coordinate local planning efforts. Furthermore, the Army intends to request funds to improve emergency response capabilities through capital improvements in fiscal years 1990 and 1991. Combined, these enhancements are aimed at upgrading the emergency response capabilities commensurate with ERCP and should greatly improve emergency response capabilities in the UMDA vicinity.

\subsection{TECHNOLOGY STATUS/MATURITY}

The purpose of this section is to provide a status report on the developments in the proposed disposal technology since the FPEIS, with an emphasis on the continuing operational experience being gained during this time. Technology status/maturity refers to the continuing refinement of designs and procedures from the conceptual design stage to the operation of the initial disposal facility, through the time the chemical stockpile is destroyed. This section focuses on technology developments that have occurred since the FPEIS.

As the implementation of the CSDP progresses, an increasing amount of the stockpile would be destroyed. Facilities built and operated in the latter stages of the program will benefit from the lessons learned in the design and operation of earlier facilities. Figure 12 illustrates the projected cumulative stockpile destruction in future years as the site-specific facilities are built and operated. By March 1995, when the UMDA facility is projected to begin disposal operation, about $21.7 \%$ of the total U.S. stockpile is projected to have been destroyed.

Experience to date in destroying agents and munitions benefits all proposed CSDP operations, but will be of greatest value to the installations where disposal operations are scheduled to begin first [e.g., Tooele Army Depot (TEAD) and Pine Bluff Arsenal (PBA)]. Chemical demilitarization operations have been conducted in demilitarization facilities in former production facilities at Rocky Mountain Arsenal 


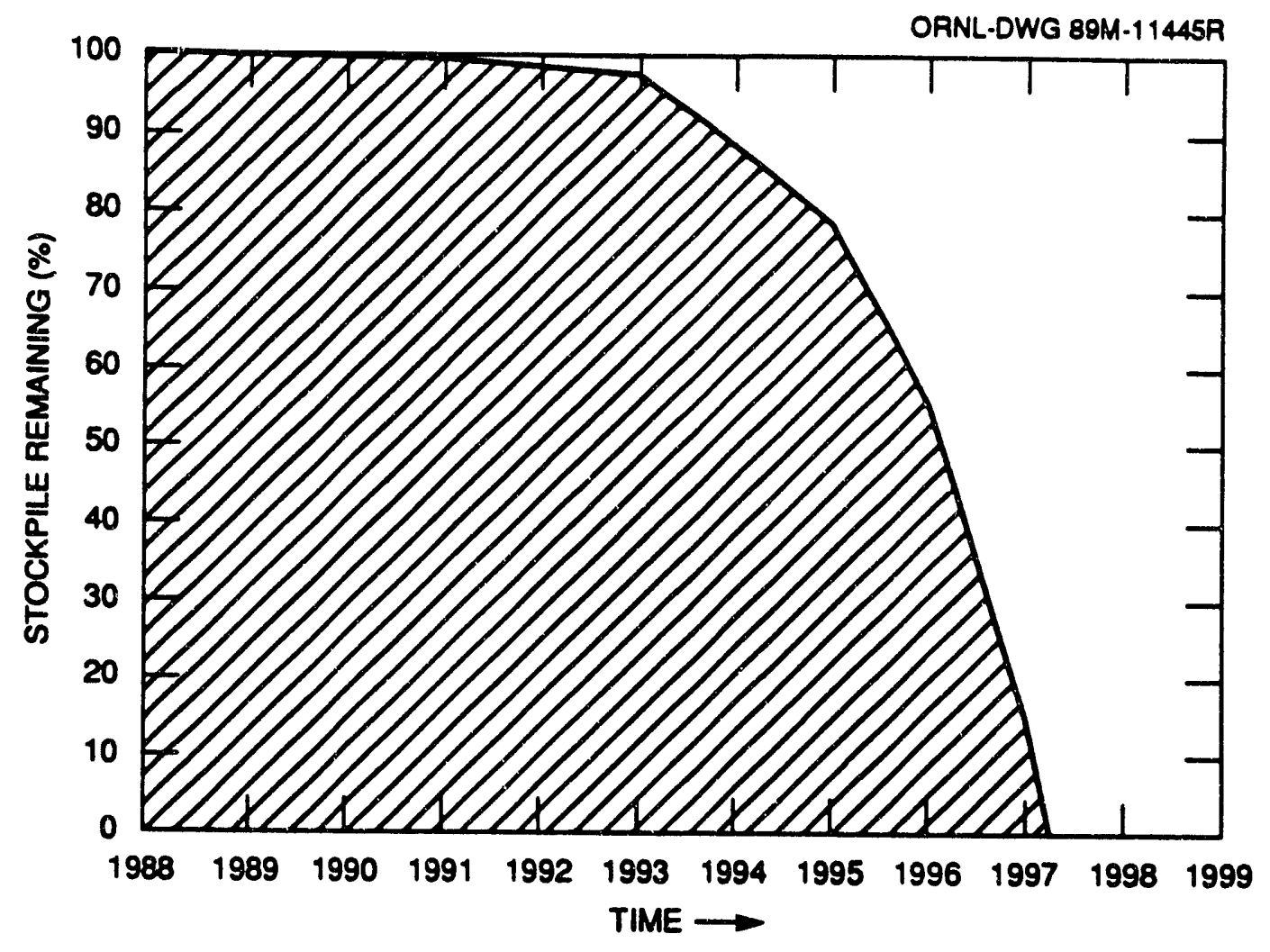

PROSECTED DURATION OF SITE-SPECIFIC DISPOSAL OPERATIONS

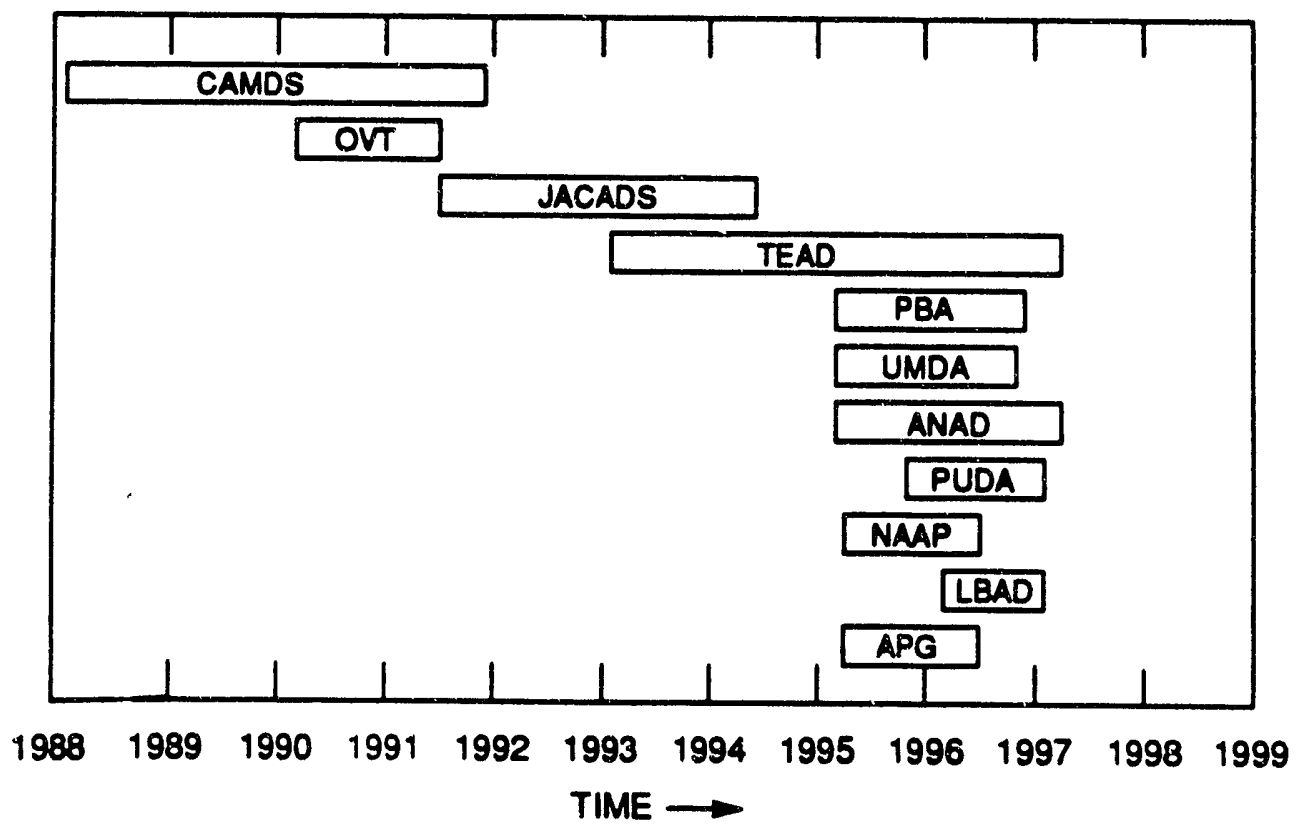

Fig. 12 Projected chemical agent stockpile destruction versus time. 


\section{3-38}

(RMA), located in Denver, and at the Chemical Agent Munitions Disposal System (CAMDS), located at TEAD, Utah. Through calendar year 1989, about 6.7 million $\mathrm{kg}$ (14.8 million lb) of agent had been destroyed at RMA and at CAMDS. Table 11 summarizes the U.S. Army's experience in industrial scale disposal of lethal chemical agents and munitions.

\subsubsection{BZ Demilitarization Operations}

Since issuance of the FPEIS, the Army has initiated the operation of a demilitarization facility at PBA for the destruction of the nonlethal but incapacitating agent BZ. The BZ disposal operations were completed in January 1990. Currently, plans are being developed for closure of the facility.

Approximately $42,600 \mathrm{~kg}(94,000 \mathrm{lb})$ of agent BZ were destroyed by incineration. The BZ disposal process was developed based on knowledge gained from disposal operations at CAMDS and RMA. Selected BZ equipment, including the deactivation furnace system and heated discharge conveyor, was purchased based on equipment technical data packages from CAMDS. Because the disposal procedures for $\mathrm{BZ}$ and the lethal unitary agents and munitions are based on a common technology, much of what was learned from disposal of the BZ has been applicable to the CSDP. In addition, although $\mathrm{BZ}$ is a nonlethal agent, the $\mathrm{BZ}$ disposal plant was operated in terms of safety, surety inspections, and guidelines as if it were disposing of lethal agents. The BZ facility and the CSDP facilities have been designed for maximum agent containment and destruction as well as maximum protection of both workers and the public from agent exposure. Specific contributions from the BZ disposal operations are as follows:

The $\mathrm{BZ}$ training program included extensive hands-on training, which, because of its success, will be implemented at Johnston Atoll Chemical Agent Disposal System (JACADS) (Sect. 3.3.2) and the Chemical Demilitarization Training Facility (CDTF) to support the CSDP.

- At the end of systemization and prior to startup of the BZ disposal operations, a preoperational survey was conducted by a team of experts [U.S. Army and U.S. Department of Human Health and Services (DHHS)] to ensure that the BZ disposal system conformed to all applicable safety, environmental, quality assurance, security and safety siandards and that an acceptable level of performance could be maintained during the $\mathrm{BZ}$ disposal operations. All findings essential to the safe and/or efficient operation of the $\mathrm{BZ}$ facility requiring correction were corrected prior to start of operations. Many of the problems identified during the $\mathrm{BZ}$ preoperational survey could have been resolved much earlier in the systemization period. For this reason, operational and readiness evaluations will be conducted at JACADS and CSDP facilities prior to the formal preoperational survey. These evaluations will be conducted periodically during the plant systemization periods to inspect designated systems and subsystems for compliance with regulatory requirements; to assess the progress of the facility 

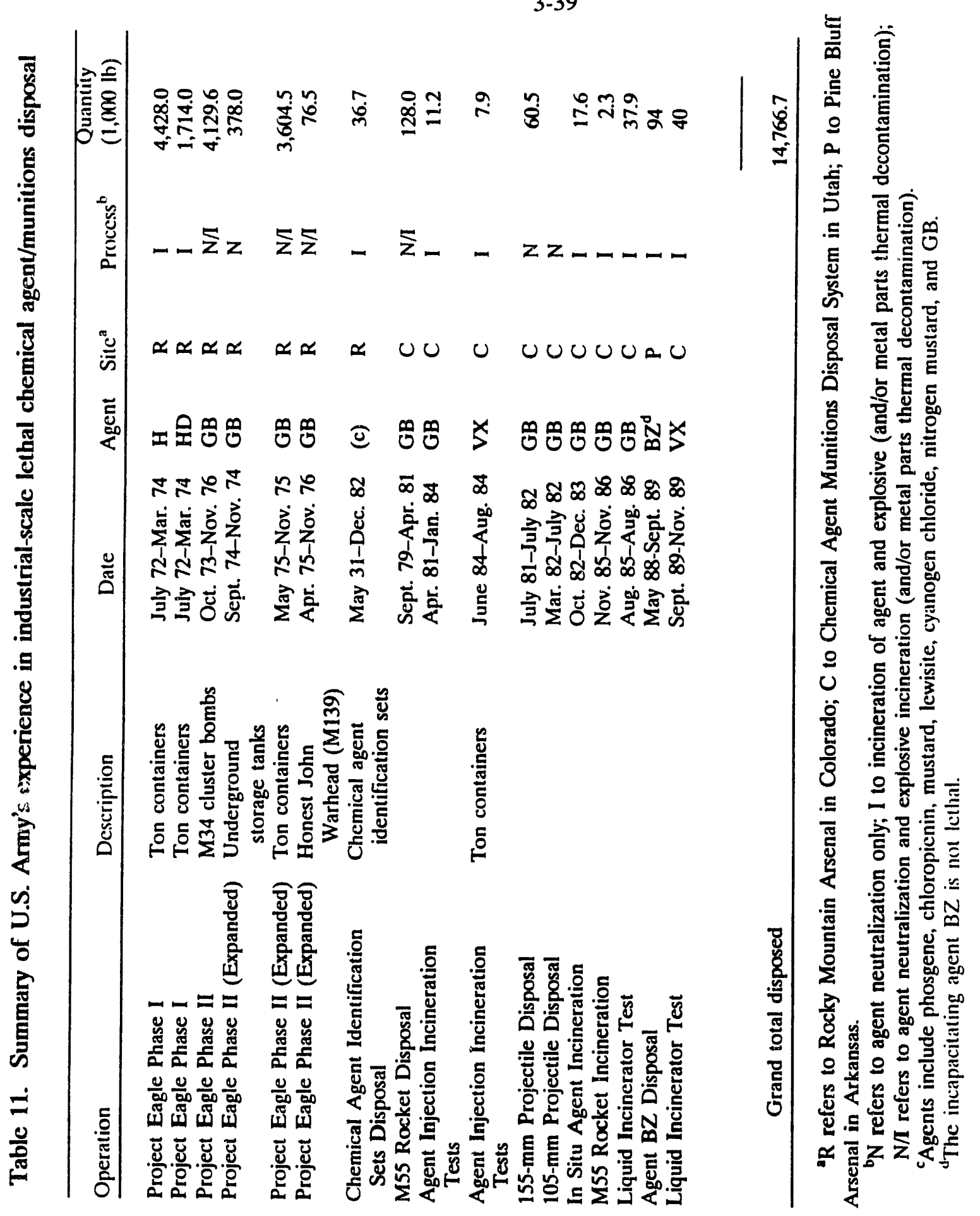
toward achieving an operational status in accordance with the schedule; and, to the maximum extent possible, to identify and resolve problem areas prior to the formal preoperational survey, thereby minimizing schedule impacts.

- The BZ disposal facility is the first government owned/contractor operated facility managed by the Program Manager for Chemical Demilitarization (PMCD). Experience has been gained regarding schedule durations and potential problems with hiring contractor personnel under the Chemical Personnel Reliability Program. This program ensures that personnel assigned to positions involving access to chemical surety material are emotionally stable, loyal to the United States, trustworthy, and physically fit to perform assigned duties. This program will also be instituted at the JACADS and CSDP facilities.

\subsubsection{Johnston Atoll}

Johnston Atoll is a coral atoll located in the central Pacific Ocean about $1300 \mathrm{~km}$ (800 miles) southwest of Honolulu, Hawaii. Johnston Island is the largest island of the atoll and is a storage site for three types of chemical agents and munitions: $\mathrm{GB}, \mathrm{VX}$, and mustard ( $\mathrm{H}$ and $\mathrm{HD}$ ). These agents are present in rockets, mines, projectiles, bombs, and ton containers. In January 1986, the U.S. Army began construction of JACADS on Johnston Island. The purpose of JACADS is to provide a capability for complete demilitarization of all lethal chemical agent-filled projectiles, rockets, mines, bombs, and bulk quantities of agent stored at Johnston Island.

JACADS equipment procurement was initiated in October 1985 and completed in November 1988. Equipment installation and field testing of the equipment required for disposal of M55 rockets was completed in August 1988. Equipment startup and personnel training have been initiated and will continue until plant operations (i.e., operational verification testing) begin, which is expected to occur in March 1990. Currently, approximately 250 personnel from the operations and maintenance contractor are on the island. This staff is being used to conduct equipment tests and perform facility systemization efforis.

Because of the experience previously acquired with the disposal technology and the means to perform operational proveouts at the JACADS facility, the Army has chosen to use the JACADS reverse assembly incineration process for the proposed disposal facilities at the eight continental United States (CONUS) disposal sites. Because JACADS and the CONUS disposal facilities will be using the same technology, experience from JACADS will be directly transferrable to the CONUS plant designs, startup, and operations.

In the 1988 CSDP Implementation Plan (U.S. Army 1988b), the Army proposed, and Congress later approved, the delay of construction of all but the TEAD CSDP facility until operational verification testing (OVT) at JACADS could be completed. This test program was developed to give additional confidence to the public and the Congress that these munitions can be safely destroyed prior to initiating demilitarization operations at the CONUS CSDP plants. The JACADS Test and Evaluation Master 
Plan (Duff et al. 1989) for the OVT program has been reviewed by DHHS and the National Research Council. JACADS OVT is to be conducted during the first 16 months of JACADS operations. This test period represents the first time the JACADS process will be tested and evaluated as a full-scale facility. During this period, the overall JACADS process, and in particular the performance of the incinerato: systems, will be evaluated with all three chemical agents (mustard, GB, and VX) in conjunction with the processing of rockets, projectiles, and ton containers. The general objective of the OVT is to demonstrate the operability of the entire plant, including personnel and all support systems, under toxic operating conditions. The plant's response to emergency situations will be demonstrated during JACADS systemization (the period prior to startup of lethal agent incineration) during which time deliberate nonagent challenges to plant subsystems will be conducted. The overall JACADS system will be evaluated for environmental compliance, industrial and chemical agent safety, and system reliability.

Test data from JACADS systemization and OVT will be evaluated for implementation into the UMDA facility prior to construction. Findings from the OVT will be incorporated into the UMDA design and equipment specifications. A 4-month design and procurement verification period following OVT has been incorporated. This verification period will be used for corrections dictated from OVT and from the experience gained from the program. In addition, the OVT findings will be evaluated after each phase of OVT and will be implemented immediately into the UMDA design as necessary.

\section{1989 Agent VX Test Program at the Chemical Agent Munitions Disposal System (CAMDS)}

CAMDS is the Army's pilot plant for proof testing chemical demilitarization technology using agents and munitions stored at TEAD. It is located at TEAD, about $50 \mathrm{~km}$ (30 miles) west of Salt Lake City.

In September 1989, VX testing began at CAMDS. Although VX has been incinerated at CAMDS in the past, this testing provided additional experience prior to the beginning of JACADS OVT. During this test period, the performance of the demilitarization equipment was further evaluated and VX incinerator tests were conducted in the liquid incinerator (LIC). A test burn was also conducted in the LIC to characterize effluents and solid residues and compare them against regulatory standards. The feed to the LIC was varied to characterize furnace performance under varying operating conditions.

The CAMDS LIC was operated between September 10 and November 2, 1989. The test plan was based on feeding agent VX to the primary chamber and water or spent decontaminating solutions (decons) into the secondary chamber. The spent decon solution was $1 \%$ sodium hypochlorite $(\mathrm{NaOCl})$. The LIC successfully incinerated $18,240 \mathrm{~kg}(40,215 \mathrm{lb})$ of agent $\mathrm{VX}$ during the test period. The average VX feed rate to the primary chamber was $92.5 \mathrm{~kg} / \mathrm{hr}(204 \mathrm{lb} / \mathrm{hr})$ during approximately $200 \mathrm{hr}$ of agent feed to the LIC. Approximately $25 \mathrm{~m}^{3}$ (6530 gal) of $1 \%$ sodium hypochlorite solution 
were incinerated in the secondary chamber at an average feed rate of $0.3 \mathrm{~m}^{3} / \mathrm{hr}$ (1.3 $\mathrm{gpm}$ ) for the 84 hours of decon operation. The chemical agent detectors did not measure agent in the stack or surrounding area at any time during the testing.

Resource Conservation and Recovery Act (RCRA) demonstration burns were conducted as a part of the VX testing. Representatives from the Utah Bureau of Solid and Hazardous Wastes witnessed four agent incineration tests conducted between September 18 and 22, 1989. The carbon monoxide emissions never exceeded the proposed Tier I hourly limit of $100 \mathrm{ppm}$. The VX destruction and removal efficiency exceeded $99.9999 \%$. The particulate emissions averaged $135 \mathrm{mg} / \mathrm{m}^{3}$ over the RCRA demonstration period with only one run exceeding the limit of $180 \mathrm{mg} / \mathrm{m}^{3}$. Hydrogen chloride $(\mathrm{HCl})$ emissions never exceeded the $1.36 \mathrm{~g} / \mathrm{hr}(0.003 \mathrm{lb} / \mathrm{hr})$ limit. A less formal test burn was conducted with the incineration of $\mathrm{VX}$ in the primary chamber and $1 \%$ sodium hypochlorite in the secondary chamber. The emissions results from the burn indicated compliance with RCRA regulations.

One of the problems developed during the VX testing was the formation of a glassy green slag in the bottom of the secondary chamber. Preliminary analysis of the slag indicated $23 \%$ phosphorus from the agent and silica and alumina from the furnace chamber refractory. Additionally, the secondary chamber refractory was damaged. The services of contractors have been procured to analyze the problems and suggest solutions. The results will be represented as soon as they are available. Tests are planned with the CAMDS LIC utilizing a high phosphorus simulant, dimethyl phosphite (DEP), in early 1990. The LIC will be operated under various conditions in order to better understand the slag formation. The removal of the slag from the secondary chamber is also being studied carefully. The current salt removal system did not appear to perform effectively during the VX tests.

\subsubsection{Mustard Agent (HD) Test Program at CAMDS}

In the summer of 1990 , testing with mustard agent (HD) is scheduled to begin at CAMDS. Although agent HD has been incinerated at RMA in the past, the CAMDS testing will provide additional experience before agent $\mathrm{HD}$ is incinerated during the JACADS OVT. During the proposed mustard tests, the performance of the demilitarization equipment will be further evaluated and incineration tests of agent HD will be conducted in the LIC and Metal Parts Furnace (MPF). A test burn will be conducted in the LIC and MPF to characterize effluents and solid residues and to compare them to the regulatory standards. The feed to the LIC will be varied to characterize furnace performance under varying operation conditions. Drained ton containers and projectile bodies will be thermally decontaminated in the MPF to confirm processing rates and to characterize emissions and residues.

\subsubsection{Award of the Systems Contract for the Chemical Demilitarization Training Facility}

In July 1989, the systems contract for the construction and operation of a CDTF was awarded to General Physics Corporation of Columbia, Maryland. This facility, which 
is being constructed at the Aberdeen Proving Ground, Maryland, will be used to ensure uniform and consistent training is provided to workers who will operate the eight demilitarization facilities planned for construction. The CDTF is scheduled to begin training operations in late 1990.

The CDTF will provide basic and prerequisite instruction in chemical agent and munition destruction for both government and contractor personnel involved in operation of the CONUS facilities. The CDTF will provide classroom instruction, handson equipment operation, computer simulation and continuation/refresher courses. A centralized training facility will enable workers to obtain training in a nonhazardous environment and will facilitate standarćization of operations and maintenance procedures between the eight CONUS facilities. A single contractor is being used to train workers at the CDTF to facilitate incorporation of lessons learned and to centralize the training expertise, increasing overall training effectiveness.

\subsubsection{Award of the Systems Contract for the Tooele Chemical Agent Disposal Facility}

In September 1989, the systems contract for the Tooele chemical agent disposal facility was awarded to EG\&G, Inc., of Falls Church, Virginia. EG\&G, Inc., is responsible for the construction, operation and decommissioning of the first full-scale CONUS chemical agent and munitions disposal facility. This facility is to be constructed at the Tooele Army Depot, Utah. Operation of the Tooele facility is scheduled to begin in 1993.

\subsubsection{Equipment Acquisition Contracts}

In November 1988, an equipment acquisition contract was awarded to Bechtel National, Inc. Bechtel is responsible for the acquisition of process equipment to be standardized between the eight CONUS demilitarization facilities. Examples of equipment to be purchased by Bechtel include the demilitarization equipment used to disassemble the munitions prior to incineration, the blast doors for the explosive containment room, and the brine reduction equipment.

Major process equipment critical to the safe operation of the facilities (e.g., furnaces, control systems and pollution abatement systems) are being purchased by Stearns-Rogers, Inc., the JACADS equipment acquisition and operations contractor. The JACADS equipment acquisition contract contains options to purchase major equipment systems for the eight CONUS demilitarization facilities from the JACADS equipment vendors. This acquisition strategy will result in purchasing systems critical to the safe operation of the facility which are essentially identical to those purchased for JACADS. As a result, safety and environmental compliance aspects of this equipment will be able to be demonstrated during JACADS OVT.

Equipment acquisition for all sites through a single equipment acquisition contractor (either Bechtel or Stearns-Rogers) will result in obtaining uniformity and standardization of equipment between the CONUS sites and will facilitate incorporation of lessons learned. 


\subsubsection{Individual Equipment Advancements}

In addition to experience gained from ongoing demilitarization programs, separate test programs and research and development efforts are ongoing to improve the performance of individual equipment systems and ensure that state-of-the-art technology is continually incorporated into the CSDP facilities. For example, since the FPEIS was written, major advancements have been made to the automatic continuous air monitoring system (ACAMS) and ventilation filtration system.

During 1988, a research and development program was initiated to modify the ACAMS so that it could detect time-weighted average (TWA) concentrations of the agents $\mathrm{HD}, \mathrm{GB}$, and $\mathrm{VX}$ within a 3 to $5 \mathrm{~min}$ cycle. This was an improvement over the response time cited in the FPEIS, in which high-level detection was assumed to be achieved within $5 \mathrm{~min}$, but detection to the TWA level could only be achieved within 8 to $22 \mathrm{~min}$. These reduced response times were successfully achieved during demonstration tests in mid-1988, and the JACADS ACAMS is being modified to include this new technology prior to the start of operations.

Dugway Proving Ground is currently conducting adsorption tests on carbon to determine the effects of agent GB concentration, relative humidity, and iumperature on adsorption and desorption performance of carbon filters. Test conditions were selected based on an experimental design chosen to provide a response surface at carbon bed depths of 5,10 , and $20 \mathrm{~cm}(2,4$, and 8 in.). The results should indicate the optimal operating conditions for the carbon and will enable the Army to assess the optimal carbon depth and the optimal operating conditions for the filters.

The FPEIS made a public commitment to transport munitions from the storage area to the disposal facility in an on-site container (ONC) which would meet certain puncture, drop, fire, and crush performance criteria. The ONC was necessary to mitigate the risk of chemical munition transportation accidents during demilitarization operations. Since the publication of the FPEIS, the Army has pursued the development of this container. As of January 1990, the ONC design has been completed, puncture and fire tests have been successfully completed on a full scale mock-up ONC, and fabrication of a prototype ONC has been initiated. Prototype testing, to include projectile penetration tests, rocket drop tests, handling demonstrations, and a compliance test are scheduled to be completed at the end of 1990. Following prototype testing, acquisition of the ONCs for the CONUS facilities will be initiated. 


\subsection{RISK ASSURANCE}

The FPEIS risk analysis was based on the JACADS $60 \%$ design as modified by conceptual changes planned for implementation at the eight proposed CONUS facilities. A risk assurance study is underway in support of the site-specific NEPA process to examine the ramifications of major procedural and conceptual changes to the design analyzed in the FPEIS. Such design changes have resulted from Army efforts to make the disposal operation safer; to make the plant more efficient in disassembling munitions and in destroying agents; to incorporate lessons learned from CAMDS, JACADS, and other facilities (as discussed in Sect. 3.3); and to comply with environmental permit requirements that change over time and vary from state to state.

Major changes will be examined as part of the risk assurance study to determine if they have the potential to significantly increase the risk of on-site disposal from that presented in the FPEIS. If such a potential increase is identified, the resuitant risk will be calculated and a determination will be made (using the FPEIS decision methodology) as to whether on-site disposal is still the preferred alternative for that site. The effectiveness of potential mitigation measures reducing the change in risk to insignificant levels would also be examined.

As individual facility designs further evolve from the concepts presented in the site-specific EIS, additional design and procedural changes may be made. Prior to finalizing these design changes, a rigorous safety review will be conducted in accordance with the System Safety Management Plan for the CSDP. This plan outlines the various safety reviews and checkpoints to be implemented during the design, construction, and operation of the proposed disposal facility, including various hazard analyses, fault tree analyses, and safety assessments and inspections. All proposed design changes will be subjected to the same extent of safety analysis as the original design. For this reason, additional site-specific risk analysis beyond that presented in the FPEIS and updated in the risk assurance study is not planned. This section highlights the results of this risk assurance process and presents conclusions about selected design changes relevant to UMDA.

\subsubsection{Rationale and Basis for Risk Assurance at the Umatilla Depot Activity}

The JACADS design (at its $60 \%$ completion level) provided the basis for the FPEIS risk analysis. Table 12 provides a summary of the principal changes in design and operating procedures for UMDA that have been approved by the Army since publication of the FPEIS. Many other minor changes are not shown in Table 12; however, based on an assessment of the potential for such changes to affect risk, the items in the table have been identified as warranting a closer examination of their associated risk values and how those values might differ from the values presented in the FPEIS for UMDA

"Risk" is determined by the probability of an accident and its consequences. Any design change that has the potential for increasing either the probability or consequence of an accident may, therefore, increase the risk and may require close examination for 
Table 12. Summary of major changes in design and operating procedures for the proposed disposal facility at the Umatilla Depot Activity

Munitions handling igloo (MHI) used for temporary storage of sufficient munitions to support multishift plant operations

On-site container (ONC) used to safeguard munitions during transport. ONC holds only one pallet or box of munitions. Four ONCs to be transported by each munition transporter; only one transporter per convoy

During demilitarization operations, only one munition type would be processed at a time

One liquid incinerator (LIC) used to destroy chemical agent
MHI replaced by container handling building (Cl:IB) that has a mustard thaw capability

ONC will still be used but has been redesigned; ONC holds up to nine pallets of munitions. Two ONCs per munition transporter

Munitions and bulk agent inside ton containers may be processed simultaneously (i.e., coprocessing)

Two LICs will be used at the Umatilla Depot Activity plant 
the purpose of risk assurance. One criterion for identifying changes that require further examination is the number of additional steps in the procedures implementing the new design. For example, if the FPEIS assumed that munition pallets were handled three times prior to their unpacking and individual munition disassembly, but the new design allows for six such handling steps, then risk must be reexamined to determine if the frequency of an accident has increased.

Another criterion involves the quantity of agent that could be involved in an accident. For example, if the accident sequence in the FPEIS assumed that only small quantities of agent could be involved, but the new design allows for larger agent quantities to be present, then reexamination of the risk implications for that design change is warranted by the potential increase in the quantity of chemical agent accidentally released.

Applying the above criteria to the potential for design changes to affect risk, the items in Table 12, with the exception of the two LICs and coprocessing, were identified for further examination.

The simultaneous processing (i.e., "coprocessing") of munitions and ton containers is being considered for implementation at UMDA. Although the FPEIS has already examined the risks of separately destroying munitions and ton containers, the simultaneous handling, unpacking, and/or storage associated with coprocessing has not yet been analyzed. If the decision is made to implement coprocessing at UMDA, then coprocessing will be conducted in accordance with standard CSDP operating procedures and will be required to meet the guidelines of RCRA. Any risks or environmental impacts unique to coprocessing will be addressed in the risk assurance study and will be incorporated into the UMDA site-specific EIS.

Operation of two LICs is also planned at UMDA. The conceptual plant operation procedures in the FPEIS risk assessment would not be changed by two-LIC operation, except for the physical reality of having two incinerators operating simultaneously. The two LICS would be fed liquid agent from the same tanks inside the same toxic cubicle (TOX) as was assumed in the FPEIS. Thus, these risks would not change. Because LIC accidents were only a minor contributor to the risks of on-site disposal at UMDA, there is little or no potential for the proposed two-LIC operation to affect risk.

The risk implications of the remaining items in Table 12 are discussed below. A report on the reassessment of the risk implications for the complete set of changes in design and operating procedures from those presented in the FPEIS is currently being prepared as part of the risk assurance stuuiy.

\subsection{Design Changes Requiring Reecamination of Risk at the Umatilla Depot Activity}

\subsubsection{Container handling building}

The FPEIS assumed that agents and munitions would be removed from their existing storage, placed inside on-site transportation containers, and transported to a munitions holding igioo (Mini). The MHI provided temporary storage of sufficient 
munition quantities to operate the plant during nondaylight hours (i.e., when on-site transport from existing storage directly to the plant could not occur). The MHI concept involved storing packaged munitions in a standard earth-covered magazine (igloo), handling the packages with forklifts inside the igloo, and moving the packages by forklift across an open area to the demilitarization building.

The MHI concept was subsequently found to be inadequate because its capacity was insufficient and there were too many handling steps to support the throughput and processing rates required by the demilitarization plant. The new UMDA design incorporates a container handling building (CHB) which eliminates these inadequacies of the MHI concept; however, the CHB introduces new design features that warrant a reexamination of risk. Because the $\mathrm{CHB}$ has a larger capacity than the $\mathrm{MHI}$ and is not as well protected from external events as was the MHI (i.e., the MHI was to have been an earth-covered concrete structure), there exists a potential for more agent to be involved in an accidental release. In addition, there are fewer handling steps-and a reduced probability of accidents-for the CHB than for the MHI. While these may appear to be offsetting factors, their relative contribution to risk is unclear. Thus, a reexamination of risk was required to define the overall risks associated with the replacement of the MHI by the CHB design.

Results of Examining CHB Risks. The result of examining the risks of this new design indicates that none of the five FPEIS measures of risk for UMDA are higher with the CHB than with the MHI (R. P. Pikul, The MITRE Corp., McLean, Va., letter report to C. R. Boston, Oak Ridge National Laboratory, Oak Ridge, Tenn., Aug. 4, 1989). The risks (primarily those risks from munitions handling) associated with the MHI were eliminated from the accident database, and new risks were developed for the CHB and added back into the database. The net result was that there was a decrease in the three probability-related measures of risk (i.e., the "probability of one or more fatalities," the "expected fatalities," and the "expected plume area"). The decrease in risk was less than $5 \%$ for each of these three measures of risk. Because the size (i.e., downwind no-deaths distance) of the largest CHB accident was no larger than other dominant on-site disposal accidents at UMDA (i.e., it was in the 50-km accident distance category), the other two measures of risk (i.e., the "maximum number of fatalities ' and the "person-years at risk") did not change. The risks associated with the new CHB design are therefore less than or equal to the risks associated with the MHI in the FPEIS for UMDR.

\subsubsection{Redesigned on-site container}

The FPEIS assumed that pallets or boxes of munitions u'ould be removed from existing storage, placed individually inside an ONC for protection during on-site movement, and transported to the disposal facility (either directly to the plant or to the MHI). During on-site movement, four ONCs would be loaded onto a munitions vehicle, and only one munitions vehicle would be in the convoy as it moved between the existing storage area and the disposal facility. 
Resolving the inadequacies of the MHI, as described above, by using the new $\mathrm{CHB}$ also required redesigning the ONC. The redesigned ONC will now carry more than one pallet or box of munitions (e.g., up to nine pallets of projectiles can be simultaneously transported inside the new ONC). Two of the new ONCs will be loaded onto a munitions transport vehicle.

Because the new ONC has a larger capacity than the ONC concept assumed in the FPEIS risk analysis, there exists a potential for a transport accident to release larger quantities of chemical agent than in the FPEIS. However, the larger capacity of the new ONC will require fewer trips between the storage area and the disposal facility. Because fewer vehicle miles will be travelled, the probability of an accident during transport will therefore decrease. The potential offsetting effects of these two factors (larger capacity and fewer vehicle miles) makes the impact on the FPEIS risk values for UMDA unclear. Therefore, a reexamination of ONC risks is warranted.

Results of Reexamining ONC Risks. The result of reexamining the risks of the new ONC design, and its accompanying transportation procedures, indicates that none of the five FPEIS measures of risk for UMDA are higher than with the old ONC conceptual design (R. P. Pikul, The MITRE Corp., McLean, Va., letter report to C. R. Boston, Oak Ridge National Laboratory, Oak Ridge, Tenn., Sept. 11, 1989). There was a decrease in the three probability-related measures of risk (i.e., the "probability of one or more fatalities," the "expected fatalities," and the "expected plume area"). The decrease in risk was $5 \%$ or less for each of these three measures of risk. Because the size (i.e., downwind no-deaths distance) of the largest ONC accidents with the new design was no larger than other dominant accidents at UMDA (i.e., the largest accident would still be placed into the $50-\mathrm{km}$ accident distance category), the "maximum number of fatalities" and the "person-years at risk" measures of risk did not change. The risks associated with the new ONC design are therefore less than or equal to the risks associated with the ONC concept in the FPEIS for UMDA.

\subsubsection{Addition of a mustard thaw capability}

The FPEIS assumed that the agents inside the bulk containers and munitions would be drained into a TOX and eventually fed into a LIC for destruction. This requires that the agent be in liquid form prior to being processed. Among the types of chemical agents to be destroyed at UMDA, mustard agent $\mathrm{HD}$ has the unique physical property that it is a solid at temperatures below $14^{\circ} \mathrm{C}\left(58^{\circ} \mathrm{F}\right)$. Only ton containers of $\mathrm{HD}$ are stored at UMDA, and these containers are stored inside a warehouse building. Because of the existing mustard storage configuration, the mustard agent at UMDA cannot be guaranteed to be in a liquid form during cold weather months.

The Army has developed a plan for thawing the mustard at UMDA by heating the ton containers inside a specially designed box in the CHB. The additional handling steps required to thaw the mustard, as well as the heating process itself, were not included in the FPEIS risk analysis. An examination of the additional risks of mustard thaw is therefore warranted. 
Results of Examining Mustard Thaw Risks. The results of examining the risks of thawing mustard indicate that three of the five FPEIS measures of risk for UMDA increase, but only slightly, above the values computed in the FPEIS (R. P. Pikul, The MITRE Corp., McLean, Va., letter report to C. R. Boston, Oak Ridge National Laboratory, Oak Ridge, Tenn., Nov. 7, 1989). There is no more than a $4 \%$ increase in those measures of risk related to probability: the "probability of one or more fatalities," the "expected fatalities," and the "expected plume area." The other two measures of risk (i.e., "maximum fatalities" and "person-years at risk") would not change as a result of adding a mustard thaw capability to the UMDA disposal facility. The increases in risk are not significant because they are within the range of uncertainty (i.e., within one pictogram shading pattern) associated with the measures of risk as given in the FPEIS. The FPEIS pictogram for UMDA does not change as a result of adding the risks from mustard thaw operations.

\subsection{REIFERENCES}

ATC (Applied Technology Council) 1978. Tentative Provisions for the Development of Seismic Regulations for Buildings, ATC/National Bureau of Standards Special Publication 510, U.S. Department of Commerce, Washington, D.C.

Davies-Smith, A., Bolke, E. L., and Collins, C. A. 1988. Geohydrology and Digital Simulation of the Ground-Water Flow System in the Umatilla Plateau and Horse Heaven Hills Area, Oregon and Washington, Water-Resources Investigations Report 87-4268, U.S. Geological Survey, Denver.

Duff, W. W., et al. 1989. Operational Verification Test and Evaluation Master Plan for the Johnston Atoll Chemical Agent Disposal System (JACADS), MTR-88W250, MTTRE Corporation, McLean, Va.

EPRI 1975. "Seismic Design of Nuclear Power Plants-An Assessment," pp. 81-86, EPRI 273, Electric Power Research Institute, Palo Alto, California.

Holzworth, G. C. 1972. Mixing Heights, Wind Speeds, and Potential for Urban Air Pollution throughout the Contiguous United States. Environmental Protection Agency, Office of Air Programs, Research Triangle Park, N.C., January.

Jacobs Engineering Group, Inc., and Schneider EC Planning and Management Services 1987. Emengency Response Concept Plan for the Chemical Stockpile Disposal Program, SAPEO-CDE-IS-87007, Program Executive Officer-Program Manager for Chemical Demilitarization, Aberdeen Proving Ground, Md.

Jacobs Engineering Group, Inc., and URS/John A. Blume and Associates 1987. Geological-Seismological Investigation of Earthquake Hazards for a Chemical Stockpile Disposal Facility at the Umatilla Depot Activity, Oregon, Office of the Program Manager for Chemical Demilitarization, Aberdeen Proving Ground, Md. NRC (Nuclear Regulatory Commission) 1982. "Safety Evaluation Report Related to the Operation of WPPSS Nuclear Project No. 2," Docket no. 50-397, NUREG-0892, Office of Nuclear Reactor Regulation, Washington, D.C. 
Robison, J. H. 1971. Hydrology of Basalt Aquifers in the Hermiston-Ordnance Area Umatilla and Morrow Counties, Oregon, Hydrologic Investigations Atlas HA-387, U.S. Geological Survey, Washington, D.C.

Roy F. Weston, Inc., 1989. Drafi Final Remedial Investigation Report-Umatilla Army Depot Activity, Vols. I and II, report CETHA-IR-CR-89038, contract number DAAA15-85-D-0015, West Chester, Pa.

U.S. Army 1982, Installation Environmental Assessment, Umatilla Depot Activity, Hermiston, Oregon, prepared by Inland Pacific Engineering Co., Haworth and Anderson, Inc., Spokane, Washington, for Headquarters, U.S. Army Depot System Command, Washington, D.C., December.

U.S. Army 1988a. Chemical Stockpile Disposal Program Final Programmatic Environmental Impact Statement, Vols. 1, 2, and 3, Program Executive Officer-Program Manager for Chemical Demilitarization, Aberdeen Proving Ground, Md., January.

U.S. Army 1988b. Chemical Stockpile Disposal Program, Implementation Plan, Program Executive Officer-Program Manager for Chemical Demilitarization, Aberdeen Proving Ground, Md., March.

U.S. Army Corps of Engineers 1982. Seismic Design for Buildings, TM-5-809-10, Washington, D.C.

U. S. Army Corps of Engineers. Geotechnical open-file data on file at U. S. Army Corps of Engineers, Huntsville District, Alabama.

Whitacre, G. C., et al. 1986. Personal Computer Program for Chemical Hazard Prediction (D2PC), U.S. Army Chemical Research and Development Center, Aberdeen Proving Ground, Md. 


\section{FINDINGS AND CONCLUSIONS}

\subsection{REEXAMINING ON-SITE DISPOSAL AT THE UMATILLA DEPOT ACTIVITY}

During the Phase I process, those data used in the FPEIS to identify the environmentally preferred alternative were identified, and recent, more detailed sitespecific data of the same types were gathered for the region around UMDA. These new data were then examined and compared with the FPEIS data to determine if they have changed sufficiently to warrant recomputation of the five measures of risk used to identify the programmatic environmentally preferred alternative. Of all of the data types examined, only two were identified as having changed enough to warrant recomputation of risk: the residential population data and the selection of a most likely meteorological condition. The population data changed primarily due to population growth (from 1980 census data in the FPEIS to 1986 data now available) and to a change in the location of the residents (instead of living within $500 \mathrm{~m}$ of the site of the proposed disposal plant, as was assumed in the FPEIS, residents were assumed to be located no closer than the actual installation boundary). In regard to data for on-site transport distance, seismicity, aircraft activity, and meteorite/tornado frequency, either new data were not identified during the Phase I process or, if identified, were not sufficiently different from FPEIS data to warrant reevaluation of risk.

As a first step in reassessing risk, the new population data were used to compute average and maximum fatalities using the same computational methods as in the FPEIS; the FPEIS values were used for all other input parameters (except population). This calculation showed that the number of fatalities for distances of $2 \mathrm{~km}$ (1.2 miles) or less drops to zero because there is no residential population this close to the site of the proposed disposal facility.

The revised fatality estimates were then used to compute the five FPEIS measures of risk for on-site disposal, continued storage, and national disposal (a surrogate for on-site risks associated with off-site transport). These risk measures were summarized in pictograms as was done in the FPEIS. Based on an examination of the Phase I pictogram, continued storage at UMDA, as well as the national disposal alternative, can be rejected because one of the measures of risk (i.e., the "maximum number of fatalities") was greater, by a significant amount, than the value for the on-site disposal alternative.

The meteorological conditions of $\mathrm{CML}$ and WC scenarios assumed in the FPEIS risk analysis were found to be appropriate for UMDA. Consideration of one other viable meteorological condition for the CML scenario produced the conclusion that there would have been no difference in FPEIS risk values if the alternate CML scenario had been used. 
The conclusion is that on-site disposal remains valid as the environmentally preferred alternative for UMDA. From the perspective of the population near UMDA, on-site disposal is better than all other alternatives in terms of the potential for human health impacts. If one adds the off-site transportation risks (not addressed in this document because they are beyond its scope), the on-site alternative is clearly preferable given the opportunity for risk reductions associated with emergency planning and preparedness activities that are under way at UMDA.

\section{RESOURCE DATA RELATED TO IMPLEMENTATION OF ON-SITE DISPOSAL}

During the Phase I process, data on resources that could be affected by on-site disposal at UMDA were gathered to determine if any new or site-specific resources are present that could affect construction and operation of the on-site disposal facility (including incident-free operations and accident scenarios). The resource categories of interest included population, meteorology/air quality, surface water and groundwater, land use, ecology, socioeconomics and aircraft activity. Some of these resources were examined in the FPEIS in assessing potential impacts of the programmatic alternatives, whereas others represent new resource categories that were not appropriate for examination on the programmatic level. No assessment of potential impacts was performed during the Phase I process with these data. Rather, the data were examined to help identify potential issues to be analyzed under Phase II. Results for the principal resource areas are presented below.

- Population. Residential population within $100 \mathrm{~km}$ (62 miles) of the proposed disposal facility at UMDA increased $1.7 \%$ between 1980 (FPEIS data) and 1986 (Phase I data). Using the location of the nearest off-site resident at UMDA, no residential population was found within $4 \mathrm{~km}(2.5$ miles) of the site. The significance of these changes with respect to risks at UMDA has been discussed above. On-post population was found to be 290 employees, with approximately 60 employees present at night. Place-of-work population data for the states of Oregon and Washington have not yet been located. All of these data will be considered, in conjunction with data on residential population, in estimating potential fatalities in the site-specific EIS for UMDA. Additional data were also collected regarding American Indians. Both the Umatilla Indian Reservation and the Yakima Indian Reservation lie within the 50- to 100-km (31- to 62-mile) zone around UMDA.

- Meteorology and air quality. The meteorological data used in the FPEIS were found to be the best available for the site of the proposed disposal facility at UMDA. These data will be used as input for dispersion modeling in the sitespecific EIS to assess potential impacts from construction and incident-free operations. A Class I prevention of significant deterioration (PSD) area located about $150 \mathrm{~km}$ (95 miles) east-southeast of UMDA was found during the Phase 1 
process. Putential impacts of air emissions from the proposed disposal facility in this area of pristine air quality will be considered in the site-specific EIS for UMDA. Several heating plants, as well as permitted open-air burning, were found to be sources of air emissions within the UMDA installation boundary. Social, economic, and cultural resources. Additional data were collected beyond the 10-km (6.2-mile) zone used in the FPEIS. These data include updates on police and fire department staffing and equipment; county school enrollment within the 50-km (31-mile) zone; post-secondary school enrollment within the $100-\mathrm{km}$ (62-mile) zone; hospital facility capacity within the $50-\mathrm{km}$ (31-mile) zone; transportation, utilities, and waste treatment within the $50-\mathrm{km}$ (31-mile) zone; employment, housing vacancy, and agricultural land use within the $100-\mathrm{km}$ (62-mile) zone; and an updated cultural resources inventory. No unique resources have been identified that would alter the conclusions of the FPEIS. The impacts to socioeconomic resources will be assessed in the site-specific EIS for construction, incident-free operations, and accidental releases of agent.

- Surface water and groundwater. During the collection of data for Phase I, no unique resources were identified. No federally designated wild or scenic rivers are located within $100 \mathrm{~km}$ (62 miles) of UMDA. No federally protected aquifers were identified near UMDA. There are no permanent bodies of water within the UMDA installation boundary, and all precipitation infiltrates the soil. The normal groundwater flow beneath UMDA is generally in a northwesterly direction. During the growing season when extensive irrigation of crops is occurring, normal groundwater flow patterns change appreciably. This information will be used in the site-specific EIS for UMDA to assess the impact of accidental spills of chemical agent.

- Ecological resources. No new federally listed threatened or endangered species have been identified beyond those mentioned in the FPEIS. No new information has been located regarding significant aquatic or terrestrial resources. There are 6 orotected ecological resources identified to date that could be affected by the proposed action and its alternatives at UMDA. Potential effects on these resources will be further evaluated in the site-specific EIS for UMDA.

- Aircraft activity. No new information, beyond that presented in the FPEIS, is available. These data may be useful, however, in the site-specific EIS for UMDA to evaluate the role of restricted airspace as an interim mitigation measure for continued storage until the UMDA stockpile is destroyed.

- Land use. No unique resources have been identified after examining recent, more detailed data than were presented in the FPEIS.

- Emergency preparedness. Enhancements and upgrades to emergency preparedness and response capabilities have been initiated since the FPEIS. The Army has begun implementing an emergency response plan at UMDA, has funded planners to work with local governments to upgrade existing plans, and is committed to providing technical assistance and coordination to local planning efforts. 


\subsection{OTHER FACTORS}

Technology maturity and technology tracking/risk assurance were also examined during the Phase I process, although neither factor was instrumental in reaching conclusions for UMDA as discussed in the previous two sections.

For technology maturity, several technological advances have occurred and several contracts have been placed for the procurement of equipment and services to support the CSDP. The advances in technology include destruction of the nonlethal agent BZ at Pine Bluff Arsenal, the construction and startup testing of JACADS at Johnston Atoll in the Pacific Ocean, incineration tests with agent VX at CAMDS in Utah, a proposed mustard agent incineration program at CAMDS, and equipment advances. The contracts include the award of a systems contract for the construction and operation of a chemical demilitarization training facility in Maryland, a systems contract for the construction and operations of lethal agent disposal facilities at Tooele Army Depot in Utah, and equipment acquisition contracts to provide uniformity and standardization between all eight proposed CONUS disposal facilities, as well as JACADS.

The destruction of agent BZ at PBA has helped to establish preoperational surveys, personnel hiring practices, and operations schedules that will be of value to UMDA disposal operations. Destruction of lethal unitary chemical agents and munitions at Johnston Atoll will provide data from equipment startup, personnel training, and OVT that will be evaluated for incorporation into the UMDA facility before construction. At TEAD, CAMDS has conducted tests with the agent VX, which provided valuable information to the Johnston Atoll operations, as well as UMDA, on equipment performance, emissions, and effluents.

Equipment advances have occurred since the FPEIS in the areas of air monitoring and air filters. Advances in air monitoring technology now facilitate detection of a TWA concentration of agent within 3 to 5 min, which is a substantial improvement over the 8 to $22 \mathrm{~min}$ time assumed in the FPEIS. Filter tests are ongoing to determine the best thickness of carbon in filters designed to remove agent GB from an air stream. Another equipment advance is the completion of the design and mock-up testing of the on-site transportation container (ONC) that will be used to package the munitions during movement between the storage area and the disposal facility. Additional prototype testing and subsequent procurement are planned for late 1990.

Technology tracking/risk assurance refers to tracking the disposal facility design changes that have occurred since the FPEIS to provide assurance that the overall levels of on-site disposal risk, as presented in the FPEIS, do not change in a manner that could revise the relative ranking of the various FPEIS alternatives. The FPEIS was based on a facility design that was largely conceptual. Since then, the design has progressed towards completion and has changed, in some respects, from that used to develop the FPEIS risk values.

A report on risk assurance is in preparation; however, several major design changes for the UMDA disposal facility have been evaluated. These items include the addition of a container handling building (CHB) to replace the munitions holding igloo, 
a redesigned on-site transportation container ( $\mathrm{ONC}$ ), and the addition of a mustard thaw capability. Using the FPEIS classified numerical values of risk for UMDA as a reference, the $\mathrm{CHB}$ decreases risk by up to $5 \%$, the $\mathrm{ONC}$ also decreases risk by up to $5 \%$, and mustard thaw increases risk by up to $4 \%$. These changes in risk are not significant because they are well within the range of uncertainty for the FPEIS measures of risk. The FPEIS pictogram for UMDA does not change as a result of including the risks for these major design changes. 


\section{APPENDIX A \\ IMPACT ANALYSES IN THE FINAL PROGRAMMATIC ENVIRONMENTAL IMPACT STATEMENT}

This appendix provides a summary of the impact analysis conducted in the final programmatic environmental impact statement (FPEIS) (U.S. Army 1988), including the method and data used to identify the programmatic environmentally preferred alternative, the examination of the acceptability of the alternative for Umatilla Depot Activity (UMDA), and nonrisk impact analyses conducted for the stockpile at UMDA. Because the Army's stockpile of chemical agents contains some of the most toxic materials in the world and because some of the present storage installations are located near highly populated areas, public concern about the safety of the proposed disposal alternatives was the key issue addressed in the FPEIS. Specifically, concerns about the safety of incineration operations and about impacts to human health from both incidentfree operations and accidental releases of chemical agent became the primary focus of the FPEIS impact analyses.

\section{A.1 IDENTIFYING THE ENVIRONMENTALIY PREFERRED ALTERNATIVE}

\section{A.1.1 Approach Taken in the Programmatic Assessment}

To categorize the environmental impacts of the programmatic disposal alternatives, the FPEIS identified three distinct activities required for the destruction of the continental United States (CONUS) stockpile: (1) construction (or modification) of disposal facilities (incinerators and/or shipping/receiving facilities); (2) disposal operations, including transportation (off-site, as well as on-site); and (3) decommissioning of all disposal facilities upon completion of the program. These activity categories existed for each programmatic disposal alternative, although the applicability and phasing of these activities at each storage installation were dependent on each particular alternative.

Early in the process, it was determined that construction and decommissioning activities have few impacts of the kind that could be used to distinguish among the various programmatic disposal alternatives. In fact, construction activity at each storage location (irrespective of the alternative) would be typical of that for any medium-scale industrial facility.

In contrast, the nature and significance of the environmental impact of disposal operations depend upon whether or not the operations would be incident-free. Therefore, incident-free disposal operations were defined as occurring without any intentional release of chemical agent in amounts greater than prescribed emission levels; abnormal operations were defined as those involving major accidents with off-site 
consequences. It is obvious that accidents could have environmental consequences of major proportions. These consequences could include human fatalities and chronic illnesses, destruction of wildlife and wildlife habitat, destruction of economic resources, and adverse impacts on the quality of life in the affected areas.

Fortunately, such high-consequence accidents would be unlikely. This low likelihood would be ensured principally through plant design, munition packaging, and well-conceived and well-implemented transportation and operating procedures. The area affected by (and the potential severity of) accidents would be specific both to the storage site and the point of occurrence along the transportation corridor. The impacts from potential accidents would be largely dependent upon population distributions, the chemical agents and munitions involved, and natural conditions and features at the accident location. Hence, the principal thrust of the FPEIS was the examination of accident scenarios, their probabilities of occurrence, and the attendant environmental impacts.

\section{A.12 Approach to the Analysis of Accidents}

In support of the FPEIS, a comprehensive study was performed to identify the credible accidents and the expected effects on human health, ecological systems, water resources, and socioeconomic resources. Such accidents were identified in risk analyses (GA Technologies 1987a, 1987b, and 1987c) and integrated by the MITRE Corporation and Oak Ridge National Laboratory (ORNL) (see U.S. Army 1988, Vol. 3, Appendix J).

Each programmatic disposal alternative was included in the study. The principal areas of focus were plant operations; off-site transportation (for national, regional, and partial relocation options); on-site transportation via truck; and munition-handling operations. Accident initiators that were considered included equipment failures and human error, as well as external events (seismic events, meteorites, tornadoes and high winds, lightning, and air crashes). In addition, crashes (truck, train, and airplane) and train derailments were considered as initiators for the transportation accidents. Except for the inventory differences among storage installations and certain site-specific events, such as earthquakes and tornadoes, the hazards associated with plant operations are the same for all sites and all disposal alternatives.

Some 3000 potential accidents were identified and included in the programmatic analysis. Each potential accident was characterized by its probability (i.e., its expected frequency); its source size (i.e., the size of the release as expressed by weight of specific chemical agent); the type of agent released; its mode of release (e.g., spill, detonation, fire); the possible accident location (e.g., storage area, disposal plant, along a transportation corridor); and the duration of time during which that accident could occur (i.e., the total time during which agent could be released, from the onset of the disposal program until the completion of that particular activity). Using a computerized atmospheric dispersion method, each accident involving agent release was also characterized in terms of its plume geometry and its lethal downwind distance; fatalities were estimated for these accidents using 1,980 census data (U.S. Dept. of Commerce 1980) around the appropriate site of release. 
Because it is impossible to develop a "no risk" alternative for the disposal of the chemical agent stockpile, the possibilities of an accident and potential adverse impacts were included in a hazards analysis to determine the relative importance of each accident. The selected measure of the hazard was the "risk." The risks associated with the numerous activities of the programmatic disposal alternatives were quantified and then used to compare the hazards associated with each programmatic alternative. Risk analyses have been widely used in the nuclear and chemical industries to evaluate related hazards and to communicate these results to both the public and to decision makers.

To assess the impacts of accidents on human health and environmental and socioeconomic resources, various probabilistic measures of risk were developed and applied to each programmatic alternative for comparing the alternatives. Five measures of risk, which are defined below, were chosen.

1. Probability of one or more fatalities is the chance that there will be at least one fatality at a given site or along a transportation corridor, or for the nation as a whole, during implementation of a given programmatic alternative. This measure was computed mathematically as the sum of probabilities for only those credible accidents that could result in one or more fatalities under most likely meteorological conditions; this measure of risk was expressed as a probability or frequency per stockpile (e.g., $2 \times 10^{-5}$ ).

2. Maximum number of fatalities is the largest potential human health consequence among all credible accidents at a site or along a transportation corridor, or for the nation as a whole, for a given programmatic alternative. This measure was computed as equal to the largest number of potential fatalities associated with the single credible accident with the greatest lethal downwind distance under worst case meteorological conditions; this measure of risk was expressed as fatalities (e.g., 2100 persons).

3. Expected fatalities is a statistical measure equal to the sum of the risk contribution of all credible accidents at a site or along a transportation corridor, or for the nation as a whole, for a given programmatic alternative. This measure was computed mathematically as the summed product of probabilities for all credible accidents and the potential fatalities for those same accidents under most likely meteorological conditions. This measure of risk was expressed as fatalities per stockpile (e.g., $9 \times 10^{-4}$ persons). This risk measure is widely used in the nuclear and chemical industries to evaluate the hazards associated with these industries; it is regarded as the best measure for representing the integrated hazards associated with numerous activities for a particular action.

4. Person-years at risk is a statistical measure equal to the product of (a) the number of persons near a site or along a transportation corridor who are at risk from the credible accident with the greatest lethal downwind distance for a given programmatic alternative and (b) the length of time during which that accident could occur. This measure of risk is expressed in person-years (e.g., $5 \times 10^{6}$ person-years). 
5. Expected plume area is a statistical measure equal to the cumulative risk contribution of all potential plume areas from all credible accidental agent reieases for a given programmatic alternative. This measure was computed mathematically as the summed product of all accident probabilities and the resulting plume areas; it is analogous to expected fatalities and is computed in an identical manner except that the plume area is used instead of the number of fatalities. This measure of risk was expressed in units of area (e.g., $3 \times 10^{-3} \mathrm{~km}^{2}$ ). This measure is sensitive not only to the size of the areas potentially affected by releases, but also to the probabilities of those releases. This risk measure was used as the surrogate for (or indicator of) impacts to environmental, cultural, and socioeconomic resources.

To present the results of this risk analysis in a format that could be easily comprehended by the public without revealing classified details (such as agent and/or munition quantities) for the site-specific stockpiles, pictograms (as shown in Figs. A.1 and A.2) were developed. Pictograms display a pictorial indicator (the darkness of the shading) of the relative magnitude of each of the above measures of risk. This array of data provides a means for directly comparing risks at all sites for a given programmatic disposal alternative or for comparing all alternatives at a given site. Both sets of pictograms are employed and presented in the FPEIS (see U.S. Army 1988). These risk pictograms provide a visual impression of the relative magnitude of public risk for all combinations of alternatives and locations; in addition, the pictograms were incorporated into the method for selecting the FPEIS environmentally preferred alternative.

\section{A13 Method for Identifying the Environmentally Preferred Alternative}

The Army and its subcontractors developed a method (see U.S. Army 1988) for systematically comparing the programmatic alternatives to select an environmentally preferred alternative. That method was based on a comparison of alternatives in terms of the activities associated with implementing each alternative and the impacts of those activities under both normal operations and accident scenarios. Although the principal purpose of the method was to facilitate the selection of the environmentally preferred alternative, the method presented in the FPEIS also allowed other interested and affected groups to (1) compare the public health and environmental impacts of the various alternatives and (2) identify the public health and environmental trade-offs associated with each programmatic alternative.

The method used to identify the environmentally preferred alternative consisted of a sequential consideration and comparison of the factors embracing the programmatic objectives of no fatalities and minimal or no environmental impact. This comparison involved three consecutive tiers of examination for each programmatic alternative:

(1) the comparisons were first made for human health impacts using the previously defined measures of risk, (2) the "expected plume area" was then used for comparison of ecosystem and environmental impacts, and, finally, (3) the feasibility and potential effectiveness of emergency planning and preparedness was used as a basis for comparison. 


\begin{tabular}{|c|c|c|c|c|c|}
\hline Site & $\begin{array}{c}\text { Probability } \\
\text { of One } \\
\text { or More } \\
\text { Fatalities }\end{array}$ & $\begin{array}{l}\text { Maximum } \\
\text { Number of } \\
\text { Fatalities }\end{array}$ & $\begin{array}{l}\text { Expected } \\
\text { Fatalities }\end{array}$ & $\begin{array}{l}\text { Person- } \\
\text { Years } \\
\text { at Risk }\end{array}$ & $\begin{array}{c}\text { Expected } \\
\text { Plume Area } \\
\left(\mathrm{km}^{2}\right)\end{array}$ \\
\hline \multicolumn{6}{|l|}{ ANAD } \\
\hline \multicolumn{6}{|l|}{ APG } \\
\hline \multicolumn{6}{|l|}{ LBAD } \\
\hline \multicolumn{6}{|l|}{ NAAP } \\
\hline \multicolumn{6}{|l|}{ PBA } \\
\hline \multicolumn{6}{|l|}{ PUDA } \\
\hline \multicolumn{6}{|l|}{ TEAD } \\
\hline UMDA & & & & & \\
\hline
\end{tabular}

\begin{tabular}{|c|c|c|c|c|c|c|}
\hline \multirow[b]{2}{*}{ Legend } & \multicolumn{6}{|c|}{ Numerical Equivalents } \\
\hline & $\begin{array}{l}\text { Relative } \\
\text { Shading }\end{array}$ & $\begin{array}{c}\text { Probability } \\
\text { of One } \\
\text { or More } \\
\text { Fatalities }\end{array}$ & $\begin{array}{l}\text { Maximum } \\
\text { Number of } \\
\text { Fatalities }\end{array}$ & $\begin{array}{l}\text { Expected } \\
\text { Fatalities }\end{array}$ & $\begin{array}{c}\text { Person- } \\
\text { Years } \\
\text { at Risk }\end{array}$ & $\begin{array}{c}\text { Expected } \\
\text { Plume } \\
\text { Area } \\
\left(\mathrm{km}^{\mathbf{2}}\right)\end{array}$ \\
\hline \multirow[t]{3}{*}{ Higher } & & $>10^{-s}$ & $>10,000$ & $>10^{-8}$ & $>10^{\circ}$ & $>10^{2}$ \\
\hline & & $10^{-4}-10^{-3}$ & $\begin{array}{l}5,000 \\
10,000\end{array}$ & $10^{-2}-10^{-2}$ & $10^{s}-10^{6}$ & $10^{-3}-10^{-2}$ \\
\hline & & $10^{-6}-10^{-4}$ & $1,000-5,000$ & $10^{-4}-10^{-0}$ & $10^{4}-10^{5}$ & $10-10-5$ \\
\hline Lower & & $<10-$ & $<1,000$ & $<10^{-4}$ & $<10^{4}$ & $<10^{-4}$ \\
\hline
\end{tabular}

Fig. A-1. Risk with mitigation: site-specific comparison for on-site disposal. (Risk along transportation corridors not included. This diagram does not include the risk associated with approximately 3 years of stockpile storage at the existing facilities.) 
A-6

ORNL-DWG 87-18566

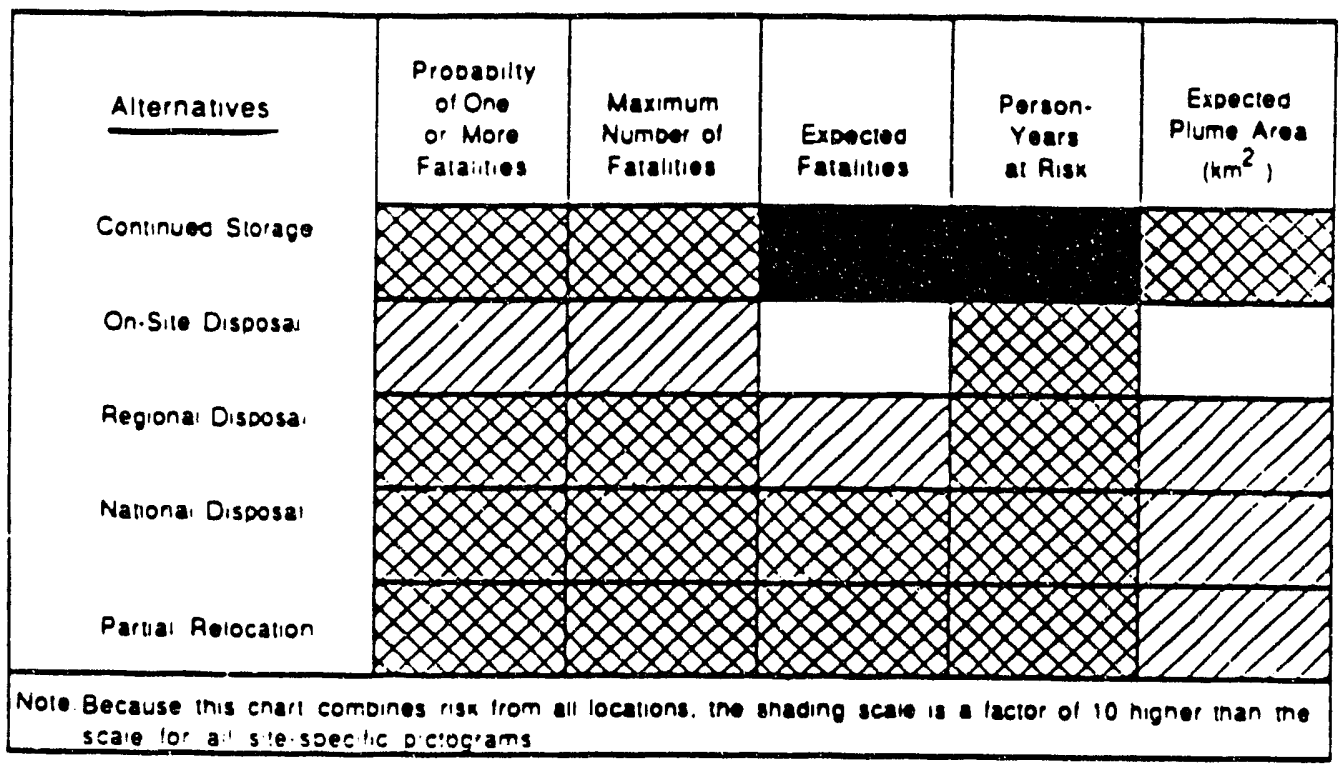

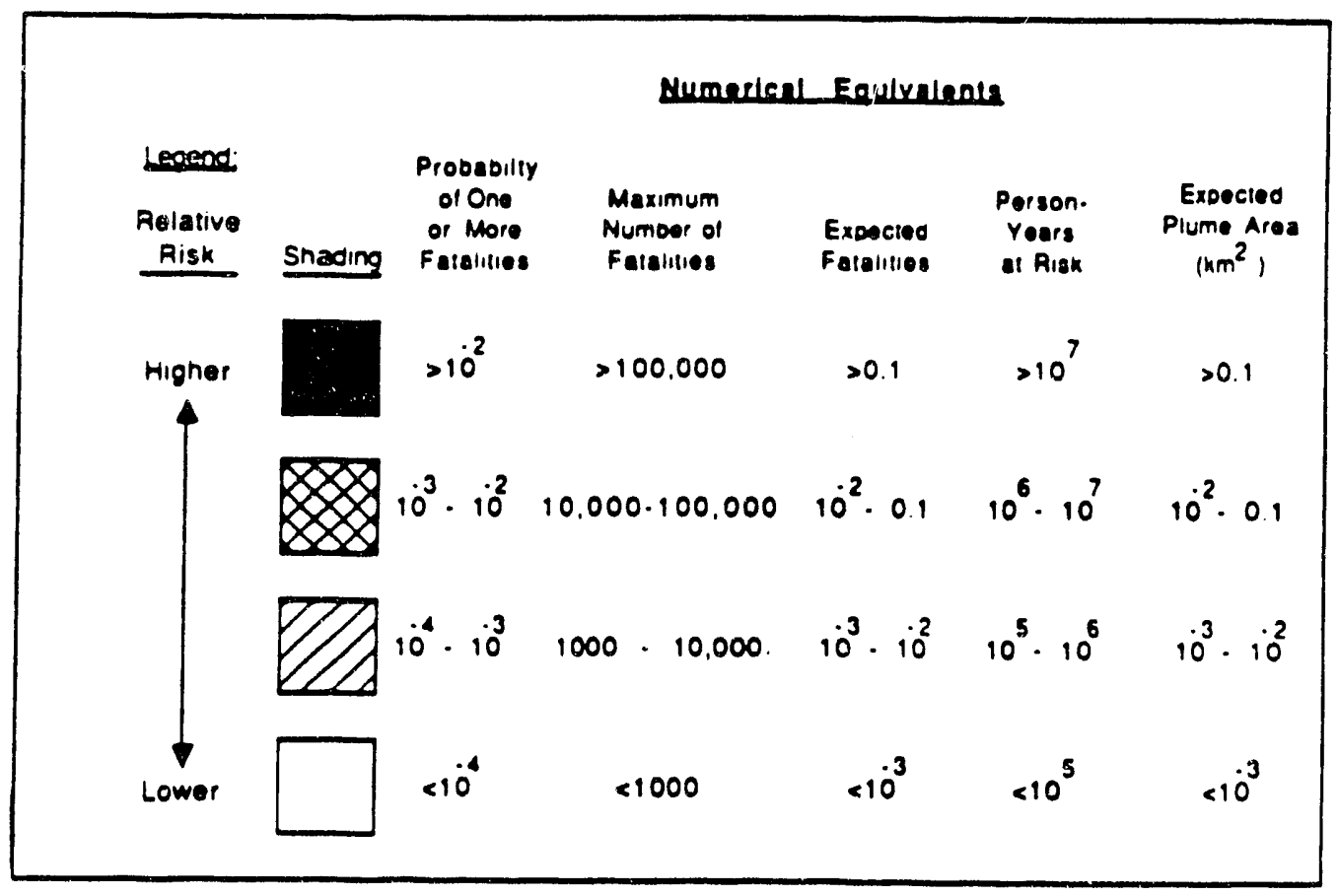

Fig. A.2 Risk with mitigation: comparison for programmatic alternatives, all locations combined. (For the disposal alternatives, this diagram does not include the risk associated with approximately three years of stockpile storage at the existing storage sites). 


\section{A-7}

These three tiers of comparison were applied sequentially; if an alternative proved to be significantly worse than others on the basis of human health impacts, it was removed from further consideration. Similarly, if a single alternative was significantly superior to all others on the basis of human health impacts, it was selected as the environmentally preferred alternative. If more than one alternative proved to be relatively equivalent (but superior to the other, rejected alternatives) during this first tier of comparison, then these alternatives were selected for inciusion in the next tier of comparison (i.e., ecosystem and envir onmental impacts).

The same technique was used ir the second tier of comparison to compare only those alternatives that survived the first tier; this second tier of comparison considered the potential for ecosystem and environmental impacts. If there were still alternatives that were judged to be relatively equivalent following this comparison, they were compared on the basis of the feasibility and potential effectiveness of emergency planning and preparedness (i.e., the third and final tier of the selection method).

Improved emergency response planning and preparedness can reduce both the maximum number of fatalities and the expected fatalities in the unlikely event of catastrophic agent release. However, no proven or acceptable method exists to quantify this potential for reduction in impacts. Nevertheless, implementation of an emergency response program yielding comparable reductions would be more difficult, if not impossible, along the transportation routes as compared to implementation at any or all of the eight existing storage installations.

Finally, if no clear choice could be made after three levels of comparison, then no single environmentally preferred alternative exists. In any event, at whichever tier a final choice was made, the environmentally preferred alternative would then be examined with respect to the stockpile at each installation to ensure that the selection method had indeed identified an alternative that was correct for each stockpile.

For the purpose of accepting or rejecting alternatives at each tier, a determination of the relative significance of the risk measures was made. The accident and risk analyses attempted to ensure that uncertainties about the values for the five measures of risk were treated consistently and systematically for all alternatives. It was acknowledged that these values might be in error by as much as a factor of 10 in either direction. However, it should be noted that the maximum number of fatalities did not depend on accident probabilities or frequencies and therefore had no expressed uncertainty. At each tier in the selection method, a comparison was made belween those risk values shown in the pictograms for each alternative. Because actual numerical values for the five measures of risk were classified and could not be released for public review, and because the pictograms used shadings and patterns to depict the range of each measure of risk, it was determined that two differences in shading (i.e., a two-order of magnitude, or factor-of-100, difference) would be used as the criterion to define a "significant difference" between alternatives.

In view of the above criterion, it is important not to emphasize the absolute values of the risk measures; rather, differences in risk measures among alternatives become the key to the comparisons. Significant differences among any of the five measures of risk define a definite risk preference and are sufficient to reject the more 
risky alternative(s). Furthermore, where there are consistent differences in the measures of risk between alternatives (even at one order of magnitude of difference in the pictograms), this consistent difference is an indication that significant differences between alternatives may exist from an overall perspective. However, such consistent differences were never used in the selection method to either select or reject an alternative.

\section{A1.4 Data Used in the Programmatic Assessment}

Data needed for the FPEIS assessment were drawn from several support studies, each of which was separately published and incorporated by reference into the FPEIS. Key support studies addressed (1) packaging, (2) transportation, (3) safety improvements. (4) hazards, (5) risk, (6) monitoring, and (7) emergency response. Of these, the analysis and results of the risk study were the most important in the selection of the environmentally preferred alternative.

The data used in the FPEIS risk analysis were of two broad types: (1) historical data, derived from records of a large number of actual events that are related to specific types of accidents or events leading to accidents, and (2) hypothesized data, derived from largely subjective modeling of assumed accident sequences with the aid of fault and event trees. The use of fault and event trees is a standard procedure to investigate sequences of occurrences in a complex system.

GA Technologies (GA Technologies 1987a, 1987b, 1987c), with technical assistance from H\&R Technical Associates, JBF Associates, and Battelle-Columbus Laboratories, conducted the comprehensive assessment of accident probabilities for all munition types. The event and fault tree analyses, together with information on mechanical and thermal threshold conditions for each munition type, were used to estimate the probability of agent release and the quantity of agent released. Some accidents were postulated to be caused by external initiating events, i.e., those outside U.S. Arn: control. Table A.1 summarizes the assumed frequencies of these accidents for the Unnatilla Depot Activity.

The human health impact at downwind locations following an accidental release of agent would be dependent on meteorological conditions that dictate the extent of atmospheric dispersion. The FPEIS used the D2PC atmospheric dispersion model (Whitacre et al. 1986) to predict downwind transport of agent. The D2PC computer program (or code) is an air dispersion model that assumes a Gaussian distribution of agent in the vertical and crosswind directions as the agent disperses downwind. This assumption has been documented extensively in the literature and is used by a multitude of current models (EPRI 1985). Although more sophisticated dispersion codes are available, the assumption of straight-line transport with unvarying meteorological conditions results in conservative estimates of the effects of releases because the major parameter used in subsequent analyses was the distance to a given dose rate. This simple, conservative approach, while inappropriate for estimating the impacts of any given release under real-time conditions, is appropriate for analyzing and comparing the 
Table A1. Site-specific frequencies of external initiating events for the Umatilla Depot Activity

Large aircraft crash

(events/year-mile ${ }^{2}$ )

Small aircraft crash

(events/year-mile ${ }^{2}$ )

Meteorite (larger than $1.0 \mathrm{lb}$ )

strikes (events/year- $\mathrm{ft}^{2}$ )

Earthquakes (events/year)

(g)

0.15

0.2

0.25

0.3

0.4

0.5

0.6

0.7

Tornadoes (events/year)

(mph windspeed)

100

140

180
$1.5 \times 10^{-5}$

$1.2 \times 10^{-5}$

$6.4 \times 10^{-13}$

$1.5 \times 10^{-4}$

$7.0 \times 10^{-5}$

$4.0 \times 10^{-5}$

$2.5 \times 10^{-5}$

$1.2 \times 10^{-5}$

$6.0 \times 10^{-6}$

$3.5 \times 10^{-6}$

$2.5 \times 10^{-6}$

$1.0 \times 10^{-5}$

$1.0 \times 10^{-6}$

$1.0 \times 10^{-7}$ 
potential effects of postulated accidental releases. A specific location was not designated in the D2PC model runs, but rather a generic location was used. This assumption was employed because of the number of potential release sites at each facility as well as the potential for release during the transportation alternatives analyzed. Therefore, identical downwind distances were obtained for identical accidents for all alternatives.

In the FPEIS, results from the D2PC model were obtained for two generic meteorological conditions: "conservative most likely" (CML) and "worst casen (WC). The CML scenario represents a frequently occurring meteorological condition that results in relatively large doses compared with other frequently occurring conditions. Specifically, neutral atmospheric stability (Class D) with a wind speed of $3 \mathrm{~m} / \mathrm{s}(6.7 \mathrm{miles} / \mathrm{hr})$ was selected for the CML condition. The WC scenario represents a credible condition that results in near-maximum doses. Specifically, a stable atmosphere (Class E) with a wind speed of $1 \mathrm{~m} / \mathrm{s}(2.2 \mathrm{miles} / \mathrm{hr})$ was chosen for the WC condition. Other atmospheric conditions were kept constant for the two meteorological scenarios. Wind direction was not specified, but was assumed to remain constant throughout individual runs of the D2PC model. Downwind distances and areas that were predicted by the model were subsequently rotated about the point of release to evaluate all possible wind directions of interest. The height of the mixed layer of the atmosphere was assumed to be $750 \mathrm{~m}(2460 \mathrm{ft})$.

The D2PC code predicts the "dose" of agent (defined as the mathematical product of agent concentration and the duration of exposure) expected at locations downwind of the release point. Within each downwind dispersion plume were three dose-response contours, representing fatality rates of 0,1 , and $50 \%$. The dose corresponding to the $0 \%$ rate (also called the "no-deaths" dose in the FPEIS) is the largest dose that would result in no fatalities to healthy adults. Figure A.3 illustrates the plume geometries and dose-response contours under the two meteorological conditions used in the FPEIS.

To simplify the analysis of the many accidents identified in the FPEIS risk analysis, the accidents were grouped into categories defined by their downwind "nodeaths" distance. These "downwind no-deaths distance categories" were used generically in the FPEIS to (1) define all accidents by category and (2) estimate fatalities by category. The distance categories used in the FPEIS are shown in Table A.2. Every accidental release was assigned a distance category, and the maximum downwind boundary of that category was used to represent the entire class of similar releases. For example, an accidental release that was predicted by the D2PC code to result in a downwind no-deaths distance of $11 \mathrm{~km}$ was placed into the 10 - to $20-\mathrm{km}$ accident category, and a distance of $20 \mathrm{~km}$ was used to characterize that particular accident in the FPEIS. Human health impacts, as defined by potential fatalities, were based upon the generic plumes described by these distance categories.

In the FPEIS, the description of the distribution of population around each Army installation was taken from 1980 Bureau of the Census data. The coordinates of the census enumeration district centroids were first used to estimate the boundaries and areas of each district. Next a population density function was developed for use within these areas. Finally, a predefined grid of very small cells [roughly $370 \times 370 \mathrm{~m}$ 


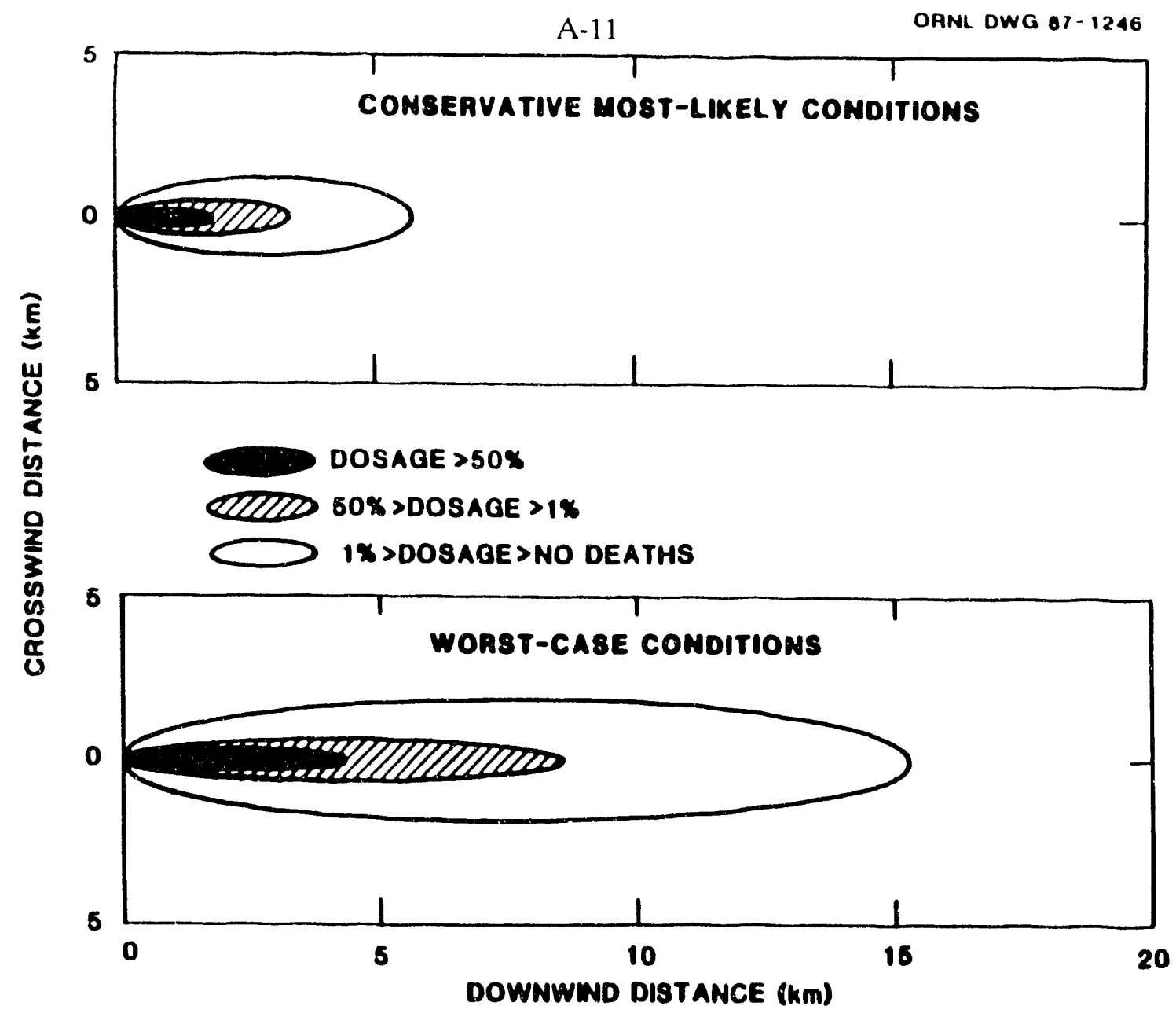

Fig. A-3. A hypothetical scenario illustrating plume distances and shapes for the same accident under different meteorological conditions. 


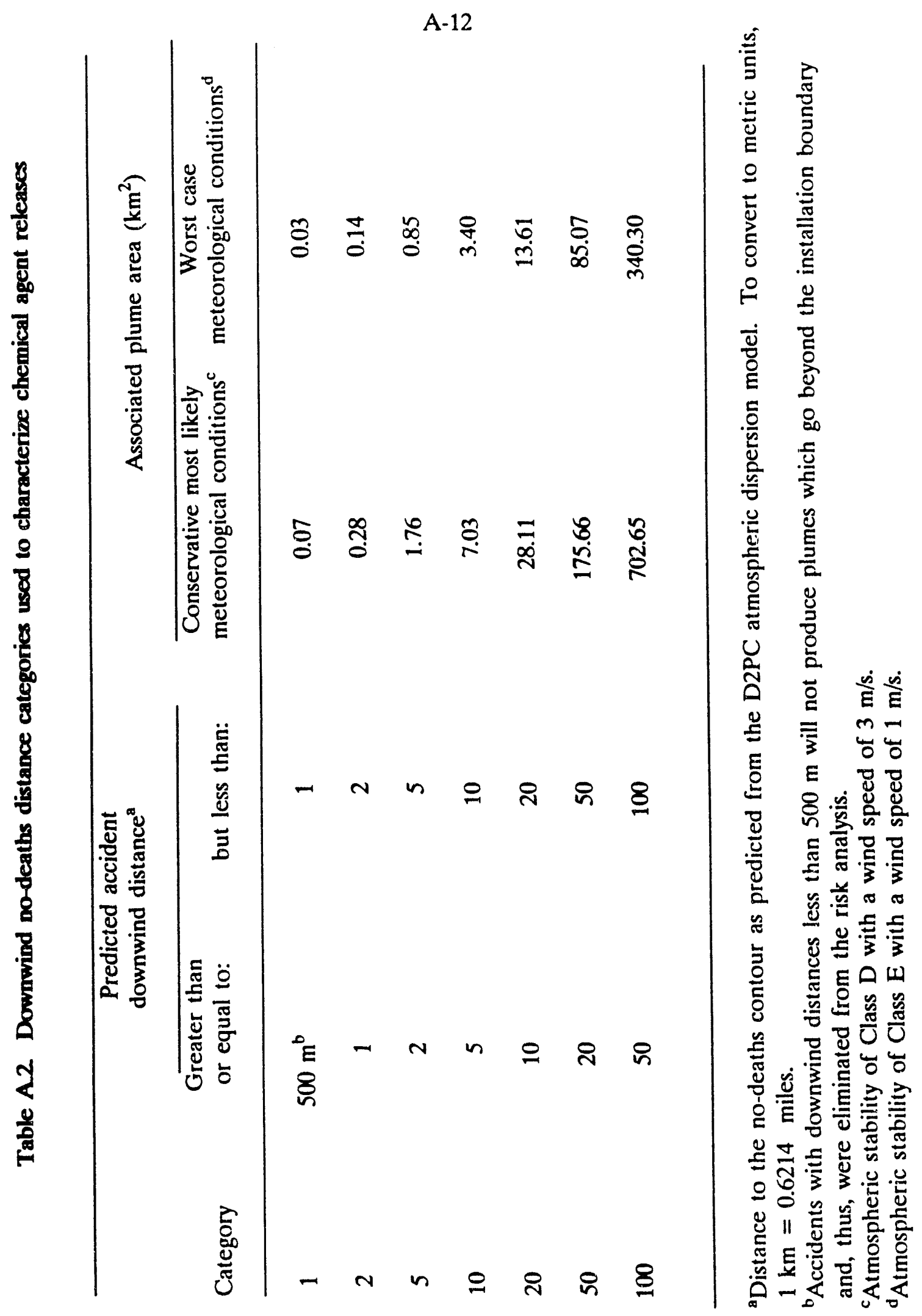


$(1200 \times 1200 \mathrm{ft})$ ] was overlaid on the distributed population, and the number of people per cell was determined. This grid-based population was used in the estimation of fatalities from accidental releases of agent.

Fatality estimates were developed by overlaying the plume geometries [including the three dose-response contours (50\% lethal dose, $1 \%$ lethal dose, and no deaths)] on the population grid. First, the number of people between each dose-response contour was counted. Then "fatality multipliers" were applied to the populations in each zone as follows: of the people inside the 50\% dose-response contour, $75 \%$ were assumed to die; $25 \%$ of the people in the region between the $50 \%$ and the $1 \%$ dose-response contours were assumed to die; and $0.5 \%$ of the people in the region between the $1 \%$ doseresponse and the no-deaths contours were assumed to die.

This fatality estimation process was repeated 360 times for each downwind nodeaths distance category and for each of the two meteorological conditions. That is, each plume was rotated in increments of one compass degree around the point of release, and fatality estimates were computed for each of these increments. Among all 360 computations, the absolute largest number of fatalities was identified in the FPEIS as the "maximum number of fatalities" associated with that particular downwind nodeaths distance category. This computational technique does not take wind direction into account; instead, it is assumed conservatively that the wind has some nonzero probability of blowing in the direction that would cause the most fatalities in the event of a release.

The following assumptions and qualifications of the fatality estimation process were enumerated in the FPEIS (U.S. Army 1988).

1. The assumed values of the fatality multipliers were based on linear variations of agent doses within each dose-response contour. In actuality, the doses decrease with distance from the release point at a greater than linear rate; thus, the FPEIS estimates of maximum fatalities are conservatively high.

2. The D2PC atmospheric dispersion model was originally developed as a planning tool for estimating the magnitude of battlefield casualties under war-game scenarios. The model predicts dose-response contours based on the expected response of healthy adult males to battlefield agent concentrations. The variation of dose response among age groups (e.g., infants, children, and the elderly) was not included in the estimation of fatalities in the FPEIS. It was assumed that the dose response of healthy adult males would closely approximate the response of an average member of the general public.

3. Downwind no-deaths distance estimates from D2PC are accurate to within only $\pm 50 \%$. This limitation of the atmospheric dispersion model resulted in a systematic uncertainty that applied equally to all fatality estimates for all alternatives.

4. Variations in wind direction, atmospheric stability, and terrain during a release would cause the plume to have a much more complex geometry than the simplistic ellipsoidal shape used in the FPEIS. The longer the time period over which the plume develops, the greater the likelihood that changes in the wind conditions will affect the plume geometry. 
5. The same variations in wind direction, atmospheric stability, and terrain make it impossible to reliably predict the shape of a very large plume contour. For this reason, fatality counts for accidents with extremely large downwind no-deaths distances were truncated at $100 \mathrm{~km}$ (62 miles) in the FPEIS.

6. The census data used to develop the distribution of population around each site are representative of the place of residence; thus, these data more closely depict nighttime populations than daytime populations. Furthermore, transient populations (such as people in shopping centers or at major sporting events) and on-post employees were not included in the population data in the FPEIS.

7. The grid-based population allowed all grid cells to be filled with a distributed population even though, in reality, no such population existed for certain cells. Likewise, known uninhabited regions (such as lakes, forested areas, federally restricted areas, as well as the actual site boundaries) were not explicitly accounted for in the FPEIS grid-based population; all such zones were filled with population according to the method described above.

8. The locations used in the FPEIS for the source of every chemical agent release were assumed to be the proposed location of the CSDP disposal facilities as estimated from a 1:250,000-scale map. All plumes used this release point for estimating fatalities. In the accident analyses, where storage area accidents or onsite transportation accidents resulted in agent release, the release point may not be exact in the FPEIS; however, the implication of this assumption would be more significant for small releases of agent than for large releases. That is, for large releases, the downwind distances predicted by the atmospheric dispersion model are substantially larger than the distance between any possible points of release at a particular site.

The probability data from GA Technologies, agent release data from GA Technologies, meteorological data from ORNL, and fatality estimates from ORNL were integrated by the MITRE Corporation (MITRE 1987) to develop the five measures of risk described in Sect. A.1.2.

\section{A.1.5 Summary of Results}

For accidental agent releases, the five measures of risk were used to distinguish among alternatives. Implementation of the three-tiered selection method resulted in the following conclusions:

1. The continued storage, national disposal, and partial relocation alternatives were rejected from further consideration based on the method's first tier of comparing human health impacts.

2. The on-site disposal and regional alternatives survived the first tier of comparison and were then subjected to the second tier. Of note, however, was that the on-site disposal alternative was consistently less risky in all areas (except person-years at risk) than the regional alternative, but not significantly better. Nevertheless, the 
consistency of less risk for the on-site option was an important factor in the overall selection method.

3. In the comparison of on-site and regional alternatives at the second tier (ecosystem and environmental impacts), again the on-site disposal alternative was better than the regional alternative, but not significantly better. Therefore, both alternatives were allowed to pass into the third tier of comparison.

4. Considering the greater degree and extent of mitigation (potential for saving lives) afforded by emergency response for the on-site alternative as compared to the regional alternative, the on-site alternative was determined to be better than the regional alternative. This conclusion is strengthened by the consistently better ranking of the on-site alternative at the first and second tiers of comparison.

The key findings of the FPEIS have resulted in the Army selecting the on-site disposal alternative as its environmentally preferred alternative. The CONUS stockpile of chemical agents and munitions can be destroyed in a safe, environmentally acceptable manner. The environmental impacts of construction and incident-free disposal operations would be minimal. The risk of catastrophic accidents is relatively low for all programmatic alternatives; however, on-site disposal poses less risk than those alternatives involving off-site movement of the stockpile and is therefore the best choice from a public health and environmental perspective.

\section{A.2 SITE-SPECIFIC ACCEPTABILITY OF PROGRAMMATIC PREFERENCE}

After the environmentally preferred alternative was identified, the final step in the FPEIS analysis was to examine this alternative (on-site disposal) in light of each installation's inventory to ensure that the method did not identify an alternative that was incorrect for one or more installations' inventories. The following discussion examines the selected alternative for the Umatilla Depot Activity, comparing the selected alternative against the site- and corridor-specific risk pictograms.

Using the "two-shadings-of-risk-difference" rule discussed previously, the likely site preference was also identified and compared with the programmatic preference for onsite disposal. Because the Army will implement enhanced emergency planning and preparedness at the installation regardless of the alternative selected, the benefits or risk reductions attributable to emergency planning and preparedness, although more relevant to the maximum fatalities and expected fatalities measures, should not affect site preference and have not been considered.

The preliminary selection of the on-site disposal alternative as the environmentally preferred alternative from a programmatic viewpoint was verified against each storage site to ensure that this alternative did not present an unusual problem or risk based on site-specific inventories, population, geography, or any other feature unique to the site. In other words, this verification step had the objective of showing whether any alternative was preferable to on-site disposal on a site-specific basis. Only 
the risks to the population around each site were considered in this verification step; the risks along off-site transportation corridors were not considered.

From the perspective of the population near UMDA, on-site disposal was found to be better than all other options in terms of human health effects measures; there was a clear choice among programmatic alternatives for UMDA (see U.S. Army 1988;

Vol. 1, Table 2.6.3). On-site and national disposal were found to be equivalent for all measures of risk except "maximum number of fatalities," for which on-site disposal was found to be significantly better. Additionally, if one added the transportation risks associated with national or regional disposal, the on-site alternative became even more preferable given the opportunity of risk reductions associated with emergency planning and preparedness that was not afforded to the population along an off-site transportation corridor.

\section{A.3 FPEIS IMPACT ASSESSMENT FOR THE UMATILLA DEPOT ACTIVITY}

In addition to the risk-based impact assessment used to select the environmentally preferred alternative, the FPEIS also presented potential environmental impacts from implementing the programmatic alternatives at each of the sites (as appropriate). Potential effects from construction, incident-free operations, accidents, and decommissioning were described. Note that the impacts from accidents were discussed in a deterministic sense and were not used to assess risk, as was done to identify the environmentally preferred alternative. This section summarizes the impact assessments in the FPEIS as they apply to the UMDA.

Disposal activities can be viewed as a threc-phase set of activities:

(1) construction involves activities to procure and build the disposal plant(s) and support functions; (2) operations involve activities to dispose of the chemical munitions, including activities at the site of existing storage, movement of stockpiles from those storage sites to disposal plants (movement is defined to include on-site handling and transport as well as off-site transport), and disposal plant operations; and (3) decommissioning involves closure and dismantlement of disposal facilities.

\section{A.3.1 Construction Impacts}

Minor impacts from increased spending, the creation of new employment, and the ecological disruption at the plant site are expected. No significant impacts to human health, air quality, or water quality are expected.

The construction of a disposal facility at UMDA will produce an average of 150 new jobs during the time required for construction. The construction will also likely result in increased sales in construction-related industries in the region. Additional tax revenues will be produced. The total economic impact of the creation of jobs and increased spending at each site under on-site disposal will be minor. The direct and indirect employment will not result in significant immigration, and impacts to local economic infrastructures are unlikely. 
Minor impacts to ecological resources are expected from construction of the disposal facilities. Construction at UMDA under the on-site disposal alternative will require about 4 ha (11 acres) of land. The impacts of construction on land use and loss of ecological resources will be described in site-specific NEPA documents.

\section{A.32 Incident-Free Operations Impacts}

Overall, the impacts of disposal operations are quite limited. Construction impacts include the socioeconomic impacts of increased spending and the creation of new employment and the ecological disruption at the plant site. By definition, incidentfree operations are characterized by no releases of agent above emission criteria. Operations impacts of concein include possible exposure to low, but permitted, levels (potentially below detectable levels) of chemical agent, air quality impacts, socioeconomic impacts to community resources and well-being, solid waste disposal, and water use. Impacts to socioeconomic resources come primarily from the need for local communities to upgrade emergency response planning for an accidental release of agent.

\section{A.33 Accident Impacts}

In order to assess the environmental impacts of accidents, it is necessary to identify the credible accidents that could occur and how agent released in those accidents could be dispersed into the environment. The identification of an accident also involves an understanding of how much chemical agent is released, which is frequently referred to as an agent source term. It also requires a knowledge of how the agent is released. It can be spilled, vaporized by an explosion, released by a fire, or some combination of these release modes. Furthermore, identification of an accident requires information on the duration of release.

The ways in which the agent is dispersed after a release are called environmental pathways. The basic paths include the movement of small droplets of agent in the air; the movement of vapor in the air; the deposition of agent from air movement onto underlying lands, vegetation, or water; the movement of agent into bodies of water through runoff or deposition; and the movement of agent into groundwater.

Once agent is released into the environment, it may have effects on human health, ecological systems, water use, and/or socioeconomic resources. Any effects would be estimated by the dispersion processes which tell us about the form and level of the agent in the environment and the response of various ecological systems to the agent.

It is important to realize that each of the three stages of the analysis have uncertainties and error bounds associated with them. These uncertainties are largely a function of imperfect knowledge. The application of these methods to the specific areas of concern (i.e., the installations and their environs, and the transportation corridors) provides assessments iff impacts.

The pictogram in Fig. A.4 summarizes the risks for accidents at UMDA as presented in the FPEIS. UMDA has a large stockpile with a variety of munition types 


\begin{tabular}{|c|c|c|c|c|c|}
\hline Alternatives & 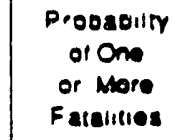 & $\begin{array}{l}\text { Maximum } \\
\text { Numoer of } \\
\text { Fatautios }\end{array}$ & $\begin{array}{l}\text { Expoctiod } \\
\text { Fatauties }\end{array}$ & $\begin{array}{l}\text { Porson. } \\
\text { Yoars } \\
\text { at Piax }\end{array}$ & $\begin{array}{l}\text { Expocine } \\
\text { P!ume Area } \\
\left(\mathrm{km}^{2} \text {, }\right.\end{array}$ \\
\hline \multicolumn{6}{|l|}{ Continued Storage } \\
\hline \multicolumn{6}{|l|}{ On.Site Disposa } \\
\hline \multicolumn{6}{|l|}{ Regione Disoosal } \\
\hline Nabona Oisoosal & & & & 888 & \\
\hline Panial Relocadon & & & & 88 & \\
\hline
\end{tabular}

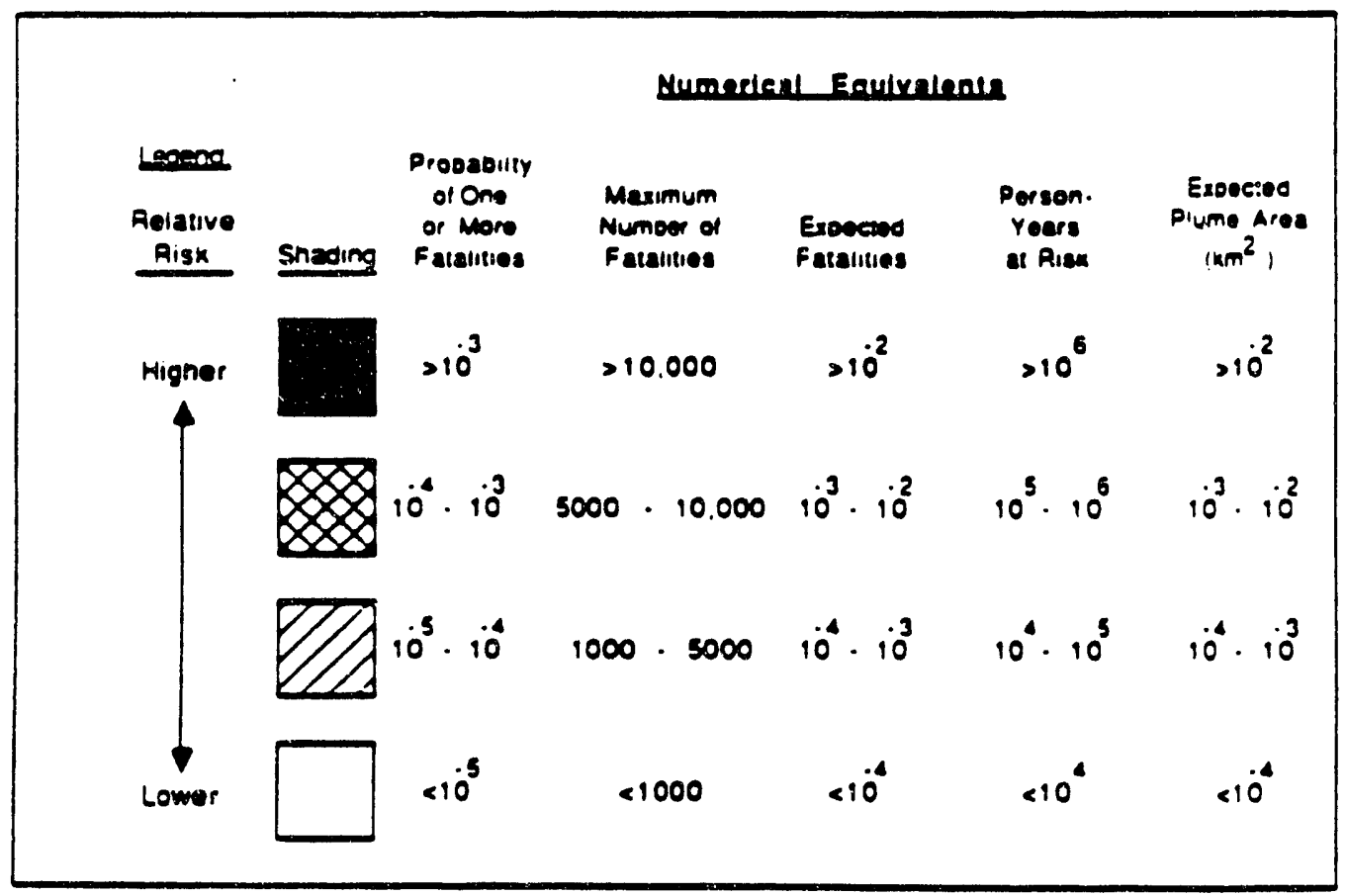

Fig. A.4. Risk with mitigation, in the vicinity of the Umatilla Depot Activity (UMDA) for programmatic alternatives. (Risk along transportation corridors or at an off-site destruction destination is not included. For the disposal alternatives, this diagram does not include the risk associated with approxinlately three years of stockpile storage at UMDA.) 
and agent types. The "probability of one or more fatalities" is small at this site for all alternatives except continued storage. This is primarily due to the remoteness of the site. The "maximum fatalities" are large for both the continued storage and the national and regional (off-site movement) alternatives; however, the very small values shown for "expected fatalities" for these latter alternatives indicate that the accidents leading to large consequences for the off-site movement are very infrequent. The continued storage accidents are dominated by seismic events. The "person-years at risk" are all large for this site because of the size and variety of the inventory at UMDA. Individual time at risk is between 4.5 and 5.5 years for all alternatives.

Because the "expected fatalities" measure of risk incorporates all of the aspects that influence the risk (i.e., probabilities as well as consequences), this measure will be described in detail below for each alternative. In the following discussions, the dominant risks are those accidents that have the largest number of "expected fatalities."

\section{Continued storage alternative}

The FPEIS "expected fatalities" risk at UMDA is dominated by accidents resulting from externally-initiated events, such as earthquakes (about $97 \%$ of the total risk) and air crashes (about $3 \%$ ). The continued storage alternative is assumed to continue for 25 years.

\section{On-site disposal alternative}

The FPEIS risk is dominated by on-site transport accidents. The largest on-site disposal risks are from (1) an on-site vehicle accident resulting in detonation (about $70 \%$ of the total risk), (2) dropping of munitions during handling (about 12\%), (3) munitions detonations inside the disposal plant (about 10\%), and (4) earthquakes that cause extensive plant damage (about $6 \%$ ).

\section{National and regional disposal alternatives}

The dominant FPEIS risks for the off-site disposal alternatives (i.e., national disposal or regional disposal) for UMDA are from (1) vehicle collisions resulting in a detonation (about $50 \%$ of the total risk), (2) aircrashes into the holding area for off-site movement (about 27\%), and (3) dropping munitions during handling (18\%).

\section{A.3.4 Decommissioning Impacts}

Based on the information available on the procedures for decommissioning (dismantling and disposing) disposal facilities, the FPEIS concluded that minor socioeconomic impacts and solid waste impacts could occur. Prior to implementing decommissioning, further NEPA documentation is required and more detailed impact assessments will be conducted. 


\begin{abstract}
A-20
On completion of the disposal program at UMDA, the decommissioning of the facility will involve the employment of both a construction- and an industrial-type work force. When decommissioning ends, local economic impacts from the increased jobs from construction, operations, and decommissioning will no longer be experienced.

Final closure activities for the UMDA disposal facilities will result in removal or decontamination of all process equipment, structures, soils, or other materials containing or contaminated with hazardous waste or hazardous constituents. The projected types of containerized wastes that will be shipped to off-site permitted waste facilities are listed below; amounts of these wastes are presently unknown: (1) brine salt, (2) incinerator ash, (3) baghouse dust and cyclone residue, and (4) miscellaneous nonagent related wastes generated during facility closure. The metal parts of agent tanks, furnaces, and incinerators will be disassembled and decontaminated to $5 \mathrm{X}$ level $\left(1000^{\circ} \mathrm{F}\right.$ for $\left.15 \mathrm{~min}\right)$, which means that an item is clean and may be released from government control. Closure plans for the UMDA facility are described in Sect. I of Part B of the RCRA permit applications.
\end{abstract}




\section{REFERENCES FOR APPENDIX A}

EPRI 1985. Operational Validation of Gaussian and First-Order Closure Plume Models at a Moderately Complex Terrain Site, EA-3759, Project 1616-9, Palo Alto, Calif.

GA Technologies, Inc. 1987a. Risk Analysis of the On-Site Disposal of Chemical Munitions, Reports GAC-18562 and SAPEO-CDE-IS-87010, prepared for Program Executive Officer-Program Manager for Chemical Demilitarization by GA Technologies, Inc., La Jolla, Calif.

GA Technologies, Inc. 1987b. Risk Analysis of the Dispasal of Chemical Munitions at National or Regional Sites, Reports GAC-18563 and SAPEO-CDE-IS-87008, prepared for Program Executive Officer-Program Manager for Chemical Demilitarization by GA Technologies, Inc., La Jolla, Calif.

GA Technologies, Inc. 1987c. Risk Analysis of the Continued Storage of Chemical Munitions, Reports GAC-18564 and SAPEO-CDE-IS-87009, prepared for Program Executive Officer-Program Manager for Chemical Demilitarization by GA Technologies, Inc., La Jolla, Calif.

MITRE Corporation 1987. Risk Analysis Supporting the Chemical Stockpile Disposal Program,SAPEO-CDE-IS-87014, McLean Va., for Program Executive Officer-Program Manager for Chemical Demilitarization, Aberdeen Proving Ground, Md.

U.S. Army 1988. Chemical Stockpile Disposal Program Final Programmatic Environmental Impact Statement, Vols. 1, 2, and 3, Program Executive OfficerProgram Manager for Chemical Demilitarization, Aberdeen Proving Ground, Md., January.

U.S. Department of Commerce, Bureau of the Census 1980. Census of Population, Vol. 1, Characteristics of the Population, U.S. Government Printing Office, Washington, D.C.

Whitacre, G. C., et al. 1986. Personal Computer Program for Chemical Hazard Prediction $(D 2 P C)$, U.S. Army Chemical Research and Development Center, Aberdeen Proving Ground, Md. 


\section{APPENDIX B \\ DESCRIPTION OF SITESPECIFIC COMMUNITY RESOURCES}

The Umatilla Depot Activity (UMDA) is situated in the midst of rich irrigated agricultural land which is presently experiencing a slow but steady growth based on primary agricultural production and food procussing. Once the home and hunting ground of the Bannock, Cayuse, Paiute, Umatilla, and Walla Walla Indian tribes, the area was claimed by the Spanish in 1775, and later by the Russians. Following the explorations by Robert Gray and later Lewis and Clark in 1805, the area became increasingly influenced by the fur trade of the United States.

With the relinquishment of claims by the Spanish and Russians in the 1840s, the area was open to agricultural settlement and logging. With the influx of settlers came increasing conflict with the Indians, resulting in the outbreak of the Cayuse War of 1847. Sporadic warfare continued until 1858 , when the discovery of gold finally compelled the U.S. Army to intensify its military policing of the area.

Oregon's statehood in 1859 and the establishment of Indian reservations opened the area for prospecting, farming, and ranching. Pendleton and Weston were established in the 1860 s as river and stagecoach transport centers; Athena, established in 1878, became a major railroad transport center in 1883 .

The last two decades of the nineteenth century saw the area develop as a wheat, cattle, and wool production center. Hermiston, Milton, and Freewater were incorporated, and Umatilla County was established. To this day, the area has remained an important agricultural center.

UMDA, while an important employer for the area, ranks fourth behind primary agriculture, secondary food processing, and local commercial enterprises. In the Tri-City area of Kennewick, Pasco, and Richland, across the Columbia River in Washington, agriculture has not achieved the same dominance, and employment appears to have been more affected by activities at the Hanford Site, operated by the Department of Energy. Because of downturns in employment at this site in the early 1980s, efforts have been made to strengthen agriculture and tourism (M. Bigby, Benton-Franklin Governmental Conference, Richland, Wash., personal communication with G. M. Schoepfle, Oak Ridge National Laboratory, Oak Ridge, Tenn., May 25, 1989).

A $100-\mathrm{km}$ (62-mile) radius study area is considered for the resources described in this section because the accident analysis presented in the final programmatic environmental impact statement (FPEIS) (U.S. Army 1988) indicates that resources as far away as $100 \mathrm{~km}$ ( 62 miles) could be impacted by low-probability events involving large accidental releases of chemical agent. The $50-\mathrm{km}(31$-mile) radius is the selected study area for the analysis of social impacts driven by population influx and economic change. 


\section{B-2}

\section{B.1 DEMOGRAPHICS}

\section{B.1.1 Off-Site Residential and Worker Populations}

The FPEIS considered residential population to $100 \mathrm{~km}$ (62 miles) to estimate human fatalities. It did not consider daytime population, nonresidential data, or on-post population on a site-specific basis. Data on daytime (e.g. place-of-work) population for the area surrounding UMDA have been sought but have not yet been located. If appropriate data can be found, they will be analyzed for inclusion in the site-specific environmental impact statement.

Table B.1 describes the total populations and overall population trends for the counties within a $100-\mathrm{km}$ (62-mile) radius from the site of the proposed disposal facility at UMDA. The data in Table B.1 are indicators that are used to document socioeconomic trends. They support a picture of Umatilla and Morrow counties as areas that experienced population increase due to rapid agricultural development and energy resources development in the 1970s, decline both in economic growth and population in the early 1980s, and an overall stabilization or slow growth of population from 1982 to the present (Street 1985). The net population increase of $1.4 \%$ indicates that no dramatic population change has occurred.

Population growth tends to be tied closely in both Umatilla and Morrow counties to development of food processing plants and the railroad sorting yard at Hinkle (Street 1985). The population changes of Washington's Benton and Franklin counties appear tied to the Hanford Plant's decline in the early 1980s, as well as to agricultural development in the area (M. Bigby, Benton-Franklin Governmental Conference, Richland, Wash., personal communication with G. M. Schoepfle, Oak Ridge National Laboratory, Oak Ridge, Tenn., May 25, 1989). Hanford employs approximately 14,400 people.

Table B.2 lists the major population centers within the $50-\mathrm{km}(31-\mathrm{mile})$ and $100-\mathrm{km}(62-\mathrm{mile})$ area around UMDA. These data indicate that relatively large concentrations of people reside close to the UMDA's operation, and that they are concentrated in the towns of Hermiston and Umatilla.

Table B.3 presents residential populations by sensitive age group. The age groups with greatest sensitivity are infants under 4 years of age, children 5 to 14 years old, and elderly people 65 years or older. Data for these age groups are important from the standpoint of human health impacts and risk assessment.

\section{B.1.2 Special Populations}

Special populations are defined as that portion of the potentially affected public who require additional effort and special attention in the event of an accidental release 
Table B.1. Overall population characteristics by county for $100 \mathrm{~km}$ (62 riles) around the Umatilla Depot Activity

\begin{tabular}{lcccc} 
County & $\begin{array}{c}\text { Population } \\
1986\end{array}$ & $\begin{array}{c}\text { Population } \\
\text { change } \\
\text { since 1980 }\end{array}$ & $\begin{array}{c}\text { Percent } \\
\text { change }\end{array}$ & $\begin{array}{c}\text { Net } \\
\text { migration }\end{array}$ \\
\hline
\end{tabular}

Within $50 \mathrm{~km}$ (31 miles) of UMDA

$\begin{array}{lrrrr}\text { Gilliam, Oreg. } & 1,800 & -200 & -11.8 & -300 \\ \text { Morrow, Oreg. } & 8,100 & 600 & 7.6 & \\ \text { Umatilla, Oreg. } & 60,200 & 1,400 & 2.4 & -1,800 \\ \text { Benton, Wash. } & 112,700 & 3,300 & 3.0 & -6,100 \\ \text { Franklin, Wash. } & 36,800 & 1,800 & 5.1 & -2,200 \\ \text { Klickitat, Wash. } & 16,200 & 400 & 2.4 & -500 \\ \text { Walla Walla, Wash. } & 48,000 & 600 & 1.2 & -800 \\ \text { Yakima, Wash. } & 183,200 & 10,700 & 6.2 & -600\end{array}$

Between 50 and $100 \mathrm{~km}$ (31 and 62 miles) from UMDA

$\begin{array}{lrrrr}\text { Grant, Oreg. } & 8,400 & 200 & 1.8 & -100 \\ \text { Sherman, Oreg. } & 2,100 & -100 & -2.7 & -100 \\ \text { Union, Oreg. } & 23,700 & -200 & -0.9 & -1,400 \\ \text { Wheeler, Oreg. } & 1,500 & -100 & -3.8 & -100 \\ \text { Grant, Wash. } & 53,100 & 4,500 & 9.4 & 900\end{array}$

${ }^{a}$ Net population change, excluding births and deaths.

Source: U.S. Bureau of the Census, City and County Data Book, 1986 Estimates: Fules on Diskette, Washington, D.C. 


\section{B-4}

Table B.2 Places with population greater than 2000 within $100 \mathrm{~km}$ (62 miles) of Umatilla Depot Activity

\begin{tabular}{lccc}
\hline Place name & $\begin{array}{c}\text { Population } \\
\text { April 1, } \\
1980\end{array}$ & $\begin{array}{c}\text { Population } \\
\text { July 1, }\end{array}$ & $\begin{array}{c}\text { Population } \\
\text { change in \% } \\
1980-86\end{array}$ \\
& & & \\
& Oregon & & \\
& & & \\
Hermiston (Umatilla) & 9,408 & 10,270 & 9.2 \\
Milton-Freewater (Umatilla) & 5,086 & 5,800 & 14.0 \\
Pendleton (Umatilla) & 14,521 & 14,280 & -1.7 \\
Umatilla (Umatilla) & 3,199 & 3,020 & -5.6 \\
& & & \\
& Washington & & \\
College Place (Walla Walla) & & & \\
Grandview (Yakima) & 5,771 & 5,930 & 2.8 \\
Kennewick (Benton) & 6,314 & 6,290 & -0.4 \\
Prosser (Benton) & 38,389 & 39,450 & 2.8 \\
Richland (Benton) & 3,896 & 4,340 & 11.4 \\
Sunnyside (Yakima) & 33,578 & 32,580 & -3 \\
Toppenish (Yakima) & 9,225 & 9,590 & 4 \\
Walla Walla (Walla Walla) & 6,517 & 6,530 & 0.2 \\
Wapato (Yakima) & 25,618 & 25,260 & -1.4 \\
West Richland (Benton) & 3,307 & 3,350 & 1.3 \\
& 2,938 & 4,010 & 36.5 \\
\hline
\end{tabular}

Source: U.S. Bureau of the Census, City and County Data Book, 1986 istimates: Files on Diskette, Washington, D.C. 
Table B.3. Sensitive population by age distribution for $100-\mathrm{km}$ (62- mile) radius around the Umatilla Depot Activity

\begin{tabular}{lcccc}
\hline & $<5$ years & $5-14$ years & $65-74$ years & $>74$ years \\
County & 1984 & 1984 & 1984 & 1984 \\
& $(\%)$ & $(\%)$ & $(\%)$ & $(\%)$ \\
\hline
\end{tabular}

Within $50 \mathrm{~km}$ of proposed UMDA disposal facilities

$\begin{array}{lrrrr}\text { Gilliam, Oreg. } & 7.2 & 13.6 & 10.5 & 6.6 \\ \text { Morrow, Oreg. } & 9.2 & 17.8 & 6.5 & 3.9 \\ \text { Umatilla, Oreg. } & 8.6 & 16 & 7.3 & 4.8 \\ \text { Benton, Wash. } & 9 & 16 & 5.2 & 2.8 \\ \text { Franklin, Wash. } & 10.7 & 17.1 & 5.5 & 3.0 \\ \text { Klickitat, Wash. } & \text { NA }^{a} & \mathrm{NA} & \mathrm{NA} & \text { NA } \\ \text { Walla Walla, Wash. } & 7 & 13.8 & 7.8 & 6.5 \\ \text { Yakima, Wash. } & 8.4 & 16.8 & 7.4 & 5\end{array}$

Within $100 \mathrm{~km}$ of proposed UMDA disposal facilities

$\begin{array}{lllll}\text { Grant, Oreg. } & 7.0 & 15.5 & 8.7 & 5.6 \\ \text { Sherman, Oreg. } & 7.9 & 16.9 & & \\ \text { Union, Oreg. } & 8.9 & 17.6 & 7.5 & 5.3 \\ \text { W'heeler, Oreg. } & & & & \\ \text { Grant, Wash. } & 8.9 & 17.1 & 7.2 & 3.8\end{array}$

${ }^{\mathrm{a}} \mathrm{NA}=$ Data not available.

Sources: U.S. Bureau of the Census, City and County Data Book, 1986 Estimates: Files on Diskette, Washington, D.C; Center for Population Research and Census, School of Urban and Public Affairs, Portland State University, Portland, Oregon. 
of chemical agent from UMDA. These special populations include the very young, who may be located in day care centers, the elderly, who may be located in nursing homes, and those located in institutions such as schools, hospitals, and prisons. Sections B.2.2 and B.2.3 contain information regarding schools, nursing homes, and hospitals.

\section{B.1.3 Transient Populations}

Data for transient populations (see Tables B.4 and B.5) are important from the standpoint of human health impact and risk assessment. Because of the predominantly agricultural character of both Morrow and Umatilla counties, those not holding jobs tend not to remain in the area. Thus, migrant workers may be an important transient population. Data for the migrant workforce can be found in Sect. B.3.3.

Table B.6 lists public use areas within $100 \mathrm{~km}$ (62 miles) of the UMDA disposal site, with visitation rates (as available) and distance from UMDA.

\section{B.1.4 Indian Groups}

The 100,000 -ha $(245,700$-acre) Umatilla Indian Reservation is located about $50 \mathrm{~km}$ ( 31 miles) from the site of the proposed UMDA disposal facility. With a population of 1610 , this reservation includes the Cayuse and the Walla Walla Indians. They are all represented by a confederated tribal council whose members are elected at large. A board of trustees oversees the tribal government's contractual and business relations and conducts negotiations on behalf of the tribal council.

The Indian families make their living primarily through agricultural wage work, farming and ranching, forestry, and employment in government or services. As with the nonreservation area, the principal economic support is agriculture. The tribal government also undertakes a series of programs intended to provide greater selfsufficiency. These include operating fish hatcheries. (C. Spencer, Safety Officer, Confederated Tribes, Pendleton, Oreg., personal communication with G. M. Schoepfle, Oak Ridge National Laboratory, Oak Ridge, Tenn., April 26, 1989.)

The 6846-member Yakima Indian Reservation borders the 100-km (62-mile) perimeter and may, therefore, be affected by a large accidental release of chemical agent from UMDA. Because of its distance from UMDA, data concerning the Yakima Indian Reservation were not collected in any detail.

\section{B.2 PUBLIC SERVICES AND INFRASTRUCTURE}

\section{B.21 Police and Fire Departments}

Table B.7 summarizes police department resources for Oregon's Umatilla and Morrow counties and Washington's Benton County. Table B.8 summarizes fire department resources for major municipalities within these counties. 
B-7

Table B.4. Local annual events and their transient populations in the region around the Umatilla Depot Activity

\begin{tabular}{lccc}
\hline Population Type & Location & Number & Period \\
\hline $\begin{array}{l}\text { 116th Cavalry, Oregon } \\
\text { National Guard }\end{array}$ & UMDA & 100 & $\begin{array}{c}12 \text { weekends } \\
\text { per year }\end{array}$ \\
$\begin{array}{l}\text { 349th Chemical Army } \\
\text { Reserve }\end{array}$ & UMDA & 130 & $\begin{array}{c}2 \text { weeks, } \\
\text { twice/year }\end{array}$ \\
$\begin{array}{l}\text { Pendleton Roundup } \\
\text { Pendleton, Oreg. }\end{array}$ & 7000 & September \\
\hline
\end{tabular}

Notes: 'R. White, UMDA Coordinator for National Guard/Reserve Activities, Hermiston, Oreg., personal communication with G. M. Schoepfle, Oak Ridge National Laboratory, Oak Ridge, Tenn., April 27, 1989. 
Table B.5. Other local annual events possibly involving transient populations

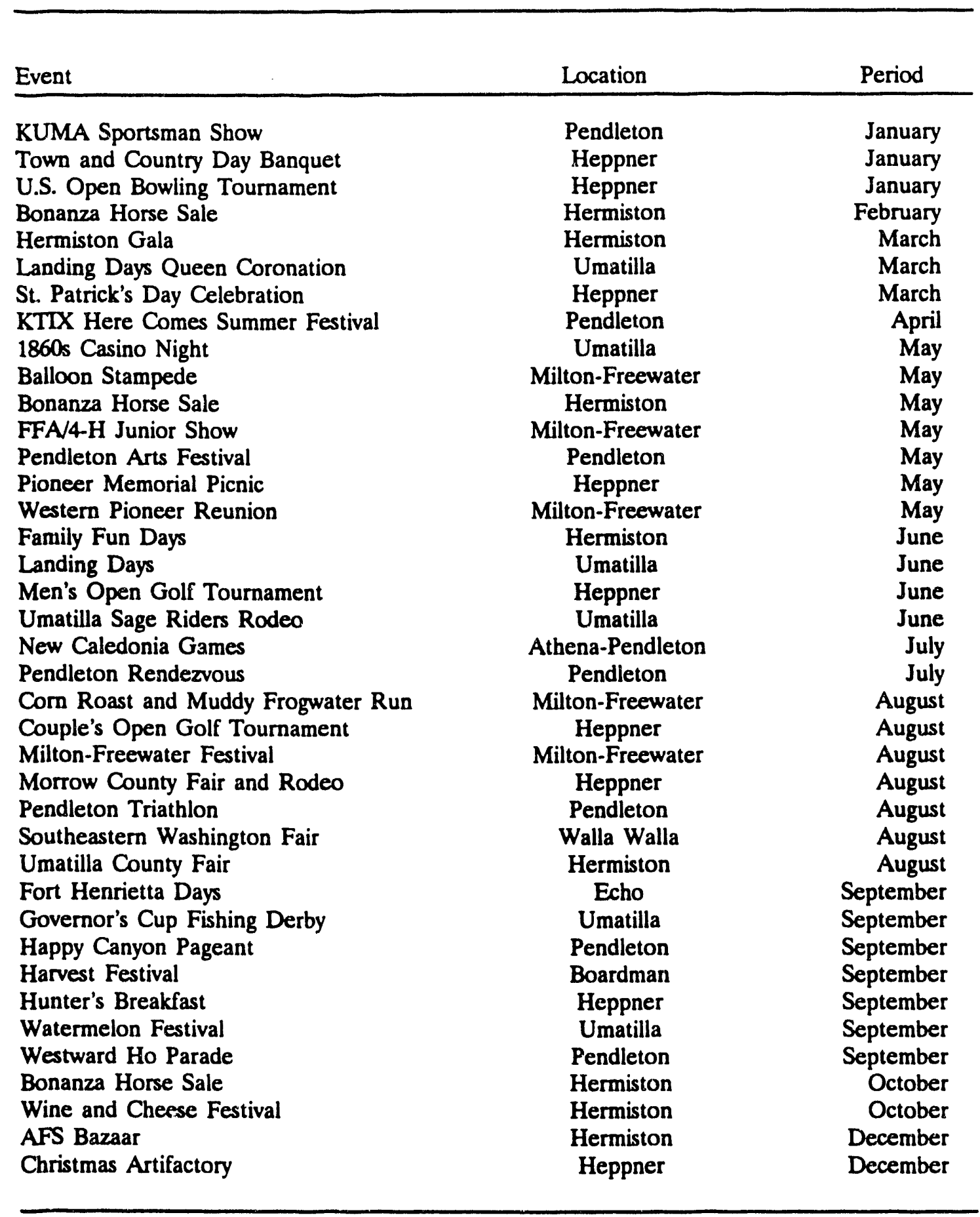

Source: U.S. West Direct, The White and Yellow Pages, February 1989/1990, for Hermiston, Echo, Irrigon, Stanfield and Umatilla, Portland, Oregon. 


\section{B-9}

Table B.6. Public use areas within $100 \mathrm{~km}$ (62 miles) of proposed disposal site at Umatilla Depot Activity

\begin{tabular}{|c|c|c|c|}
\hline Area & County & $\begin{array}{l}\text { Distance } \\
\text { from UMDA }\end{array}$ & $\begin{array}{l}\text { Visitor use } \\
\text { (M/RVDS) }^{\mathbf{a}}\end{array}$ \\
\hline \multicolumn{4}{|c|}{ National Forests (NF) } \\
\hline Umatilla NF, Oregon & Morrow & $\begin{array}{l}\text { S } 75 \mathrm{~km} \\
\text { Umatilla } \\
\text { Union }\end{array}$ & $\begin{array}{l}1,311^{\mathrm{b}} \\
\text { SSE } 80 \mathrm{~km}(F Y ~ 86) \\
\text { SE } 80 \mathrm{~km}\end{array}$ \\
\hline \multicolumn{4}{|c|}{ National Wilderness Areas } \\
\hline $\begin{array}{l}\text { North Fork Umatilla, Oregon } \\
\text { Juniper Dunes, Washington }{ }^{c}\end{array}$ & $\begin{array}{l}\text { Umatilla } \\
\text { Franklin }\end{array}$ & $\begin{array}{l}\text { ESE } 95 \mathrm{~km} \\
\text { NE } 70 \mathrm{~km}\end{array}$ & $\begin{array}{l}7 \text { (FY 86) } \\
379 \text { (FY 88) }\end{array}$ \\
\hline \multicolumn{4}{|c|}{ National Wildlife Refuges (NWR) } \\
\hline $\begin{array}{l}\text { Cold Springs NWR, Oregon } \\
\text { McKay Creek NWR, Oregon } \\
\text { Umatilla NWR, Oregon } \\
\text { McNary NWR, Washington } \\
\text { Saddle Mtn. NWR, Washington } \\
\text { Toppenish NWR, Washington }\end{array}$ & $\begin{array}{l}\text { Umatilla } \\
\text { Umatilla } \\
\text { Morrow } \\
\text { Walla Walla } \\
\text { Grant } \\
\text { Yakima }\end{array}$ & $\begin{array}{l}\text { E } 15 \mathrm{~km} \\
\text { ESE } 60 \mathrm{~km} \\
W 15 \mathrm{~km} \\
N E 50 \mathrm{~km} \\
N N W 90 \mathrm{~km} \\
W N W 90 \mathrm{~km}\end{array}$ & $\begin{array}{l}51,226 \text { (FY 87) } \\
60,259 \text { (FY 87) } \\
139,768 \text { (FY 87) } \\
15,361 \text { (FY 87) } \\
\text { N/A } \\
8,668 \text { (FY 87) }\end{array}$ \\
\hline \multicolumn{4}{|c|}{ State Fish Hatcheries } \\
\hline $\begin{array}{l}\text { Irrigon Fish Hatchery, } \\
\text { Oregon }\end{array}$ & Morrow & & N/A \\
\hline $\begin{array}{l}\text { Ringold Pond Fish } \\
\text { Hatchery, Washington }\end{array}$ & Franklin & & N/A \\
\hline $\begin{array}{l}\text { Union Gap Fish Hatchery, } \\
\text { Washington }\end{array}$ & Yakima & & N/A \\
\hline \multicolumn{4}{|c|}{ State Forest Waysides (Ws) } \\
\hline $\begin{array}{l}\text { Blue Mtn. Ws, Oregon } \\
\text { Ukiah Dale Ws, Oregon }\end{array}$ & $\begin{array}{l}\text { Umatilla } \\
\text { Umatilla }\end{array}$ & $\begin{array}{l}\text { ESE } 85 \mathrm{~km} \\
\text { SSE } 75 \mathrm{~km}\end{array}$ & $\begin{array}{l}284,616(\text { FY 87) } \\
\text { N/A }\end{array}$ \\
\hline
\end{tabular}


B-10

Table B.: (continued)

\begin{tabular}{|c|c|c|c|}
\hline Area & County & $\begin{array}{l}\text { Distance } \\
\text { from UMDA }\end{array}$ & $\begin{array}{l}\text { Visitor use } \\
\text { (M/RVDS) }^{\mathrm{a}}\end{array}$ \\
\hline \multicolumn{4}{|c|}{ State Parks (SP) } \\
\hline $\begin{array}{l}\text { Battle Mtn. SP, Oregon } \\
\text { Emigrant Springs SP, Oregon } \\
\text { Hat Rock SP, Oregon } \\
\text { J. S. Burres SP, Oregon } \\
\text { Crow Butte SP, Washington } \\
\text { Sacajawea SP, Nashington }\end{array}$ & $\begin{array}{l}\text { Umatilla } \\
\text { Umatilla } \\
\text { Umatilla } \\
\text { Gilliam } \\
\text { Benton } \\
\text { Franklin }\end{array}$ & $\begin{array}{l}\text { SSE } 70 \mathrm{~km} \\
\text { ESE } 80 \mathrm{~km} \\
\text { E } 15 \mathrm{~km} \\
W S W 100 \mathrm{~km} \\
W 40 \mathrm{~km} \\
\text { NE } 50 \mathrm{~km}\end{array}$ & $\begin{array}{l}42,272 \text { (FY 88) } \\
284,616 \text { (FY 88) } \\
355,894 \text { (FY 88) } \\
25,894 \text { (FY 88) } \\
193,691(1988) \\
137,403(1988)\end{array}$ \\
\hline \multicolumn{4}{|c|}{ Siate Habitat Management Units/Areas (HMU/HMA) } \\
\hline $\begin{array}{l}\text { McNary KMA, Washir.gton } \\
\text { Rattlesnake Slope HMU, } \\
\text { Washington }\end{array}$ & $\begin{array}{l}\text { Walla Walla } \\
\text { Benton }\end{array}$ & $\begin{array}{l}\text { NE } 50 \mathrm{~km} \\
\text { N } 50 \mathrm{~km}\end{array}$ & $\begin{array}{l}\text { NA } \\
\text { NA }\end{array}$ \\
\hline Snake River HMA, Washington & $\begin{array}{l}\text { Franklin/ } \\
\text { Walla Walla }\end{array}$ & $\mathrm{NE} 80 \mathrm{~km}$ & NA \\
\hline $\begin{array}{l}\text { Sunnyside Wildlife } \\
\text { Recreation Area, IVashington }\end{array}$ & Yakima & NW $50 \mathrm{~km}$ & NA \\
\hline Wahluke Slope HMU, Washingto & nGrant & N $100 \mathrm{~km}$ & NA \\
\hline \multicolumn{4}{|c|}{ County Parks } \\
\hline $\begin{array}{l}\text { Columbia Park, Washington } \\
\text { Hood Park, Washington } \\
\text { Horn Rapids County } \\
\text { Park, Washington }\end{array}$ & $\begin{array}{l}\text { Benton } \\
\text { Walla Walla } \\
\text { Benton }\end{array}$ & $\begin{array}{l}\text { NNE } 40 \mathrm{~km} \\
\text { NE } 50 \mathrm{~km} \\
\text { N } 50 \mathrm{~km}\end{array}$ & $\begin{array}{l}\text { NA } \\
\text { NA } \\
\text { NA }\end{array}$ \\
\hline
\end{tabular}

aM/RVDS = thousands of recreation visitor days. One recreation visite- day is equal to one visitor in the area for 12 hours, or twelve visitors for 1 hour, or any combination to equal 12.

${ }^{b}$ Acreage represents about $57 \%$ of total forest area; visitor data are for entire forest, including four other counties sutside the $100-\mathrm{km}$ radius.

In the 17,367-acre Juniper Foiest, public domain forestland is managed by the Bureau of Land Management.

'NA = data not available.

Sources: A. E Lehman, Guide to Four-Year Colleges 1987, 17th ed., Peterson's Guides, Princeton, N.J., 1987; A. E., Lehman, Guide to Two-Year Colleges 1987, 17th ed., Peterson's Guides, Princeton, N.T., 1987; Oregon Department of Transportation, Parks and Recreation Division, Day L'se Parks \& Recreation Areas July 1, 1987-June 30, 1988, Salcm, Oreg., 1988; P. Reed, National Wilderness Preservation System, Wilderness Research Foundation, Fort Collins, Colo., 1987; U.S. Fish and Wildlife Service, Annual Report of Lands Under Control of the U.S. Fish and Wildlife Service as of September 30, 1987; U.S. Forest Service, Land Areas of the National Forest System, as of September 30, 1987, Washington, D.C., 1988; U.S. Forest Service, A Summary of Recreation Use (M/RVDS) for FY 1986 by Activity, Washington, D.C., 1987; Washington Department of Game, Habitat Management Areas, Department of Game, Fish and Wildlife Facilities, Olympia Headquarters (no date.) 
B-11

Table B.7. Police protection summary

\begin{tabular}{llcccc}
\hline $\begin{array}{l}\text { City/county } \\
\text { entity }\end{array}$ & $\begin{array}{l}\text { Total } \\
\text { staff }\end{array}$ & $\begin{array}{c}\text { Total } \\
\text { police } \\
\text { officers }\end{array}$ & $\begin{array}{c}\text { Total } \\
\text { reserve } \\
\text { officers }\end{array}$ & $\begin{array}{c}\text { Police } \\
\text { vehicles }\end{array}$ & $\begin{array}{c}\text { Jail } \\
\text { capacity }\end{array}$
\end{tabular}

Washington

$\begin{array}{lrrrrr}\text { Echo } & 0 & 0 & 0 & 0 & 0 \\ \text { Benton County } & 0 & 0 & 0 & 0 & 0 \\ \text { Pasco } & 39 & 25 & 0 & 0 & 0 \\ \text { Kennewick } & 41 & 27 & 0 & 0 & 0 \\ \text { Richland } & 50 & 43 & 0 & 0 & 0\end{array}$

$\begin{array}{lrrrrr}\text { Morrow County }^{\text {a }} & 15 & 9 & 0 & 7 & 0 \\ \text { Heppner }^{\text {b }} & 3 & 3 & 0 & 2 & 0 \\ \text { Boardman }^{\text {b }} & 0 & 3 & 0 & 2 & 0 \\ \text { Irrigon }^{\text {b }} & 6 & 2 & 3 & 2 & 0 \\ \text { Umatilla } & 7 & 6 & 0 & 6 & 0 \\ \text { Stanfield } & 0 & 3 & 1 & 2 & 0 \\ \text { Umatilla County }^{c} & 45 & 9 & 0 & 26 & 80 \\ \text { Hermiston }^{\text {d }} & 0 & 14 & 0 & 0 & 0 \\ \text { Pendleton }^{\text {d }} & 31 & 21 & 0 & 16 & 0\end{array}$

Note: A " 0 " entry does not indicate lack of resources, but may imply interagency agreement for their access. Please see footnotes below.

${ }^{a}$ Mutual aid agreement for jailing contract with Kennewick, Wash.

butual aid agreement for service through Morrow County. (T. Denton, Morrow County Sheriff's Office, Heppner, Oreg.; T. Wainright, City Clerk, Stanfield, Oreg.; S. Zielinski, City Clerk, Boardman, Oreg.; M. Cowett, Assistant Chief, Heppner Police Department, Heppner, Oreg., personal communication with S. Schexnayder, Oak Ridge National Laboratory, Oak Ridge, Tenn., May 26, 1989).

'Umatilla County Sheriff's Office jail serves all cities and towns within the county. The present number of inmates (38) is unusually small. (T. Hamby, Umatilla County Sheriff's Office, Pendleton, Oreg., personal communication with S. Schexnayder, Oak Ridge National Laboratory, Oak Ridge, Tenn., May 25, 1989).

'Mutual aid agreement to use Umatilla County facilities. 
B-12

Table B.8. Fire department staffing by city in the vicinity of the Umatilla Depot Activity

\begin{tabular}{llcccc}
\hline City & $\begin{array}{l}\text { Total } \\
\text { staff }\end{array}$ & Officers & Volunteers & Vehicles & $\begin{array}{c}\text { Funding } \\
\text { source }\end{array}$ \\
\hline Richland & 42 & 40 & 0 & 0 & municipal \\
Pasco & 26 & 25 & 0 & 0 & municipal \\
Kennewick & 34 & 33 & 0 & 0 & municipal \\
Hermiston & 40 & 30 & 10 & 9 & municipal \\
Irrigon & 10 & 0 & 10 & 4 & municipal \\
Lexington & 10 & 0 & 10 & 2 & minicipal \\
Heppner & 23 & 0 & 23 & 0 & municipal \\
\hline
\end{tabular}

Note: A "0" entry does not indicate lack of resources, but may imply agreement for their access with other agencies. 
Umatilla County's system is supported by a $\$ 1.5$ million budget, $\$ 1$ million of which goes to the jail. The general position taken by officials is that the jail should be increased in size, but recently a proposed budget was defeated by the voters (T. Hamby, Umatilla County Sheriff's Office, Umatilla, Oreg., personal communication with S. Schexnayder, Oak Ridge National Laboratory, Oak Ridge, Tenn., May 25, 1989).

Stanfield officials reported that their town contains another major municipal police department. They maintained that they operate at a ratio of about 1.6 police to 1000 people, a state-wide accepted ratio (C. Strafy, Chief o: Police, Stanfield, Oreg., personal communication with S. Schexnayder, Oak Ridge National Laboratory, Oak Ridge, Tenn., May 26, 1989). The cities of Boardman and Heppner both maintained that their departments were adequate by present standards (S. Zielinski, City Clerk, Boardman, Oreg., personal communication with S. Schexnayder, Oak Ridge National Laboratory, Oak Ridge, Tenn., May 26, 1989). Heppner's ratio was 3 officers to 1400 people (M. Cowett, Assistant Chief, Heppner Police Department, Heppner, Oreg., personal communication with S. Schexnayder, Oak Ridge National Laboratory, Oak Ridge, Tenn., May 26, 1989).

\section{B.2.2 Schools}

Table B.9 summarizes the schools within $50 \mathrm{~km}$ ( 31 miles) of UMDA. Table B.10 summarizes the two-year and four-year college attendance within the $100-\mathrm{km}$ (62-mile) range. Colleges include Blue Mountain Community College in Pendleton, Columbia Basin College in the Tri-Cities area, and a branch campus of Washington State University that is being planned for Tri-Cities (K. Cooper, East Central Oregon Association of Counties, Pendleton, Oreg., perscual communication with J. Morrissey, SAIC Corp., Oak Ridge, Tenn., April 27, 1989).

\section{B.23 Hospitals and Nursing Homes}

Table B.11 lists the hospitals in the 100-km (62-mile) range. This range is used because all these services would be available through regional health care delivery planning. Table B.12 lists the nursing homes within the $50-\mathrm{km}$ (31-mile) radius of UMDA.

\section{B24 Utilities}

Natural gas is provided for Umatilla and Morrow Counties through Cascade Natural Gas Corporation, which draws its gas from Northwest Pipeline's Canadian reserves and from Pacific Gas and Electric's reserves in the Four Corners. Both lines presently run at low to medium pressure ( 25 to $45 \mathrm{psi}$ ), with a full capacity of 200 psi (A. Piquet, Cascade Natural Gas Corporation, Salem, Oreg., personal communication with G. M. Schoepfle, Oak Ridge National Laboratory, Oak Ridge, Tenn., July 7, 1989). 
B-14

Table B.9. Primary, elementary and secondary schools within the $50-\mathrm{km}$ (31-mile) radius of Umatilla Depot Activity

\begin{tabular}{lllll}
\hline $\begin{array}{c}\text { School district } \\
\text { and town }\end{array}$ & $\begin{array}{l}\text { Number of } \\
\text { students }\end{array}$ & $\begin{array}{c}\text { Staff } \\
\text { (full-time } \\
\text { equivalent) }\end{array}$ & $\begin{array}{c}\text { Number of } \\
\text { teachers in } \\
\text { district }\end{array}$ & $\begin{array}{c}\text { Teacher/ } \\
\text { student } \\
\text { ratio (est.) }\end{array}$ \\
\hline
\end{tabular}

Umatilla County, Oregon

$\begin{array}{lrrrr}\text { Echo District 5, Echo } & 151 & 21 & 28 & 5.4 \\ \text { Hermiston District 8, Hermiston } & 3,728 & 311 & 178 & 20.9 \\ \text { Pendleton District 16, Pendleton } & 3,428 & \text { NA } & 171 & 20.0 \\ \text { Stanfield District 61, Stanfield } & 590 & 95 & 34 & 17.4 \\ \text { Umatilla Community Preschool } & 12 & \text { NA } & \text { NA } & \text { NA } \\ \text { Umatilla District 6R } & 940 & 73 & 50 & 18.8\end{array}$

Morrow County, Oregon

Morrow School District

Morrow County District (Irrigon,

Boardman, Heppner, Ione)

$\begin{array}{rrrr}58 & \text { NA } & \text { NA } & \text { NA } \\ 1,785 & 79 & 260 & 6.9\end{array}$

Benton County, Washington

$\begin{array}{lrrrr}\text { Benton Tri-City Montessori } & \text { NA } & \text { NA } & \text { NA } & \text { NA } \\ \text { Finely District 53, Kennewick } & 861 & 50.3 & 116 & 7.4 \\ \text { Kennewick District 17, Kennewick } & 14,572 & 126.3 & 593 & 24.6 \\ \text { Kiona Benton District, Benton Co. } & 1,171 & 47.8 & 63 & 18.6 \\ \text { Paterson District 5 } & 53 & 6.4 & 3 & 17.7 \\ \text { Richland District 40 } & 6,004 & 103.8 & 358 & 16.8\end{array}$

Franklin County, Washington

\begin{tabular}{lllll} 
Pasco District 1 & 6,339 & 75.2 & 720 & 8.8 \\
\hline
\end{tabular}

Note: $\mathrm{NA}=$ Data not available. 
Table B.10. Colleges and universities within $100 \mathrm{~km}$ (62 miles) of the Umatilla Depot Activity

\begin{tabular}{|c|c|c|c|}
\hline College & County & $\begin{array}{c}\text { Direction/ } \\
\text { distance } \\
\text { from UMDA }\end{array}$ & Enrollment \\
\hline $\begin{array}{l}\text { Blue Mountain Community } \\
\text { College, Oreg. }\end{array}$ & Umatilla & ESE $50 \mathrm{~km}$ & 2061 \\
\hline $\begin{array}{l}\text { Columbia Basin Community } \\
\text { College, Wash. }\end{array}$ & Franklin & $\mathrm{NE} 50 \mathrm{~km}$ & 5500 \\
\hline Heritage College, Wash. & Yakima & NW 90 km & 265 \\
\hline Walla Walla College, Wash. & Walla Walla & ENE $70 \mathrm{~km}$ & 1469 \\
\hline $\begin{array}{l}\text { Walla Walla Community } \\
\text { College, Wash. }\end{array}$ & Walla Walla & ENE $90 \mathrm{~km}$ & 5000 \\
\hline Whitman College, Wash. & Walla Walla & ENE $90 \mathrm{~km}$ & 1171 \\
\hline
\end{tabular}

Sources: Lehman, A. E., Guide to Four-Year Colleges 1987, 17th ed., Princeton, N.J., 1987; Lehman, A. E., Guide to Two-Year Colleges 1987, 17th ed., Princeton, N.J., 1987. 
Table B.11. Hospitals within $100 \mathrm{~km}$ (62 miles) of the Umatilla Army Depot

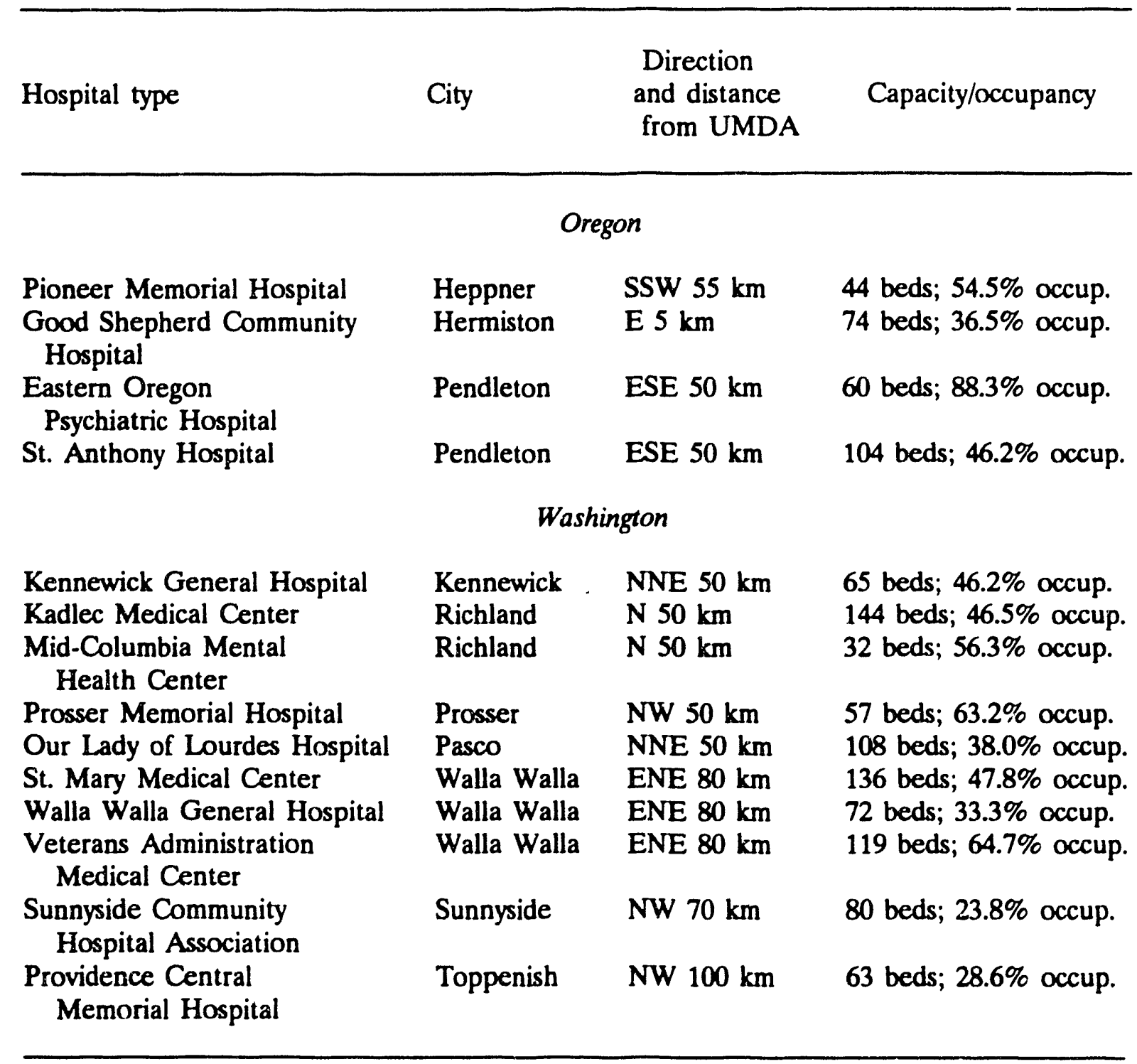

Source: American Hospital Association, American Hospital Association Guide to the Health Care Field, Chicago, 1988. 
Table B.12 Nursing homes within $50 \mathrm{~km}$ (31 miles) of the Umatilla Depot Activity

\begin{tabular}{|c|c|c|c|}
\hline Name of facility & Location & $\begin{array}{l}\text { Facility } \\
\text { type }\end{array}$ & $\begin{array}{c}\text { Certified } \\
\text { no. of beds }\end{array}$ \\
\hline \multicolumn{4}{|c|}{ Oregon } \\
\hline $\begin{array}{l}\text { Hermiston Good Samaritan } \\
\text { Care Center }\end{array}$ & Hermiston, Oreg. & $\begin{array}{l}\text { Intermediate care/ } \\
\text { retirement home }\end{array}$ & $\begin{array}{r}105 \\
15\end{array}$ \\
\hline Amber Valley Care Center & Pendleton, Oreg. & Intermediate care & 98 \\
\hline Delmarter Care Center & Pendleton, Oreg. & Intermediate care & 68 \\
\hline \multicolumn{4}{|c|}{ Washington } \\
\hline $\begin{array}{l}\text { Lifecare Center of } \\
\text { Kennewick }\end{array}$ & Kennewick, Wash. & $\begin{array}{l}\text { Skilled and inter- } \\
\text { mediate care }\end{array}$ & 136 \\
\hline Vista View Care Center & Kennewick, Wash. & Skilled care & 53 \\
\hline $\begin{array}{l}\text { Royal Columbia } \\
\text { Retirement Inn }\end{array}$ & Kennewick, Wash. & NA & NA \\
\hline
\end{tabular}

Note: NA = Data not available. 


\section{B-18}

Umatilla Electric Cooperative Association presently serves Umatilla and Morrow counties at $140 \mathrm{MW} / \mathrm{year}$ incurred, with a capability of $180 \mathrm{MW} / \mathrm{year}$. The Cooperative has tentative plans to build an additional substation to serve the increased load demand that would result from the construction and operation of disposal facilities at UMDA (T. Worrell, Portland General Electric Company, Portland, Oreg., personal communication with G. M. Schoepfle, Oak Ridge National Laboratory, Oak Ridge, Tenn.)

Water is provided to Hermiston from one shallow-water and three deep-water wells. Present capacity is $8600 \mathrm{gal} / \mathrm{min}$, with a 2.25 million gal storage capacity. Studies completed in 1984 indicate that Hermiston has the capacity to serve a total of 96,000 people, with storage upgraded an additional 1.25 million gal (Kramer, Chin and Mayo Cogan and Associates 1984).

Hermiston is served by two sewer lines, a $60-\mathrm{cm}$ (24-in.) gravity main and a 45-cm (18-in.) interceptor. Sewage treatment facilities presently treat $1 \mathrm{Mgd}$. The present capacity of these is $2.9 \mathrm{Mgd}$.

Solid waste is hauled by private company to a landfill on the north side of town on Highway 395. Estimated lifetime of the landfill at its current use rate is 20 years (Kramer, Chin and Mayo Cogan and Associates 1984).

\section{B.25 Transportation}

Highway travel. Interstate 84 is the primary east/west route from Portland, Oregon, to Boise, Idaho, and is connected with UMDA from the south. Interstate 82 leads to I-84, which passes the Tri-Cities on its route north to Yakima, Washington. State Highway 730 is a two-lane road that joins I-84 twelve miles west of UMDA. It continues east of the depot into Washington, where it joins Highway 12. Highway 207 goes north and south, connecting the city of Umatilla with Highway 730 and following the Columbia River.

A commercial bus depot is available at Hermiston, Oregon, $18 \mathrm{~km}$ (11 miles) from UMDA.

Air travel. Commercial air travel is provided by Mesa Airport in Pendleton, $53 \mathrm{~km}$ (33 miles) from UMDA. Mesa serves Portland and nearby cities, with limited flights to Walla Walla, and is served by Delta, Alaska, and other airlines. An additional flight connects Pasco and Redmond, Oregon, passing almost directly over the depot (K. Cooper, East Central Oregon Association of Counties, Pendleton, Oreg., personal communication with J. Morrissey, SAIC Corp., Oak Ridge, Tenn., April 27, 1989.) Military air transport connects UMDA to Fairchild Air Force Base (AFB), $290 \mathrm{~km}$ (180 miles) distant, and to McCord AFB, Washington $480 \mathrm{~km}$ (300 miles) away. Available at UMDA is a $900-\mathrm{m}(3000-\mathrm{ft})$ airstrip with an $3600-\mathrm{kg}(8000-\mathrm{lb})$ capacity capable of supporting DC-3-type aircraft. This airstrip, however, has not been used recently because of the imposition of new criteria that it could not meet.

Rail transportation. UMDA has storage facilities for 800 freight cars, including troop trains. Union Pacific Railroad provides trackage from UMDA to Portland, Oregon. There, bi-level and tri-level freight car storage facilities are also available. 
Commercial rail facilities are available at Hinkle, Oregon, $3 \mathrm{~km}$ ( 5 miles) east of UMDA. It is the main freight terminal and rail classification yard for all parts of the Pacific Northwest. An AMTRAK ticketing station is also located at the Hinkle Railyard (K. Cooper, East Central Oregon Association of Counties, Pendleton, Oreg., personal communication with J. Morrissey, SAIC Corp., Oak Ridge, Tenn., April 27, 1989).

Water transportation. The Columbia River is an important conduit for barge and other boat traffic. With the Snake River tributary, the river system connects the area around UMDA with the Pacific Northwest and the Northern Great Basin of Idaho. Docking facilities at the $6-\mathrm{m}(20-\mathrm{ft})$ depth are available for all commodities, at Portland, Oregon, $290 \mathrm{~km}$ (180 miles) from UMDA. Barge traffic docking facilities are available at McNary Dam on the Columbia River for all commodities except Class A or B explosives. Docking facilities for barge traffic carrying Class $\mathrm{A}$ and $\mathrm{B}$ explosives are available at Hague-Warner moorage on the Columbia River $11 \mathrm{~km}$ ( 7 miles) from UMDA.

The McNary Dam on the Columbia River is the only river lock affecting barge traffic within $50 \mathrm{~km}$ (31 miles) of UMDA. The Ice Harbor Dam on the Snake River is within $100 \mathrm{~km}$ (62 miles) of UMDA. The Willamette Falls Locks on the Willamette River and the Bonneville Dam and Dalles Dam on the Columbia River are the other lockpoints for commercial traffic.

From McNary Dam, the greatest downstream traffic consists mainly of wheat and other grains. Upstream traffic consists mainly of petroleum and fertilizer.

At present, the locks require approximately one hour for transit, and could thus handle approximately 20 vessels per day. The normal traffic is five to six vessels per day. Included in this traffic are recreational craft.

This capacity could be decreased in the event of drought, or if existing hydropower projects increased their capacity, but at present no new projects were scheduled for construction. (Approximately $\mathbf{4 0}$ million gal of water are required to move each boat through the locks.). As a result, officials hope that full capacity on these existing projects is not attained. Should competition for water increase to a critical point, the first option open to officials is to control recreational traffic through scheduling. No dramatic commercial expansion is anticipated (O. Dugger, Port of Umatilla, Umatilla, Oreg., personal communication with G. M. Schoepfle, Oak Ridge National Laboratory, Oak Ridge, Tenn., May 17, 1989).

\section{B.3 ECONOMIC RESOURCES}

Dominant primary economic activity in the UMDA area is in agriculture, forestry, and wood products ( $\mathrm{K}$. Cooper, East Central Oregon Association of Counties, Pendleton, Oreg., personal communication with J. Morrissey, SAIC Corp., Oak Ridge, Tenn., April 27, 1989). Other employment is in secondary agricultural services, such as aerial spraying, seeding operations, and food processing. 


\section{B3.1 Employment}

The economies of Morrow and Umatilla Counties grew rapidly throughout the 1970 secause of expansion in the agricultural sector and related food processing, as well as energy resources development. These economies declined in the early 1980s, resulting in increases in seasonal, cyclical and structural unemployment. Seasonal unemployment depends on the annual cycle of agricultural activities; cyclical unemployment depends on upturns and downturns in businesses, while structural unemployment pertains to the departure of an industry from an area or to decreases in jobs due to automation. Structural unemployment is the most serious because it requires either the relocation or retraining of workers. It also affects minorities more severely (Street 1985). In both Umatilla and Morrow counties, in Oregon, as well as Benton County, Washington, cyclical and structural unemployment are difficult to distinguish because of the rural and isolated character of the regions.

For Morrow and Umatilla counties the size of the labor force has declined throughout the early 1980 s, but is highly competitive among all occupations. While this decline in employment appears to have stabilized, it is highly vulnerable to national cyclical upturns and downturns.

Table B.13 summarizes the total economic and employment situation for the 50 and $100-\mathrm{km}$ (31- and 62-mile) region around UMDA. Unemployment rates of $11.5 \%$ for the $50 \mathrm{~km}$ region and $11.4 \%$ for the $100-\mathrm{km}$ region are significantly higher than the $7 \%$ average for the United States.

\section{B.32 Housing}

Table B.14 provides a summary of housing data for all the counties within $100 \mathrm{~km}$ (62 miles) of UMDA. This range, while not directly relevant to assessing housing for socioeconomic study, does provide a basis for assessing the areas that could be affected by population influx resulting from disposal of the UMDA chemical stockpile. Vacancy rates as of 1980 are estimated at $17.8 \%$ for Morrow, $10.3 \%$ for Umatilla, $8.6 \%$ foi Benton, and $10.0 \%$ for Franklin counties. Compared with the minimal acceptable rates of about $4.0 \%$ from the U.S. Department of Housing and Urban Development, the holssing, particularly in Oregon counties, appears depressed.

Recent population influences on housing are (1) Umatilla's population has grown from 1500 to 3000 (K Cooper, East Central Oregon Association of Counties, Pendleton, Oreg., personal communication with J. Morrissey, SAIC Corp., Oak Ridge,Tenn., April 27,1989 ) and (2) the Tri-Cities population has fluctuated considerably since 1980, due to the clnsing of the nuclear facilities at Hanford.

Unique circumstances in Hermiston and Umatilla may require that they be given consideration for potential impact from the proposed UMDA disposal facilities: (1) these two cities have experienced the greatest growth in rental housing; (2) both have the greatest economic diversity, because they include many commercial, as well as agricultural and economic resources (Street 1985); (3) both are close to UMDA; 
Table B.13. Employment data for counties in the Umatilla Depot Activity vicinity

\begin{tabular}{|c|c|c|c|}
\hline County & $\begin{array}{c}\text { Civilian } \\
\text { labor force } \\
1986\end{array}$ & $\begin{array}{c}\text { Labor force } \\
\text { unemployed } \\
1986\end{array}$ & $\begin{array}{c}\text { Unemployment } \\
\text { rate }(\%) \\
1986\end{array}$ \\
\hline \multicolumn{4}{|c|}{ Within $50 \mathrm{~km}$ (31 iniles) of UMDA } \\
\hline Gilliam, Oreg & 883 & 58 & 6.6 \\
\hline Morrow, Oreg & 4,047 & 551 & 13.6 \\
\hline Umatilla, Oreg & 31,047 & 3,663 & 11.8 \\
\hline Benton, Wash. & 53,017 & 5,105 & 9.6 \\
\hline Franklin, Wash. & 16,003 & 1,804 & 11.3 \\
\hline Klickitat, Wash. & 7,793 & 1,237 & 15.9 \\
\hline Walla Walla, Wash. & 23,516 & 2,310 & 9.8 \\
\hline Yakima, Wash. & 89,148 & 12,205 & 13.7 \\
\hline Average & & & 11.5 \\
\hline \multicolumn{4}{|c|}{ Between 50 and $100 \mathrm{~km}$ ( 31 and 62 miles) from UMDA } \\
\hline Grant, Oreg. & 4,385 & 530 & 12.1 \\
\hline Sherman, Oreg. & 1,006 & 100 & 9.9 \\
\hline Union, Oreg. & 11,183 & 1,220 & 10.9 \\
\hline Wheeler, Oreg. & 596 & 71 & 11.9 \\
\hline Grant, Wash. & 25,413 & 2,714 & 10.7 \\
\hline Average & & & 11.4 \\
\hline
\end{tabular}

Source: U.S. Bureau of the Census, City and County Data Book, 1986 Estimates: Files on Diskette, Washington, D.C. 
B-22

Table B.14. Housing data summary for the Umatilla Depot Activity vicinity

\begin{tabular}{|c|c|c|c|c|c|c|}
\hline County & $\begin{array}{l}\text { Housing } \\
\text { units } \\
\text { (\% change) } \\
1970-80\end{array}$ & $\begin{array}{l}\text { Total } \\
\text { housing } \\
\text { units } \\
1980\end{array}$ & $\begin{array}{l}\text { Occupied } \\
\text { housing } \\
\text { units } \\
1980\end{array}$ & $\begin{array}{c}\text { Total } \\
\text { housing } \\
\text { vacancies } \\
\text { (est.) }\end{array}$ & $\begin{array}{l}\text { New } \\
\text { housing } \\
\text { permits } \\
1980-86\end{array}$ & $\begin{array}{l}\text { Total } \\
\text { housing } \\
\text { units } \\
\text { (est.) } 1986\end{array}$ \\
\hline
\end{tabular}

Within $50 \mathrm{~km}$ (31 miles) of UMDA

\begin{tabular}{lrrrrrr} 
Gilliam, Oreg. & 11.0 & 1,049 & 778 & 271 & 9 & 1,058 \\
Morrow, Oreg. & 82.1 & 3,213 & 2,642 & 571 & 105 & 3,318 \\
Umatilla, Oreg. & 44.5 & 23,504 & 21,077 & 2,427 & 989 & 24,493 \\
Benton, Wash. & 95.4 & 42,651 & 38,978 & 3,673 & 2,054 & 44,705 \\
Franklin, Wash. & 58.1 & 13,316 & 11,985 & 1,331 & 473 & 13,789 \\
Klickitat, Wash. & 39.2 & 6,498 & 5,754 & 744 & 374 & 6,872 \\
Walla Walla, Wash. & 24.6 & 18,138 & 16,975 & 1,163 & 856 & 18,994 \\
Yakima, Wash. & 30.4 & $\underline{66,851}$ & $\underline{61,341}$ & $\underline{5,510}$ & $\underline{3,029}$ & $\underline{69,880}$ \\
\multicolumn{1}{l}{ Subtotal } & & 175,220 & 159,530 & 15,690 & 7,889 & 183,109
\end{tabular}

Between 50 and $100 \mathrm{~km}$ (31 and 62 miles) from UMDA

\begin{tabular}{|c|c|c|c|c|c|c|}
\hline Grant, Oreg. & 36.6 & 3,812 & 3,006 & 806 & 116 & 3,928 \\
\hline Sherman, Oreg. & 12.5 & 983 & 820 & 163 & 8 & 991 \\
\hline Union, Oreg. & 36.2 & 9,693 & 8,707 & 986 & 569 & 10,262 \\
\hline Wheeler, Oreg. & -0.1 & 775 & 586 & 189 & 28 & 803 \\
\hline Grant, Wash. & 36.7 & $\underline{20,271}$ & $\underline{17,158}$ & $\underline{3,113}$ & 960 & 21,231 \\
\hline Subtotal & & 35,534 & 30,277 & 5,257 & 1,681 & 37,215 \\
\hline Total & & 210,754 & 189,807 & 20,947 & 9,570 & 220,324 \\
\hline
\end{tabular}

Source: U.S. Bureau of the Census, 1986 Estimates: Files on Diskette, Washington, D.C. 
and (4) there are strict, legislatively mandated restrictions on the conversion of agricultural land to urban use. Legislation mandates that Exclusive Farm Use (EFU) areas be part of a larger set of administrative rules and goals for state land use planning. Under these rules, county governments draft a land use plan designating EFUs that is then reviewed by a state land conservation and development commission (LCDC). Exceptions that allow urban use, such as for housing developments, are granted by the LCDC only after it is demonstrated that sufficient housing in already designated urban use areas (such as Hermiston, Umatilla and Pendleton) within a 15 to 20 min commute is an unavailable (S. Randolph, Planning Coordinator, Umatilla County Planning Department, Pendleton, Oreg., personal communication with G.M. Schoepfle, Oak Ridge National Laboratory, Oak Ridge, Tenn., July 7, 1989).

\section{B.3.3 Agriculture and Land Use}

Agriculture is the dominant economic activity near UMDA and is, thus, the dominant income producer and employer in the $50-\mathrm{km}$ (31-mile) region. Immediately surrounding UMDA are approximately 60,750 ha (150,000 acres) of irrigated sandy land, most of which is used for growing potatoes (L. Fitch, Umatilla County Agricultural

Extension Agent, Pendleton, Oreg., personal communication with G. M. Schoepfle, Oak Ridge National Laboratory, Oak Ridge, Tenn., April 26, 1989).

The overall economic downiurn in the area has stopped, and agricultural development is gradually increasing. This cycle followed a general trend in the 1970s toward greater acreage under cultivation and an increase of large farms (i.e., greater than 500 acres) at the expense of smaller farms. However, the existence of installations such as Hanford tends to suppress development of local agriculture in favor of overdevelopment in the commercial and consumer market sectors. The resulting regional vulnerability to cyclical upturns and downturns appears to have affected Benton County and the Tri-City areas more than Umatilla and Morrow counties (M. Bigby, Benton-Franklin Governmental Conference, Richland, Wash., personal communication with G. M. Schoepfle, Oak Ridge National Laboratory, Oak Ridge, Tenn., May 25, 1989).

Table B.15 summarizes the overall agricultural population and land use for both the 50-km (31-mile) and 100-km (62-mile) regions around UMDA. For Umatilla and Morrow counties, the percentage of farms with fewer than 50 acres differs little from the U.S. average, while the percentage with 500 acres or more is significantly larger. The same pattern holds true for Benton County but not for Franklin County. This pattern further illustrates the tendency for large farms in the area.

Because of the predominantly agricultural character of the region surrounding UMDA, there is a rather large, seasonal demand for agricultural workers. A portion of this demand is met by migrant workers. The size of the migrant workforce is shown in Table B.16. 
Table B.15. Agricultural population and land use for the Umatilla Depot Activity vicinity

\begin{tabular}{|c|c|c|c|c|}
\hline County & $\begin{array}{l}\text { Farms } \\
<50 \text { acres } \\
1982 \\
(\%)\end{array}$ & $\begin{array}{c}\text { Farms } \\
>500 \text { acres } \\
1982 \\
(\%)\end{array}$ & $\begin{array}{l}\text { Farms w/ } \\
\text { farming } \\
\text { as principal } \\
\text { occupation } \\
(\%)\end{array}$ & $\begin{array}{l}\text { Farms w/ } \\
\text { operator } \\
\text { residing } \\
\text { on farm } \\
(\%)\end{array}$ \\
\hline \multicolumn{5}{|c|}{ Within $50 \mathrm{~km}$ (31 miles) of UMDA } \\
\hline $\begin{array}{l}\text { Gilliam, Oreg. } \\
\text { Morrow, Oreg. } \\
\text { Umatilla, Oreg. } \\
\text { Benton, Wash. } \\
\text { Franklin, Wash. } \\
\text { Klickitat, Wash. } \\
\text { Walla Walla, Wash. } \\
\text { Yakima, Wash. } \\
\quad \text { Average }\end{array}$ & $\begin{array}{r}8.5 \\
26.9 \\
50.9 \\
70.5 \\
23.8 \\
29.6 \\
47.3 \\
\underline{68.8} \\
40.8\end{array}$ & $\begin{array}{r}82.3 \\
55.8 \\
27.1 \\
9.4 \\
24.2 \\
31.1 \\
30.6 \\
4.4 \\
33.1\end{array}$ & $\begin{array}{l}80.5 \\
70.0 \\
56.1 \\
37.0 \\
75.4 \\
54.3 \\
62.5 \\
\underline{53.6} \\
61.2\end{array}$ & $\begin{array}{l}66.5 \\
75.9 \\
76.1 \\
76.7 \\
77.5 \\
80.9 \\
71.5 \\
79.1 \\
75.5\end{array}$ \\
\hline \multicolumn{5}{|c|}{ Between 50 and $100 \mathrm{~km}$ (31 and 62 miles) from UMDA } \\
\hline $\begin{array}{l}\text { Grant, Oreg. } \\
\text { Sherman, Oreg. } \\
\text { Union, Oreg. } \\
\text { Wheeler, Oreg. } \\
\text { Grant, Wash. } \\
\text { Average }\end{array}$ & \begin{tabular}{r|}
20.1 \\
9.1 \\
36.4 \\
8.1 \\
25.4 \\
19.8
\end{tabular} & $\begin{array}{l}52.5 \\
73.7 \\
25.5 \\
65.3 \\
23.6 \\
48.1\end{array}$ & $\begin{array}{l}63.2 \\
84.3 \\
47.6 \\
65.3 \\
70.2 \\
66.1\end{array}$ & $\begin{array}{l}80.5 \\
70.2 \\
82.7 \\
80.6 \\
74.9 \\
77.8\end{array}$ \\
\hline U.S. average & 28.4 & 16.3 & 55.1 & 70.6 \\
\hline
\end{tabular}

Source: U.S. Bureau of the Census, City and County Data Book, 1986 Estimates: Fules on Diskette, Washington, D.C. 
Table B.16. Monthly agricultural employment of migrant workers in 1989

\begin{tabular}{lll} 
Month & $\begin{array}{l}\text { Employment in } \\
\text { Morow County }\end{array}$ & Employment in \\
& Umatilla County \\
\hline
\end{tabular}

$\begin{array}{lrr}\text { January } & 14 & \\ \text { February } & 13 & 130 \\ \text { March } & 54 & 165 \\ \text { April } & 157 & 202 \\ \text { May } & 163 & 668 \\ \text { June } & 92 & 867 \\ \text { July } & 132 & 1,009 \\ \text { August } & 247 & 958 \\ \text { September } & 119 & 692 \\ \text { October } & 145 & 835 \\ \text { November } & 64 & 542 \\ \text { December } & \text { N/A } & 260 \\ & & \text { N/A }\end{array}$

N/A = Data not available.

Source: J. Woods, Regional Economist, Oregon Employment Division, Pendleton, Oreg., personal communication to M. Thompson, Office of the Program Manager for Chemical Demilitarization, Aberdeen Proving Ground, Md., December 8, 1989. 


\section{B.4 CULTURAL, ARCHAEOLOGICAL, AND HISTORICAL RESOURCES}

In Oregon, over $\mathbf{5 0 0}$ historical and archaeological sites are listed for Gilliam, Grant, Sherman, Union, Wheeler, Umatilla and Morrow counties. In comparison with Umatilla and Morrow counties, however, Benton, Franklin, and Yakima counties in Washington, are by far the more plentiful in archaeological sites. Benton and Franklin counties are located within the mid-Columbia Study Unit, while Yakima County is located within the south Cascades Study Unit of the State's Office of Archaeological and Historical Preservation. Within the Mid-Columbia unit, there are 12 archaeological and historic sites and 9 archaeological districts listed in the National Register of Historic Places. An additional 15 properties are listed on the State Register, 5 of which are archaeological districts. Within the south Cascade District, Yakima County has no archaeological properties belonging on the National Register. Sixteen properties are listed on the State Register.

Neither the $50-\mathrm{km}$ (31-mile) zone nor the $100-\mathrm{km}(62-\mathrm{mile})$ zone lists any locally designated properties or resources. The resources are located mostly near rivers, lakes, and streams (75\% south Cascade, $80 \%$ mid-Columbia) and thus either in flood plains or river confluences. Most of the archaeological sites include pits, food hunting and gathering camps, food processing camps, fishing stations, burial sites, rock cairns, and small temporary camps. The preservation of these sites is threatened primarily by erosion, agricultural development, urbanization and vandalism (Stilson et al. 1987; Stilson 1988).

Information regarding the status of archaeological sites for Oregon is available in less detail than for Washington, and is confined to lists of historic sites (R. Whitlam, State Archaeologist, Salem, Oreg., personal communication with G.M. Schoepfle, Oak Ridge National Laboratory, Oak Ridge, Tenn., June 10, 1989). Data regarding archaeological and cultural resources are only partially available and are summarized in Table B.17. 
B-27

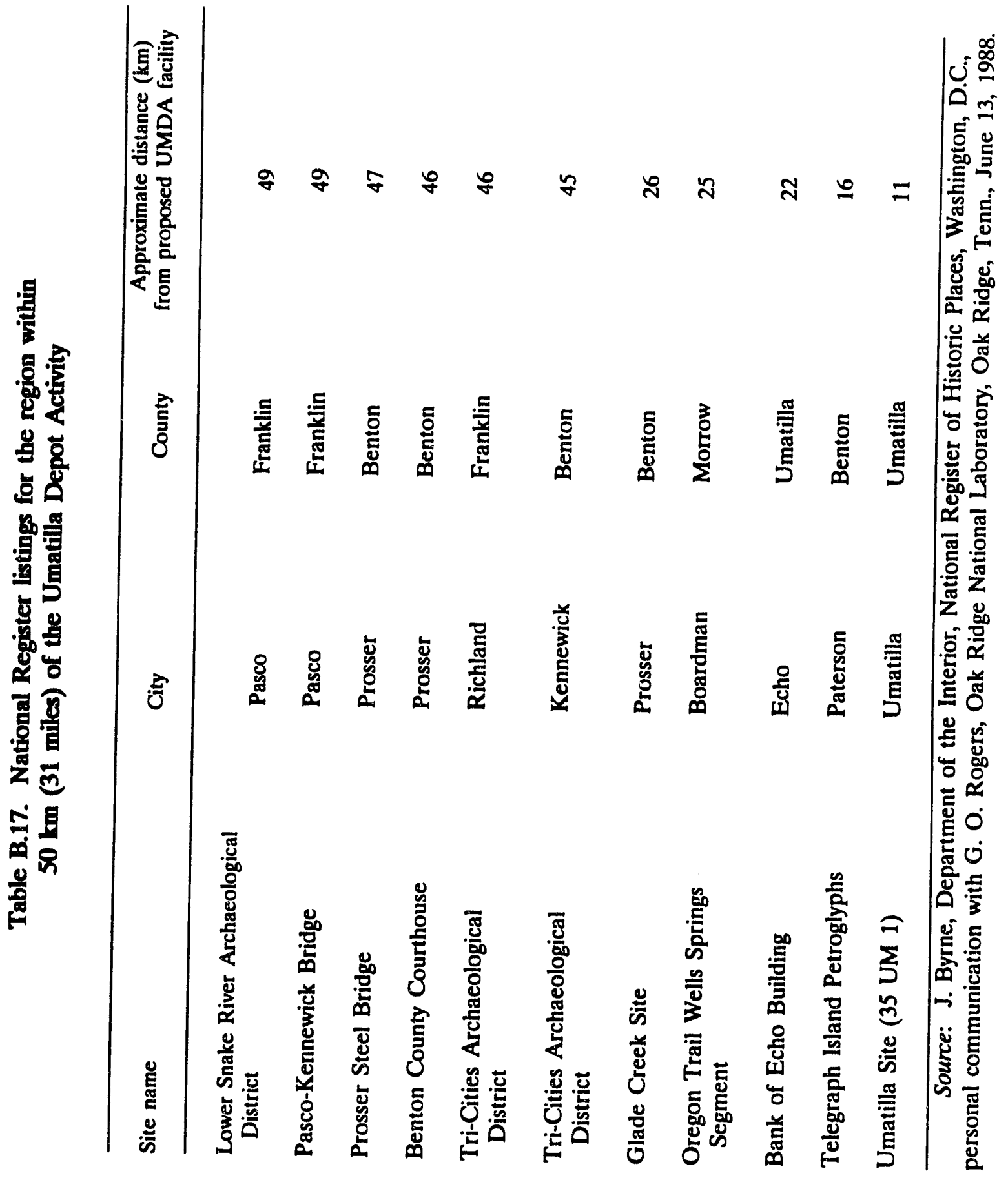




\section{B-28}

\section{REFERENCES FOR APPENDIX B}

Kramer, Chin and Mayo Cogan and Associates 1984. Hermiston Comprehensive Plan, prepared for the City of Hermiston, Hermiston, Oreg.

Stilson, M. L., 1988. Resource Protection Planning Process: South Cascades Study Unit State of Washington Department of Community Development, Office of Archaeological and Historic Preservation, Olympia, Wash.

Stilson, M. L., et al. 1987. Resource Protection Planning Process: Mid-Columbia Study Unit, State of Washington, Department of Community Development, Office of Archaeological and Historic Preservation, Olympia, Wash.

Street, W. 1985. Business and Employment Outlook: JTPA District 12, Oregon Employment Division, Research and Statistics Unit, Salem, Oreg.

U.S. Army 1988. Chemical Stockpile Disposal Program Final Programmatic Impact Statement, Vols. 1, 2 and 3, Program Executive Officer-Program Manager for Chemical Demilitarization, Aberdeen Proving Ground, Md., January. 


\section{APPENDIX C \\ DESCRIPTION OF SITESPECIFIC SURFACE WATER AND GROUNDWATER RESOURCES}

\section{C.1 SURFACE WATER}

The Columbia River basin is the principal watershed near the Umatilla Depot Activity (UMDA) (see Fig. C.1). The Columbia River flows in a westerly direction approximately $5 \mathrm{~km}$ ( 3 miles) above the northern UMDA boundary after traversing east central Washington in a sweeping curve known as the Big Bend. McNary Dam regulates the flow of the Columbia River northeast of UMDA. Additional dams are located both upstream and downstream of McNary Dam. The average discharge of the Columbia River at McNary Dam is $5,165 \mathrm{~m}^{3} / \mathrm{s}\left(182,400 \mathrm{ft}^{3} / \mathrm{s}\right.$ ) (Davies-Smith, Bolke, and Collins 1988). Snowmelt on the mountainous watershed causes high flows in late spring and early summer; low flows occur in autumn and winter. Numerous pumping stations, which lift water to irrigate lowland farms, are located along the Columbia River. The city of Boardman, due west of UMDA, does not take surface water directly from the Columbia River but withdraws water from the river through a Ranney well (S. Zielinski, City of Boardman, Boardman, Oreg., personal communication to J. E. Breck, Environmental Sciences Division, Oak Ridge National Laboratory, Oak Ridge, Tenn., Sept. 18, 1987).

The Yakima and Snake rivers in Washington empty into the Columbia River north of UMDA. In Oregon, the Umatilla River and Willow Creek, which are located approximately $10 \mathrm{~km}$ (6 miles) east and $45 \mathrm{~km}$ ( 28 miles) west of the installation, respectively, discharge into the Columbia River. Butter Creek joins the Umatilla River near the southeastern corner of the depot. The Umatilla River is regulated by dams and reservoirs. Many diversions are made from the river for irrigation of agricultural land within the river basin, including a pumping station near the confluence with the Columbia River at the city of Umatilla (U.S. Army 1988). The average annual discharge approximately $3 \mathrm{~km}$ ( 2 miles) upstream of the confluence with the Columbia River is $23.8 \mathrm{~m}^{3} / \mathrm{s}\left(841 \mathrm{ft}^{3} / \mathrm{s}\right)$ and has a minimum summer flow of $0.031 \mathrm{~m}^{3} / \mathrm{s}\left(1.1 \mathrm{ft}^{3} / \mathrm{s}\right)$

(U.S. Geological Survey 1983). Willow Creek has an occasional flow during the summer months that has been appropriated for irrigation approximately $32 \mathrm{~km}$ ( 20 miles) south of the site (Roy F. Weston 1989). Sand Hollow Creek, which is located south of UMDA, and Butter Creek have water in their upper reaches only during the winter months and are dry the remainder of the year (Roy F. Weston, Inc., 1989).

Bodies of surface water in the vicinity of UMDA include Cold Springs Reservoir, northeast of Hermiston, and McKay Reservoir, due south of Pendleton. A small, 


\section{C.2}

OANL.OWG 89-9947

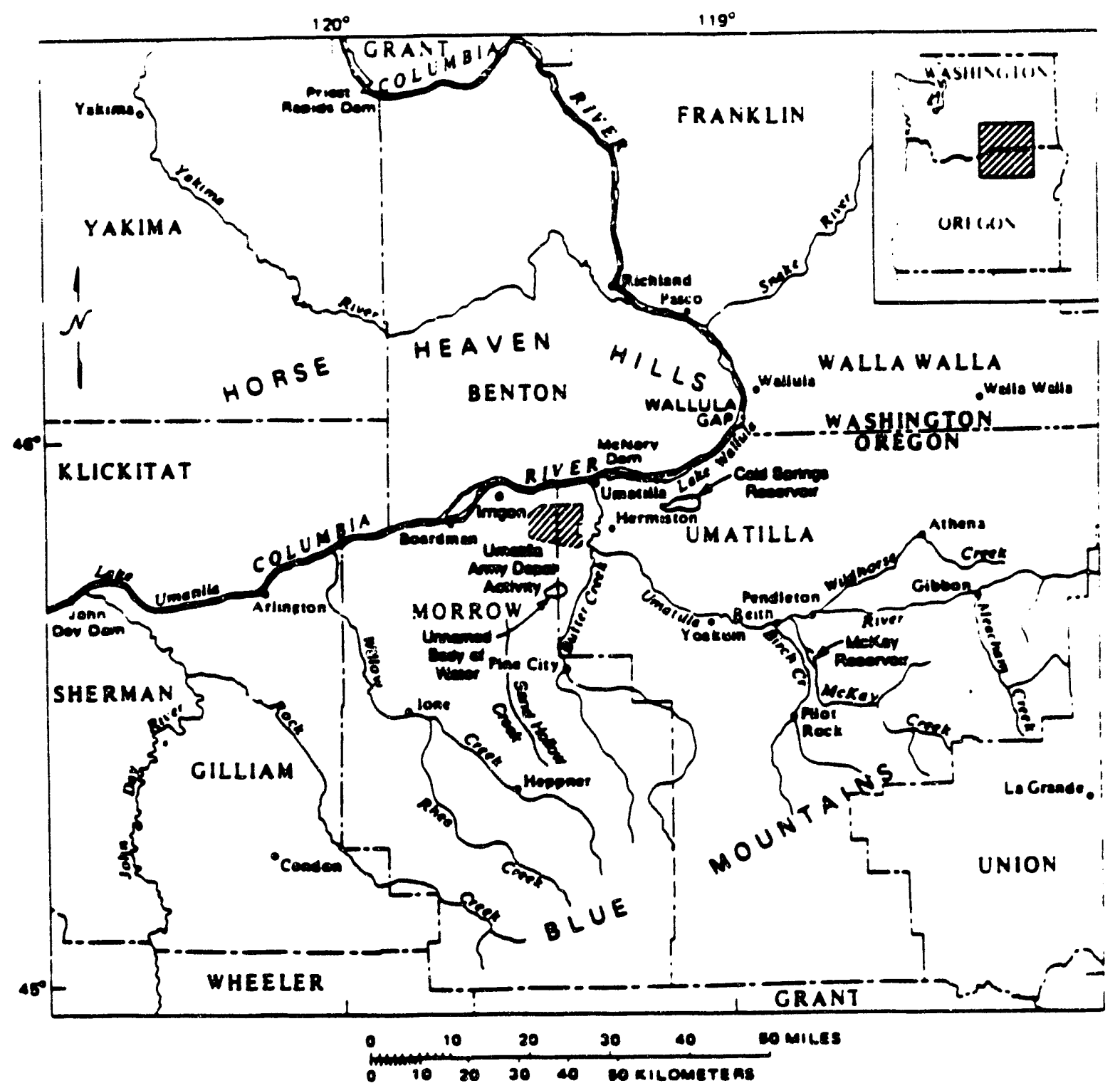

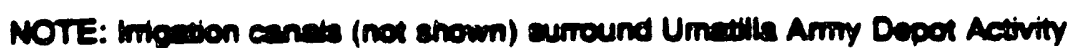

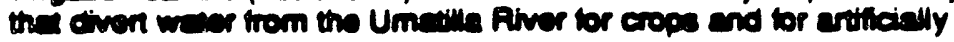
nereging the groundmator.

Fig. C.1. Major surface water discharge routes and bodies of water in the vicinity of Umatilla Army Depot Activity, Hermiston, Oregon. Sources: A. Davies-Smith, C.A. Collins, and L.J. Olson, Selected Groundwater Data in Parts of Gilliam, Morrow, and Umatilla Counties, Oregon, Open-file Report 83-34, U.S. Geological Survey, Portland, Oreg., 1983; A. Davies-Smith, E.L. Bolke, and C.A. Collins, Geohydrology and Digital Simulation of the Groundwater Flow System in the Umatilla Plateau and Horse Heaven Hills Area, Oregon and Washington, Water Resources Investigations Report 87-4268, U.S. Geological Survey, Denver, Colo., 1988; and Roy F. Weston, Inc., Draft Final Remedial Investigation Report-Umatilla Army Depot Activity, (Vols. I and II), Report CETHA-IRCR-89038, West Chester, Pa., 1989. 
unnamed body of surface water is located approximately $6 \mathrm{~km}$ (4 miles) due south of UMDA and northwest of Ward Butte on the Morrow-Umatilla County line (Davies-Smith, Collins, and Olson 1983).

Irrigation canals surround the eastern, western, and northern sides of the depot in a horseshoe pattern. Water is diverted from the Umatilla River into the canals for irrigation of crops.

Most surface water in the vicinity of UMDA is slightly alkaline and of the calcium, sodium calcium, or sodium bicarbonate type (Robison 1971). The concentration of total dissolved solids ranges from about 70 to $150 \mathrm{mg} / \mathrm{L}$ on the Columbia River, and is significantly larger-from 200 to $400 \mathrm{mg} / \mathrm{L}$-in the river's tributaries, such as the Umatilla River and Willow Creek. The Columbia River contains soft to moderately hard water. Hard water, which is attributable to the increased level of total dissolved solids, is present in the Umatilla River and Willow Creek. An abundance of volcanic rocks in this locale causes elevated levels of silica to be present in surface water. The quality of surface water in the vicinity of McNary Dam on the Columbia River is excellent. Irrigation water returns, agricultural wastes, and municipal as well as industrial wastes result in high nutrients, increased temperatures, suspended solids, and algal blooms in the Umatilla River (U.S. Army 1988).

On a regional basis, surface runoff generally flows north-to-northwest towards the Columbia River. Stream and creek flows that have slightly dissected the area originate in the Blue Mountains approximately $65 \mathrm{~km}$ (40 miles) south of UMDA. Gently rolling lowland plains and hills rise from an elevation of about $75 \mathrm{~m}(250 \mathrm{ft})$ near the Columbia River to approximately $1000 \mathrm{~m}(3300 \mathrm{ft})$ at the base of the Blue Mountains (Roy F. Weston, Inc., 1989). Minimal surface runoff occurs in the vicinity of UMDA because of limited precipitation [20 to $23 \mathrm{~cm}$ (8 to 9 in.) per year] (Davies-Smith, Bolke, and Collins 1988; Roy F. Weston, Inc., 1989).

The north-central portion of UMDA is situated on a subdued topographic high point (Jacobs Engineering Group, Inc., and URS/John A. Blume 1987). The land slopes gently away from this high point to the southeast on the eastern portion of the depot, to the south in the central part, and to the northwest in the western section. Runoff from the western part of the site tends to flow toward the West Extension Irrigation Canal, while along the eastern portion of the depot, runoff is collected by a shallow, elongated depression that parallels the Union Pacific Railroad and Interstate 84 (Roy F. Weston, Inc., 1989). No well-defined drainage pattern exists in the central part of the site. The flat to gently rolling terrain consists of numerous shallow depressions that collect surface runoff. Sediments at the site consist of poorly sorted deposits of sand, gravel, silt, and clay. Little or no runoff leaves the depot because of minimal precipitation coupled with the presence of very permeable soils.

The central and eastern drainage areas are separated from each other by Coyote Coulee, a prominent, northeasterly trending, steep sided canyon that was carved out of the basalt and alluvium by glacial meltwater and that extends through the central part of UMDA (Dawson, Meuser, and Schalla 1982). The eastern bank of the coulee is a very steep, westward-facing bluff approximately $15 \mathrm{~m}$ (50 ft) tall (Jacobs Engineering Group, 


\section{$\mathrm{C}-4$}

Inc., and URS/John A. Blume 1987). The western bank, situated at the base of the bluff, is separated from the eastern bank by a line of shallow depressions along which several gravel pits have been dug. The site of the proposed disposal facility is situated in the north central part of UMDA at the western margin of Coyote Coulee. The surficial topography slopes moderately downward into the coulee at this location. Runoff from the site will, however, be very small or nonexistent because the surficial soil is sandy and underlain at shallow depth by glaciofluvial deposits consisting of coarse sand and gravel.

\section{C2 GROUNDWATER}

\section{C21 Geology}

UMDA is located in the Dalles-Umatilla Basin, which is one of several physiographic depressions occupying the Columbia Plateau physiographic province (Jacobs Engineering Group, Inc., and URS/John A. Blume 1987). Surficial topography slopes gently downward to the Columbia River from the Horse Heaven Hills in Washington and the Blue Mountains in Oregon. The southern side of this trough in Oregon, where UMDA is situated, also is known as the Umatilla Plateau and Umatilla lowlands (Davies-Smith, Bolke, and Collins 1988).

A north-to-south geologic cross section typical of the stratigraphy existing beneath UMDA is shown in Fig. C.2. The surficial stratum of the Umatilla Plateau consists of Holocene-to-Pliocene sediments underlain by flood or plateau basalts of the Miocene (5 to 12 million years old) Columbia River Basalt Group. On the north slope of the Blue Mountains between elevations of 229 and $457 \mathrm{~m}$ (750 and $1500 \mathrm{ft}$ ), tightly cemented Pliocene ( 2 to 5 million years old) fanglomerates overlie the basalts (Robison 1971; U.S. Army Corps of Engineers 1985). Below elevations of $229 \mathrm{~m}(750 \mathrm{ft})$, these surficial sediments grade into coarser Pleistocene (10,000 to 2 million years old) glaciofluviatile (or alluvial) deposits laid down by the ancestral Columbia River. Some lacustrine sediments were laid down at or near the base of the glaciofluviatile deposits when the ancestral Columbia River was blocked by ice and debris further downstream. The higher ground throughout the area is blanketed by a thin veneer of Holocene (less than 10,000 years old) loess. Surface elevations at UMDA range from $125 \mathrm{~m}(410 \mathrm{ft})$ near the northwest corner to $201 \mathrm{~m}(660 \mathrm{ft})$ in the southeastern part (Roy F. Weston, Inc., 1989). The thickness of the glaciofluviatile deposits beneath UMDA range from 18 to $61 \mathrm{~m}(60$ to $200 \mathrm{ft})$.

The topography of the Columbia River Basalt Group roughly parallels that of the surface. These basalts, which encompass an area of approximately $163,000 \mathrm{~km}^{2}$ $\left(63,000\right.$ mile $\left.^{2}\right)$ and extend to depths of more than $3,050 \mathrm{~m}(10,000 \mathrm{ft})$ in the Boardman area, were formed by massive lava outpourings [i.e., lava flood (or fissure eruption)] (Davies-Smith, Bolke, and Collins 1988; Roy F. Weston, Inc., 1989). Proceeding downward from the youngest to the oidest formation, the Columbia River Basalt Group consists of the Saddle Mountains, the Wanapum Basalts, and the Grande Ronde Basalts. 


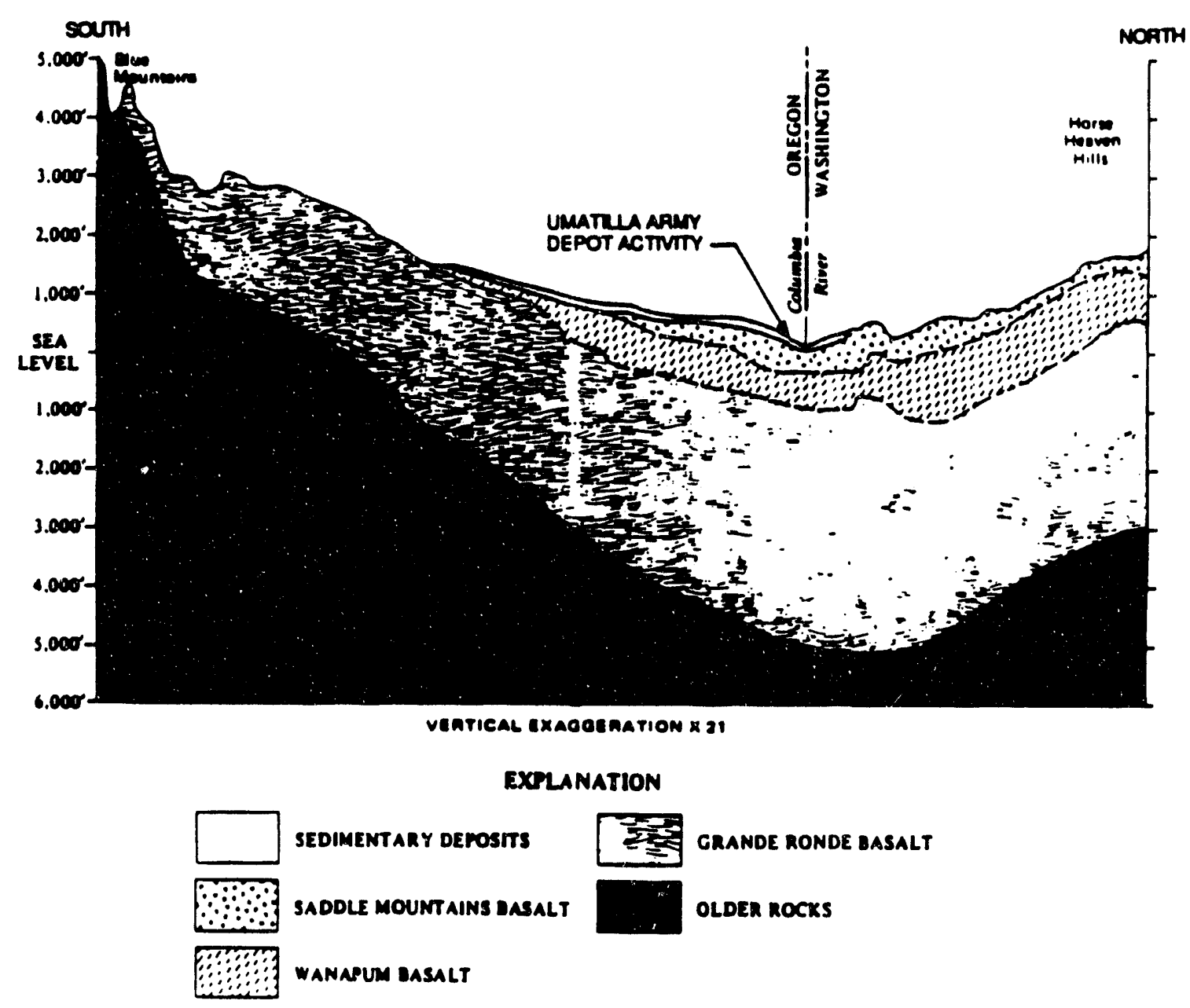

Divide teet by 3.2810 obtain motors.

Fig. C.2 North-to-south geological cross-section through the Umatilla Depot Activity, Hermiston, Oregon. Source: A. Davies-Smith, E.L. Bolke, and C.A. Collins, Geohydrology and Digital Simulation of the Groundwater Flow System in the Umatilla Plateau and Horse Heaven Hills Area, Oregon and Washington, Water Resources Investigation Report 87-4268, U.S. Geological Survey, Denver, 1988. 


\section{C-6}

The Saddle Mountains and Wanapum Basalts are included in the Yakima Basalt subgroup. The maximum thickness of each of these formations occurs in the vicinity of the Columbia River, being approximately $244 \mathrm{~m}(800 \mathrm{ft}), 305 \mathrm{~m}(1000 \mathrm{ft})$, and $2440 \mathrm{~m}$ $(8000 \mathrm{ft})$ for the Saddle Mountains, Wanapum Basalts, and Grande Ronde Basalts, respectively.

Each basalt formation was formed by many individual lava, or basalt, flows of varying thickness. These flows have a dense center with vertical jointing while the top and bottom may be scoriaceous or brecciated (Davies-Smith, Bolke, and Collins 1988). The upper surface of each individual flow may be weathered. Porous interflow zones are present between the individual basalt flows that consist of weathered basalt, flow-top breccia, scoria, and interbedded sedimentary deposits. Hence, each basalt formation consists of an alternating sequence of solidified lava with layers composed of clay, silt, sand, and gravel.

\section{C.22 Groundwater Hydrology}

Beneath the Umatilla Plateau, an unconfined alluvial aquifer within the surficial sediments overlies a confined basalt aquifer system. Some local hydraulic interconnection occurs between the saturated alluvium and the uppermost portion of the basalt aquifer system within the Saddle Mountains Basalt (Roy F. Weston, Inc., 1989). Groundwater flow is primarily horizontal in the alluvial aquifer and the interflow zones between basalt flows. The vertical flow of groundwater is predominant in the basalt flows where vertical jointing significantly increases the permeability in the vertical direction. All of the interflow zones within the Columbia River Basalt Group are hydraulically interconnected, resulting in the formation of a large aquifer system. The unconfined aquifer along the surface resides mainly in the glaciofluviatile deposits. The fanglomerate is not considered to be a good aquifer because cementing agents have filled many of the porous spaces in it that normally would be occupied by water. Additionally, much of the fanglomerate has been dewatered because it is located above the water table. None of these water-bearing formations is a federally protected aquifer.

Groundwater beneath the Umatilla Plateau and UMDA in the unconfined alluvial aquifer and the basalt aquifer system flows northwestward towards the Columbia River from recharge areas in the Blue Mountains (Dawson, Meuser, and Schalla 1982; Davies-Smith, Bolke, and Collins 1988; Roy F. Weston, Inc., 1989). A northward diversion of this overall groundwater flow pattern occurs on the southeastern corner of the depot and probably is caused by year-round pumping at the Lamb-Weston well, which provides water for potato processing (Dawson, Meuser, and Schalla 1982). Groundwater discharge from the unconfined alluvial aquifer and possibly the Saddle Mountains Basalt portion of the basalt aquifer system enters local streams and rivers from springs and seeps and ultimately discharges into the Columbia River. The deeper portions of the basalt aquifer system in the Wanapum Basalt, and particularly the Grande Ronde Basalt, provide minimal contributions to these baseflows.

Wells that tap the glaciofluviatile deposits typically yield from 545 to $2,730 \mathrm{~m}^{3} /$ day (100 to $500 \mathrm{gal} / \mathrm{min}$ ), while maximum yields can be as high as 10,900 or $16,400 \mathrm{~m}^{3} /$ day 
(2,000 or $3,000 \mathrm{gal} / \mathrm{min}$ ) (Gonthier 1985 ; Roy F. Weston, Inc., 1989). Maximum yields in nearby lacustrine deposits are generally less than $2730 \mathrm{~m}^{3} /$ day $(500 \mathrm{gal} / \mathrm{min})$ (Roy F. Weston, Inc., 1989). Wells installed in the Columbia River Basalt Group usually range from 1,090 to $2,730 \mathrm{~m}^{3} /$ day (200 to $500 \mathrm{gal} / \mathrm{min}$ ) with maximum yields that can exceed $10,900 \mathrm{~m}^{3} /$ day $(2,000 \mathrm{gal} / \mathrm{min})$ (Gonthier 1985$)$.

Groundwater in the vicinity of UMDA is slightly alkaline and of the calcium, sodium calcium, or sodium hicarbonate type (Robison 1971). The concentration of total dissolved solids ranges from 200 to $400 \mathrm{mg} / \mathrm{L}$ (Robison 1971) with a mean value of $230 \mathrm{mg} / \mathrm{L}$ (Edwards and Pettit 1988) in the basalt aquifer system. The higher values of total dissolved solids occur in the alluvial aquifer at the surface. Increased levels of silica are caused by the presence of volcanic rocks. Concentrations of iron do not exceed acceptable limits. Groundwater is suitable for most uses, although the hardness of water obtained from the surficial aquifer is greater than is preferred for domestic use.

Groundwater from the deeper portions of the basalt aquifer system has shown increased levels of sodium and fluoride but has shown decreased concentrations of bicarbonate, sulfate, and hardness (Robison 1971). Fluoride concentrations as high as $2.0 \mathrm{mg} / \mathrm{L}$ have been measured. Fluoride concentrations greater than $2.4 \mathrm{mg} / \mathrm{L}$ are not permitted in drinking water, and fluoride is toxic in the range from 5 to $10 \mathrm{mg} / \mathrm{L}$ if the water is consumed on a regular basis (Freeze and Cherry 1979). The elevated level of sodium affects the suitability of the groundwater for irrigation of crops. The sodium acts as a deflocculent, decreasing the permeability of the soil (Bouwer 1978). Infiltration then is restricted, which limits crop yield. The permeability of surficial soil is high in this region. Hence, no deleterious effects have, as yet, been observed that would indicate groundwater from the deeper portions of the basalt aquifer system cannot be used for agricultural irrigation.

Seven water-supply wells that tap the upper portion of the basalt aquifer system are located on the UMDA installation. The capacity of these wells ranges from 160 to $5,400 \mathrm{~m}^{3} /$ day (30 to $1,000 \mathrm{gal} / \mathrm{min}$ ), while the combined capacity of all seven wells is $18,400 \mathrm{~m}^{3} /$ day (3,380 gal/min) (Roy F. Weston, Inc., 1989). Approximately $20 \%$ of the total capacity is used for domestic purposes, while most of the remainder is reserved for fire protection.

Off-site from UMDA, approximately 2,300 ha-m/year (19,000 acre-ft/year) of groundwater is withdrawn from the surficial aquifer which is used primarily for irrigation of crops with some consumption by local industry. Large quantities of groundwater are pumped from the basalt aquifer system for agricultural irrigation. Approximately 636 wells supply 48,700 ha-m/year (395,000 acre-ft/year) in the immediate vicinity of UMDA including the Butter Creek area for the irrigation of more than 40,500 ha (100,000 acres) of crops (Roy F. Wesion, Inc., 1989). An additional 3467 wells located in this same region produce 694 ha-m/year (5600 acre-ft/year) for domestic consumption and livestock production. The nearby municipalities of Umatilla, Hermiston, and Irrigon obtain their drinking water from wells (U.S. Army 1988). Irrigon's well is located close to the Columbia River, and induced infiltration from the river probably contributes significantly to its yield (D. V. Eppenbach, Mayor of Irrigon, Irrigon, Oreg., personal 
communication to J. E. Breck, Environmental Sciences Division, Oak Ridge National Laboratory, Oak Ridge, Tenn., June 24, 1985).

The arid climate on the Umatilla Plateau causes precipitation to evaporate quickly. Recharge to the groundwater regime is very low, being less than $0.5 \mathrm{~cm}$ (0.2 in.) annually throughout most of the plateau, including UMDA, and increasing to approximately $8 \mathrm{~cm}$ ( 3 in.) per year in the Blue Mountains (Davies-Smith, Bolke, and Collins 1988). Large groundwater withdrawals for irrigation of crops began about 1950, with increasing consumption each year thereafter. Since then, excessive consumption, coupled with insufficient recharge, has caused water levels to decline as much as $91 \mathrm{~m}$ (300 ft) in the aquifer system beneath the Umatilla Plateau (Davies-Smith, Collins, and Olson 1983; Davies-Smith, Bolke, and Collins 1988; Bolke 1988). A moratorium on future withdrawals of groundwater was instituted in 1976 by the Water Resources Department for the state of Oregon. This moratorium, which halts the construction of new wells is still in effect.

Since 1978, a recharge canal system located $1.6 \mathrm{~km}$ (1 mile) due south of UMDA has provided artificial recharge to the surficial aquifer. Steady rises in groundwater levels in the surficial aquifer have been observed since the recharge canal was placed into service.

The large vertical hydraulic gradients induced by pumping cause both upward and downward movements of groundwater beneath the Umatilla Plateau and UMDA. Many of the wells are either uncased or only partially cased over their completed depth, which locally increases the vertical movement of groundwater between stratigraphic units. Reversals of the regional flow direction, which is northwestward beneath UMDA, occur during the growing season when pumping of groundwater for irrigation is greatest.

Contamination of groundwater beneath UMDA has already occurred as a result of past disposal practices. Much of this contamination has been caused by the explosive washout lagoons. Constituents that comprise explosives have been detected in the surficial aquifer. Elevated concentrations of 2,4,6-trinitrotoluene (TNT); 2,4-dinitrotoluene (DNT); 2,6-dinitrotoluene (DNT); hexahydro-1,3,5-trinitro-1,3,4-triazine (RDX); cyclotetramethylenetetranitramine (HMX); 2,4,6-trinitrophenylmethylnitramine (tetryl); and nitrate have been measured in the groundwater (Dawson, Meuser, and Schalla 1982; Fitzwater 1988; Koy F. Weston, Inc., 1989). High nitrate levels have been observed in most on-site monitor wells, while the remaining species are confined to an area of approximately 18 ha (45 acres) surrounding the washout lagoons (Fitzwater 1988). A large pig farm (17,000 head) located upgradient from UMDA and the use of fertilizers in this predominantly agricultural area contribute to the observed nitrate levels. The explosive washout lagoons were placed on the National Priorities List of hazardous waste sites by the U.S. Environmental Protection Agency in late 1987. This Superfund site is being evaluated under the Comprehensive Environmental Response, Compensation, and Liability Act (CERCLA) of 1980 as amended by the Superfund Amendments and Reauthorization Act (SARA) of 1986.

A total of twenty-five sites at which toxic or hazardous materials were used, stored, or disposed of have been identified at UMDA (Fitzwater 1988). Roy F. Weston, Inc., (1989) has completed an investigation of many of these sites. A system of forty 
wells in the aquifer system is used to monitor the concentration of contaminants in the groundwater so that corrective action can be taken if off-site migration occurs. No off-site migration of contaminants has been observed.

\section{REFERENCES FOR APPENDIX C}

Bolke, E. L. 1988. U.S. Geological Survey Ground-Water Studies in Oregon, Open-File Report 88-129, Water Fact Sheet, U.S. Geological Survey, Portland, Oreg.

Bouwer, H. 1978. Groundwater Hydrology. McGraw-Hill Book Company, Inc., New York.

Davies-Smith, A., Bolke, E. L., and Collins, C. A. 1988. Geohydrology and Digital Simulation of the Ground-Water Flow System in the Umatilla Plateau and Horse Heaven Hills Area, Oregon and Washington, Water-Resources Investigations Report 87-4268, U.S. Geological Survey, Denver.

Davies-Smith, A. Collins, C. A., and Olson, L. J. 1983. Selected Ground-Water Data in Parts of Gilliam, Morrow, and Umatilla Counties, Oregon, Open-File Report 83-34, U.S. Geological Survey, Portland, Oreg.

Dawson, G. W., Meuser, J. M., and Schalla, R. 1982. Environmental Contamination Survey and Assessment of Umatilla Army Depot Activity (UMAD), Report DRXTH-FS-CR-82127, Battelle Pacific Northwest Laboratories, Richland, Wash.

Edwards, T. K., and Pettit, G. 1988. "Oregon Ground-Water Quality," in National Water Summary 1986-Hydrologic Events and Ground-Water Quality, D. W. Moody, J. Carr, E. B. Chase, and R. W. Paulson (compilers), Water-Supply Paper 2325, pp. 423-28, U.S. Geological Survey, Portland, Oreg.

Fitzwater, J. 1988. Installation Restoration Program Plan for Umatilla Army Depot Activity, U.S. Army Toxic and Hazardous Materials Agency (USATHAMA), Aberdeen Proving Ground, Md.

Freeze, R. A., and Cherry, J. A. 1979. Groundwater, Prentice-Hall, Inc., Englewood Cliffs, N.J.

Gonthier, J. B. 1985. National Water Summary 1984-Oregon Ground-Water Resources, Water Supply Paper 2275, pp. 355-60, U.S. Geological Survey, Portland, Oreg.

Jacobs Engineering Group, Inc., and URS/John A. Blume and Associates, Engineers 1987. Geological-Seismological Investigation of Earthquake Hazards for a Chemical Stockpile Disposal Facility at the Umatilla Depot Activity, Oregon, prepared under contract number DACA87-86-D-0085, for the U.S. Army Engineer Division, Huntsville, Ala.

Robison, J. H. 1971. Hydrology of Basalt Aquifers in the Hermiston-Ordnance Area Umatilla and Morrow Counties, Oregon, Hydrologic Investigations Atlas HA-387, U.S. Geological Survey, Washington, D.C.

Roy F. Weston, Inc., 1989. Draft Final Remedial Investigation Report-Umatilla Army Depot Activity, Vols. I and II, Report CETHA-IR-CR-89038, West Chester, Pa. 
C-10

U.S. Army 1988. Chemical Stockpile Disposal Program Final Programmatic Environmental Impact Statement, Vols. 1, 2, and 3, Program Executive Officer-Program Manager for Chemical Demilitarization, Aberdeen Proving Ground, Md.

U.S. Army Corps of Engineers 1985. Munition Demilitarization Facility Umatilla Army Depot, Oregon, Project 440, Geotechnical Report, Foundation and Materials Branch, Seattle District, Wash.

U.S. Geclogical Survey 1983. Water Resource Data for Oregon, Water Year 1983, Vol. 1, Eastern Oregon, Report USGS/WDR/OR-83/1, Portland, Oreg. 


\section{APPENDIX D \\ DESCRIPTION OF SITESPECIFIC LAND USE}

The region within $100 \mathrm{~km}$ (62 miles) of UMDA is predominantly agricultural, having an average of about $76 \%$ of the county acreage in farmland or pasture (Table D.1). Other land uses occupying significant acreages in this area include national forests (Umatilla and Morrow counties in Oregon), military reservations (Benton and Yakima counties in Washington), and a wilderness area and a national wildlife refuge (Franklin County in Washington) (see also Appendix E, Table E.1). The national forests provide for the greatest variety of land uses including forestry and various forms of recreation. Significant acreage (some of which is included in farm acreages in Table D.1) is also occupied oy Indian reservations (Umatilla, Yakima, and Klickitat counties). Croplands occupy nearly twice as much acreage as pasture, and the production value of all crops is over twice that of all livestock and livestock products (Table D.2).

The predominant agricultural commodities in Oregon, in order of decreasing 1986 production value, were cattle and calves (\$254 million), hay (\$217 million), greenhouse/nursery products (\$203 million), milk (\$188 million), wheat (\$143 million), and forest products (\$127 million) (Oregon Agricultural Statistics Service 1988). In Washington during 1987 , they were milk ( $\$ 475$ million), cattle and calves (\$326 million), apples (\$312 million), wheat (\$309 million), potatoes (\$244 million), hay (\$147 million), and greenhouse/nursery ( $\$ 100$ million) (Washington Agricultural Statistics Service 1988). Other important categories of commodities include fruit/nut crops, vegetable crops, and seed crops (Table D.2).

The three Oregon counties lying wholly or mostly within $100 \mathrm{~km}$ (62 miles) of UMDA rank very high among the state's 36 counties in certain categories of crop acreage or livestock production (Table D-3). Umatilla County ranks first, second, or third in the production of wheat, barley, hogs and pigs, green peas, field corn, potatoes, snap beans, and sheep and lambs. Morrow County ranks first, second, or third in the production of potatoes, wine grapes, wheat, production barley, and field corn. Gilliam County ranks third in wheat and seventh in barley production.

Of Washington's 39 counties, the five counties lying wholly or mostly within $100 \mathrm{~km}$ (62 miles) of UMDA rank relatively high in many agricultural commodities. Most of the counties are ranked among the top ten counties in Washington for production of potatoes, hay, barley, asparagus, sweet corn, field corn, onions, cattle and calves, hogs and pigs, and sheep and lambs (Table D.4). The average ranking of the five counties for milk and for cattle and calves are 16 and 10, respectively; these relatively high rankings, and the fact that, of all plant and animal commodities, these commodities are the top two in the state reflect the importance of land use for these commodities in the area. 
Table D.1. Percentage of land use in counties located mostly within $100 \mathrm{~km}$ of the Umatilla Depot Activity

\begin{tabular}{|c|c|c|c|c|c|}
\hline Counties $^{\mathrm{a}}$ & $\begin{array}{l}\text { Land in } \\
\text { farms } \\
(\%)\end{array}$ & $\begin{array}{c}\text { Cropland } \\
(\%)\end{array}$ & $\begin{array}{c}\text { Pasture } \\
(\%)\end{array}$ & $\begin{array}{l}\text { Farm } \\
\text { woodland } \\
(\%)\end{array}$ & $\begin{array}{l}\text { Other } \\
\text { farmland } \\
(\%)\end{array}$ \\
\hline & \multicolumn{5}{|c|}{ Oregon } \\
\hline Gilliam & $96.2 \%$ & $35.9 \%$ & $N^{b}$ & $4.5 \%$ & NA \\
\hline Morrow & 84.1 & 38.7 & NA & 3.5 & NA \\
\hline \multirow[t]{2}{*}{ Umatilla } & 68.3 & 35.8 & $24.9 \%$ & 6.2 & $1.4 \%$ \\
\hline & \multicolumn{5}{|c|}{ Washington } \\
\hline Benton & $61.7 \%$ & $40.8 \%$ & $18.0 \%$ & $0.4 \%$ & $2.5 \%$ \\
\hline Franklin & 79.5 & NA & 22.7 & NA & 3.7 \\
\hline Klickitat & 60.3 & 17.4 & 27.4 & 12.4 & 3.2 \\
\hline Walla Walla & 93.5 & 75.9 & 10.6 & 2.2 & 4.9 \\
\hline Yakima & 62.5 & NA & 26.2 & $\mathbf{N A}$ & 2.3 \\
\hline
\end{tabular}

a Counties having a small fraction of land within $100 \mathrm{~km}$ of the Umatilla Depot Activity were not included (Grant, Sherman, Union and Wheeler counties in Oregon, and Grant and Adams counties in Washington.)

bNA = Data are not available because of the need to avoid disclosing information for individual farms.

Source: U.S. Bureau of the Census, 1982 Census of Agriculture, Washington, D.C., 1982. 
Table D.2. Value of agricultural production in Oregon and Washington

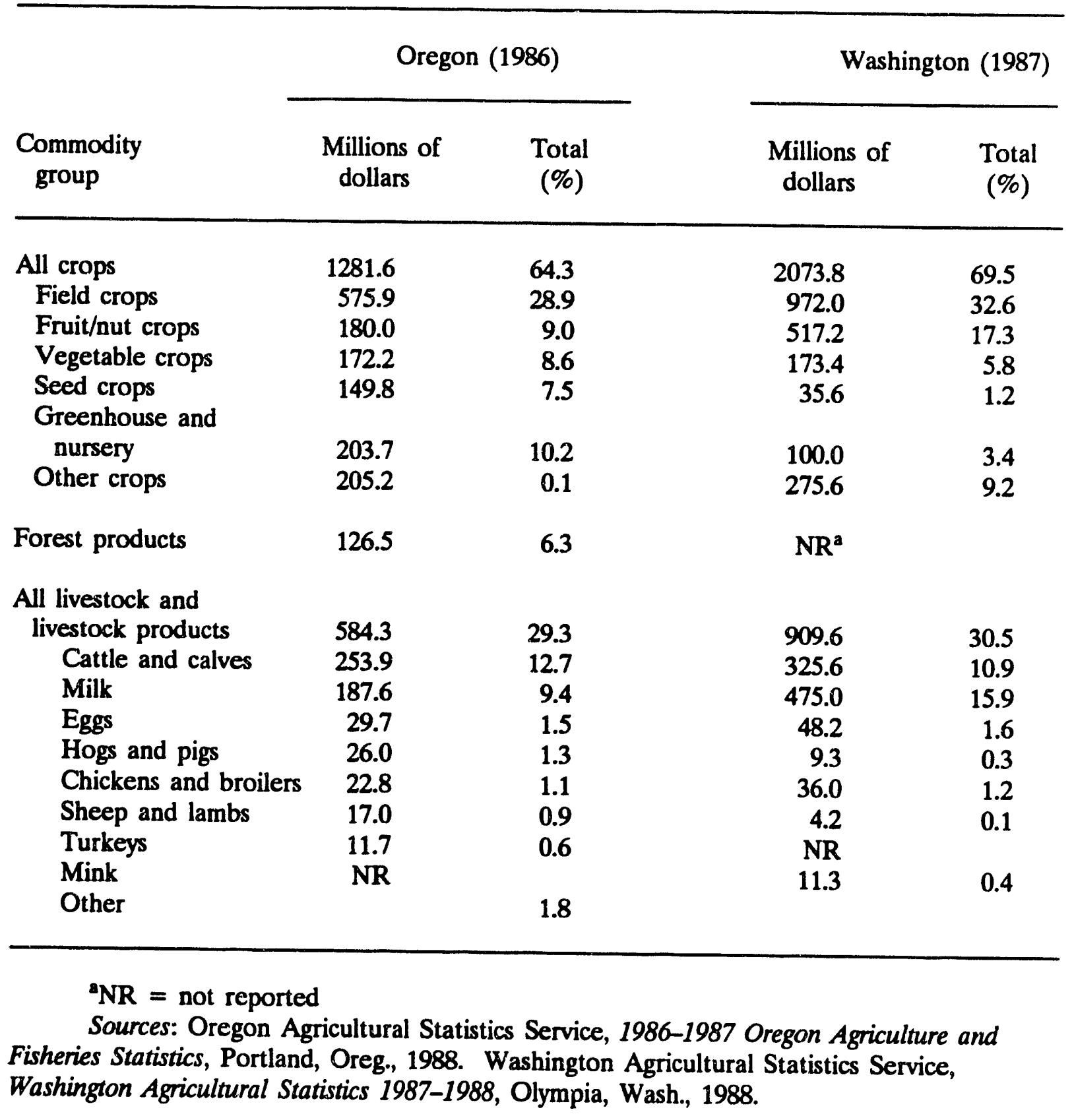


Table D.3. Ranks of study area counties in Oregon for crops, poultry, and livestock Crops $^{c}$

\begin{tabular}{lcccccccccccc} 
County $^{\mathrm{b}}$ & Wh & Ba & Oa & FC & Po & WG & SC & SB & GP & On & Be & FT \\
\hline Gilliam & 3 & 7 & 20 & 22 & $>13$ & $>14$ & $>10$ & $>9$ & NR $^{d}$ & NR & NR & NR \\
Morrow & 2 & 3 & 18 & 3 & 1 & 1 & $>10$ & $>9$ & NR & NR & NR & NR \\
Umatilla & 1 & 1 & 24 & 2 & 2 & 11 & $>10$ & 3 & 1 & NR & NR & 5
\end{tabular}

Livestock and poultry

\begin{tabular}{lcccccc} 
County & $\begin{array}{l}\text { All cattle } \\
\text { and calves }\end{array}$ & $\begin{array}{c}\text { Beef } \\
\text { cows }\end{array}$ & $\begin{array}{l}\text { Milk } \\
\text { cows }\end{array}$ & $\begin{array}{l}\text { Sheep and } \\
\text { lambs }\end{array}$ & $\begin{array}{l}\text { Hogs and } \\
\text { pigs }\end{array}$ & Chickens \\
\hline Gilliam & 24 & 17 & 32 & 31 & 27 & 31 \\
Morrow & 7 & 11 & 22 & 8 & 15 & 25 \\
Umatilla & 6 & 6 & 24 & 3 & 1 & 14 \\
\hline
\end{tabular}

${ }^{a}$ Ranks of crops are for 1986 acres planted (except acres harvested for potatoes) within Oregon's 36 counties.

${ }^{b} \mathrm{Grant}$, Sherman, Union, and Wheeler counties have relative small areas within the study area and were therefore not included.

${ }^{\mathrm{C}} \mathrm{Wh}=$ wheat; $\mathrm{Ba}=$ barley; $\mathrm{Oa}=$ oats; $\mathrm{FC}=$ field corn; Po $=$ potatoes; $\mathrm{WG}=$ wine grapes; $\mathrm{SC}=$ sweet corn; $\mathrm{SB}=$ snap beans; $\mathrm{GP}=$ green peas; $\mathrm{On}=$ onions; $\mathrm{Be}=$ berries; and $\mathrm{FT}=$ fruit trees.

${ }^{\mathrm{d}} \mathrm{NR}=$ not ranked among leading counties.

Source: Oregon Agricultural Statistics Service, 1986-1987 Oregon Agriculture and Fisheries Statistics, Portland, Oreg., 1988. 
D-5

Table D.4. Ranks of study area counties in Washington for principal crops, poultry, and livestock

Principal crops ${ }^{b}$

(listed in order of decreasing production value)

County $\mathrm{Ap}^{\mathrm{c}}$ Wh Po Ha NG Ch Pe Ba Gr Ho As SC Co On Cs

$\begin{array}{lrrrrrrrrrrrrrrr}\text { Benton } & \text { NAd } & 11 & 3 & 11 & \text { NA } & \text { NA } & \text { NA } & 14 & \text { NA } & \text { NA } & 4 & 5 & 1 & 5 & 1 \\ \text { Franklin } & \text { NA } & 8 & 2 & 2 & \text { NA } & \text { NA } & \text { NA } & 9 & \text { NA } & \text { NA } & 2 & 3 & 4 & 6 & 3 \\ \text { Kickitat } & \text { NA } & 13 & 7 & 6 & \text { NA } & \text { NA } & \text { NA } & 13 & \text { NA } & \text { NA } & >6 & >12 & 9 & \text { NA } & 15 \\ \text { Walla Walla } & \text { NA } & 3 & 5 & 14 & \text { NA } & \text { NA } & \text { NA } & 7 & \text { NA } & \text { NA } & 3 & 6 & 7 & 2 & 6 \\ \text { Yakima } & \text { NA } & 12 & 9 & 5 & \text { NA } & \text { NA } & \text { NA } & 10 & \text { NA } & \text { NA } & 1 & 2 & 5 & 4 & 4\end{array}$

Livestock and poultry

(listed in order of decreasing production value)

\begin{tabular}{|c|c|c|c|c|c|}
\hline County & $\begin{array}{l}\text { Milk } \\
\text { cows }\end{array}$ & $\begin{array}{l}\text { Cattle \& } \\
\text { calves }\end{array}$ & $\begin{array}{c}\text { Chickens \& } \\
\text { broilers }\end{array}$ & $\begin{array}{l}\text { Hogs \& } \\
\text { pigs }\end{array}$ & $\begin{array}{c}\text { Sheep \& } \\
\text { lambs }\end{array}$ \\
\hline
\end{tabular}

\begin{tabular}{lrrrrr}
\hline & & & & \\
Benton & 16 & 16 & $>12$ & 7 & 4 \\
Franklin & 15 & 4 & $>12$ & 4 & 9 \\
Klickitat & 20 & 21 & $>12$ & 15 & 5 \\
Walia Walla & 22 & 8 & $>12$ & 13 & 17 \\
Yakima & 5 & 1 & 9 & 6 & 1
\end{tabular}

'Ranks of crops are for 1987 acres planted (except acres harvested for hay, asparagus, sweet corn, and onions) within Washington's 39 counties.

bAp=apples; $W h=$ wheat; $P o=$ potatoes; $\mathrm{Ha}=$ hay; $\mathrm{NG}=$ nursery/greenhouse; $\mathrm{Ch}=$ cherries; $\mathrm{Pe}=$ pears; $\mathrm{Ba}=$ barley; $\mathrm{Gr}=$ grapes; $\mathrm{Ho}=$ hops; $\mathrm{As}=$ asparagus; $\mathrm{SC}=$ sweet $\mathrm{corn} ; \mathrm{Co}=$ corn for grain; $\mathrm{On}=$ onions; $C S=$ corn for silage.

'Grant and Adams counties have relatively small areas within the study area and were therefore not included.

${ }^{d} \mathrm{NA}=$ County ranks were not available.

Source: Washington Agricultural Statistics Service, Washington Agricultural Statistics 1987-1988, Olympia, Wash., 1988. 
D-6

\section{REFERENCES FOR APPENDIX D}

Oregon Agricultural Statistics Service 1988. 1986-1987 Oregon Agriculture and Fisheries Statistics, Portland, Oreg.

U.S. Bureau of the Census 1982. 1982 Census of Agriculture, Washington, D.C. Washington Agricultural Statistics Service 1988. Washington Agricultural Statistics 1987-1988, Olympia, Wash. 


\section{APPENDIX E}

\section{DESCRIPTION OF SITESPECIFIC ECOLOGICAL RESOURCES}

Ecological resources include all living organisms, except humans, as well as areas containing important terrestrial and/or aquatic resources (i.e., parklands, wilderness areas, Nature Conservancy Areas, and wetlands). Terrestrial and aquatic species protected by the Endangered Species Act are identified in this appendix for the 20-, 50-, and 100-km (12-, 31- and 62-mile) zones around the Umatilla Depot Activity (UMDA). Aspects of land use related to ecological resources are described in this appendix, while the human aspects of land use are addressed in Appendix D.

The maximum no-effects radius [100 km (62 miles)] at UMDA for accidental releases of chemical agent GB and VX includes 13 counties or parts of counties in Oregon and Washington; approximately $68 \%$ of this area is in Oregon. The no-deaths distance for mustard agent is $50 \mathrm{~km}$ (31 miles) (see Appendix A); mustard agent is carcinogenic and does not have a no-effects distance. The 50-km (31-mile) zone for mustard agent includes three counties within Oregon and five counties within Washington. Ecological data for resources of special concern are summarized in Table E.1. Additional site-specific information is found in the environmental analysis of on-site disposal of M55 rockets at Umatilla Depot Activity (U.S. Army 1984), the Roy F. Weston, Inc., Draft Final Remedial Investigation Report (1989), and in Installation Assessments (U.S. Army 1979; 1984).

\section{E1 TERRESTRIAL RESOURCES}

The 100-km (62-mile) study area is primarily within the steppe and shrub-steppe vegetation types that occupy the Columbia River Basin province in the rain shadow east of the Cascades. Approximately $10 \%$ of the southeast quadrant lies within the Blue Mountain Province (Daubenmire 1970). The natural vegetation of the steppe and shrub-steppe is mostly sagebrush and bunchgrass communities with introduced cheatgrass and bluegrass invading overgrazed areas. The blue mountains are forested with Pacific silver fir, subalpine fir, shasta red fir, and mountain hemlock (Franklin and Dyrness 1973).

The Sierra Club (Perry and Perry 1983) lists 11 natural areas within the study area (Table E.2). Lakes within these areas are used extensively for irrigation and winter habitat for approximately 500,000 ducks and 200,000 geese. The study area lies within a major migration route of the pintail duck. Approximately 200 species of birds have been identified within the study area. Fur-bearing mammals include mule deer, badger, 
E-2

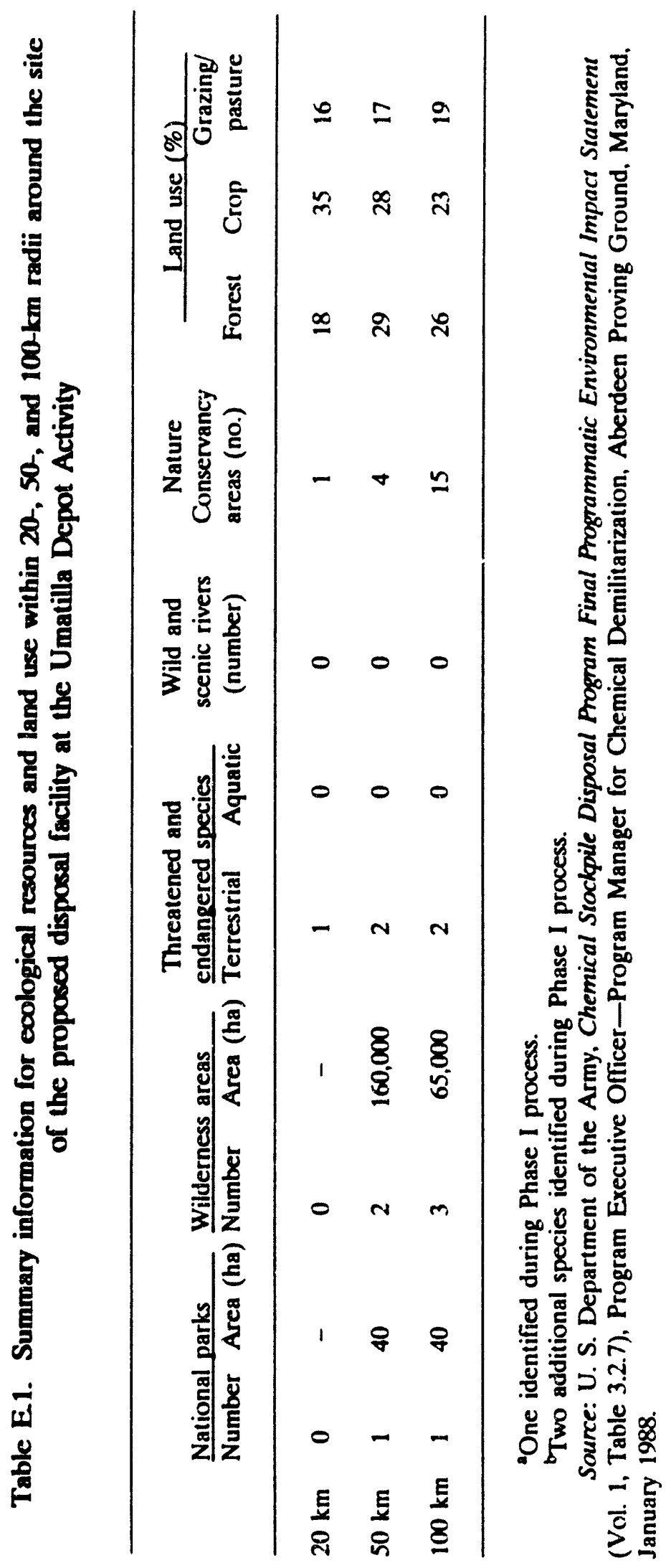


E-3

Table E2. List of Sierra Club Natural Areas within $100-\mathrm{km}$ of the Umatilla Depot Activity

\begin{tabular}{|c|c|}
\hline Area & Acres \\
\hline \multicolumn{2}{|c|}{ Oregon } \\
\hline $\begin{array}{l}\text { Umatilla National Wildlife Refuge } \\
\text { McNary Wildlife Park } \\
\text { Cold Springs National Wildlife Refuge } \\
\text { Umatilla National Forest }^{\mathrm{a}} \\
\text { McKay Creek National Wildlife Refuge } \\
\text { Bridge Creek Wildlife Area }\end{array}$ & $\begin{array}{r}22,879 \\
500 \\
3,117 \\
1,398,914 \\
1,836 \\
13,086\end{array}$ \\
\hline \multicolumn{2}{|c|}{ Washington } \\
\hline $\begin{array}{l}\text { Columbia Basin Recreation Areas } \\
\text { Wahluke Slope Habitat Management Area } \\
\text { Toppenish National Wildlife Refuge } \\
\text { Sunnyside Habitat Management Area } \\
\text { Juniper Forest }\end{array}$ & $\begin{array}{r}49,285 \\
57,839 \\
1,763 \\
7,604 \\
7,806\end{array}$ \\
\hline Total & $1,564,629$ \\
\hline
\end{tabular}

a Common to both Oregon and Washington.

Note: To convert to metric units, 1 acre $=0.405$ hectares. 


\section{E-4}

beaver, muskrat, elk, squirrel, river otter, mink, bobcat, cottontail rabbit, raccoon, and jackrabbit. Three birds, one mammal, and 46 plants are listed by the U.S. Fish and Wildlife Service (FWS) as candidates for endangered and threatened classification.

\section{E2 AQUATIC RESOURCES}

The major bodies of water within the $100-\mathrm{km}$ (62-mile) zone around UMDA are shown in Fig. E.1. There are no on-site water bodies within the UMDA installation boundary. The aquatic resources of the water bodies (Fig. E.1) within the $100-\mathrm{km}$ (62-mile) zone will be discussed in the site-specific EIS.

The Columbia and Umatilla rivers, as well as the Cold Springs and McNary National Wildlife Refuges lie within the 100-km (62-mile) zone.

Information has been requested from the Federal Emergency Management Agency (FEMA) and FWS on wetlands within the UMDA. This information will be included in the site-specific EIS documentation.

The fish community in the Columbia River within the $100-\mathrm{km}(62-$ mile) zone surrounding the site of the proposed UMDA disposal facility includes both anadromous (migratory) and resident species. This reach provides a migration corridor for chinook, coho, and sockeye salmon, and steelhead trout enroute to upstream spawning areas and rearing habitat for salmonid juveniles in their downstream migration. Principal resident fish species sought by anglers include rainbow trout, whitefish, white sturgeon, and smallmouth bass (U.S. Department of Transportation 1972).

An important steelhead run currently exists in the Umatilla River, and efforts are under way to reestablish chinook and coho salmon runs. Rainbow trout are an important cold-water species, and smallmouth bass, largemouth bass, black crappie, yellow perch, walleye, and channel catfish are important warm-water species (U.S. Department of Transportation 1972).

\section{E3 THREATENED AND ENDANGERED SPECIES}

Two federally listed endangered species are present within the $100-\mathrm{km}$ (62-mile) zone: peregrine falcons and bald eagles (R. D. Peterson, FWS, Portland, Oreg., personal communication to V. R. Tolbert, Oak Ridge National Laboratory, Oak Ridge, Tenn, Apr. 19, 1989). These two species were also identified during preparation of the FPEIS. Both species could be present wherever there is suitable habitat within the $100-\mathrm{km}$ (62-mile) zone. Peregrine falcons are present along the Columbia River during migration periods. Reintroduction efforts are presently underway for this species within the potential impact zone. Bald eagles are present during the winter along almost all large rivers, lakes, and reservoirs in the region. There are no federally listed aquatic species within $100 \mathrm{~km}$ (62 miles) of UMDA. 
E-5

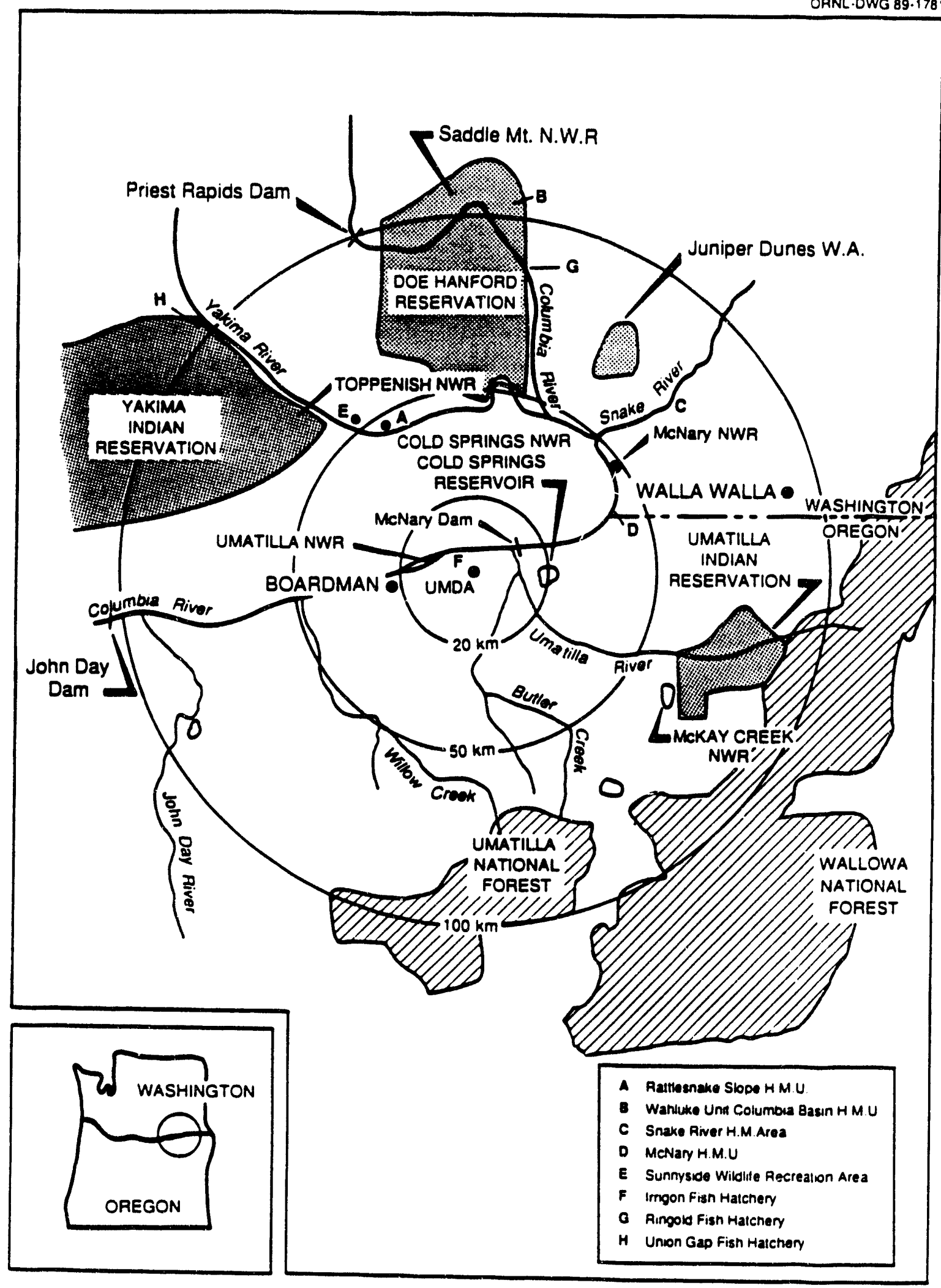

Fig. E.1. Water resources within the $100-\mathrm{km}$ (62-mile) zone around the Umatilla Depot Activity. 


\section{E-6}

\section{REFERENCES FOR APPENDIX E}

Daubenmire, R. 1970. Steppe Vegetation of Washington, Technical Bulletin 62, Washington Agricultural Experiment Station.

Franklin, J. F., and Dyrness, C. T. 1973. Natural Vegetation of Oregon and Washington, General Technical Report PNW-8, U.S. Forest Service.

Perry, J., and Perry, J. G. 1983. Guide to the Natural Areas of Oregon and Washington. Sierra Club Book, San Francisco.

Roy F. Weston, Inc., 1989. Draft Final Remedial Investigation Report-Umatilla Army Depot Activity, Vols. I and II, Report CETHA-IR-CR-89038, contract number DAAA15-85-D-0015, West Chester, Pa.

U.S. Army 1979. Installation Assessment of Umatilla Depot Activity, Report 142, U.S. Army Toxic and Hazardous Materials Agency, Aberdeen Proving Ground, Md.

U.S. Army 1984. Draft Environmental Impact Statement, M55 Rocket Disposal Facility, U.S. Army Depot Activity, Umatilla, Oregon, U.S. Army Toxic and Hazardous Materials Agency, Aberdeen Proving Ground, Md.

U.S. Department of Transportatior: 1972. Interstate 82/182 Prosser, Washington, to Interstate $80 \mathrm{~N}$ in Oregon, Draft Environmental Impact Statement, EIS-WA-73-0026-D, Washington State Department of Highways and Oregon State Highway Division. 


\section{APPENDIX F \\ RESPONSES TO COMMENTS FROM STATE AND FEDERAL AGENCIES}

A draft version of this document was circulated among the relevant state and federal agencies, and comments were solicited. Written comments were received from

- State of Oregon, Emergency Management Division;

- U.S. Department of Health and Human Services, Centers for Disease Control;

- State of Washington, Department of Ecology;

- U.S. Environmental Protection Agency; and

- U.S. Federal Emergency Management Agency.

This appendix presents copies of th- letters received (in Sect. F.1) and offers responses to those comments (in Sect. F.2).

\section{F.1. WRITTEN COMMENTS RECEIVED FROM STATE AND FEDERAL AGENCIES}

It should be noted that the specific page numbers or line numbers referenced in the following letters are related to the draft version of this document and, therefore, may not exactly match the corresponding page or line in this Final Phase I Report. 
October 25,1989

PM CML DEMIL

Bldg. E4585

ATTN: SAIL-PMM-E (PeggY Thompson)

Aberdeen Proving Ground, MD 21010-5401

Dear Peggy:

Enclosed you will find oregon Emergeney Management Division's comments to the phase 1 environmentay report draft for the "Disposal of Chemical Agents and Munitions Stored at Umatilla Depot Activity" (September, 1989).

As stated in our comments, we feel that the draft is a useful document and gives valuable weight to the effort that lies ahead.

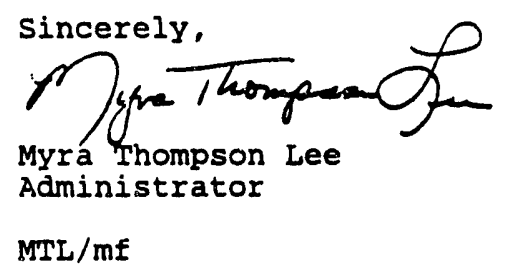


F-3

\author{
CSDP PHASE 1 ENVIRONMENTAL REPORT (DRAFT) COMMENTS
}

Page 1-1, lines 22 through 34 state: "This Phase 1 Environmental Report is the starting point for the site-specific decision-making process at UMDA; it provides the environmental information by which the site-specific impacts of the proposed action are to be assessed in Phase II." For the purpose of an overview, the Draft looks good. It has made comprehensive study and, by using the five stated factors, eliminated off-site disposal of chemical agents at UMDA as a viable alternative. Now that the FPEIS assumptions of Conservative Most Likely (CML) and Worse Case (WC) scenarios have been confirmed, we can get to work on site specific problems and issues not addressed in the Draft. For purpose of identification and clarification of points made and studies named, I will systematically go through the draft and cite (page and line number) some concerns:

1. Page xiv, line 4: If there are any records of incidents related to CSDP which have occurred at operational sites, they should be provided to the state of oregon, CSDP Coordinator. Knowing the history at other sites could help reduce duplication of error and therefore related CSD incidents.

2. Page xvii, line 23: "Useful 10\%" needs to be defined. Without clear definition all participants in CSD operations could become subject to increasing expected skepticism by local environmental groups and the local populace when facility construction and actual destruction begins. We, as a group (all agencies involved with CSDP), must be acutely aware of public information and attitude toward the CSDP program.

3. Page 2-8, line 36: This recommendation is valid and should include well defined and documented baseline data. Coordinating agencies should compare notes and conduct applicable studies.

4. Page 2-9, line 15: The FPEIS atmospheric dispersion models mentioned here and in many other places in the Draft will further evolve within the Integrated Emergency Management Information System (IEMIS) to be refined by the State CSDP Coordinator as a pilot product. All references to dispersion models in the future site-specific plan should be related to IEMIS.

5. Page 3-10, paragraph 3.1.1.2 Population: These figures need to be clarified. According to Table B-7, the migrant worker population is estimated at 70 . This number is possibly far greater during the harvest season due to changes in migrant worker laws. The site specific EIS seeds to show accurate census information.

The following are comments which need greater attention:

1. Agencies with expertise in the area of carcinogenetic and lethal chemicals/byproducts need to become actively involved in setting Threshold Limit vaiues (TLVs) for agents and their 


\section{$\mathrm{F}-4$}

constituents which are subject to chem demil.

2. Relating to the statistical models used, we have two questions: 1. Were significance levels defined prior or post test? The latter is not a well defined procedure (Statistical Analysis, Kachigan, 1986). 2. Were the models used in the Draft univariate or multivariate?

3. The Draft's description of weather patterns comes from a weather station (site) approximately four ki ometers south of UMDA. All of us who live in Oregon know that weather patterns in and around the Columbia River are subject to differences at short intervals. A portable weather station needs to be set up for the site specific EIS in order to gain accurate wind data.

Again, I must restate my feelings that the Draft is a good document to be used as a starting point for the Phase II site specific EIS. It also is valid in that it backs up conclusions of the FPEIS for on site chemical demilitarization. The next step involved agencies need to take is an in depth study of site-specific criteria. It is obvious that this step (Phase II) is presently being geared up. I am looking forward to hearing from state/Federal agencies and starting the process for the site specific EIS. 
Public Health Service

Centers for Di-a ase Control Atlanta GA 30333

October 27, 1989

Mrs. Peg8y Thompson

Office of the Program Manager

for Chemical Demilitarization

ATTN: Environmental and Monitoring Division

Aberdeen Proving Ground, Maryland 21010-5401

Deex Mrs. Thompson:

Our comments to the Draft Phase I Envixonmental Report for the proposed Omat1lla Depot Activity (UIDA) Chemfcal Stockp1le Disposal Program Facility
are:

1. We feel that the document 1 well written and organized and concur with the essential findings and conclusions.

2. Page 3-2, IIne 41, shouldn't the last word be "disposal" rather than "storage."

3. The meteorological data for tridA may be subject to criticism because of the unsultability for use in this document of the wind data from the UWDA meteorological tower and the lack of data on the actual height of the mixed layer at or near ODDA. Perhaps a short description of planned improvements in meteorological monitoring at UIDA (if any) would be reassuring.

4. We find the argument on page 3-5, 18t full paragraph (1Ines 12-24) to be neither clear nor compelling. Suggest that this paragraph be rewritten.

5. Suggest that section 3.3 .3 be reuritten in the past or present tense.

6. We note with approval the saction on risk assurance. You are to be commended for examining the effects of design and operating procedure changes for their potential impacts on risk analysis in order to ensure that safety is equally considered along with other engineering criteria.

7. Page 3-39, 11ne 23, suggest changing the fourth word from "w111" to

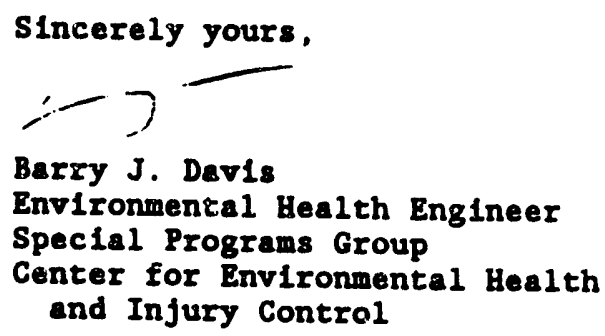




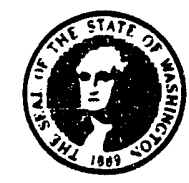

STATE OF WASHINCTON

\section{DEPARTMENT OF ECOLOGY}

Mail Stop PV-11 • Olympia, Washington 985' 8711 • (206) 4596000

October 24, 1989

David A. Nydam

Brigadier General, U.S. Army

Chemical Demilitarization Manager

Environmental \& Monitoring Division

Aberdeen Proving Ground, Maryland 21010-5401

Dear General Nydam:

Thank you for the opportunity to comment on the Draft Phase I Environmental Report for Disposal of Chemical Agents and Munitions at the Umatilla Depot in Hermiston, Oregon. We reviewed the Report and have the following comments.

1. Tables $B-2$ and $B-3$ should be checked for accuracy: Some of the distances given to towns in Washington state seem incorrect.

2. Will there be any kind of warning system in case of accidental release, and if so, when will it be in place?

3. Will the site specific construction design and operations plans be the subject of subsequent environmental review and documentation?

If you have any questions, please call Mr. Mike Palko at (206) 459-6237.

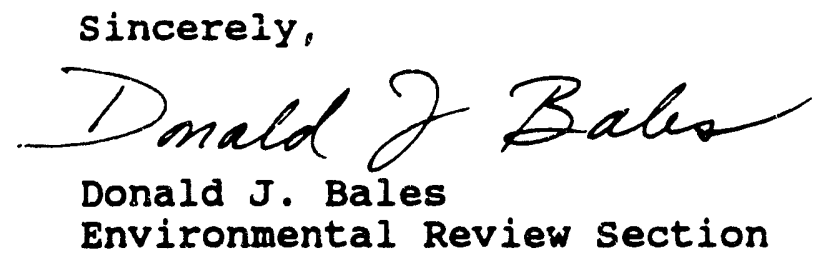

DJB :

cc: Mike Palko 


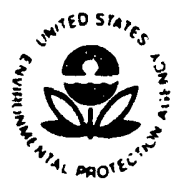

F-7

UNITED STATES ENVIRONMENTAL PROTECTION AGENCY

WASHINGTON, D.C. 20460

OCT 171989

OFFICE OF COMPLLANCE MONITORING

Brigadier General David A. Nydam

U.S. Army

Program Manager for Chemical Demilitarization

Aberdeen Proving Ground, MD 21010-5401

ATTN: Environmental and Monitoring Division

Dear General Nydam:

In September, you requested that the Environmental Protection Agency (EPA) review the draft "Phase I" Report for the proposed chemical munitions incinerator at Umatilla Depot Activity. The report contains new site-specific data relating to the selection of the Umatilla site for the Chemical

Demilitarization Program. Based on this new information, the report's purpose is to verify the Army's prior decision for onsite disposal of the chemical munitions at Umatilla and to identify any significant resources that might be adversely affected at the site. To some extent, the report is a sitespecific up-dating of the earlier Environmental Impact statement (EIS) for the Chemical stockpile Disposal Program.

Pursuant to your request, EPA has reviewed the draft in the time available to us. Our review was based on the draft phase I Report as well as the earlier EIS and permit related materials. The report was reviewed by appropriate staff in EPA's headquarters and in EPA's Seattle Regional office.

Based upon our review, we concur with the draft Phase I Report's conclusion that on-site disposal remains valid as the environmentally preferable alternative. similarly, no unique resources were identified in the report that would preclude the use of Umatilla Depot Activity in the disposal program. As you know, the disposal of the munitions is subject to a number of environmental requirements and will be regulated by EPA and oregon.

We appreciate the opportunity of reviewing the draft Phase I Report, and look forward to working with you and your staff on the site-specific EIS for the disposal facilities at umatilla Depot Activity.

sincerely,

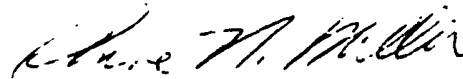

Richard E. Sanderson

$\therefore$ ! Director

office of Federal Activities 
F-8

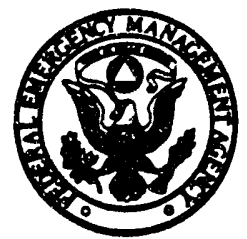

Brigadier General David Nydam

\section{Federal Emergency Management Agency}

Washington, D.C. 20472

Program Manager for Chemical Denilitarization

Department of the Arwy

Aberdeen Proving Ground, ID 21010-5401

Dear General Mydam:

FEMA would like to thank you for the opportunity to review the "Phase I Enviramental Report for the Disposal of Crewical Agents and hunitions Stored at Umatilla Depot Activity." The Report provides a couprehensive examination of the proposed implementation of on-site disposal at Umatilla Depot Activity (UNDA).

We believe the document can be strengthened by considering the following:

(1) Table 1 presented on page 3-4 needs to have its horizontal axis windspeeds stated in either knots or mph in addition to the present meters/second. This will facilitate use in corventional meteorological formulae without the risk of conversion errors.

(2) Meteorological data should be interpreted or expanded from data obtained from the Poxtiand General Electric Company (PGDC) tower $6.5 \mathrm{~km}$ south of U.DA and the National Weather Service (NMS) at Pendleton. Because of wind chameling and other localized weather phenomena along the columbia River, and the fact that UMA is measurably closer to the Columbia River than are the PGEC or Pendleton NWS sites, the weather data may be inacarrate. Because significant populations exist both in the direction of the river and closer to the UMDA, than at the PGEC or NWS facilities, we suxgest the Army establish or upgrade thoir meteorological tower to produce urDA site specific data that is comparable to the data from the FGEC or NWS sources. Five years of past weather data would permit validations of the assumptions gleaned from the PGEC and NiS sources. A second Army meteorological tower, perhaps at Mallary Dam, would assure a statistically valid model as well as a source both remote from U.DA and amidst the population for use in the event of actual release energency response.

Again, thank you for the opportumity to cament on this document. If you have any questions, please contact Denzel Fisher at (202) 646-2876.

sincerely,

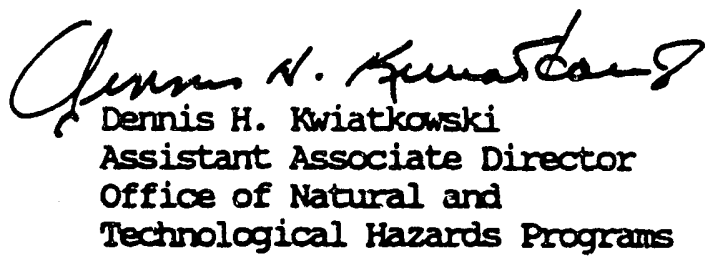

c: Peggy Thampson

SAII-PALE 


\section{F.2 RESPONSES TO COMMENTS}

F21 Responses to October 25, 1989 letter from Myra Thompson Lee, State of Oregon, Emergency Management Division, Salem, Oregon.

Response to concern \#1: The Army has a stringent, ongoing chemical storage surveillance program in which all storage facilities are sampled for agent on a periodic basis based on the history of the individual items. Normally, leaks found during this surveillance operation are low level vapor leaks. When found, leaking munitions are immediately overpacked and then returned to storage. Other than for the obsolete M55 rockets, leaker reports are confidential for national security reasons.

Response to concern \#2: Under emergency conditions or if there is a significant delay in the acquisition of an adequate number of binary chemical weapons to meet the requirements of the armed forces, Public Law 99-145 allows the Secretary of Defense to defer, beyond April 30, 1997, the destruction of not more than 10\% (the "useful 10\%") of the total U.S. unitary stockpile. This $10 \%$ has been identified by an inventory of the munitions at all storage installations and by identifying those which are in the most "useful" condition for military purposes. As currently defined, the UMDA stockpile does contain a portion of the useful $10 \%$. The actual number and munition types which are part of the useful $10 \%$ is classified.

Response to concern \#3: Comment is noted.

Response to concern \#4: The Integrated Emergency Management Information System is currently planned for inclusion in a pilot study in both Utah and Oregon. This model has not been selected by the Chemical Stockpile Emergency Preparedness (CSEP) Steering Committee for use in this program but is under consideration. The Computer Applications Subcommittee will recommend a model(s) for the CSEP and the Steering Committee will make the selection. The subcommittee recommendations will be based on studies and field trials. For the purposes of the site-specific EIS, which is used to develop an impact analysis and compare alternative sitings for the facility, the D2PC model provides conservative results and is believed to be appropriate.

Response to concern \#5: As suggested, we have made contact with the Oregon Employment Division in Pendleton and obtained additional information on Seasonal Agricultural Employment. The updated information is included in Appendix B, Sect. B.3.3. of this Final Phase I Report.

Response to comment \#1: The Department of Health and Human Services (DHHS) participated in the Programmatic EIS and is currently participating as a cooperating agency in the site-specific National Environmental Policy Act (NEPA) process for the Chemical Stockpile Disposal Program. In addition, Public Laws 91-121 and 91-441 require DHHS to review demilitarization plans and provide comments on human health 
aspects prior to the start of operations. Through this participation in CSDP, DHHS has provided and continues to provide valuable oversight and information in the area of chronic and acute human health effects from the chemical agents and their potential byproducts. The "Maximum Allowable Agent Stack Concentration Limit" for the program has been accepted by DHHS as not posing a threat to human health. In addition, we have adopted the agent "General Population Limits" recommended by DHHS in the March 15, 1988, Federal Register.

Response to comment \#2: The term "statistical significance" has been deleted from this Final Phase I Report. This terms was defined in the programmatic EIS as two-shading patterns difference in the risk pictograms. Since the actual risk values in the Programmatic EIS were classified, risks were presented in a pictogram format with shading patterns representing the actual numerical value of risk. A two-shading-pattern difference (that is, a two-order of magnitude or factor of 100 ) was used when discussing site-specific (pictogram) risks to adequately convey to the public the site-specific comparison of alterratives. At the programmatic level, the risk values were not classified (see Table 2.6.2 in the Programmatic EIS), and a one-order of magnitude (or factor of 10) criteria was applied to reach a conclusion about the preferred

programmatic alternative. The uncertainty associated with the estimates of impacts and risks and the basis for the two pictogram shading difference is explained in Sect. 2.6.2.7 of the Programmatic EIS. The same rationale also applies to this Phase I Report, although the term "statistical" has been deleted to avoid confusion.

Response to comment \#3: Currently, UMDA has a meteorological station which measures only wind speed and wind direction. This data is collected on meteorological instrumentation which is 1940 s technology. The data is recorded on analog 24-hr circular charts, but the information bas not been digitized and therefore is not in a ready-to-access form. A comparison of the UMDA meteorological data with the Portland General Electric Company (PGEC) data (as collected from a station located approximately $6.5 \mathrm{~km}$ from the proposed disposal site and as used in the Phase I analysis) cannot be made directly because the applicable UMDA data cannot be located. However, the wind rose for the PGEC meteorological data has also been included in this final Phase I Report. From reviewing this windrose, it is apparent from the predominant wind direction that the Columbia River also affects the wind patteins in the vicinity of the PGEC station. Under the Chemical Stockpile Emergency Preparedness program, existing meteorological capabilities at each chemical agent storage site are to be reviewed and upgrades will be implemented in those areas found to be deficient. The Emergency Management Division for the state of Oregon will have the opportunity to provide input to this study prior to finalization. 
F22 Responses to October 27, 1989, letter from Barry J. Davis, Department of Health and Human Services, Centers for Disease Control, Atlanta, Georgia.

Response to comment \#1: Comment noted.

Response to comment \#2: Comment incorporated into this Final Phase I Report.

Response to comment \#3: Comment incorporated into this Final Phase I Report. The UMDA meteorological data (wind speed and wind direction) cannot be directly compared with the data collected at the Portland General Electric Company meteorological station because the applicable UMDA data cannot be located. Upgrades to the existing meteorological equipment at UMDA is planned. The type of equipment and number of stations is currently under review.

Response to comment \#4: The referenced paragraph has been rewritten in this Final Phase I Report. A sensitivity analysis has been conducted to determine the affect of varying $\mathrm{CML}$ and WC meteorological conditions on the risk pictograms. Results of this analysis are provided in Sect. 3.1.2.2 of this Final Phase I Report.

Response to comment \#5: The referenced paragraph has been rewritten in this Final Phase I Report to provide preliminary results from the CAMDS VX testing conducted in September-November 1989. During these tests, approximately $18,240 \mathrm{~kg}(40,215 \mathrm{lb})$ of VX were incinerated in the liquid incinerator and valuable environmental compliance data was collected. Overall the test burn was very successful.

Response to comment \#6: Comment is noted.

Response to comment \#7: Comment incorporated into this Final Phase I Report.

F.23 Responses to October 24, 1989 letter from Donald J. Bales, State of Washington, Department of Ecology, Olympia, Washington.

Response to comment \#1: Comment incorporated into this Final Phase I Report.

Response to comment \#2: Under the Chemical Stockpile Emergency Preparedness program, Oak Ridge National Laboratory, contracted by the Federal Emergency Management Agency, is developing site-specific concept plans which will recommend to the state and local officials the type of alert/notification equipment which will be most effective at each site. The state and local officials will be requested to select the alert/notification equipment that they feel will best serve the communities around the storage locations. 


\section{F-12}

Response to comment \#3: The site-specific construction design and operations plans are required to undergo additional environmental reviews. Some of the more extensive environmental reviews to be conducted are as follous. Environmental impacts from the construction and operation of the proposed demil facility will be assessed in an Environmental Impact Statement subsequent to the completion of the Phase I process. A Resource Conservation and Recovery Act (RCRA) Permit Application and Clean Air Act Permit Application was submitted to the U.S. Environmental Protection Agency and the state of Oregon in 1987. These applications are currently under revision with resubmittal anticipated in mid-1990. These permits are required prior to beginning construction of the proposed disposal facility. In addition, according to Public Law 91-121 (Armed Forces Appropriations Act of 1970) and Public Law 91-441 (Armed Forces Appropriations Act of 1971), the Department of Health and Human Services is required to review plans for disposing of these munitions and make recommendations to protect human health prior to the start of disposal operations.

\section{F24 Responses to October 17, 1989 letter from Richard E Sanderson, United States} Environmental Protection Agency, Washington, D.C.

The comments contained in the letter are noted.

\section{F25 Responses to November 20, 1989 letter from Dennis H. Kwiatkowski, United} States Federal Emergency Management Agency, Washington, D.C.

Response to comment \#1: Comment incorporated into this Final Phase I Report.

Response to comment \#2: The wind speed and wind direction data collected at UMDA cannot be directly compared to that data collected at the Portland General Electric Company (PGEC) meteorological station because the applicable UMDA data cannot be located. However, the wind rose for the PGEC meteorological data has been included in this Final Phase I Report. In reviewing this windrose, it is apparent from the predominant wind direction that the Columbia River also affects the wind patterns in the vicinity of the PGEC station. Under the Chemical Stockpile Emergency Preparedness program, existing meteorological capabilities at each chemical agent storage site are to be reviewed and upgrades will be implemented in those areas found to be deficient. 
ORNL/TM-11212

\section{INTERNAL DISTRIBUTION}

$\begin{array}{rlll}\text { 1-5. } & \text { G.P. Zimmerman } & 20 . & \text { J. T. Ensminger } \\ \text { 6. } & \text { D. L. Feldman } & 21 . & \text { R. K. Gryder } \\ \text { 7. } & \text { E. L. Hillsman } & 22 . & \text { C. R. Kerley } \\ \text { 8. } & \text { D. B. Hunsaker, Jr. } & 23 . & \text { M. A. Kuliasha } \\ \text { 9. } & \text { R. O. Johnson } & 24 . & \text { D. P. Lombardi } \\ \text { 10. } & \text { R. L. Kroodsman } & 25 . & \text { R. M. Reed } \\ \text { 11. } & \text { R. L. Miller } & 26 . & \text { B. M. Sorensen } \\ \text { 12. } & \text { T. G. Patton } & 27 . & \text { T. J. Wilbanks } \\ \text { 13. } & \text { W. P. Staub } & 28 . & \text { ORNL Patent Office } \\ \text { 14. } & \text { V. R. Tolbert } & 29-30 . & \text { Central Research Library } \\ \text { 15. } & \text { D. C. West } & 31 . & \text { Document Reference } \\ \text { 16. } & \text { C. R. Boston } & 32-33 . & \text { Laboratory Records } \\ \text { 17. } & \text { J. B. Cannon } & 34 . & \text { Laboratory Records--RC } \\ \text { 18. } & \text { S. A. Carnes } & & \\ \text { 19. } & \text { E. D. Copenhaver } & & \end{array}$

\section{EXTERNAL DISTRIBUTION}

35. G. Mark Schoepfle, U.S. Government Accounting Office (GAO), PEMD, Room 5532, 441 G Street NW, Washington, DC 20548

36. Janice A. Morrissey, Science Applications International Corporation (SAIC), 301 Laboratory Road, Oak Ridge, TN 37830

37. Dr. Helen Ingram, Director, Udall Center for Studies in Public Policy, University of Arizona, 803/811 East First Street, Tucson, AZ 85719

38. Calvin D. MacCracken, President, Calmac Manufacturing Corporation, 101 West Sheffield Ave., P.O. Box 710, Englewood, NJ 07631

39. Jacquelin B. Shrago, Director, Office of Technology Transfer, 405 Kirkland Hall, Vanderbilt University, Nashville, TN 37240

40. Office of Assistant Manager for Energy, Research, and Development, DOE/OR, P.O. Box 2001, Oak Ridge, TN 37831-8600

41. U.S. Army Chemical Materiel Destruction Agency, ATTN: SFIL-CMP (Marilyn Tischbin), Bldg. 4585, Edgewood Area, Aberdeen Proving Ground, MD 21010-5401

42. U.S. Army Chemical Materiel Destruction Agency, ATTN: SFIL-CME-N (Don Pugh), Bldg. 4517, Edgewood Area, Aberdeen Proving Ground, MD 21010-5401

43. U.S. Army Chemical Materiel Destruction Agency, ATTN: SFIL-CME-N (MAJ L.Y. Pilcher), Bldg. 4517, Edgewood Area, Aberdeen Proving Ground, MD 21010-5401

44-53. Office of Scientific and Technical Information (OSTI), U.S. Department of Energy, P.O. Box 62, Oak Ridge, TN 37831 

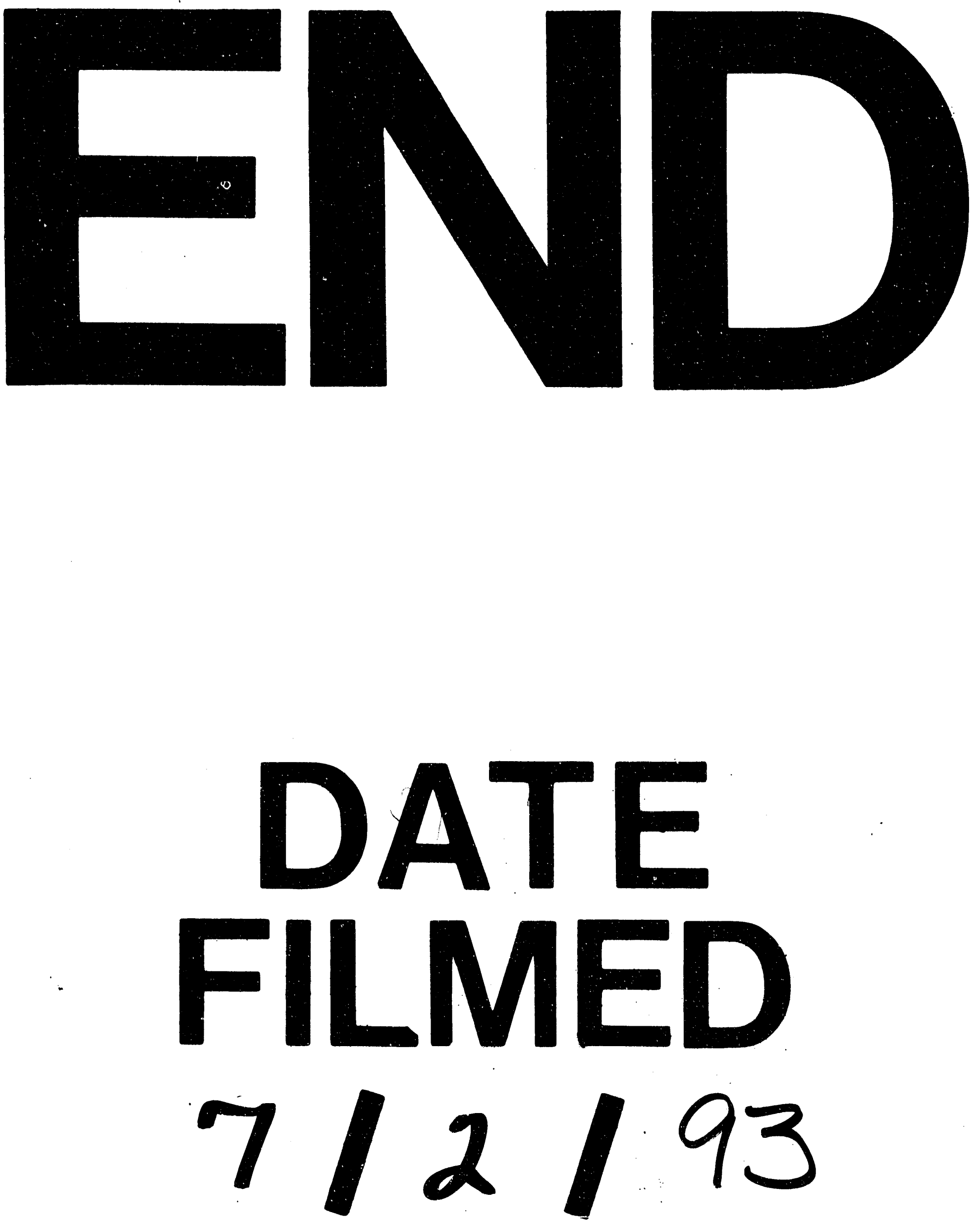
